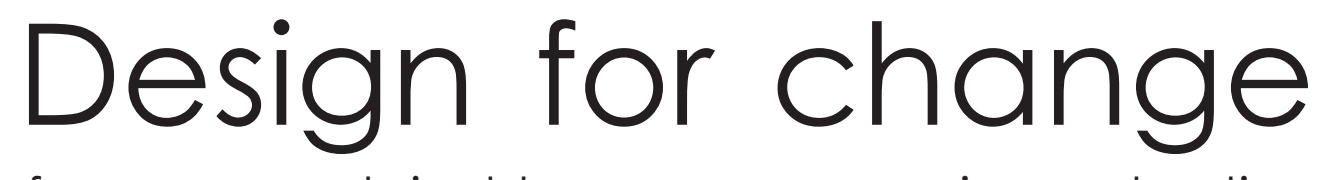
for a more sustainable resource usage in construction

Patrick de Laat 



\section{DESIGN FOR CHANGE FOR A MORE \\ SUSTAINABLE RESOURCE USAGE IN CONSTRUCTION}

\section{DISSERTATION}

to obtain

the degree of doctor at the University of Twente,

on the authority of the rector magnificus

Prof.dr. T.T.M. Palstra

on account of the decision of the graduation committee,

to be publicly defended

on Wednesday the 30th of September 2020 at 14:45

by

Patrick de Laat

born on the 26th of April 1991

in 's-Hertogenbosch, the Netherlands 
This dissertation has been approved by the supervisor:

Prof. dr. ir. F.J.A.M. van Houten,

and the co-supervisor:

Dr. ir. E. Durmisevic.

Cover design: Patrick de Laat

Printed by: Ipskamp printing

Lay-out: Patrick de Laat

ISBN: 978-90-365-4851-9

DOI: $10.3990 / 1.9789036548519$

(C) 2020 Patrick de Laat, The Netherlands. All rights reserved. No parts of this thesis may be reproduced, stored in a retrieval system or transmitted in any form or by any means without permission of the author.

ii | 
Graduation committee

Chair and secretary:

Prof. dr. ir. H.F.J.M. Koopman

Supervisor:

Prof. dr. ir. F.J.A.M. van Houten

Co-supervisor:

Dr. ir. E. Durmisevic

Other committee members:

Prof. dr. ir. arch. N. de Temmerman

Prof. dr. ir. J.I.M. Halman

Prof. dr. ir. J.J.N. Lichtenberg

Prof. dr. ir. M. Mohammadi

Prof. dr. ir. A.A.J.F. van den Dobbelsteen

Dr. J.T. Voordijk 
"The whole of science is nothing more than a refinement of every day thinking."

Albert Einstein, 1936 (p. 349) 


\section{Summary}

The current usage of natural resources cannot be maintained forever - our resources are depleting. A substantial share of resource usage, and therefore the problem, is related to the construction sector. Meanwhile, there are signs that buildings are being demolished prematurely. This premature demolition of buildings is a waste of resources. This dissertation's end goal is to contribute towards mitigating the problem of resource depletion. Changeability has been selected as the means through which to pursue this goal. This research aims to both understand design and to create support to help improve design, specifically regarding the topic of design for change in relation to sustainable resource usage.

In Chapter 2, i.e. "Resource depletion, where is an intervention most effective?", the topic of resource depletion is dealt with. Chapter 2's aim is to rank areas of the resource system, according to how much of an impact can be expected from interventions in the area, in relation to the problem of depleting resources. Firstly, principles of Structured Analysis are used to model the process of resource usage, and, from this model, five intervention areas are defined. Secondly, these intervention areas are ranked in terms of effectiveness, through the use of Analytic Hierarchy Process. To be most effective, one must prioritize intervention areas as follows: (1) material inputs to the operation phase; (2a) process inputs to the operation phase and (2b) products' longevity; (4) process inputs to the manufacturing phase; and (5) material inputs to the manufacturing phase. In this study, changeability is not pursued for the sake of changeability. Changeability is pursued for the sake of mitigating the problem of resource depletion. Chapter 2's outcome can guide this pursuit of changeability in the right direction.

In Chapter 3, i.e. "The evolution of ordinary houses, does it justify demolition?", the topic of longevity in relation to change is dealt with. Chapter 3's aim is to determine how the ordinary house, in the Netherlands, has changed throughout the last 100 years. This information is then used to discuss: to what extent the house's evolution justifies demolition. A non-random sampling method is used to select 68 housing projects from the city of Nijmegen. These projects contain a total of 8270 housing units $(\approx 10 \%$ of Nijmegen's housing stock). Of each project, a standard housing unit is analysed in terms of: (1) length and width; (2) floor-to-ceiling height; (3) utilitarian rooms; (4) spatial layout; (5) type of structure; (6) roof structure; (7) insulation; and (8) separating wall's thickness. Chapter 3 's outcome provides a first indication of to what extent a building's longevity is determined by its design. This knowledge contributes to a more valid assessment of changeability's contribution towards mitigating the problem of 
resource depletion.

In Chapter 4, i.e. "How to set up criteria for evaluating a building's changeability?", the topic of changeability is dealt with. In Chapter 4, a method is proposed in which: (1) scenarios are developed to identify potential problems; and (2) evaluation criteria are based on design solutions to those potential problems. To support and guide the development of both scenarios and design solutions, changeability levels and types of design tactics are defined. A top-down approach is used to define changeability levels, while a bottom-up approach, i.e. the constant comparative method, is used to define types of design tactics. This research's main contribution is that it provides a method for unpacking the black box of design for change. This method is presented in Chapter 4.

In Chapter 5, i.e. "How adjustable is the Environmental Building?", the application of the evaluation method, that has been presented in Chapter 4, is tested. To do so, the Environmental Building's adjustability is evaluated by following the steps described in this method. Adjustability is the first of four changeability levels, as defined in Chapter 4. The Environmental Building has the ability to comply with changing requirements of the individual in terms of indoor climate conditions. However, it lacks the ability to comply with changing requirements of the individual in terms of space, privacy and interaction. Chapter 5 demonstrates that by using this method, specific strengths and weaknesses of the building's design can be identified. 


\section{Samenvatting}

Het huidige verbruik van natuurlijke grondstoffen kan niet blijvend worden doorgezet - onze grondstoffen raken op. Een substantieel deel van dit verbruik, en daarmee het probleem, is gerelateerd aan de bouwsector. Ondertussen zijn er ook tekens dat gebouwen vroegtijdig worden gesloopt. Deze vroegtijdige sloop is een verspilling van grondstoffen. De uiteindelijke doelstelling van deze dissertatie is om bij te dragen aan een vermindering van de uitputting van grondstoffen. Veranderbaarheid is de manier waarop dit doel wordt nagestreefd. Dit onderzoek heeft zowel het streven om het ontwerpen te begrijpen, maar ook om ondersteuning op te zetten die helpt met het verbeteren van het ontwerpen, en dit alles specifiek in relatie tot het volgende onderwerp: ontwerpen voor verandering in relatie tot duurzaam grondstofgebruik.

In hoofdstuk 2, genaamd "Resource depletion, where is an intervention most effective?", wordt het volgende onderwerp behandeld: de uitputting van grondstoffen. Het doel van hoofdstuk 2 is om de gebieden van het grondstoffensysteem te rangschikken in hoeverre een impact, op het probleem van de uitputting van grondstoffen, verwacht kan worden van interventies in het betreffende gebied. Als eerste zijn principes van "Structured Analysis" toegepast om het grondstoffenverbruik proces in kaart te brengen, en op basis hiervan zijn vijf interventiegebieden gedefinieerd. Als tweede zijn deze gebieden gerangschikt op effectiviteit door middel van "Analytic Hierarchy Process". Om het meest effectief te zijn moet men de interventiegebieden als volgt prioriteren: (1) materiaalinput in de gebruiksfase; (2a) procesinput in de gebruiksfase en (2b) de levensduur van producten; (4) procesinput in de vervaardigingsfase; en (5) materiaalinput in de vervaardigingsfase. In dit onderzoek wordt veranderbaarheid niet nagestreefd omwille van veranderbaarheid. Veranderbaarheid wordt nagestreefd met als doel om bij te dragen aan een vermindering van de uitputting van grondstoffen. Het resultaat van hoofstuk 2 moet ervoor zorgen dat dit streven naar veranderbaarheid zijn doel niet voorbij schiet.

In hoofdstuk 3, genaamd "The evolution of ordinary houses, does it justify demolition?", wordt het volgende onderwerp behandeld: levensduur in relatie tot verandering. Het doel van hoofdstuk 3 is om vast te stellen hoe het alledaagse huis, in Nederland, veranderd is gedurende de afgelopen 100 jaar. Vervolgens wordt deze informatie gebruikt om te bediscussiëren in hoeverre de sloop van het huis gerechtvaardigd is door de evolutie van het huis. Door middel van een niet-willekeurige steekproefmethode zijn 68 woningbouwprojecten geselecteerd in de stad Nijmegen. Gezamenlijk omvatten deze projecten een totaal van 8270 individuele woningen $(\approx 10 \%$ van de woningvoorraad in 
Nijmegen). Binnen elk project is een standaardwoning geanalyseerd op de volgende aspecten: (1) lengte en breedte; (2) vloer-tot-plafond hoogte; (3) utilitaire ruimtes; (4) ruimtelijke indeling; (5) constructietype; (6) dakconstructie; (7) isolatie; en (8) dikte van de woningscheidende wand. Hoofstuk 3 geeft een eerste indicatie van in hoeverre het ontwerp bepalend is voor de levensduur van een gebouw. Deze kennis draagt bij aan een meer valide beoordeling van de bijdragen van veranderbaarheid aan de vermindering van de uitputting van grondstoffen.

In hoofdstuk 4, genaamd "How to set up criteria for evaluating a building's changeability?", wordt het volgende onderwerp behandeld: de veranderbaarheid van gebouwen. In hoofdstuk 4 wordt een methode voorgesteld waarin: (1) scenario's ontwikkeld worden om potentiele problemen te identificeren; en (2) evaluatiecriteria gebaseerd zijn op ontwerpoplossingen voor deze potentiele problemen. Om de ontwikkeling van zowel scenario's als ontwerpoplossingen te ondersteunen en te sturen zijn veranderbaarheidslevels en type ontwerptactieken gedefinieerd. Een topdown aanpak is gebruikt om veranderbaarheidslevels te definiëren, terwijl een bottomup aanpak, de "constant comparative method", gebruikt is om type ontwerptactieken te definiëren. De hoofdbijdrage van dit onderzoek is een methode om de black box van ontwerpen voor verandering uit te pakken. In hoofdstuk 4 wordt deze methode gepresenteerd.

In hoofdstuk 5, genaamd "How adjustable is the Environmental Building?", wordt de toepassing van de evaluatiemethode getest, die in hoofdstuk 4 is gepresenteerd. Hiervoor is de afstelbaarheid van het "Environmental Building" geëvalueerd door de in de methode beschreven stappen te volgen. Afstelbaarheid is de eerste van de vier in hoofdstuk 4 gedefinieerde veranderbaarheidslevels. Het "Environmental Building" heeft het vermogen om zich te schikken naar veranderende eisen van het individu omtrent het binnenklimaat. Echter ontbreekt bij dit gebouw het vermogen om zich te schikken naar veranderende eisen van het individu omtrent ruimtegebruik, privacy en interactie. Hoofdstuk 5 laat zien dat specifieke sterktes en zwaktes van het gebouwontwerp geïdentificeerd kunnen worden met behulp van de methode. 


\section{Table of contents}

1. Introduction 2

1.1. Introduction 4

1.2. Goal 5

1.3. Methodology 10

1.4. Structure 14

2. Resource depletion, where is an intervention most effective? 16

2.1. Introduction $\quad 20$

2.2. Method 21

2.3. Results 23

2.4. Discussion and conclusion $\quad 38$

3. The evolution of ordinary houses, does it justify demolition? 40

3.1. Introduction 43

3.2. Method 46

3.3. Results $\quad 52$

3.4. Discussion and conclusion $\quad 66$

4. How to set up criteria for evaluating a building's changeability? 70

4.1. Introduction $\quad 73$

4.2. Method 78

4.3. Results 81

4.4. Discussion and conclusion 93

5. How adjustable is the Environmental Building? 96

5.1. Introduction 100

5.2. Method 101

5.3. Results 103

$\begin{array}{lr}\text { 5.4. Discussion and conclusion } & 120\end{array}$

6. Discussion and conclusion $\quad 122$

6.1. Discussion 123

$\begin{array}{ll}\text { 6.2. Conclusion } & 128\end{array}$ 
References

Appendix 1: Cases' information

148

Appendix 2: Design tactics' mentions

156

Appendix 3: Probability estimates

186 


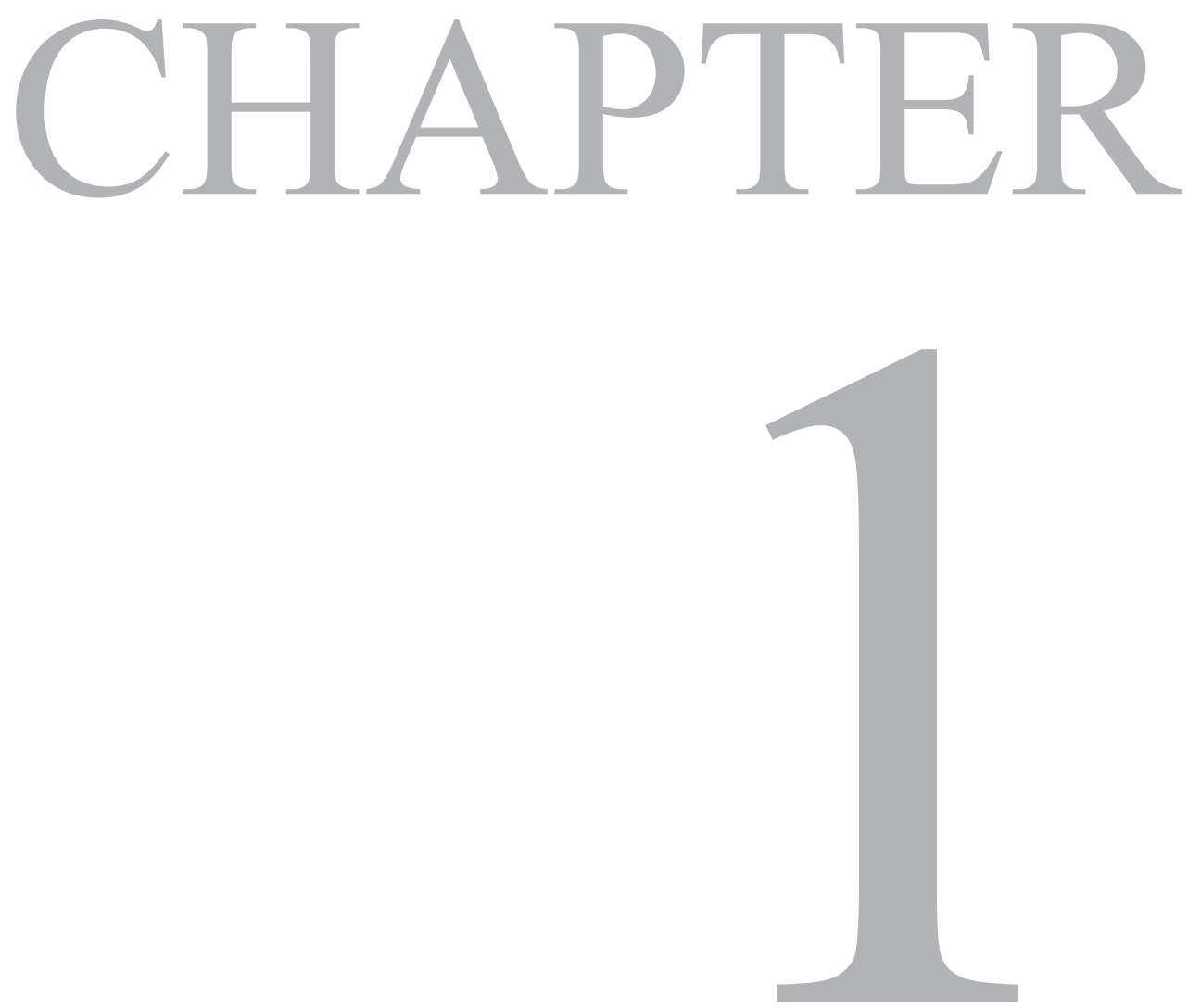

Introduction. 
This page is intentionally left blank. 


\subsection{Introduction}

Many authors have pointed out that the current usage of natural resources cannot be maintained forever (Boulding, 1966; Diederen, 2010; McDonough and Braungart, 2002; Meadows et al., 1972; Stahel, 1984). Some claim that society's standards are too high and that this is part of the problem (e.g. Diederen, 2010), while others deny that lower standards are necessary to resolve resource depletion (e.g. McDonough and Braungart, 2002). However, all agree that the take, make and dispose approach to achieving those standards is unsustainable. A substantial share of resource usage, and therefore the problem, is related to the construction sector (see Krausmann et al., 2009). Meanwhile, there are signs that buildings are being demolished prematurely. In Zurich (Switzerland), buildings do not even last half as long as they used to (Aksözen et al., 2017, p. 254, Fig. 10). Furthermore, a study (O'Connor, 2004) in Minneapolis-Saint Paul (USA) shows that especially non-residential buildings generally do not last as long as architects, engineers and developers expect them to last. In Finland, for example, non-residential buildings are on average only 43 years old when they are demolished (Huuhka and Lahdensivu, 2016, p. 87, Table 10). This premature demolition of buildings is a waste of resources.

According to Bocken et al. (2016, p. 309), there are three solutions to mitigate the problem of resource depletion: (1) closing resource flows, i.e. ensuring that the post-use material output feeds into manufacturing; (2) slowing resource flows, i.e. prolonging the use period of products and parts; and (3) narrowing resource flows, i.e. using less resources overall. This dissertation focusses on the second solution: slowing resource flows. 


\subsection{Goal}

\subsubsection{Introduction}

This $\mathrm{PhD}$ research was part of an EU-funded project: Buildings as Material Banks (BAMB). As a result, both the goal and the background were pre-determined at the start of this research. The goal was to create a support method, for designers, that can evaluate a building's changeability ${ }^{1}$, and the background was resource depletion. In other words, it was pre-determined that the changeability evaluation method needed to be a solution to the problem of resource depletion. The pre-determined project goal is based on the following premise: (1) a method for evaluating a building's changeability will improve the changeability of future buildings; (2) buildings with greater changeability will have greater longevity; and (3) when buildings have greater longevity, the problem of resource depletion is significantly reduced.

Thus, the project goal is to create a method that can evaluate a building's changeability, and therewith support the design of changeable buildings. However, changeable buildings is not the societal end goal, it is the means through which the end goal is pursued. This dissertation's societal end goal is to contribute towards mitigating the problem of resource depletion. Both these goals, i.e. the project goal and the societal goal, resulted in the following main research question: (Q-main) 'How can a building design's changeability, and the effect of this changeability on the problem of resource depletion, be evaluated?'. This main research question is composed of two smaller research questions: (Q1) 'How can the effect of a building design's changeability on the problem of resource depletion be evaluated?'; and (Q2) 'How can a building design's changeability be evaluated?'.

This dissertation's focus includes not two but three research topics: resource depletion, longevity and changeability. In Figure 1 is shown: how the topics of resource depletion, longevity and changeability are related to each other. In Figure 1, an arrow, with a minus symbol next to it, represents a negative relation. This means that an increase at the arrow's beginning will result in a decrease at the arrow's end. Thus, when longevity increases, resource depletion decreases. Also, when change increases, longevity decreases. Furthermore, in Figure 1, the relation itself, between change and longevity, is the target of another negative relation. This means the following: when changeability increases, the negative relation between change and longevity weakens.

${ }^{1}$ The project uses the term "transformation capacity" instead of changeability. 


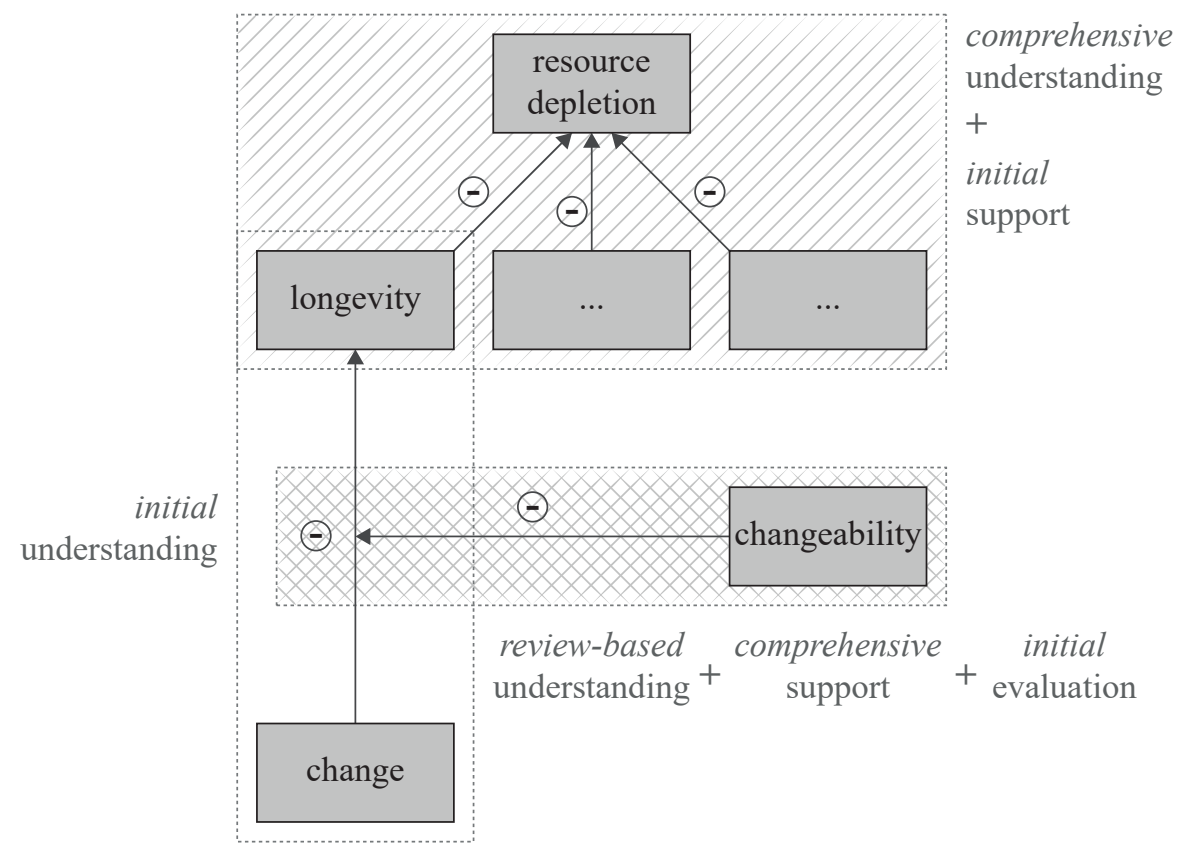

Figure 1. An overview of: how the topics of resource depletion, longevity and changeability are related to each other; and the outcomes that are aimed for in this dissertation, per topic. An arrow, with a minus symbol next to it represents a negative relation, e.g. when longevity increases, resource depletion decreases. Furthermore, the relation itself, between change and longevity, is the target of another negative relation. This means the following: when changeability increases, the negative relation between change and longevity weakens.

\subsubsection{Changeability}

The project goal is to create a method that can evaluate a building's changeability, and therewith support the design of changeable building. Thus, the primary goal is to understand design in relation to change, while a secondary goal is to create support to help improve design in relation to change. The term "changeability" is derived from the term "design for change". Design for change is a form of "design for X". The term design for $\mathrm{X}$ is used to describe the approach in which a particular perspective is adopted, represented by $\mathrm{X}$, from which to improve the product design. The particular perspective is either: (1) a specific property; or (2) a life-cycle phase of the product (Tomiyama et al., 2009, p. 552). The main challenge in the design for change approach is that its perspective is not at all specific. A changeable building is a building that is optimized from the perspective of future change. However, future change is neither a 
single nor a specific event; future change represents countless possible events. There are two ways to deal with this challenge: (1) the "black box" approach, i.e. primarily focussing on the inputs (design solutions) and the resulting impact; and (2) the "white box" approach, primarily focussing on the "mechanisms" that describe how and why certain design solutions have an impact (see Astbury and Leeuw, 2010).

The strength of the black box approach is that it does not try to specify something that cannot be specified comprehensively - it does not try to predict the future. However, validation is a problem with this approach. Monitoring the effects, of an intervention, on the lifespan of a building is practically not feasible. Alternatively, Wilkinson (see 2014b) focussed on a different resulting impact: the number of adaptation occurrences. However, more adaptation occurrences are not necessarily beneficial to a building's lifespan. More adaptation occurrences may indicate that the building is highly adaptable, or it may indicate that the building was highly in need of adaptation. There are two types of changeability: (1) adaptability, i.e. a building's ability to comply with changes through physical alterations to the building fabric; and (2) flexibility, i.e. a building's ability to comply with changes without physical alterations to the building fabric (see Engel and Browning, 2008, p. 126; Heidrich et al., 2017, p. 288; Schmidt III, 2014, p. 66). Especially in relation to flexibility, it is very difficult to measure design solutions' resulting impact.

Therefore, in this dissertation, the white box approach is used to deal with the nonspecific optimization goal of design for change. Thus, the primary focus is not the link between design solution and resulting impact, but the link between design solution and future change. Thus, this dissertation's goal is to create a method that can evaluate a building's changeability, based on an deep understanding of the relation between future change and design solutions.

\subsubsection{Resource depletion}

This dissertation's societal end goal is to contribute towards mitigating the problem of resource depletion. Changeability has been selected as the means through which to pursue this goal. However, are there not more effective means to achieve this goal? Furthermore, at times, changeability may conflict with other means of achieving the same goal. If so, at what cost may changeability be pursued, in order for it to still be considered a contribution towards mitigating the problem of resource depletion. To help deal with such questions, it helps to know which interventions are more effective. Therefore, a secondary goal of this dissertation is to prioritize interventions, in relation to the problem of depleting resources. 


\subsubsection{Longevity}

Longevity is the link between the topics of changeability and resource depletion. Thus, in order for changeability to have an effect on resource depletion, change must have an effect on longevity. Furthermore, within this effect that change has on longevity, design must matter. When a building's physical qualities are not taken into account in the decision-making process of the building's demolition, there is no point in improving a building's design in relation to future change. The decision-making process of a building's demolition is a topic in its own right. However, since the topic is such an essential link between the topics of changeability and resource depletion, some understanding, of the role of a building's physical qualities within the decision-making process of the building's demolition, is important. Therefore, another secondary goal of this dissertation is to verify whether or not the evolution in building design is a likely cause of premature demolition. 
This page is intentionally left blank. 


\subsection{Methodology}

\subsubsection{Introduction}

Research that not only aims to understand design, but also to create support to help improve design is termed "design research" (Blessing and Chakrabarti, 2009, pp. 2-6). According to the book "DRM, A design research methodology" (Blessing and Chakrabarti, 2009, pp. 18-19), a comprehensive design research study includes the following stages: (1) research clarification; (2) descriptive study I; (3) prescriptive study; and (4) descriptive study II. Furthermore, these stages are expected to result in the following outcomes (p. 15), respectively: (1) goals; (2) understanding; (3) support; and (4) evaluation. Furthermore, in DRM, a distinction is made between initial, reviewbased and comprehensive studies (p. 18).

\subsubsection{Research clarification}

The first stage in a design research study is the research clarification stage. The objective of this stage is to identify the goals that the research is expected to realise (Blessing and Chakrabarti, 2009, p. 30). This dissertation's focus is the topic of changeability. More specifically, this dissertation's focus is the topic of changeability in relation to the topics of longevity and resource depletion. This dissertation aims to contribute to both the overall subject matter and the three separate topics. To do so, the book "DRM, A design research methodology" prescribes multiple research clarification stages, i.e. one per topic.

In this dissertation, the research clarification is dealt with in the following manners. First, this chapter, i.e. Chapter 1, contains the general research clarification related to the overall subject matter. Second, the Chapters 2, 3 and 4 contain brief, and specific, research clarifications related to the topics of resource depletion, longevity, and changeability, respectively. Third, the chapters regarding resource depletion and longevity provide an extensive research clarification related to the overall subject matter, i.e. changeability in relation to longevity and resource depletion.

\subsubsection{Descriptive study I}

The second stage in a design research study is the (first) descriptive study stage. The objective of this stage is to increase understanding of design and its success factors, in relation to the specific topic (Blessing and Chakrabarti, 2009, p. 31). This dissertation aims to increase understanding regarding the overall subject matter, i.e. changeability in relation to longevity and resource depletion, by gaining: (1) an initial understanding 
of the topic of building longevity; (2) a review-based understanding of the topic of changeability; and (3) a comprehensive understanding of the topic of resource depletion. For resource depletion, an "explicative model" can be developed to gain a comprehensive understanding of the topic. An explicative model is a model that describes how the process works, and why the process works the way it does (see Klaasen, 2002, p. 184). This model will be developed to answer the following research question: (Q1a) 'What are the different intervention areas for the problem of resource depletion?'. The topic of changeability however, lacks a specific optimization goal. Therefore, it is not possible to develop a comprehensive understanding of how future change affects buildings. Instead, the goal in this stage will be to gain a review-based understanding, specifically of the design solutions, or success factors, of changeability. This goal is stated in the following research question: (Q2a) 'What are the types of design tactics used in design solutions of changeability?'.

For longevity, the historical evolution of buildings can be examined to gain an initial understanding of the topic in relation to change. This examination will be conducted to answer the following research question: (Q1c) 'Is the evolution of buildings' design a justifiable reason for a building's demolition?'.

\subsubsection{Prescriptive study}

The third stage in a design research study is the prescriptive study stage. The objective of this stage is to develop design support, in relation to the specific topic. This dissertation aims to set up support regarding the overall subject matter, i.e. changeability in relation to longevity and resource depletion, by developing: (1) initial support for the topic of resource depletion; and (2) comprehensive support for the topic of changeability.

For resource depletion, the initial support will be based on an explicative model. In the previous stage, different intervention areas are identified. In this stage, they are compared and ranked. The goal of this step is to answer the following research question: (Q1b) 'How do the different intervention areas rank, in terms of how much of an impact can be expected from an intervention in the area?'.

For the topic of changeability, it is not possible to base the support on an explicative model that describes, in general, how and why future change affects buildings. Instead, the support will be based on an "explorative model" (see Klaasen, 2002, p. 184) describing how future change may affect a specific building, and why it is expected to work that way. For changeability, setting up this model is an essential part of the support. To develop comprehensive support for the topic of changeability, the following research questions must be answered: (Q2b) 'How can potential problems of a building 
design be identified, in relation to future change?'; (Q2c) 'How can design solutions to these potential problems be developed?'; and (Q2d) 'How can the relative importance of design solutions' inclusion in the building's design be determined, in relation to the building's changeability?'.

\subsubsection{Descriptive study II}

The fourth stage in a design research study is another descriptive study stage. The objective of this stage is to evaluate the design support that has been developed in the previous stage. There are two distinct aspects of design support that can be evaluated (Blessing and Chakrabarti, 2009, p. 37): (1) its application - can the support be used for the task for which it is intended; and (2) its success - does the support have the expected impact. Due to time constraints, the initial evaluation, of this method for evaluating a building's changeability, only focusses on the method's application. The goal of this stage is to answer the following research question: (Q2e) 'Can the evaluation method, that is presented in this study, be used to identify specific strengths and weaknesses of the building's design in relation to the user's changing requirements?'. 
This page is intentionally left blank. 


\subsection{Structure}

Figure 1 shows how the topics of resource depletion, longevity and changeability are related to each other. In addition, Figure 1 shows the outcomes that are aimed for in this dissertation, per topic. The topic of resource depletion, and thus Q1a and Q1b, is dealt with in chapter 2: "Resource depletion, where is an intervention most effective?". This chapter's aim is comprehensive understanding and initial support, in relation to resource depletion. The topic of longevity, and thus Q1c, is dealt with in chapter 3: "The evolution of ordinary houses, does it justify demolition?". This chapter's aim is initial understanding, in relation to longevity. The topic of changeability, and thus Q2a, Q2b, Q2c, Q2d and Q2e, is dealt with in chapters 3 and 4: (3) "How to set up criteria for evaluating a building's changeability?"; and (4) "How adjustable is the Environmental Building?". Chapter 3's aim is review-based understanding and comprehensive support, in relation to changeability. Chapter 4's aim is initial evaluation, in relation to changeability. To summarize, this dissertation's research goals are stated in the following research questions:

(Q-main) 'How can a building design's changeability, and the effect of this changeability on the problem of resource depletion, be evaluated?';

(Q1) 'How can the effect of a building design's changeability on the problem of resource depletion be evaluated?';

(Q1a) 'What are the different intervention areas for the problem of resource depletion?';

(Q1b) 'How do the different intervention areas rank, in terms of how much of an impact can be expected from an intervention in the area?';

(Q1c) 'Is the evolution of buildings' design a justifiable reason for a building's demolition?';

(Q2) 'How can a building design's changeability be evaluated?';

(Q2a) 'What are the types of design tactics used in design solutions of changeability?'; (Q2b) 'How can potential problems of a building design be identified, in relation to future change?';

(Q2c) 'How can design solutions to these potential problems be developed?';

(Q2d) 'How can the relative importance of design solutions' inclusion in the building's design be determined, in relation to the building's changeability?'; and

(Q2e) 'Can the evaluation method, that is presented in this study, be used to identify specific strengths and weaknesses of the building's design in relation to the user's changing requirements?'. 
Chapter 2 is based on:

de Laat, P. (2019), "Resource depletion, where is an intervention most effective?", Smart and Sustainable Built Environment, Vol. 8 No. 4, pp. 307-321. 

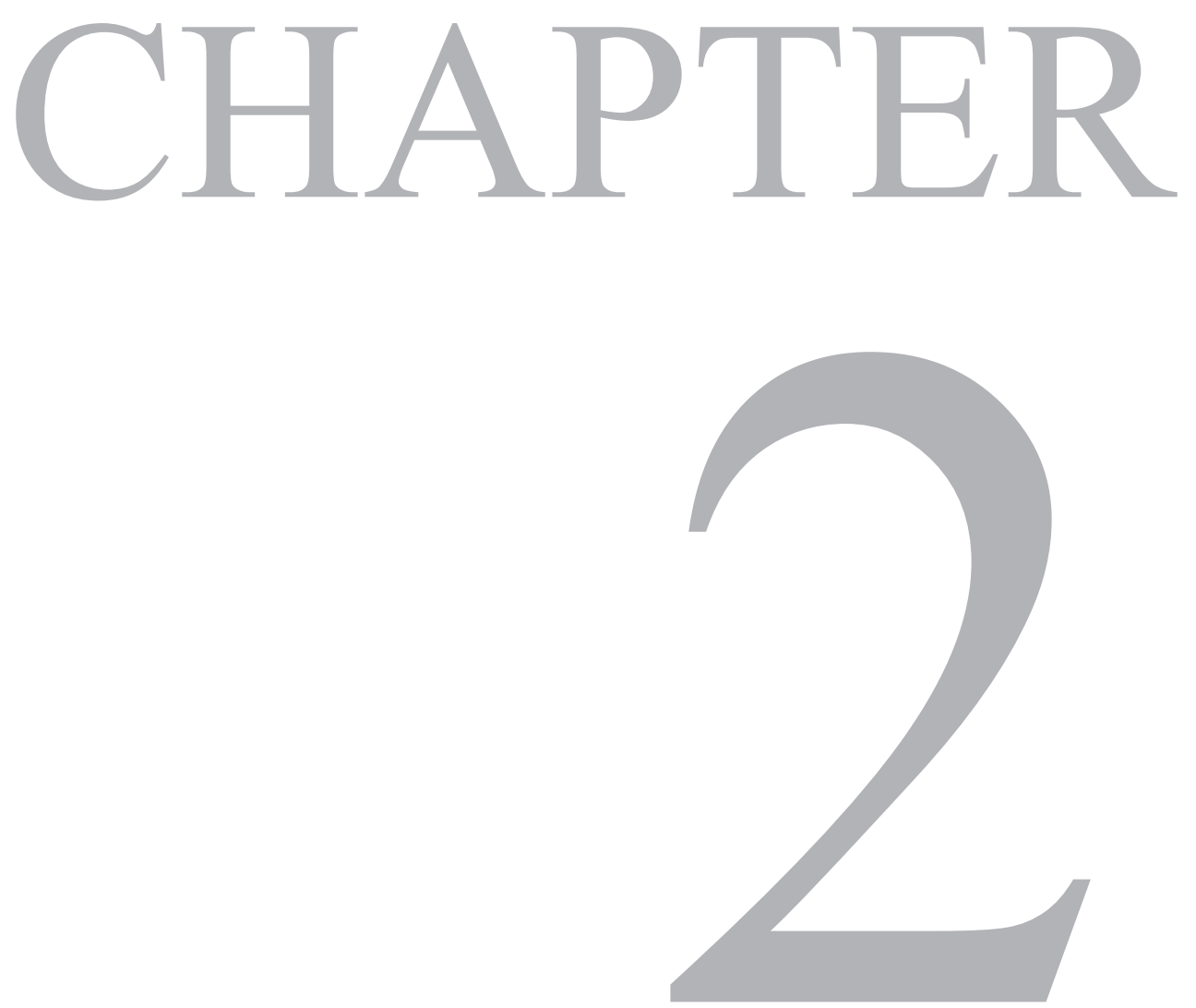

Resource depletion, where

is an intervention most effective? 
This page is intentionally left blank. 


\section{Chapter 2's purpose}

This study's societal end goal is to contribute towards mitigating the problem of resource depletion. Changeability has been selected as the means through which to pursue this goal. To understand the limitations of pursuing this goal through these means, it is necessary to understand the problem of resource depletion. Chapter 2's purpose is to develop both a comprehensive understanding of, and initial support for, the problem of resource depletion. In this study, changeability is not pursued for the sake of changeability. Changeability is pursued for the sake of mitigating the problem of resource depletion. Chapter 2's outcomes must guide this pursuit of changeability in the right direction. 
This page is intentionally left blank. 


\subsection{Introduction}

Many authors have pointed out that the current usage of natural resources cannot be maintained forever (Boulding, 1966; Diederen, 2010; McDonough and Braungart, 2002; Meadows et al., 1972; Stahel, 1984). Some claim that society's standards are too high and that this is part of the problem (e.g. Diederen, 2010), while others deny that lower standards are necessary to resolve resource depletion (e.g. McDonough and Braungart, 2002). However, all agree that the take, make and dispose approach to achieving those standards is unsustainable. A substantial share of resource usage, and therefore the problem, is related to the construction sector (see Krausmann et al., 2009). According to Rittel and Webber (1973, p. 159), with such problems, known as "wicked problems", it is "...less apparent where and how we should intervene even if we do happen to know what aims we seek". Practitioners often use heuristics, i.e. rules of thumb, to make such decisions (see Persson and Ryals, 2014), because the available time to both search for information and make tough decisions are limited in real-world decisions.

A distinction can be made between two types of heuristics (rules of thumb): (1) rules that prioritize certain actions; and (2) rules that prioritize certain intervention areas. An example of the first type is the triad approach. It prescribes the following sequence of actions, ranging from most to least effective: (1) prevention of unnecessary use; (2) substitutional use; and (3) prudent conduct (see Entrop and Brouwers, 2010). An example of the second type is to prioritize energy efficiency during a building's daily operation over energy efficiency during its construction. In the first type of heuristics, one generalizes the impact of content, irrespective of its context. In the second type, one generalizes the role of context, irrespective of its content.

Rules of thumb can be very useful. However, many mistakes are made when practitioners rely on heuristics that they have developed informally themselves over time and based on their own experiences (see Tversky and Kahneman, 1974). Therefore, there is value in developing such heuristics in a more systematic manner. This chapter focuses on heuristics of the second type, i.e. rules that prioritize certain intervention areas. Of the two types, this type is arguably the least established within the field of construction. 


\subsection{Method}

\subsubsection{Introduction}

This chapter's aim is to rank areas of the resource system, according to how much of a change can be expected from interventions in an area, in relation to the problem of depleting resources. In other words, where does one need to intervene in to be most effective? First, the areas are defined. After that, they are compared and ranked.

\subsubsection{Define the areas}

The resource system can be viewed in two ways: (1) as a process, i.e. a sequence of steps (e.g. Stahel, 1984); or (2) as a hierarchy, i.e. a cumulation of levels (e.g. Meadows, 1999). In this chapter, the process perspective has been adopted to define the intervention areas. To first define areas and afterwards rank them is only possible in this perspective. In the hierarchy perspective, the ranking of areas is the relation between them. The following principles of Structured Analysis (Ross, 1977) are used to create a process perspective of the resource system: (1) each model must have precisely one "viewpoint" and one "purpose"; (2) nothing which fits the purpose and viewpoint may be excluded; (3) each model must be composed of "things" and "happenings"; and (4) each model must be composed of neither too few nor too many pieces. Furthermore, Boulding (1966) noted that a perspective with too much emphasize on "throughput" may be part of the problem. Therefore, stocks have been added to the list of building blocks (things and happenings). The intervention areas will become clear from the resulting model.

\subsubsection{Compare and rank the areas}

According to Saaty (1990, p. 12), "the most effective way to concentrate judgement is to take a pair of elements and compare them on a single property without concern for other properties". When this has been done for all elements and all properties, the results are added together. This is termed the Analytic Hierarchy Process. The effectiveness of intervening in an area is determined by the following two properties: (1) how much there is to be gained in an area; and (2) how much an intervention in an area is expected to snowball, i.e. to cause a snowball effect.

The first property, i.e. how much there is to be gained in an area, is composed of both: (a) the initial amount and (b) its previous exploitation, i.e. how much of that amount has already been exploited. Hayek (1967, pp. 96-105) used the term "human action" to describe something that happened without purposeful human design but not without 
human influence. The initial amount is a result of human action, while the previous exploitation is a result of purposeful human design.

This distinction is useful because an area's previous exploitation indicates how effective future exploitations of that area will be. In economics, there is a rule of thumb named "the law of diminishing returns" (Oxford Dictionary of Economics, 2012). It states that a continuing application of effort toward a particular goal will decline in effectiveness after a certain level of result has been achieved (see von Bertalanffy, 1968, pp. 60-63). In other words, when an area has already been substantially exploited, future interventions will be increasingly less effective.

The second property, i.e. how much an intervention in an area is expected to snowball, also comprises two parts: (a) the connectedness between areas; and (b) the range of potential interventions. Firstly, when an area is closely connected to other areas, a change in that area will ripple through the areas directly next to it. This ripple effect will not happen in an isolated area. Thus, more of a snowball effect is expected in more connected areas. Secondly, only certain interventions are possible within each area. Some interventions cause more of a snowball effect than others. Thus, when such interventions are not possible within an area, less of a snowball effect can be caused there. However, more of an effect is expected from interventions in areas where the less effective interventions are not possible.

Table 1 shows how the intervention areas will be compared. First, the areas are scored (between 1 and 5) on each sub-property. These scores are all relative. They are based on answers for the following type of question: why is area $[\mathrm{x}]$ better/worse in property $[\mathrm{y}]$ than others? Each score is then multiplied by a weighting factor $\left(1 / 3^{\text {rd }}\right.$ or $\left.1 / 6^{\text {th }}\right)$, because two of the properties are more important than the others. The final score is calculated by adding the weighted scores together.

\begin{tabular}{|c|c|c|c|c|c|}
\hline $\begin{array}{c}\text { intervention } \\
\text { areas }\end{array}$ & $\begin{array}{c}\text { scores } \\
\text { on }(1 \mathrm{a}) \\
\text { initial } \\
\text { amount }\end{array}$ & $\begin{array}{c}\text { scores } \\
\text { on }(1 \mathrm{~b}) \\
\text { previous } \\
\text { exploitation }\end{array}$ & $\begin{array}{c}\text { scores } \\
\text { on }(2 \mathrm{a}) \\
\text { connectedness } \\
\text { between areas }\end{array}$ & $\begin{array}{c}\text { scores } \\
\text { on }(2 \mathrm{~b}) \\
\text { range of } \mathrm{p} . \\
\text { interventions }\end{array}$ & $\begin{array}{c}\text { final } \\
\text { scores }\end{array}$ \\
\cline { 1 - 2 } area 1 & score $\cdot(1 / 3)+\operatorname{score} \cdot(1 / 6)+\operatorname{score} \cdot(1 / 3)+\operatorname{score} \cdot(1 / 6)=$ & $\ldots$ \\
\cline { 1 - 1 } area 2 & score $\cdot(1 / 3)+\operatorname{score} \cdot(1 / 6)+\operatorname{score} \cdot(1 / 3)+\operatorname{score} \cdot(1 / 6)=$ & $\ldots$ \\
\cline { 1 - 1 } area 3 & score $\cdot(1 / 3)+\operatorname{score} \cdot(1 / 6)+\operatorname{score} \cdot(1 / 3)+\operatorname{score} \cdot(1 / 6)=$ & $\ldots$ \\
\hline
\end{tabular}

Table 1. How the intervention areas will be compared. 


\subsection{Results}

\subsubsection{A process perspective}

\subsubsection{Introduction}

Figure 2 shows the process of using resources. A grey box represents a stock and a white box represents an activity. The symbols $(-)$ and $(+)$ show when things are subtracted from or added to a stock, respectively, while the symbols $(--)$ and $(++)$ show when something is consumed or generated, respectively. Furthermore, the symbols (») and («) show when products' lifespans are unfavourably or favourably affected, respectively.

\subsubsection{Viewpoint and purpose}

The "viewpoint" is the topic of a Structured Analysis (Ross, 1977, p. 18), in this case: resource usage. The "purpose" determines the importance of things and happenings in the systemization (Ross, 1977, p. 18). It determines what is and what is not to be included from the viewpoint. The purpose of this model: to optimize resource effectiveness in the interests of the collective, i.e. humankind.

Owning or having access to certain amounts of particular products is a universal preference. Through the use of such products, people attain something intangible which is termed material well-being. Material well-being is seen as a condition of the psyche (see Boulding, 1966, pp. 8-10) which lessens overtime and is supplemented through the use of products. In other words, material well-being is a stock which regularly needs to be replenished. The optimum level of material well-being which should be strived for - and its distribution amongst society - is beyond the scope of this chapter. However, maximizing the level of material well-being that can be sustained provides the most suitable boundary conditions for addressing resource allocation.

\subsubsection{Phases}

A distinction can be made between two phases: the manufacturing phase and the operation phase. Eekhout (1997, pp. 27-33) describes the process of manufacturing building products in six steps: (1) raw materials are purified to mono materials; (2) mono materials are mixed to form composites; (3) composites are shaped to materials of commerce; (4) materials of commerce are adapted to elements; (5) elements are assembled into components; and (6) components are assembled into products. This sequence of steps is universally applicable, though not all manufacturing processes go through all of the steps. Each process always starts with a resource. Thus, before any of these six steps can happen, resources need to be extracted (step 0 ). Also, all products 


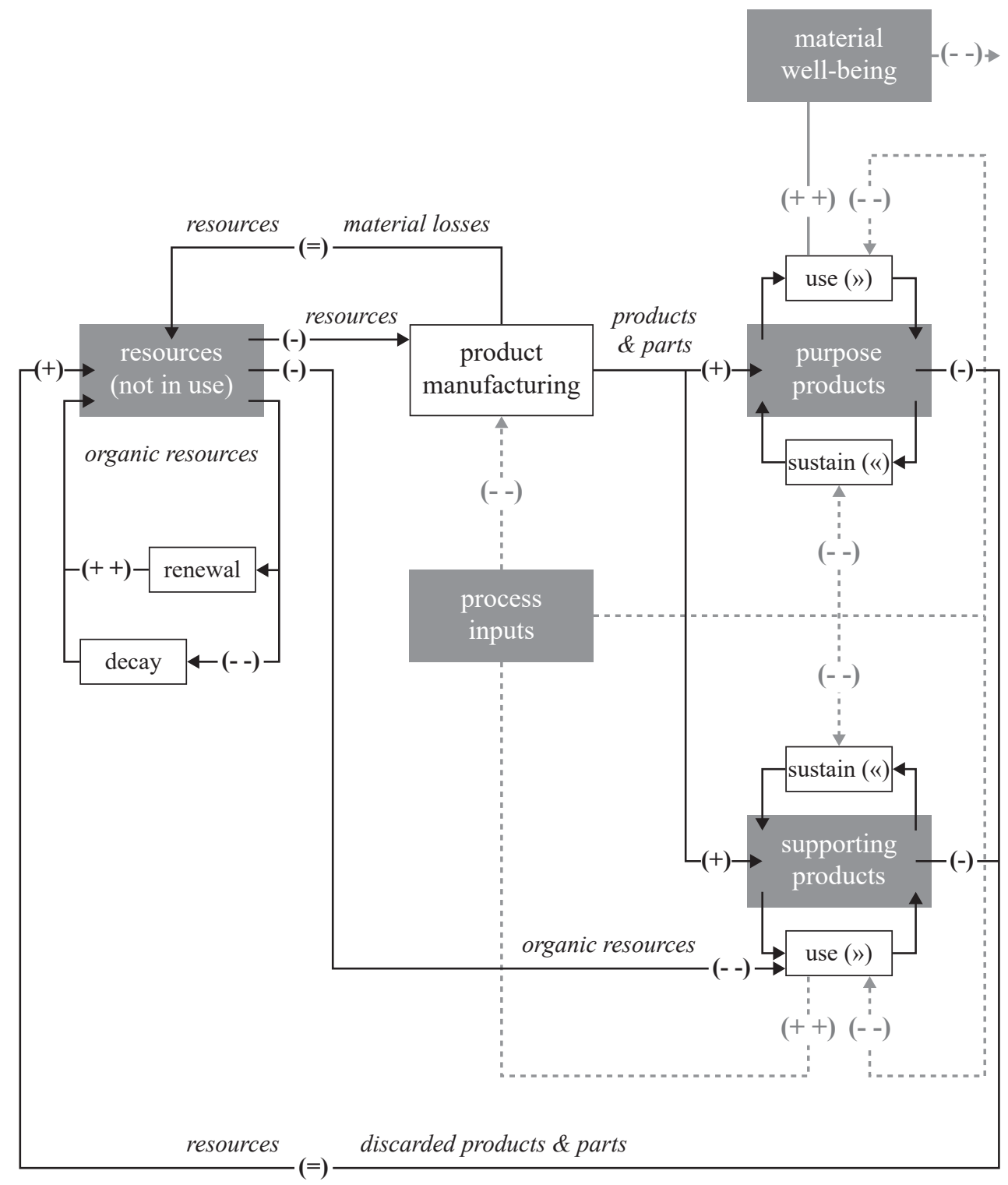

Figure 2. The process of using resources. A grey box represents a stock and a white box represents an activity. The symbols (-) and (+) show when things are subtracted from or added to a stock, respectively, while the symbols (- $)$ and $(++)$ show when something is consumed or generated, respectively. Furthermore, the symbols (») and («) show when products' lifespans are unfavourably or favourably affected, respectively. 
are made for a purpose. After all the other steps have been completed, the product is handed over (step 7). In the construction sector, this generally means that the product is placed or installed at a specific location.

When a product is handed over, this conventionally means that its ownership is also handed over. The operation phase is associated with the concept of ownership. The operation phase begins when the product is handed over to a consumer. It ends when this ownership ends. Ownership can end in two ways: (1) a party willingly takes over the product; or (2) it is disposed of. In the first situation, the product's removal is the first step of the manufacturing phase, i.e. the extraction of a resource. In the second situation, the product's disposal is the final step of the operation phase. Afterwards, if the product is salvaged from the place it was dumped at, this salvaging action is the first step of a new manufacturing phase.

Furthermore, products' longevity is closely associated with the phases. Though it cannot be referred to as a phase itself, products' longevity does determine the relative importance of the manufacturing phase versus the operation phase. With longer lifespans, the operation phases become longer. Therefore, products do not need to be remanufactured as often.

\subsubsection{Material inputs}

Materials can be classified as either organic or inorganic (Czichos, 2006). Organic materials can then be classified as materials that quickly renew (grow back) or materials that require a long time to renew. This distinction is useful because even crude oil is organic in origin (see Oxford Dictionary of Chemical Engineering, 2014), despite the fact that almost no oil 'grows back' in a generation's lifetime because its renewal rate is so low.

Material inputs are presented (in Figure 2) as something which is only redistributed and reconfigured. There are two exceptions: (1) the renewal and decay of organic resources; and (2) the incineration of organic resources to generate energy. Other than that, there is no way for resources to enter or leave the system. This may seem somewhat counterintuitive in relation to the concept of waste. However, waste is not a physical loss of resources, but a loss in value. Since people extract materials from their natural settings rather than from disposed and valueless products, it must be easier and cheaper to exploit virgin resources. In other words, due to the initial manufacturing process, materials have become less suitable for future manufacturing processes.

For energy, the concept of exergy, which describes the usefulness of energy states (Rant, 1956), was introduced to describe such a loss of usefulness. A similar concept 
can be used to describe the usefulness of material states, as matter and energy are alike in the fact that it is more troublesome to concentrate diffused particles than it is to diffuse concentrated ones (see Diederen, 2010, p. 8). In Figure 2, both material losses in manufacturing and discarded products $\&$ parts in operation are categorized as resources. They both only differ from virgin resources in terms of material states.

\subsubsection{Process inputs}

All products do not contribute in the same way to material well-being. A distinction is made between products that contribute directly and those that contribute indirectly to material well-being. For example, a pair of trousers fulfils a clear purpose; a person benefits directly from wearing it. Such a product is referred to as a purpose product. A washing machine, on the other hand, makes it easier to maintain products such as a pair of trousers. People do not benefit from a washing machine in and of itself. However, it improves the ease of use of other products greatly. Such a product is referred to as a supporting product. This distinction is useful because products that have a more direct link to material well-being are harder to change without affecting their contribution to material well-being.

In Figure 2, the relation between purpose products and supporting products is shown as follows: (1) supporting products produce process inputs; and (2) the consumption of such inputs represents the use of such products. This is similar to how a lay person, i.e. a non-physicist, describes energy: a source that is generated and consumed. For supporting products, this description makes sense from the perspective of products' technical lifespan (see Gijsbers, 2011, pp. 21-23). All products undergo wear and tear that will eventually break them down.

From this perspective, a screwdriver does not differ from a solar panel. Both are made to provide a certain supporting service. For the solar panel, this service is generating energy. For the screwdriver, this service is tightening and loosening screws. A solar panel is limited in the amount of energy it can generate in its lifetime, because all products only remain functional for a limited time. Similarly, a screwdriver is limited in the amount of times it can be used. A process input represents a supporting product's functional contribution. This can thus be an amount of energy, but also the application of a product.

\subsubsection{Intervention areas}

From the model, five intervention areas are defined. These areas are listed in Table 2. An area is defined by two focusses. Each area focusses on either (a) the manufacturing 
phase or (b) the operation phase, and within that scope, each area focusses on (a) material inputs or (b) process inputs. However, the fifth area is an exception. It does not focus on one of the phases, but instead it focusses on the longevity of products. Products' longevity determines the relative importance of the manufacturing phase versus the operation phase. With longer lifespans, the operation phases become longer. Therefore, products do not need to be remanufactured as often. The manufacturing process consumes process inputs (see Figure 2). So, when products do not need to be remanufactured as often, fewer process inputs are required for manufacturing. This is the numerical effect of an intervention in products' longevity.

Nonetheless, the effects of such interventions are mostly visible during the operation phase. Buildings last longer when it is easy to modify them and when it is easy to use them differently. Both these activities are related to the operation phase. When a building is adaptable, it is easily modified. Therefore, when a part of such a building needs to be updated, it is easier to make space for the update. This implies a numerical effect on the process inputs to the operation phase. However, in a non-adaptable building, such an update will often be too costly. Instead, updates are postponed until the entire building is replaced, which would happen a lot sooner without updates. So, despite the fact that an intervention in products' longevity mostly changes how the operation phase works, it mostly has a numerical effect on the manufacturing phase. Neither of the two phases completely cover the effects of an intervention in products' longevity. Therefore, products' longevity is set apart as a separate area.

\begin{tabular}{|l|l|l|}
\hline no. & \multicolumn{1}{|c|}{ description } & code \\
\hline 1 & (a) material inputs (a) to manufacturing & a.a. \\
\hline 2 & (b) process inputs (a) to manufacturing & b.a. \\
\hline 3 & (a) material inputs (b) to operations & a.b. \\
\hline 4 & (b) process inputs (b) to operations & b.b. \\
\hline 5 & (c) products' longevity & c. \\
\hline
\end{tabular}

Table 2. The five intervention areas.

\subsubsection{Ranking}

\subsubsection{Introduction}

In this section, all areas are ranked, i.e. put in a sequence from best to worst. A separate ranking is made for each of the following sub-properties: (1) initial amount; (2) previous exploitation; (3) connectedness between areas; and (4) range of potential interventions. 
Each area is given a score of between 1 and 5 based on its position in a ranking. Priority is given to providing a complete picture. So, some reasons behind a ranking will be better than others. Markings are used to clarify the author's thoughts about the validity of an area's rank. Each time a rank is assigned, it is marked with either two asterisks $(* *)$, one asterisk $(*)$ or no asterisks $(-)$. The number of asterisks symbolizes the author's confidence in the ranking, in which more asterisks signifies more confidence (this marking system is adopted from Alexander et al., 1977, pp. xiv-xv).

\subsubsection{Initial amount}

Table 3 shows how the five areas are ranked according to how much there initially was to be gained in an area. There are three reasons behind this ranking. Reason \#1: a shortage of materials is not different from a shortage of process inputs. A distinction can be made between "resource reserves" and the "resource base" (Ashby, 2012, pp. 32-33). The resource base represents all resources that exist on this planet. The resource reserves represent a share of the resource base. It includes all resources that can be accessed using today's technology for a reasonable price. Many authors (e.g. Allwood et al., 2011; Boulding, 1966; Diederen, 2010; Meadows et al., 1972) seem to believe that depleting resources does not mean that the base is running out of resources, but that the reserves are depleting.

When the reserves of a specific resource are running out, there are two options: (1) to not use the material anymore, because it has become too costly to extract; or (2) to reserve a greater share of all process inputs for its extraction, because the resource cannot be missed. A lack of a specific material can thus be compensated for by allocating more process inputs. On the other hand, insufficient process inputs makes the extraction of materials more difficult. A shortage of materials and a shortage of process inputs cannot be isolated from one another; they represent the same problem.

Reason \#2: more can be gained in operations than in manufacturing. Of the two, the operation phase is the most significant phase, because buildings and building products last a long time. For example, the exterior of a building changes "every 20 years or so", and its installations "wear out or obsolesce every 7 to 15 years" (Brand, 1994, p. 13). Also, a house lasts on average about 30 years in Japan, 55 years in the United States and 77 years in the United Kingdom (Eguchi et al., 2011, p. 74, Figure 1).

The time that a house is used can be more than 50 times as long as the time it takes to construct it (e.g. 9 months of construction and 50 years of use). During that time, a building requires a lot of energy, for example for heating and lighting; "it has been confirmed [by several studies] that operation energy is by far the most important 
contributor to life cycle impacts of conventional buildings" (Blengini and Di Carlo, 2010, p. 869).

Furthermore, not all materials pass through the manufacturing phase before they go into the operation phase: a substantial share of all extracted resources are immediately combusted to generate energy (see Krausmann et al., 2009). The operation phase involves more materials, than the manufacturing phase, in this regard. However, a similar claim can also be made for manufacturing: not all materials that are processed in the manufacturing phase end up in the final products. For example, Hicks et al. (2004, p. 170) studied a manufacturing process in which (about) $23 \%$ of incoming materials were wasted by the end of the process. This is referred to as yield loss (Allwood et al., 2011, p. 365).

Reason \#3: products' longevity and the manufacturing phase are also significant intervention areas. Seeing how the average lifespan of houses varies across different cultures, each with their own construction methods, gives some idea about how much longevity can be gained by a good design, a suitable financial model and a suitable construction process. However, research mostly highlights the importance of the operation phase. Little information points towards the potential of the manufacturing phase or products' longevity. Therefore, these areas are given a neutral score (3).

\begin{tabular}{|l|l|c|c|}
\hline rank & area & score & validity \\
\hline 1 & material inputs to operations (a.b) & 5 & $* *$ \\
& process inputs to operations (b.b) & 5 & $* *$ \\
\hline \multirow{2}{*}{2} & products' longevity (c) & 3 & - \\
& material inputs to manufacturing (a.a) & 3 & $*$ \\
& process inputs to manufacturing (b.a) & 3 & $*$ \\
\hline
\end{tabular}

Table 3. The ranking of intervention areas in terms of the initial amount. A score of 5, 3 or 1 means that an area scores best, neutral or worst, respectively, on this sub-property. A validity of 2, 1 or 0 asterisks means that the author is most, averagely or least confident, respectively, in the validity of the ranking.

\subsubsection{Previous exploitation}

Table 4 shows how the five areas are ranked according to how little of an area has already been exploited. There are three reasons behind this ranking. Reason $\# 1$ : operation energy has been a very popular intervention area. For example, the European Parliament's energy directive (2010) mandates that future buildings have to be built as "nearly zero-energy buildings". It is no wonder that "...especially for new and low 
energy buildings, the relative role and the importance of life cycle phases are changing" (Blengini and Di Carlo, 2010, p. 869). However, only $0.25 \%$ of old houses are replaced annually in the Netherlands (Thomsen and van der Flier, 2009, p. 653). Thus, it will take quite some time before all houses are nearly zero-energy buildings.

Reason \#2: the manufacturing phase has not received the same amount of attention as operation energy. The manufacturing phase has received some attention. For example, yield losses in Sweden have been halved in eight years (Shahbazi et al., 2016). This attention just has not been at the same level as the attention to reducing operation energy.

Reason \#3: of the five areas, products' longevity has received the least attention. Instead of improving, buildings' longevity may very well be decreasing over time. In Zurich (Switzerland) for example, buildings do not even last half as long as they used to (Aksözen et al., 2017, p. 254, Fig. 10). A similar trend can be seen for consumer products. For example, the expected lifespan of personal computers has almost been halved in fifteen years (Babbitt et al., 2009). This intervention area may have received less attention than the others, because the threshold is higher for intervening in longevity - such interventions are not straightforward.

\begin{tabular}{|l|l|c|c|}
\hline rank & area & score & validity \\
\hline 1 & products' longevity (c) & 5 & $*$ \\
\hline 2 & material inputs to manufacturing (a.a) & 3 & - \\
& process inputs to manufacturing (b.a) & 3 & $*$ \\
& material inputs to operations (a.b) & 3 & $*$ \\
& process inputs to operations (b.b) & 2 & $* *$ \\
\hline
\end{tabular}

Table 4. The ranking of intervention areas in terms of the previous exploitation. A score of 5, 3 or 1 means that an area scores best, neutral or worst, respectively, on this sub-property. A validity of 2, 1 or 0 asterisks means that the author is most, averagely or least confident, respectively, in the validity of the ranking.

\subsubsection{Connectedness between areas}

Figure 3 shows how an intervention in one area affects the others. In Figure 3, a number 1 is placed in all cells across the diagonal. A number 1 represents the focus area, i.e. the area that people try to change through an intervention. Next, horizontal arrows start from number 1 cells and end up in number 2 cells. These arrows represent ripple effects. An intervention's effect on a number 1 cell ripples through the number 2 cells 


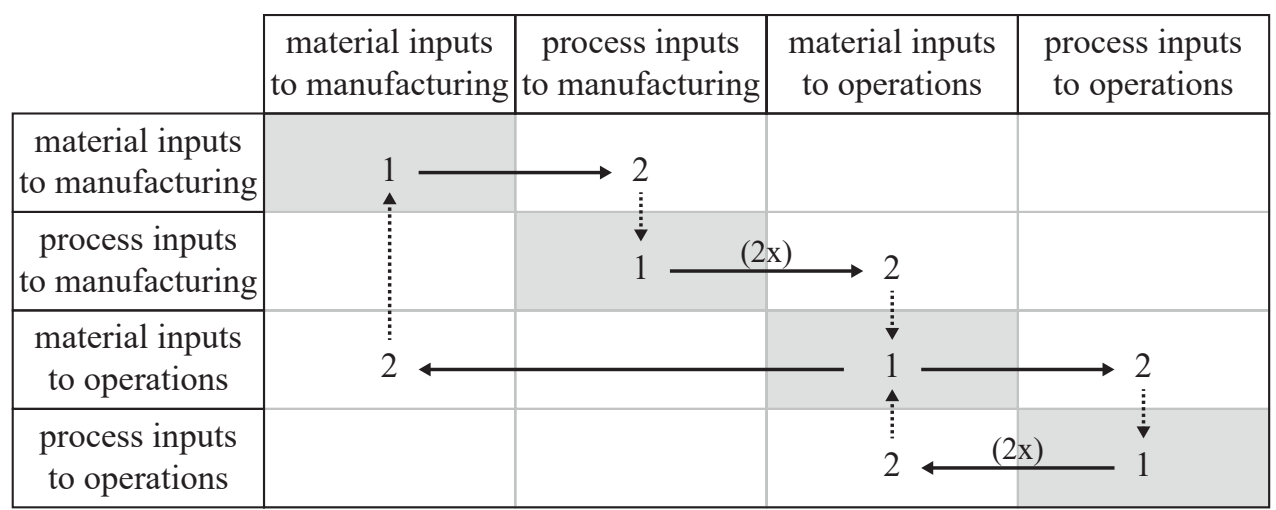

Figure 3. How an intervention in one area affects the others. A number 1 cell represents the focus area. The horizontal arrows represent a ripple effect. An intervention's effect on a number 1 cell ripples through the number 2 cells within the same row. How this effect ripples further is made clear by the vertical arrows. For every number 2 cell, a vertical arrow points towards the row that describes its further progress.

within the same row. After that, the effect on a number 2 cell ripples further (although, the effect becomes increasingly less). How this effect ripples further is made clear by the vertical arrows. For every number 2 cell, a vertical arrow points towards the row that describes its further progress.

The first row of Figure 3 describes the following: when less material goes into the manufacturing process, fewer process inputs are required (assuming a constant requirement per processed quantity of material). The third row describes something similar: when fewer products are used, fewer process inputs are required. For example, each product requires some maintenance. Thus, when people have more products, they have more things to maintain. However, the third row also describes a situation in which fewer products are used and, therefore, fewer products need to be made. This affects the material inputs to manufacturing. However, this does not hold true for the other way around; less material can be used in manufacturing without making fewer products (e.g. by making lighter products).

The second and fourth rows of Figure 3 describe the following: when fewer process inputs are required, fewer supporting products are needed to generate such inputs, and fewer inputs will be combusted for generating energy, i.e. two times a reduction of material inputs to the operation phase. An intervention in the inputs that are combusted for generating energy is the only type of intervention that does not have a further effect on any of the other areas. 
In summation: (1) an intervention in the material inputs to operations indirectly affects two other areas; (2) an intervention in the process inputs affects one other area in two different ways, and only one of those ways has a further effect on another area; and (3) an intervention in the material inputs to manufacturing only affects one other area. Table 5 shows how the five areas are ranked according to how connected an area is to other areas. Products' longevity is scored the same as the process inputs to the manufacturing phase, because an intervention in longevity only has a numerical effect on this area (see 3.1.6.).

\begin{tabular}{|l|l|c|c|}
\hline rank & \multicolumn{1}{|c|}{ area } & score & validity \\
\hline 1 & material inputs to operations (a.b) & 5 & $* *$ \\
\hline 2 & products' longevity (c) & 3 & - \\
& process inputs to operations (b.b) & 3 & $*$ \\
& process inputs to manufacturing (b.a) & 3 & $*$ \\
\hline 3 & material inputs to manufacturing (a.a) & 2 & $*$ \\
\hline
\end{tabular}

Table 5. The ranking of intervention areas in terms of the connectedness between areas. A score of 5, 3 or 1 means that an area scores best, neutral or worst, respectively, on this sub-property. A validity of 2, 1 or 0 asterisks means that the author is most, averagely or least confident, respectively, in the validity of the ranking.

\subsubsection{Range of potential interventions}

Table 6 shows how the five areas are ranked in terms of their range of potential interventions. The reasons behind this ranking are as follows: (1) all potential interventions in products' longevity cause a considerable snowball effect; (2) none of the potential interventions in manufacturing cause much of a snowball effect; and (3) of the potential interventions in operations, some do and some do not cause a considerable snowball effect.

According to Meadows (1999), one of the greatest snowball effects is achieved by changing the "rules" of a system. On the other hand, changing the "parameters" of a system does not cause much of a snowball effect. The parameters of a system include everything that can be described by a number. For example, the number of elements is a parameter, but also the strength of a relation between two elements. The rules of a system describe where the relations between elements are placed and how they work (cf. Meadows, 1999, pp. 5-7; von Bertalanffy, 1968, pp. 54-55). Table 7 lists 14 interventions in resource usage that have been mentioned by other authors. For each of 
these interventions, Table 7 shows the following: (1) the intervention area; and (2) the intervention level, i.e. whether the intervention affects the system's parameters or the system's rules.

Light-weighting, i.e. making products that contain less material, is an example of an intervention in the system's parameters. Such an intervention changes the product, but it does not change how the product is handled and, therefore, it does not cause much of a snowball effect. Selling things on a performance based lease (see Stahel, 2010) is an example of an intervention in the system's rules. Normally a person buys a product and becomes its owner. Then, if the product is not working as it should be, or if it is not as efficient as it should be, a person can complain and, the next time, he or she can buy a different product. However, when the manufacturer remains responsible for the performance of the product, the situation will be different. For example, when the product wastes energy, the owner has to pay for that. When the manufacturer is the owner, they will be stimulated to improve on such aspects of their product. This changes how the product is handled and, therefore, it causes a considerable snowball effect.

In Table 7, four interventions are categorized as the type parameters/rules. This means that these interventions are harder to put in one of the two categories. For example, there are two ways to interpret remanufacturing and component re-use: (1) as new relations, i.e. material flows that previously did not exist; or (2) as a strengthened relations, i.e. more product and parts are re-used and remanufactured than they used to be. For this ranking, these four borderline cases are put in the same category as other interventions associated with the same area. Thus, remanufacturing and component re-use affect a system's parameters, while physical durability and reliability affect a system's rules.

\begin{tabular}{|l|l|c|c|}
\hline rank & \multicolumn{1}{|c|}{ area } & score & validity \\
\hline 1 & products' longevity (c) & 4 & $*$ \\
2 & material inputs to operations (a.b) & 3 & $*$ \\
& process inputs to operations (b.b) & 3 & $* *$ \\
\multirow{2}{*}{3} & process inputs to manufacturing (b.a) & 2 & - \\
& material inputs to manufacturing (a.a) & 2 & $*$ \\
\hline
\end{tabular}

Table 6. The ranking of intervention areas in terms of the range of potential interventions. A score of 5,3 or 1 means that an area scores best, neutral or worst, respectively, on this sub-property. A validity of 2, 1 or 0 asterisks means that the author is most, averagely or least confident, respectively, in the validity of the ranking. 


\begin{tabular}{|l|l|c|c|}
\hline \multicolumn{1}{|c|}{ source } & \multicolumn{1}{|c|}{ intervention } & \multicolumn{1}{c|}{ area } & level \\
\hline Allwood et al., 2011 & increased recycling rates & p. inputs to manufacturing & parameters \\
Allwood et al., 2011 & yield improvement & m. inputs to manufacturing & parameters \\
Allwood et al., 2011 & more intense use & m. inputs to operations & rules \\
Allwood et al., 2011 & remanufacturing & p. inputs to manufacturing & parameters/rules \\
Allwood et al., 2011 & component re-use & p. inputs to manufacturing & parameters/rules \\
Allwood et al., 2011 & light-weighting & m. inputs to manufacturing & parameters \\
Stahel, 2010 & performance based leasing & p. inputs to operations & rules \\
Bocken et al., 2016 & emotional durability & products' longevity & rules \\
Bocken et al., 2016 & physical durability & products' longevity & parameters/rules \\
Bocken et al., 2016 & reliability & products'longevity & parameters/rules \\
Bocken et al., 2016 & ease of maintenance and repair & products' longevity & rules \\
Bocken et al., 2016 & upgradability and adaptability & products' longevity & rules \\
Bocken et al., 2016 & standardization and & products' longevity & rules \\
& compatibility & products' longevity & rules \\
\hline Bocken et al., 2016 & dis- and reassembly & \multicolumn{2}{|c}{} \\
\hline
\end{tabular}

Table 7. Interventions in resource usage mentioned by other authors. They are categorized in both intervention area and intervention level, i.e. whether the intervention affects the system's parameters or the system's rules.

\subsubsection{Final ranking}

Table 8 shows the final ranking. Each area has been given a score for each determining sub-property. The final score is calculated by multiplying each score by a weighting factor and by then adding the weighted scores together. The highest rank is given to the highest score. 


\begin{tabular}{|c|c|c|c|c|c|}
\hline $\begin{array}{l}\text { intervention } \\
\text { areas }\end{array}$ & $\begin{array}{c}\text { scores } \\
\text { on (1a) } \\
\text { initial } \\
\text { amount }\end{array}$ & $\begin{array}{l}\text { scores } \\
\text { on }(1 \mathrm{~b}) \\
\text { previous } \\
\text { exploitation }\end{array}$ & $\begin{array}{c}\text { scores } \\
\text { on }(2 \mathrm{a}) \\
\text { connectedness } \\
\text { between areas }\end{array}$ & $\begin{array}{c}\text { scores } \\
\text { on }(2 \mathrm{~b}) \\
\text { range of } \mathrm{p} \text {. } \\
\text { interventions }\end{array}$ & $\begin{array}{c}\text { final } \\
\text { scores }\end{array}$ \\
\hline $\begin{array}{l}\text { a) material inputs } \\
\text { b) to operations }\end{array}$ & $5 \cdot(1 / 3)$ & $3 \cdot(1 / 6)$ & $5 \cdot(1 / 3)$ & $3 \cdot(1 / 6)$ & $41 / 3$ \\
\hline $\begin{array}{l}\text { b) process inputs } \\
\text { b) to operations }\end{array}$ & $5 \cdot(1 / 3)$ & $2 \cdot(1 / 6)$ & $3 \cdot(1 / 3)$ & $3 \cdot(1 / 6)$ & $31 / 2$ \\
\hline $\begin{array}{l}\text { c) products' } \\
\text { longevity }\end{array}$ & $3 \cdot(1 / 3)$ & $5 \cdot(1 / 6)$ & $3 \cdot(1 / 3)$ & $4 \cdot(1 / 6)$ & $31 / 2$ \\
\hline $\begin{array}{l}\text { b) process inputs } \\
\text { a) to manufacturing }\end{array}$ & $3 \cdot(1 / 3)$ & $3 \cdot(1 / 6)$ & $3 \cdot(1 / 3)$ & $2 \cdot(1 / 6)$ & $25 / 6$ \\
\hline $\begin{array}{l}\text { a) material inputs } \\
\text { a) to manufacturing }\end{array}$ & $3 \cdot(1 / 3)$ & $3 \cdot(1 / 6)$ & $2 \cdot(1 / 3)$ & $2 \cdot(1 / 6)$ & $21 / 2$ \\
\hline
\end{tabular}

Table 8 . The final ranking. The final score is calculated by multiplying each score by a weighting factor and by then adding the weighted scores together. 
This page is intentionally left blank. 
This page is intentionally left blank. 


\subsection{Discussion and conclusion}

\subsubsection{Discussion}

In the Introduction, two types of heuristics were mentioned: (1) rules that prioritize certain actions; and (2) rules that prioritize certain intervention areas. The first type is easier to use; a person just does the action that is prescribed. For the second type, there are two options. Option 1: a person picks the intervention area that is prescribed, and comes up with an action that focusses on that particular area. Option 2: for each action that a person is considering, he or she thinks of the intervention area that it focusses on. That person then picks the action that focusses on the most important intervention area. To use heuristics of the second type, a good understanding is required of how actions affect the system. In this case, a good understanding is required of Figure 2. That makes it harder for decision makers to use such rules of thumb. However, when they do invest the time that is needed to learn how to use such heuristics, they will be more aware of what they are using. As a result, decision makers will make fewer mistakes; they will not use generalizations when they are not applicable. By following rules of thumb that prescribe actions, on the other hand, it is easy to oversimplify matters.

In this chapter, priority was given to providing a complete picture. Therefore, further improvements are necessary, especially in the individual sub-scores. The asterisks show which rankings are the least certain and thus require additional work the most. The Analytic Hierarchy Process makes explicit how the final ranking is composed. Therefore, it is easy to add to or improve the current reasoning.

\subsubsection{Conclusion}

This chapter's aim was to determine where one needs to intervene to be most effective. The answer is that one must prioritize intervention areas as follows: (1) material inputs to the operation phase; (2) process inputs to the operation phase and products' longevity; (4) process inputs to the manufacturing phase; and (5) material inputs to the manufacturing phase.

These results are generalizations, expressed as rules of thumb, and relying on rules of thumb is always risky. However, most decision are not made on the basis of rigorous analysis. These rules of thumb can help decision makers prioritize what is most important. When that happens, they will be one step closer to solving the problem of depleting resources. 
Chapter 3 was made in collaboration with Pieter R. Beurskens. The author of this dissertation wrote the final text, but earlier versions were written together. Data was also gathered and analysed together. Pieter has read the final version, and he gave permission to include this version in this dissertation. 

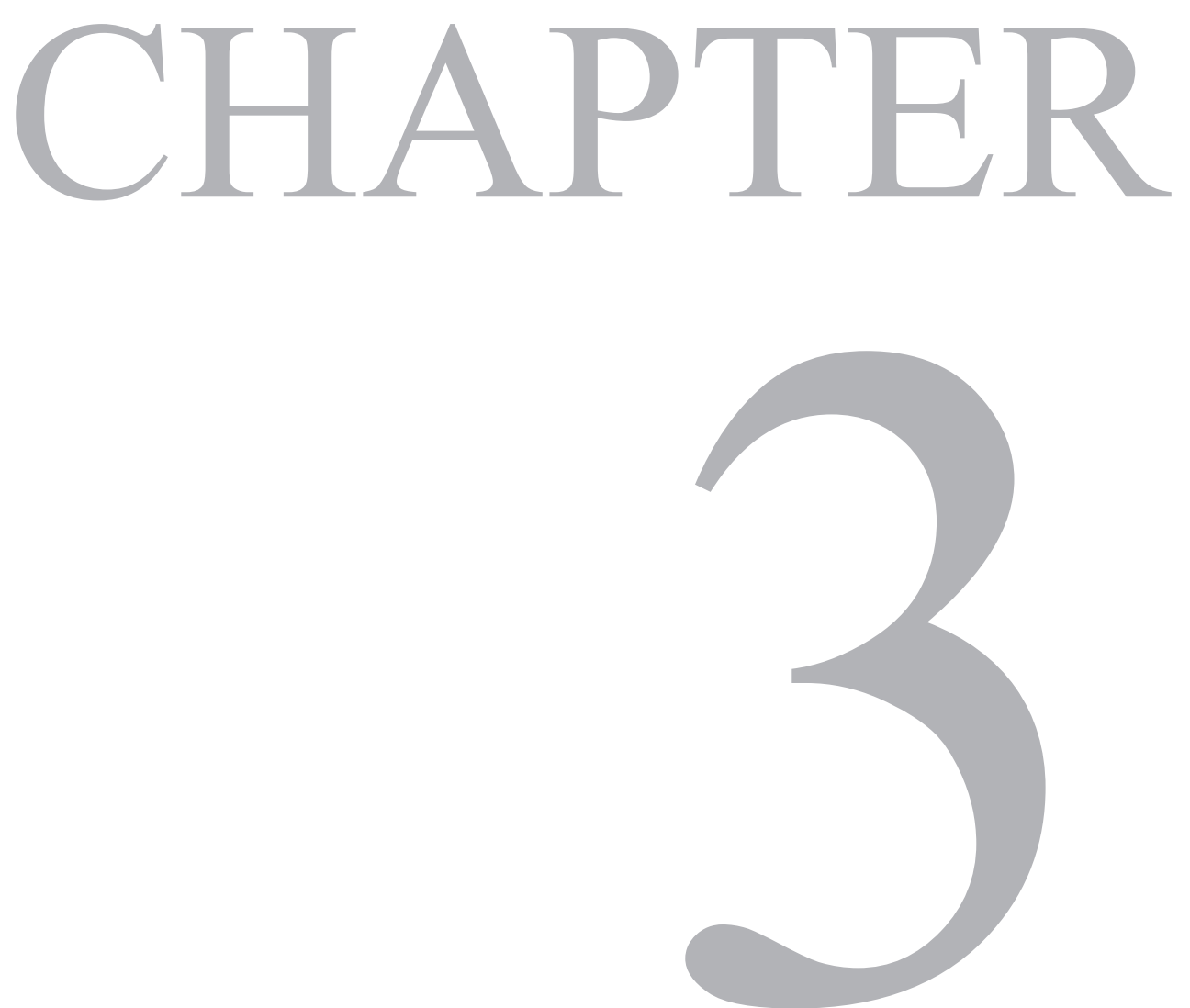

The evolution of ordinary

houses, does it justify

demolition? 
This page is intentionally left blank. 


\section{Chapter 3's purpose}

Longevity is the link between the topics of changeability and resource depletion. Thus, in order for changeability to have an effect on resource depletion, change must have an effect on longevity. Furthermore, within this effect that change has on longevity, design must matter. When a building's physical qualities are not taken into account in the decision-making process of the building's demolition, there is no point in improving a building's design in relation to future change. Chapter 3's purpose is to develop an initial understanding of the role of a building's physical qualities within the decisionmaking process of the building's demolition. Chapter 3's outcome must provide a first indication of to what extent a building's longevity is determined by its design. This knowledge will contribute to a more valid assessment of changeability's contribution towards mitigating the problem of resource depletion. 


\subsection{Introduction}

A house plays a central role in a person's life. More than half of a person's time is spend at home (Schweizer et al., 2006). In the Netherlands, annual investments in houses are twice as high as the combined annual investments in all other buildings (Soeter, 2010 , p. 2). On the one hand, developments in housing supply and demand indicate that houses must last hundreds of years (Meikle and Connaughton, 1994; Soeter, 2010, pp. 93-96). On the other hand, the average age of demolished buildings is not so high (see Huuhka and Lahdensivu, 2016, p. 87, Table 10; O'Connor, 2004, p. 6, Fig. 3), and may even be decreasing (see Aksözen et al., 2017, p. 254, Fig. 10).

The ordinary house is changing. Today's houses are not the same as houses from 100 years ago, and future houses will also differ from today's houses. Buildings are often demolished to make room for new buildings (Huuhka and Lahdensivu, 2016, p. 89, Table 12). Furthermore, people often say that a building needed to be demolished because it was "no longer suitable for [its] intended use" (O'Connor, 2004, p. 8, Fig. 7). However, according to Thomsen (2006, p. 21), social houses' demolition often has little to do with their physical qualities, instead various social factors mainly determine whether they are demolished or not.

This chapter's aim is to determine how the ordinary house, in the Netherlands, has changed throughout the last 100 years. This chapter focusses on both the spatial characteristics and the technical characteristics of houses. This information will be used to discuss: to what extent the house's evolution justifies demolition.

In the Netherlands, a lot of studies have already been done on housing (Bruggeman, 1981; Hasselaar, 2001; Liebregts and van Nunen, 2014; Prak, 1991; Priemus and van Elk, 1970; Thijssen 1999; Thijssen and Meijer, 1988; Vreeze, 2001). However, none of these studies completely fulfil this chapter's purpose. Half of them only focus on houses built in the 20 years after the Second World War (Bruggeman, 1981; Priemus and van Elk, 1970; Thijssen 1999; Thijssen and Meijer, 1988). Prak (1991) focused on an earlier time period (1800-1940), and Hasselaar's study (2001) focused only on the health and indoor climate aspects of buildings. In the two studies (Liebregts and van Nunen, 2014; Vreeze, 2001) that did cover a large enough part of recent history (100 years), it is unclear where their findings are based on. Therefore, this additional research is necessary.

In this chapter, 68 building projects are analysed. For this analysis, the documents included in building permit applications are used. These documents show how a building was originally constructed. Nijmegen is about the only city in the Netherlands with a 
completely digitalized building archive, that is publicly available online. Therefore, all selected projects are from Nijmegen. Previous studies did not focus on a single city. Therefore, whenever possible, this chapter's results are compared to the results of those previous studies. 
This page is intentionally left blank. 


\subsection{Method}

\subsubsection{Introduction}

A non-random sampling method is used to select the 68 cases. It is especially important, with such a method, to describe how cases are selected, how the data is collected and what the conclusions are based on (Baker et al., 2013, pp. 106-107). Without such transparency, it is impossible to judge how generally applicable the conclusions are. In the Method (3.2.) is described how cases are selected. In the Results (3.3.) is explained how the actual data is collected and what the conclusions are based on.

Four selection criteria are used: (1) type of residential building; (2) project size; (3) construction year; and (4) location. The first and second criteria must make sure that only ordinary houses are selected. These criteria are based on the "typicalness criterion" (Bull, 2005, p. 168). The third and fourth criteria must make sure that no type of ordinary house is excluded. These selection criteria are based on the "distinctness criterion" (Bull, 2005, p. 167).

\subsubsection{Type of residential building}

The type of residential building is determined by three characteristics: (1) type of entrance; (2) type of stack; and (3) type of row. The type of entrance refers to how a housing unit is entered. Option 1: the front door is directly connected to the public space. Option 2: the circulation space, directly in front of the front door, is intended for two housing units. Option 3: the circulation space, directly in front of the front door, is intended for more than two housing units.

The type of stack refers to how housing units are stacked on top of one another. A housing unit can be not part of a stack. Otherwise, a housing unit can be part of a stack of two, or a housing unit can be part of a stack of more than two. The type of row refers to how housing units are put in a row. A housing unit can be not part of a row. Otherwise, a housing unit can be part of a row of two, or a housing unit can be part of a row of more than two.

Figure 4 shows how the types of residential building are specified by different combinations of the options under each of these three characteristics. The following types are specified: freestanding house; double house; row house; two-family house; and block of flats. Block of flats is a broad term. Figure 4 shows the four different combinations, from the sample, that are referred to as a block of flats. Freestanding houses, double houses and row houses are all single-family houses. Two-family houses and blocks of flats are referred to as multiple-family houses. 
single-family housing

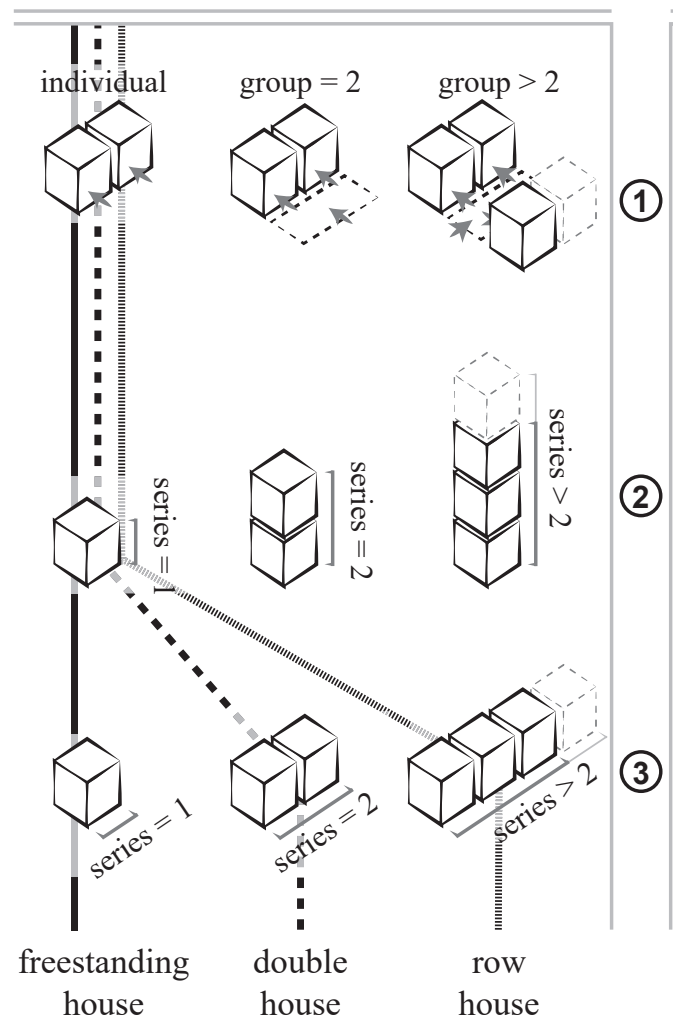

multiple-family housing

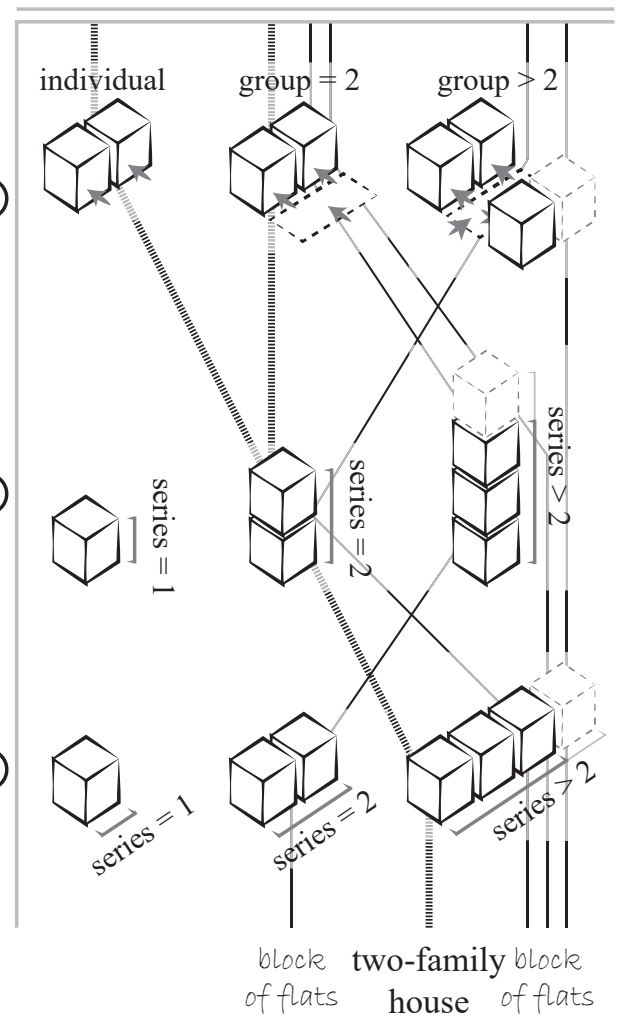

Figure 4. How the types of residential building are specified by different combinations of the options under each of the three characteristics, i.e. (1) type of entrance; (2) type of stack; and (3) type of row.

There is one exception to Figure 4. Some houses, that are in a row, are not referred to as row houses. These houses are known as "linked" houses. Two common examples are the "linked freestanding house" and the "linked double house" (see NVM et al., 2013). Row houses have a large part of their main-volume $(\geq 50 \%)$ directly next to each other. A weaker connection is referred to as a link.

Table 9 shows how common each type of residential building is in the Netherlands. These numbers are based on the "WoON12 dataset" (BZK \& CBS, 2013). In that study, almost 70.000 respondents filled in the type of building they live in. The row house is the most common type (41\%), in the Netherlands. The block of flats is the second most common type (20\%). The row house is a single-family house, and the block of flats is a multiple-family housing building. However, the block of flats is a relatively new 
type; high-rise buildings were introduced quite late in the Netherlands (Prak, 1991, p. 179; Wagenaar, 1992). Therefore, the two-family house (8\%) is added to the scope. As a result, the evolution of both single-family houses and multiple-family houses is included in the chapter.

Furthermore, three linked double houses are included in the sample. In Nijmegen, a lot of the houses, built between 1990 and 2000, are linked double houses. These three exceptions are included because they match best with the other selection criteria (project size, construction year and location).

\begin{tabular}{|lrrlr|}
\multicolumn{1}{l|}{ single-family housing } & $69,5 \%$ & & multiple-family housing & $30,6 \%$ \\
\cline { 2 - 2 } freestanding houses & $14,0 \%$ & & two-family houses & $8,4 \%$ \\
double houses & $12,3 \%$ & & blocks of flats & $20,0 \%$ \\
row houses & $41,0 \%$ & & others & $2,2 \%$ \\
others & $2,2 \%$ & &
\end{tabular}

Table 9. How common is each type of residential building in the Netherlands (percentages based on the WoON12 dataset).

\subsubsection{Project size}

Usually, a construction project involves more than one housing unit. However, most single-family houses were built in small projects (Prak, 1991, p. 4; Thijssen, 1999, p. 1). On the other hand, by including large projects the sample quickly becomes larger. Therefore, large projects are preferred. In the earlier time periods, it is not always possible to select large projects. They were not as common. The smallest project that is selected includes 5 housing units, while the largest includes 468 units. On average, a project includes about 122 housing units. In total, 8270 housing units are included, which is about $10 \%$ of all housing units in Nijmegen (based on data from the central agency for statistics (CBS) in the Netherlands).

Only one unit per project is actually analysed. Often, a housing unit is marked in the architect's drawings as a standard unit. Otherwise, it is up to the researchers to select the most common one. The two-family houses are treated a bit differently. They include two standard units, i.e. a downstairs unit and an upstairs unit. Both of them are analysed.

\subsubsection{Construction year}

This chapter's focus is the period from 1900 to 2012. About 90\% (based on data from the CBS of 2018) of today's buildings were built in this time period. Key moments are used to divide the period into parts. From each part, about four single-family projects 
and four multiple-family projects are analysed. A key moment is an event in time after which new construction projects, probably, had become different from what they used to be. Figure 5 shows how the timeline is divided into parts.

The three most significant key moments for the construction industry were the Second World War ('39-'45), the oil crisis ('73-'74) and the introduction of the Dutch Building Code ('92). Other important years are 1920, 1930, 1960 and 2003. The updated building code was introduced in 2003. New regulations have a significant impact on the construction industry; over $30 \%$ of all innovations, in this sector, are the result of new regulations (Pries \& Dorée, 2005). In 1920, the cavity wall was introduced in the Netherlands (Rentier et al., 2005, p. 18). However, it took until 1930 for it to become a widespread practice (Archidat \& Bouwinformatie, 2012, p. 9). Lastly, 1960 is referred to as a "turning point" in the post-war period (Pries, 1995, pp. 93-95). Around this time, some flaws in the way houses were rebuild had become clear and, from then on, people started working towards better results.

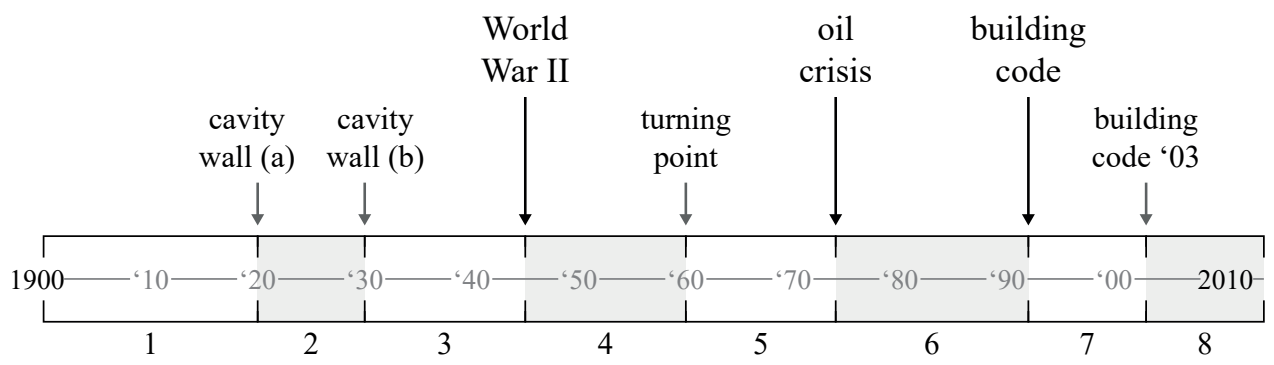

Figure 5. How key moments are used to divide the timeline into 8 parts.

\subsubsection{Location}

Figure 6 shows a map on which all selected cases are marked black. The smaller projects are, unfortunately, hard to see due to the small size of the map. However, each case's specific information is included in Appendix 1. The projects are spread out as much as possible. This was not always possible, because the city has a history of planned expansions (Ekkers \& Ganzevles, 2005). 


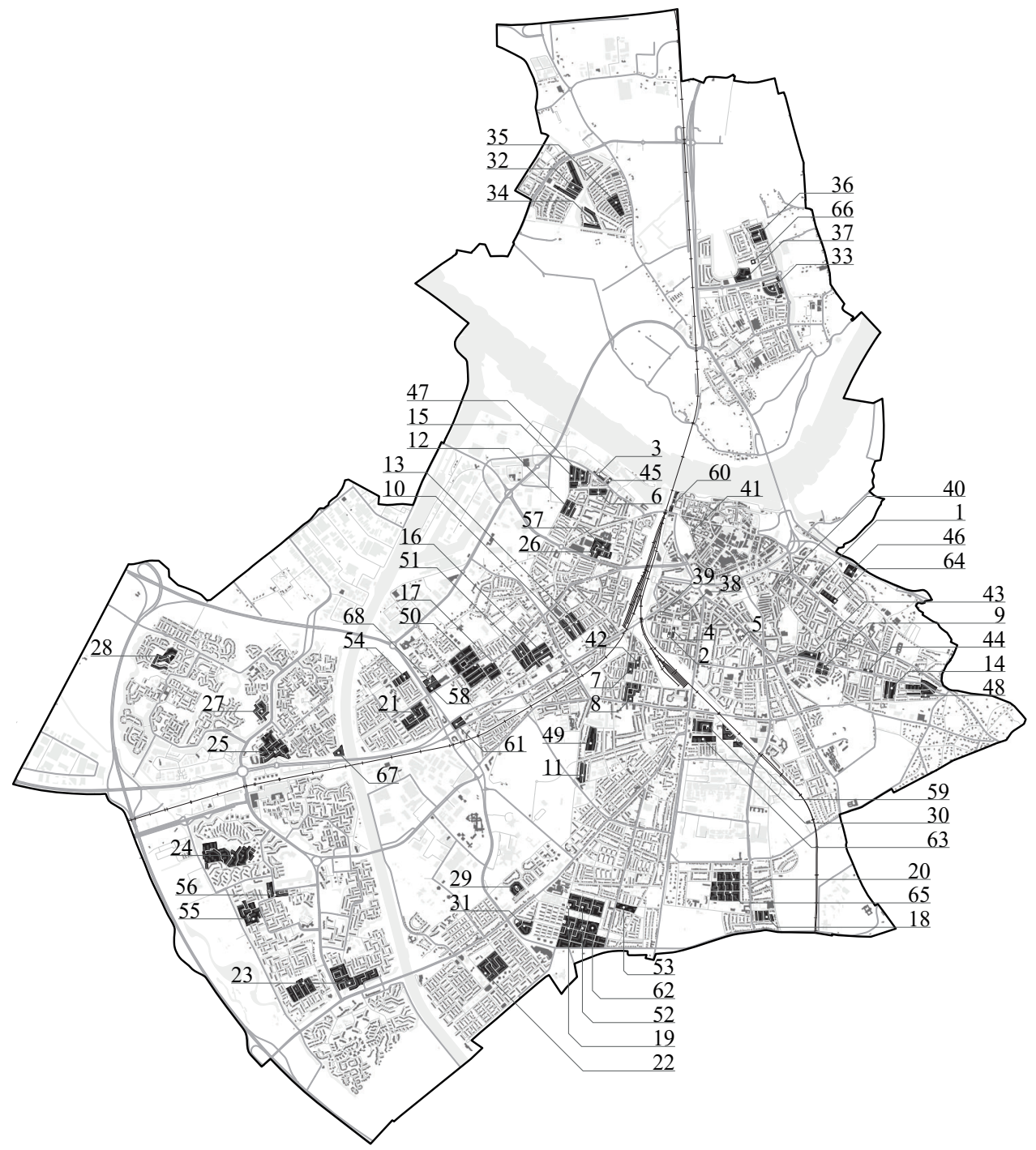

Figure 6. A map of Nijmegen with the locations of all selected cases marked black. 
This page is intentionally left blank. 


\subsection{Results}

\subsubsection{Introduction}

Figure 7 shows a timeline on which all 68 cases have been placed. In Figure 7, the single-family cases (\#1-\#37) are shown directly above the timeline, and the multiplefamily cases (\#38-\#68) are shown directly below the timeline. The place on the timeline shows a case's construction year. For example, in Figure 7, case \#9 is placed at 1930, this means that case \#9 was built in 1930. The following figures present results in a similar way: Figure 8; Figure 9; Figure 10; Figure 11; Figure 12; Figure 14; Figure 15; Figure 16; Figure 18; Figure 19; Figure 20; Figure 21; Figure 22; Figure 23; Figure 24; and Figure 25. However, in these figures, categories are placed on the timeline, instead of case numbers. For example, when category A's symbol is placed at 1930, this means that a case, that was built in 1930, is classified under category A. This way of presenting data shows how a building characteristic has evolved throughout the timeline. Specific information about the cases is included in Appendix 1.

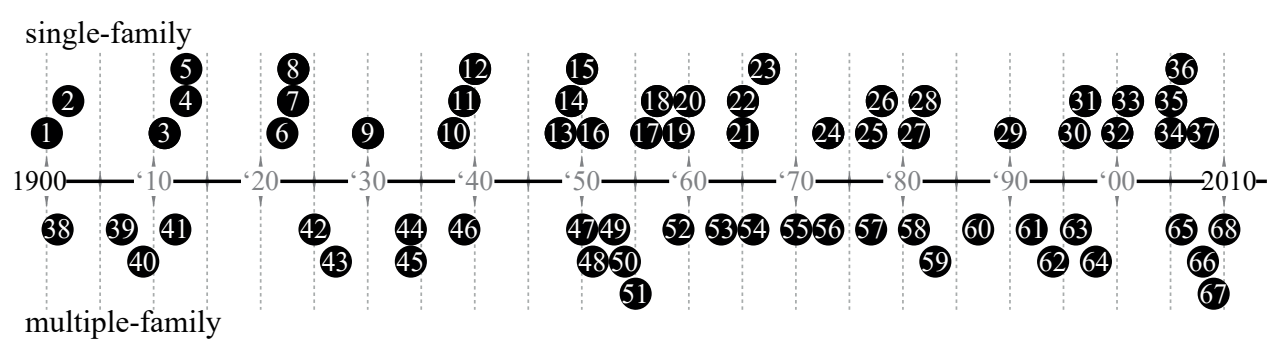

Figure 7. Each case's number on the timeline. Single-family cases (\#1-\#37) are shown above the line, and multiple-family cases (\#38-\#68) are shown below the line.

\subsubsection{Spatial characteristics}

\subsubsection{Length and width}

Figure 8 and Figure 9 show how the sample is categorized in terms of length and width, respectively. These figures show measurements of buildings' main volumes. Both the length and width were obtained by measuring the distance between one wall's inner face and another wall's inner face. Three conclusions can be drawn from these figures. Conclusion \#1: since 1990, houses have become deeper. Between 1900 and 1990, a single-family house's length was on average 7,8 meters. Between 1990 and 2012, a single-family house's length was on average 9,5 meters. Similarly, a multiple-family house's average length has increased from 9,0 to 12,5 meters, in around 1990. 
Conclusion \#2: houses' footprints were squarest between 1945 and 1970. Single-family houses from between 1945 and 1970 had, on average, a length-to-width ratio of 1 : 1,25. Similarly, multiple-family houses from that period had, on average, a lengthto-width ratio of $1: 1,30$. Throughout the rest of the timeline, single-family houses' average length-to-width ratio is $1: 1,67$, and multiple-family houses' average lengthto-width ratio is $1: 1,54$. Conclusion \#3: the width of single-family houses has been quite consistent throughout the time period. More than $70 \%$ of all single-family houses, in the sample, have a width of between 5 and 6 meters. The largest width in the sample is 6,3 meters, and the smallest width in the sample is 4,5 meters.

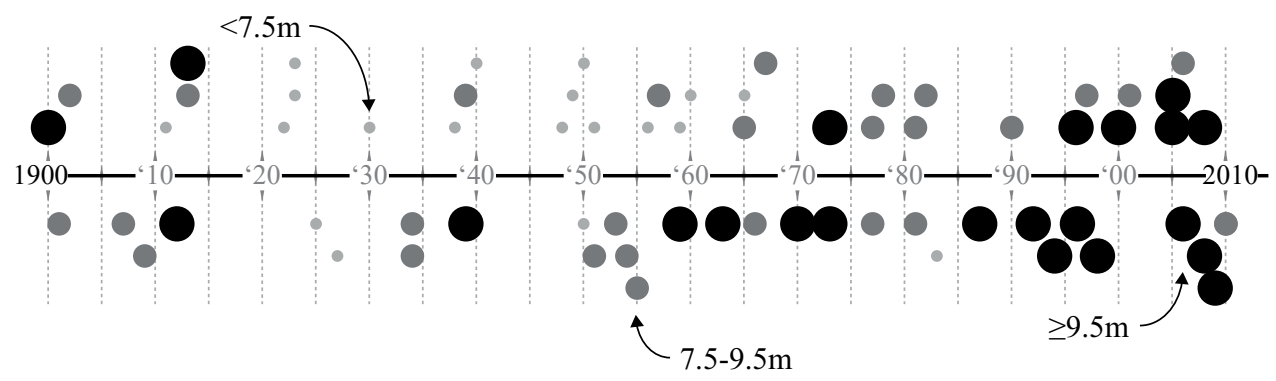

Figure 8 . Each case's length on the timeline. Both the single-family cases and the multiple-family cases are categorized in the following categories: $<7.5$ meters; between 7.5 and 9.5 meters; and $\geq$ 9.5 meters.

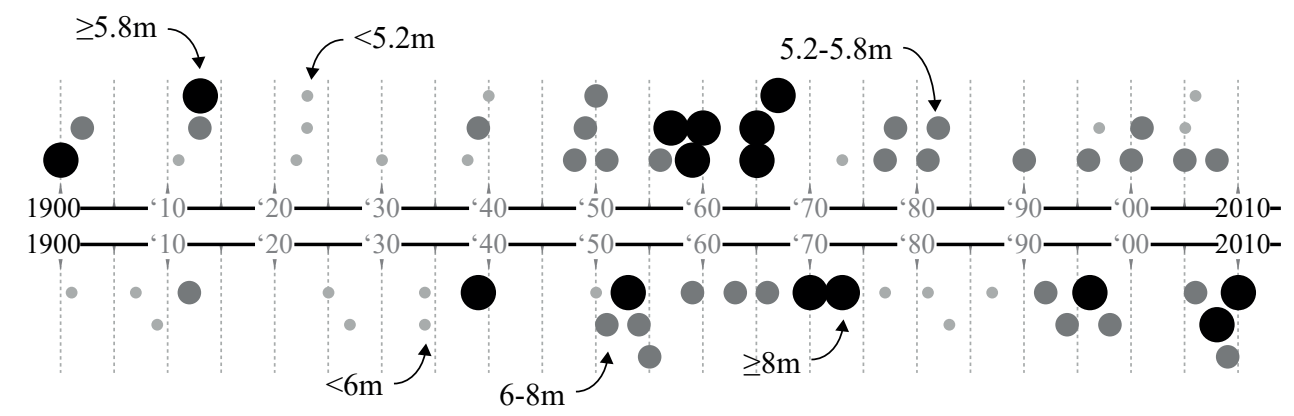

Figure 9. Each case's width on the timeline. The cases in the upper row, i.e. the single-family cases, are categorized in the following categories: $<5.2$ meters; between 5.2 and 5.8 meters; and $\geq 5.8$ meters. However, the cases in the bottom row, i.e. the multiple-family cases are categorized in the following categories: $<6$ meters; between 6 and 8 meters; and $\geq 8$ meters.

\subsubsection{Floor-to-ceiling height}

Figure 10 shows how the sample is categorized in terms of floor-to-ceiling height. This 
figure contains an additional row on top. The additional row shows the first floor's floor-to-ceiling height for all single-family houses. The first floor is the level directly above the main floor. The main floor is the level that includes the living room. The other two rows in Figure 10 show the main floor's floor-to-ceiling height for all houses.

It is often stated that the legally mandatory floor-to-ceiling height is, in general, representative for the actual floor-to-ceiling height, in a given time period (e.g. Liebregts and van Nunen, 2014, p. 21). A greater floor-to-ceiling height results in substantially greater costs (see Gijsbers, 2011, pp. 33-34). So, why would anyone exceed the legally mandatory minimum? This phenomenon especially holds true for houses that have been built after the national building code's introduction in 1992. Since 1992, no house in the sample has exceeded the legally mandatory minimum floor-to-ceiling height by more than ten centimeters.

Before the national building code's introduction in 1992, regulations were neither completely uniform throughout the country nor completely uniform for every situation (see Scholten, 2001, pp. 11-29). Nonetheless, a clear trend can be seen in Figure 10. Between 1900 and 2003, the main floor's average floor-to-ceiling height has decreased steadily from about 3,0 meters to about 2,4 meters. Furthermore, the first floor's average floor-to-ceiling height has remained unchanged, i.e. 2,4 meters, throughout the period of 1915 to 2003.

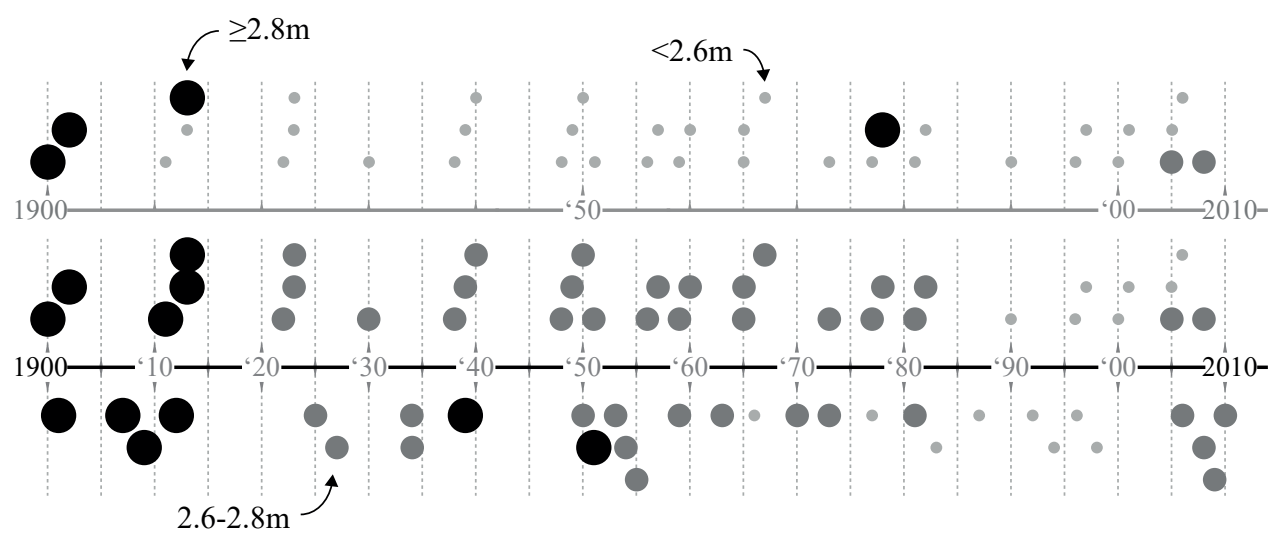

Figure 10. The main floor's floor-to-ceiling height of each case on the timeline. Additionally, the extra upper row shows the first floor's floor-to-ceiling height for all single-family houses. All cases in all three rows are categorized in the following categories: $<2.6$ meters; between 2.6 and 2.8 meters; and $\geq 2.8$ meters. 


\subsubsection{Utilitarian rooms}

A utilitarian room is a room that is intended for specific uses and not for a prolonged stay (Boekholt et al., 1974, p. 49). In the last 100 years, a new utilitarian room was introduced to the ordinary house, i.e. a bathroom. A bathroom is a separate room specifically intended for personal hygiene activities. Figure 11 shows that a bathroom was included in almost $97 \%$ of the post-Second World War houses, while a bathroom was only included in about $10 \%$ of the older houses. According to Prak (1991, p. 95), a bathroom had become a standard by 1914 in town houses in the Netherlands. Furthermore, in the municipality of Amsterdam, a bathroom became a mandatory feature for all houses in 1933. However, this law did not immediately lead to the desired results (Prak, 1991, pp. 174-175). The result shown in Figure 11 correspond rather well with the statements of Prak.

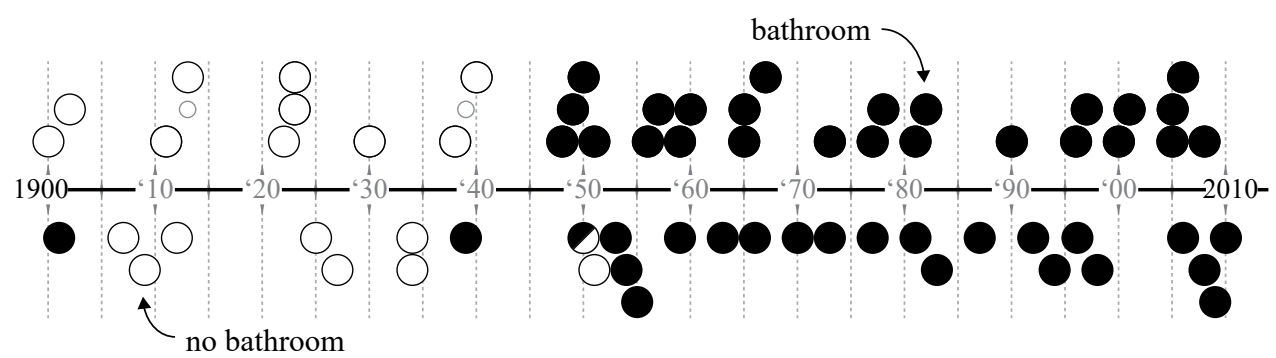

Figure 11. Whether or not a bathroom is present in each case on the timeline. Case \#47, i.e. a multiple family case from 1950, is categorized as both a case with a bathroom and a case without a bathroom. This means that case \#47 is a two-family house in which only one of the two units originally had a bathroom.

The bathroom's introduction is not the only change of the last 100 years to the house's utilitarian rooms. In the last 100 years, it became rare to build a house with underground storage. Figure 12 shows that almost $90 \%$ of the houses, before 1965 , either had a basement or a basement closet. A basement closet is a small space, partially underground, which was primarily intended for the storage of food. In the sample, no single-family house after 1965 includes a basement or a basement closet. Thijssen (1999, p. 25) came to the same conclusion. In his study, there were also no singlefamily houses, after 1965, that included a basement or a basement closet. 


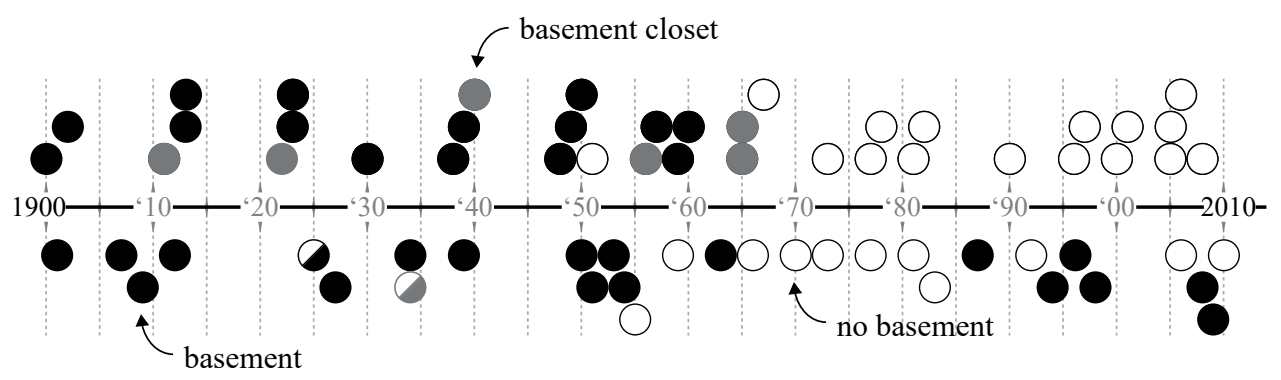

Figure 12. Whether or not a basement or basement closet is present in each case on the timeline. Case \#42, i.e. a multiple family case from 1925 , and case \#45, i.e. a multiple family case from 1934 , are both categorized as a case with underground storage and as a case without underground storage. This means that both case \#42 and case \#45 are two-family houses in which only one of the two units originally had underground storage.

\subsubsection{Spatial layout}

Two features characterize a house's spatial layout: (1) private rooms; and (2) extra doors. Figure 13 shows the differences between three spatial layouts: (1) a basic layout; (2) a layout that includes an extra door; and (3) a layout that includes a private room. An extra door is a door that is not necessary to reach every room. The extra door is the one that is not part of the shortest route between a room and the main circulation space. The main circulation space in a house is generally the hallway. A room is termed private when it is not directly accessible from a house's main navigation space (see Alexander, 1977, pp. 610-613; Habraken, 1998, pp. 134-179). In other words, a private room is only accessible, from the hallway, by passing through another room.

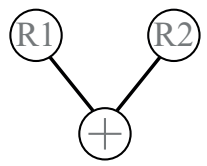

hallway

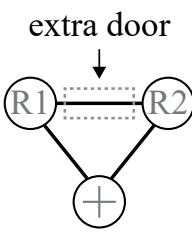

hallway

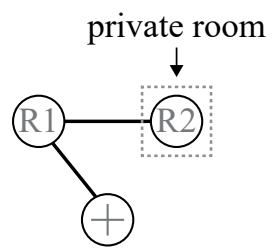

hallway

Figure 13. The differences between three spatial layouts: (1) a basic layout; (2) a layout that includes an extra door; and (3) a layout that includes a private room. In this figure, a circle represents a room, and a line between two circles represents a door between those two rooms (see Hillier, 1993, pp. 1114). 
Figure 14 and Figure 15 show how the sample's main floors are categorized in terms of private rooms and extra doors, respectively. Four conclusions can be drawn from these figures. Conclusion \#1: private rooms and extra doors are more common in multiplefamily houses than in single-family houses. About $40 \%$ of the single-family houses, in the sample, has a basic layout, i.e. a layout without extra doors and without private rooms. However, less than $20 \%$ of the multiple-family houses, in the sample, has a basic layout. A multiple-family house usually only contains a single floor or level. A singlefamily house usually contains two or three floors. In multiple-family houses, more rooms need to be fitted in a single floor. As a result, the main floor's spatial layout is generally more straightforward in single-family houses than in multiple-family houses. Conclusion \#2: between 1920 and 1945, a single-family house's main floor layout commonly included a private room, but no extra doors. In four of the six cases, the

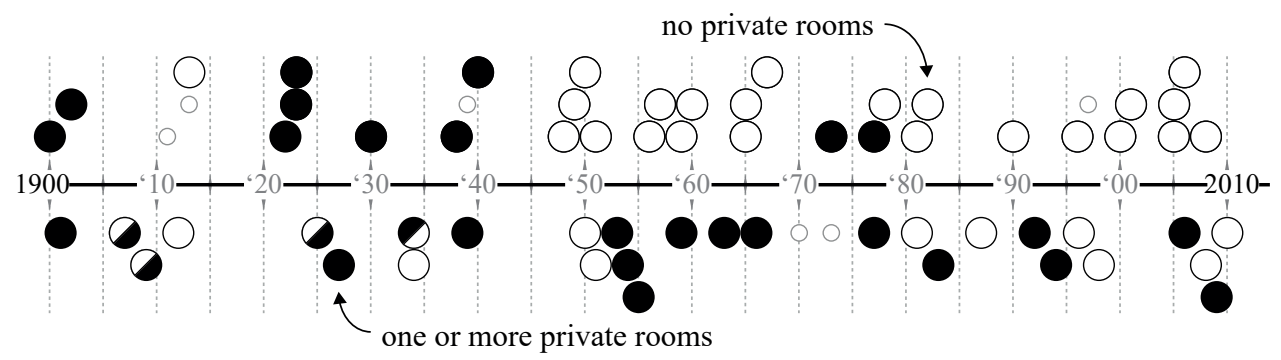

Figure 14. Whether or not one or more private rooms are present in each case on the timeline. Four multiple family cases (case \#39, case \#40, case \#42 and case \#44) are categorized as both a case with one or more private rooms and a case without private rooms. This means that each of those cases is a two-family house in which only one of the two units originally had one or more private rooms.

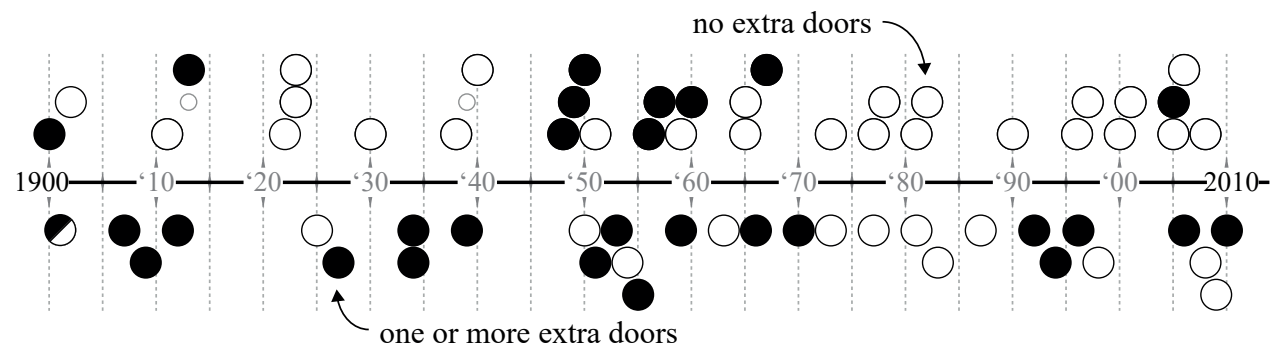

Figure 15. Whether or not one or more extra doors are present in each case on the timeline. Case \#38, i.e. a multiple family case from 1901, is categorized as both a case with one or more extra doors and a case without extra doors. This means that case \#38 is a two-family house in which only one of the two units originally had one or more extra doors. 
kitchen was only accessible, from the main circulation space, by passing through the living room. Conclusion \#3: between 1945 and 1970, a single-family house's main floor layout commonly included an extra door, but no private rooms. About $65 \%$ of single-family houses, between 1945 and 1970, had an extra door in the main floor layout. This extra door connected the living room to another sitting room.

Conclusion \#4: after 1970, a single-family house's main floor layout, commonly, neither include private rooms nor extra doors. Between 1970 and 2012, more than $75 \%$ of the single-family houses had a basic layout, i.e. a layout without extra doors and without private rooms. Figure 16 shows that, between 1970 and 2012, more than $90 \%$ of the houses had an open kitchen. Previously, it was common to have a separate room that people referred to as the kitchen. In 1970, it became common to have one large room that serves the purposes of both the kitchen and the living room. An open kitchen layout contains fewer rooms than a separate kitchen layout. Therefore, private rooms and extra doors became rare in a single-family house's main floor layout.

In the study of Thijssen (1999, p. 74), about 58\% of single-family houses between 1968 and 1980 had an open kitchen. The oldest open kitchen layout in Thijssen's sample is from 1969. The result shown in Figure 16 correspond quite well with the statements of Thijssen. This study and Thijssen's study both identified the same turning point, i.e. the moment that the open kitchen became standard. However, Figure 16 shows a more immediate transition from a separate kitchen to an open kitchen, compared to Thijssen's results.

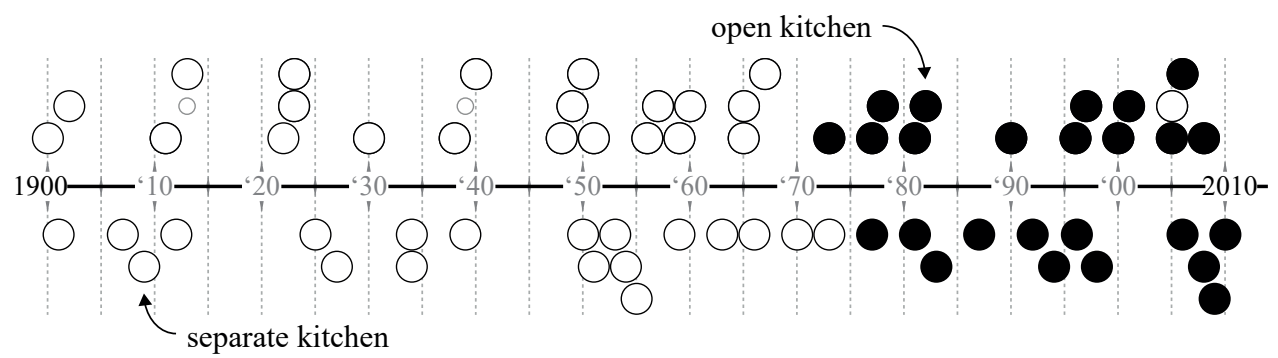

Figure 16. Each case's type of kitchen, i.e. separate kitchen or open kitchen, on the timeline.

Finally, a house's first-floor spatial layout did not change at all throughout the last 100 years. In the sample, $95 \%$ of the houses' first floors has a basic layout, i.e. a layout without extra doors and without private rooms (see Appendix 1). 


\subsubsection{Technical characteristics}

\subsubsection{Type of structure}

The type of a house's structure is determined by three characteristics: (1) structural layout; (2) vertical elements; and (3) horizontal elements. Structural layout refers to the positioning of structural elements on the main floor. A single-span structure only includes structural elements at the boundaries of a housing unit's floorplan. However, a multiple-span structure and a mixed-span structure have structural elements in between those boundaries. Furthermore, in a multiple-span structure, vertical loads are transferred along a single axis, whereas in a mixed-span structure, vertical loads are transferred along at least two distinct axes. A structure's vertical elements are either walls, posts, or a mix of walls and posts. A structure's horizontal elements are either slabs, beams, or a mix of slabs and beams. Figure 17 shows how the types of structure are specified by

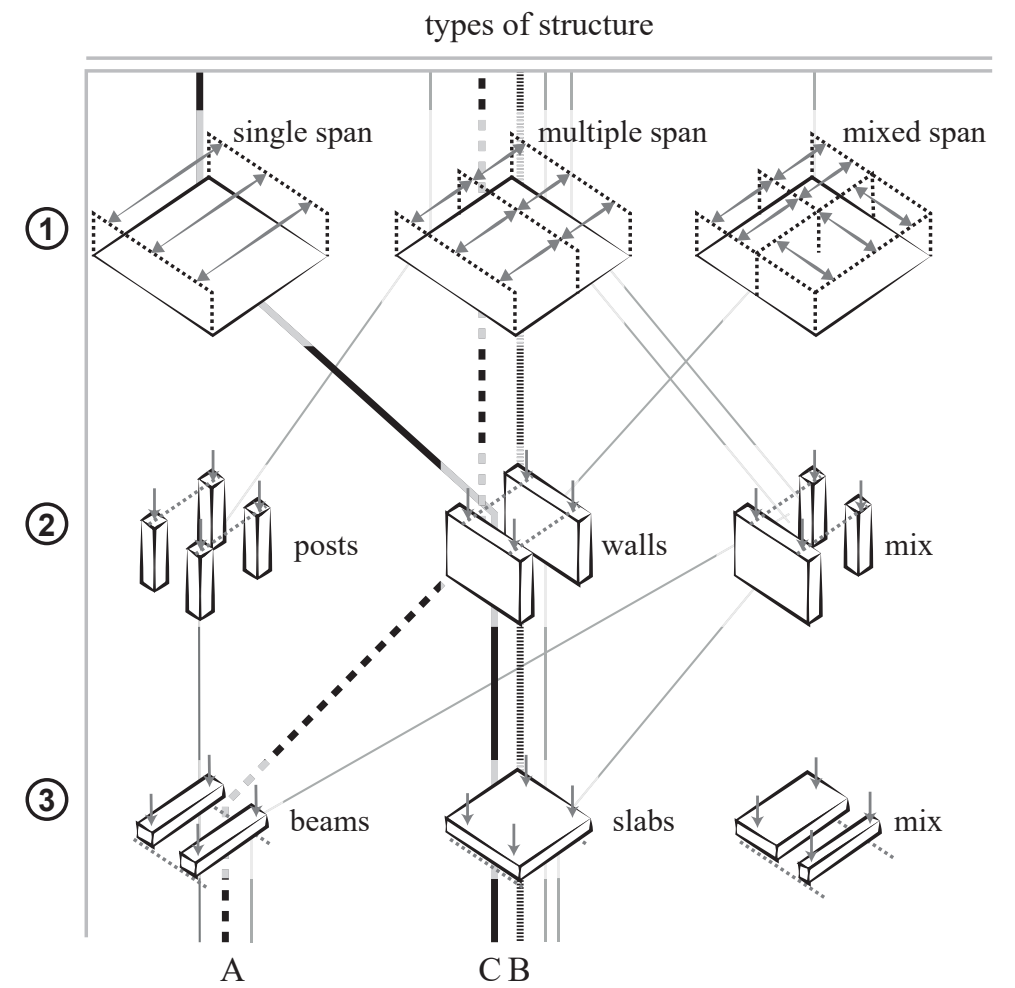

Figure 17. How the types of structure are specified by different combinations of the options under each of the three characteristics, i.e. (1) structural layout; (2) vertical elements; and (3) horizontal elements. Type A is a multiple-span structure of walls \& beams. Type B is a multiple-span structure of walls \& slabs. Type $\mathrm{C}$ is a single-span structure of walls \& slabs. 
different combinations of the options under each of the three characteristics.

Figure 18 shows how the sample is categorized in terms of type of structure, and Figure 19 shows the material from which each structure's horizontal elements were made. Three conclusions can be drawn from these figures. Conclusion \#1: between 1900 and 1945 , a house commonly was built with a multiple-span structure made from walls and wooden beams. More than $90 \%$ of the houses, before 1945, was built in this manner. Conclusion \#2: between 1945 and 1975, a house commonly was built with a multiplespan structure made from walls and concrete slabs. Almost $70 \%$ of the houses, between 1945 and 1975, was built in this manner. In about 40\% of these cases, the concrete slabs were made primarily by pouring concrete on site. In the other $60 \%$, the concrete slabs were made by floor systems that involve prefab concrete elements.

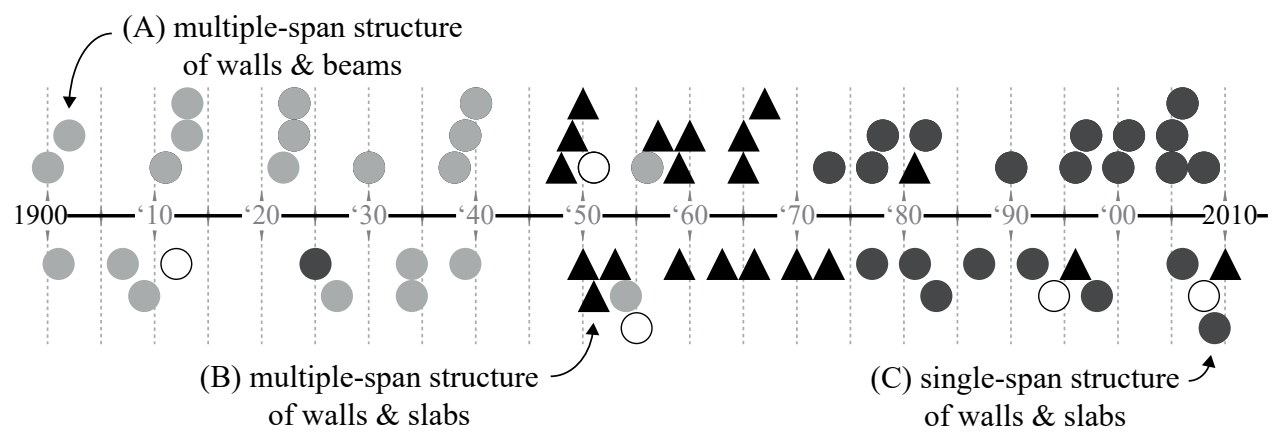

Figure 18. Each case's type of structure on the timeline. Both the single-family cases and the multiplefamily cases are categorized in the following categories: (A) multiple-span structure of walls \& beams; (B) multiple-span structure of walls \& slabs; and (C) single-span structure of walls \& slabs.

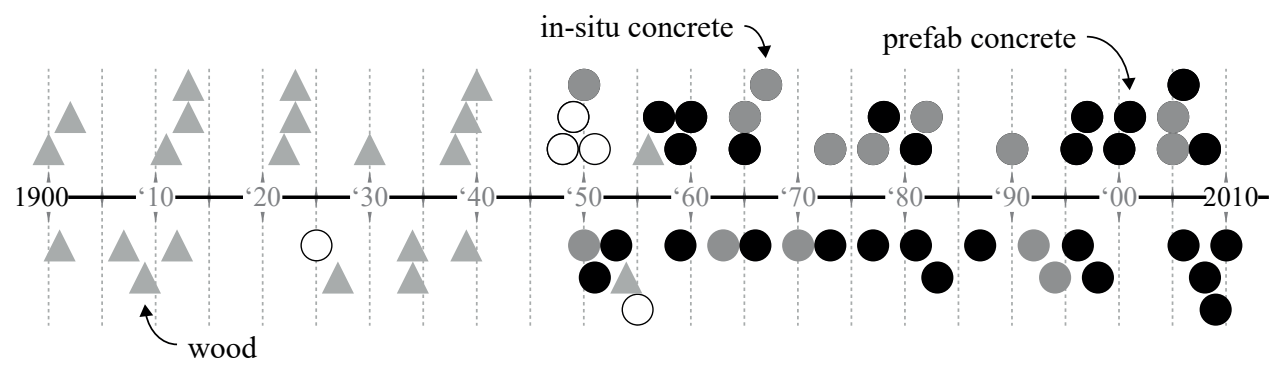

Figure 19. The material, from which each structure's horizontal elements were made, on the timeline. Both the single-family cases and the multiple-family cases are categorized in the following categories: in-situ concrete; prefab concrete; and wood. 
Conclusion \#3: between 1975 and 2012, a house commonly was built with a singlespan structure made from walls and concrete slabs. Between 1975 and 2012, 80\% of the houses was built in this manner. In $30 \%$ of these cases, the concrete slabs were made primarily by pouring concrete on site. In the other $70 \%$, the concrete slabs were made by floor systems that involve prefab concrete elements.

The result shown in Figure 19 deviate somewhat from Thijssen's (1999) results. Figure 19 shows that only about $8 \%$ of the houses, between 1945 and 1980, was built with a first floor made from wooden beams. Furthermore, the most recent wooden floor, in the sample, is from 1956. In Thijssen's study (1999), 19\% of the houses, between 1945 and 1980, was built with a first floor made from wooden beams (p. 131), and the most recent wooden floor in his sample is from 1969 (p. 55). On the other hand, both this study and Thijssen's study conclude that, by 1945, a wooden beam structure was no longer the most common type of structure.

\subsubsection{Roof structure}

Figure 20 and Figure 21 show how the sample is categorized in terms of roof type and roof structure's material, respectively. About $70 \%$ of the houses, in the sample, was built with a wooden roof structure. More than $60 \%$ of the wooden roof structures, in the sample, is categorized as a side-gabled roof. Throughout the last 100 years, a singlefamily house commonly was built with a wooden side-gabled roof. Half of the singlefamily houses, in the sample, was built in this manner.

The oldest concrete roof structure, in the sample, is from 1959. Concrete is mostly used to build flat roofs. More than $80 \%$ of the concrete roof structures, in the sample, is categorized as a flat roof. Furthermore, these concrete flat roof structures are mostly used for multiple-family houses. More than $70 \%$ of concrete flat roof structures, in the sample, was used for blocks of flats (see Appendix 1). By 1955, it had become

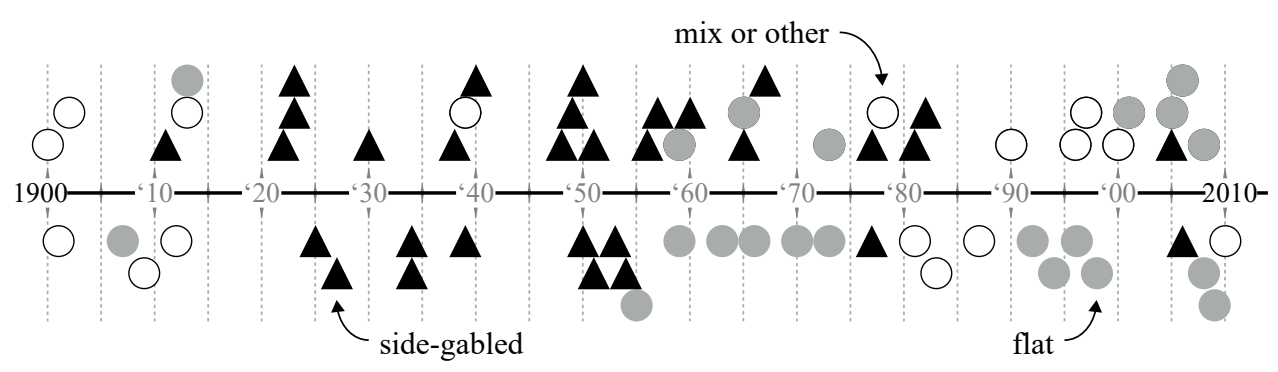

Figure 20. Each case's type of roof on the timeline. Both the single-family cases and the multiplefamily cases are categorized in the following categories: side-gabled; flat; and mix or other. 


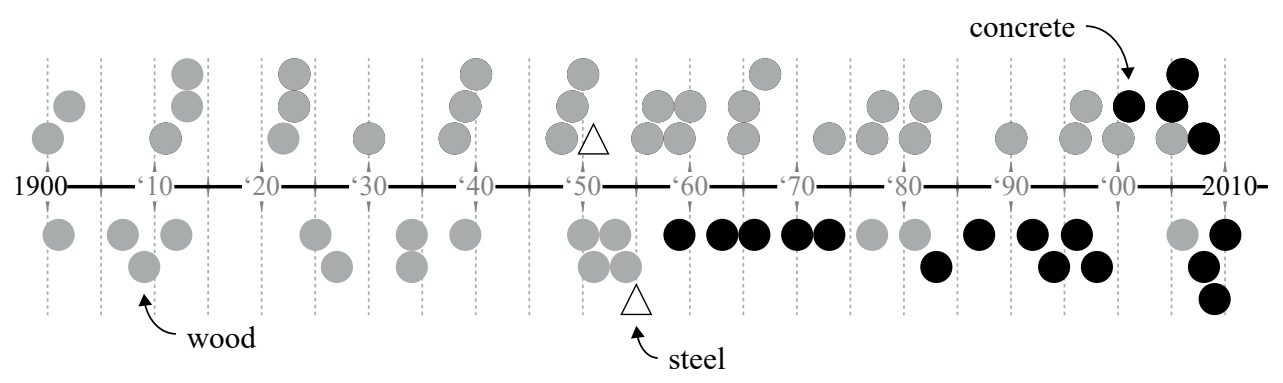

Figure 21. The material, from which each roof structure is made, on the timeline. Both the singlefamily cases and the multiple-family cases are categorized in the following categories: concrete; wood; and steel.

common to build multiple-family houses with concrete flat roofs. Between 1955 and 2012 , more than $60 \%$ of the multiple-family houses was built in this manner. However, before 1955, a multiple-family house commonly was built with a wooden side-gabled roof. Between 1900 and 1955, about $65 \%$ of the multiple-family houses was built in this manner.

\subsubsection{Insulation}

Figure 22, Figure 23 and Figure 24 show how the sample is categorized in terms of exterior wall insulation, roof insulation and ground floor insulation, respectively. Three conclusions can be drawn from these figures. Conclusion \#1: between 1975 and 2012, the average exterior wall insulation has increased steadily from 0 millimeters to about 120 millimeters. Between 1900 and 1975, less than 5\% of the houses was built with exterior wall insulation. However, between 1975 and 2012, 100\% of the houses was built with exterior wall insulation.

Conclusion \#2: between 1970 and 2012, the average roof insulation has increased steadily from 0 millimeters to about 110 millimeters. Between 1900 and 1970, 15\% of the houses was built with roof insulation. However, between 1970 and 2012, almost $90 \%$ of the houses was built with roof insulation. Conclusion \#3: between 1985 and 2012, the average ground floor insulation has increased steadily from 0 millimeters to about 150 millimeters. Between 1985 and 2012, about $95 \%$ of the houses was built with ground floor insulation. Furthermore, the oldest building that was built with ground floor insulation, in the sample, is from 1983.

In the study of Thijssen (1999, p. 93), no traditionally built houses before 1971 had exterior wall insulation. Furthermore, wooden sloped roofs in Thijssen's sample, from 
after 1974, were all insulated (1999, p. 95). The result shown in Figure 22 and Figure 23 correspond quite well with the statements of Thijssen.

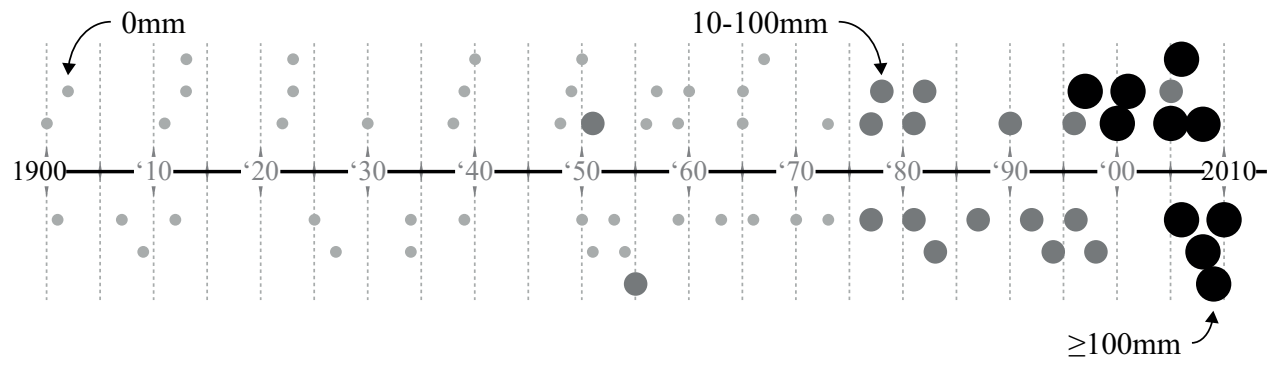

Figure 22. Each case's exterior wall insulation on the timeline. Both the single-family cases and the multiple-family cases are categorized in the following categories: 0 millimeters; between 10 and 100 millimeters; and $\geq 100$ millimeters.

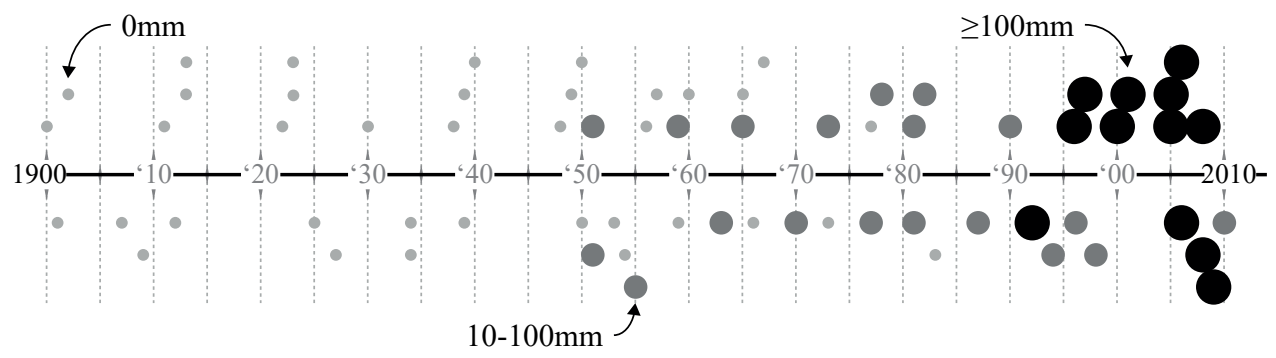

Figure 23. Each case's roof insulation on the timeline. Both the single-family cases and the multiplefamily cases are categorized in the following categories: 0 millimeters; between 10 and 100 millimeters; and $\geq 100$ millimeters.

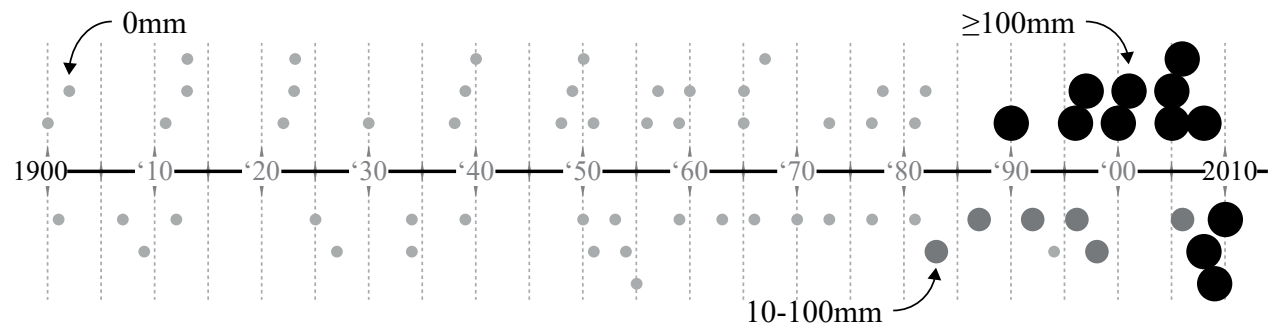

Figure 24. Each case's ground floor insulation on the timeline. Both the single-family cases and the multiple-family cases are categorized in the following categories: 0 millimeters; between 10 and 100 millimeters; and $\geq 100$ millimeters. 
Finally, this chapter's results do not confirm that it took 10 years for the use of the cavity wall to become a widespread practice (see Appendix 1), as was mentioned in the Method (see 3.2.4. Construction year).

\subsubsection{Separating wall's thickness}

Figure 25 shows how the sample is categorized in terms of the total thickness of the separating walls, i.e. the walls that separates one house from another. Since 1980, the separating wall's average thickness has increased. Between 1900 and 1980, the separating wall's average thickness in the sample is a bit above 215 millimeters, while between 1980 and 2012, the separating wall's average thickness in the sample is almost 250 millimeters.

The oldest building, in the sample, that was built with decoupled separating walls is from 1967 (see Appendix 1). A decoupled separating wall is a separating wall that contains two layers and a cavity in between those layers. After 1967, more than 40\% of the single-family houses in the sample was built with decoupled separating walls. However, no multiple-family house, in the sample, was built with decoupled separating walls. These results deviate somewhat from Thijssen's (1999) results. In Thijssen's sample (1999, p. 41), the oldest building that was built with decoupled separating walls is from 1976.

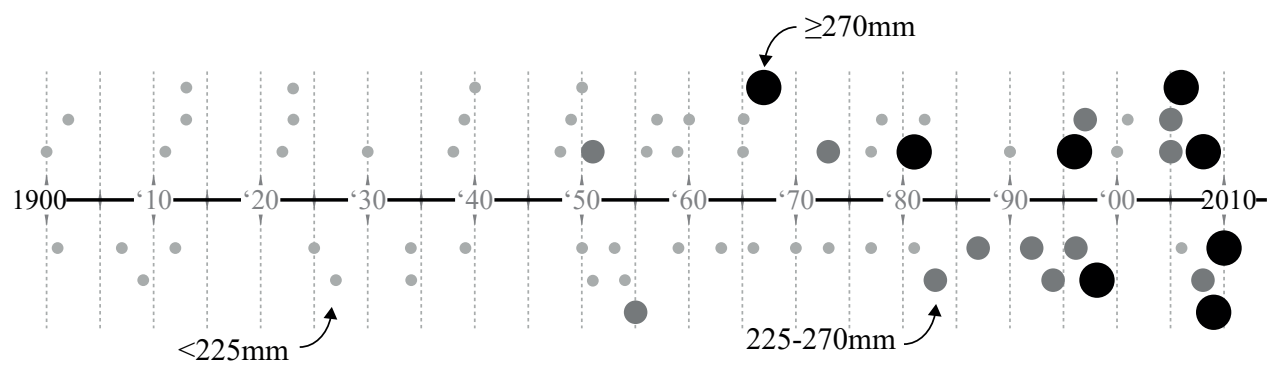

Figure 25. The separating wall's thickness of each case on the timeline. Both the single-family cases and the multiple-family cases are categorized in the following categories: $<225$ millimeters; between 225 and 270 millimeters; and $\geq 270$ millimeters. 
This page is intentionally left blank. 


\subsection{Discussion and conclusion}

\subsubsection{Discussion}

To what extent does the house's evolution justify demolition? The result section shows that many of the house's characteristics have evolved throughout the last 100 years. However, not every evolution is equally harmful for a house's longevity. How harmful an evolution is to a house's longevity is determined by: (1) whether or not an evolution introduces a higher performance standard; and (2) whether an evolution reinvents or adds on the previously established ways of constructing buildings.

Figure 26 shows how well each of the identified evolutions matches with the description of: (1) reinvention or add-on; and (2) performance increase or performance decrease. Thus, for example, the more an evolution is positioned to the left, the more it is seen as a reinvention of the previously established ways of constructing buildings, instead of an addition onto it. Furthermore, the size of each circle shows how much that characteristic

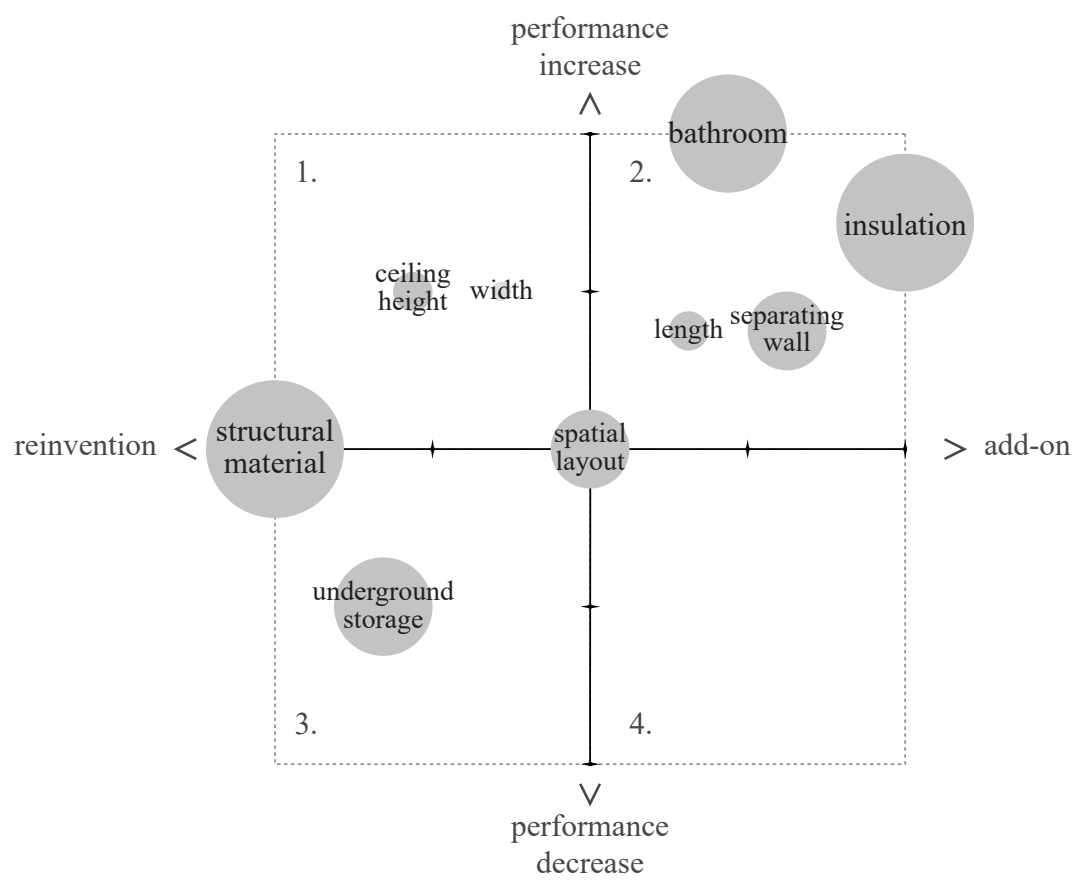

Figure 26. How well each of the identified evolutions matches with the description of: (1) reinvention or add-on; and (2) performance increase or performance decrease. The size of each circle shows how much that characteristic has evolved in the last 100 years. Both the position and size of each circle are estimates of the author. 
has evolved in the last 100 years.

According to Lichtenberg (2004, pp. 11-13), the construction industry mainly innovated in the 20th century by adding things onto the previously established ways of constructing buildings. He named this type of innovation "innovation-by-addition". In Figure 26, these types of innovations are shown in quadrant \#2 (the top right). With such innovations, the process of adding them on at a later stage is not that much different from including them in the initial design. Therefore, an innovation-by-addition - on its own - does not necessitate the replacement of houses.

However, a reinvention is the type of innovation that may - on its own - necessitate replacement, but only if it introduces a higher performance standard. For example, the switch from wood to concrete as one of the primary structural materials was the largest reinvention of the house in the 20th century (see Figure 26). However, this innovation's aim was not to improve the standard of houses - previous houses were not suddenly inferior to the new ones. The switch from wood to concrete was beneficial to the maker, instead of the consumer.

In Figure 26, evolutions in quadrant \#1 (the top left) are the best justification for the demolition and replacement of houses. However, not much has evolved in this quadrant. Not all of a house's physical characteristics were included in this chapter. Therefore, it is possible that some relevant evolutions were overlooked, e.g. the evolution of a house's aesthetical qualities. However, currently, the results indicate that the house's evolution from 1900 to 2012, in terms of spatial and technical characteristics, provides little justification for its demolition. If this statement is true, i.e. if the house's evolution provides little justification for its demolition, this implies one of two things: either (1) a building's physical qualities are not significantly taken into account in the decisionmaking process of the building's demolition; or (2), as stated by Thomsen and van der Flier (2011, p. 354), “...housing [in contrast to non-residential functions] is a rather stable function with a long life cycle expectancy".

Statistics regarding the average lifespan of buildings are scarce, because most of today's building stock is still relatively young (Thomsen, 2006, p. 7). The function of housing was examined in this chapter due to its importance in volume. However, non-residential buildings, on average, do not last as long as residential buildings (see Huuhka and Lah-densivu, 2016, p. 87, Table 10; O'Connor, 2004, pp. 6-7). Also, the vacancy rates for offices, for example, are generally much higher than the vacancy rates for residential buildings (e.g. see CBS, 2018). Therefore, it seems likely that, on average, the premature demolition of buildings primarily occurs in the non-residential building sector. 


\subsubsection{Conclusion}

This chapter's aim was to determine how the ordinary house, in the Netherlands, has changed throughout the last 100 years. Firstly, in terms of a house's spatial characteristics, the following changes have occurred: (1) houses became deeper in 1990; (2) houses' main floor floor-to-ceiling height steadily became lower up to 2003, and houses' floorto-ceiling height, i.e. the floor-to-ceiling height of both the main floor and the first floor, have become higher since 2003; (3) having a bathroom became a standard in housing in 1945; (4) having underground storage was no longer a standard in housing by 1965 ; and (5) having an open kitchen became a standard in housing in 1970.

Secondly, in terms of a house's technical characteristics, the following changes have occurred: (1) constructing floors with concrete slabs, instead of wooden beams, became a standard in housing in 1945; (2) single-span structures, instead of multiple-span structures, became a standard in housing in 1975; (3) insulated exterior walls, insulated roofs and insulated ground floors became a standard in housing in 1975, 1970 and 1985, respectively, and their insulation values have since gradually increased; and (4) separating walls became thicker in 1980 .

However, none of these changes - on their own - seem to be sufficient reason for demolishing a house. It is likely that, on average, the premature demolition of buildings is primarily a problem of the non-residential building sector. 


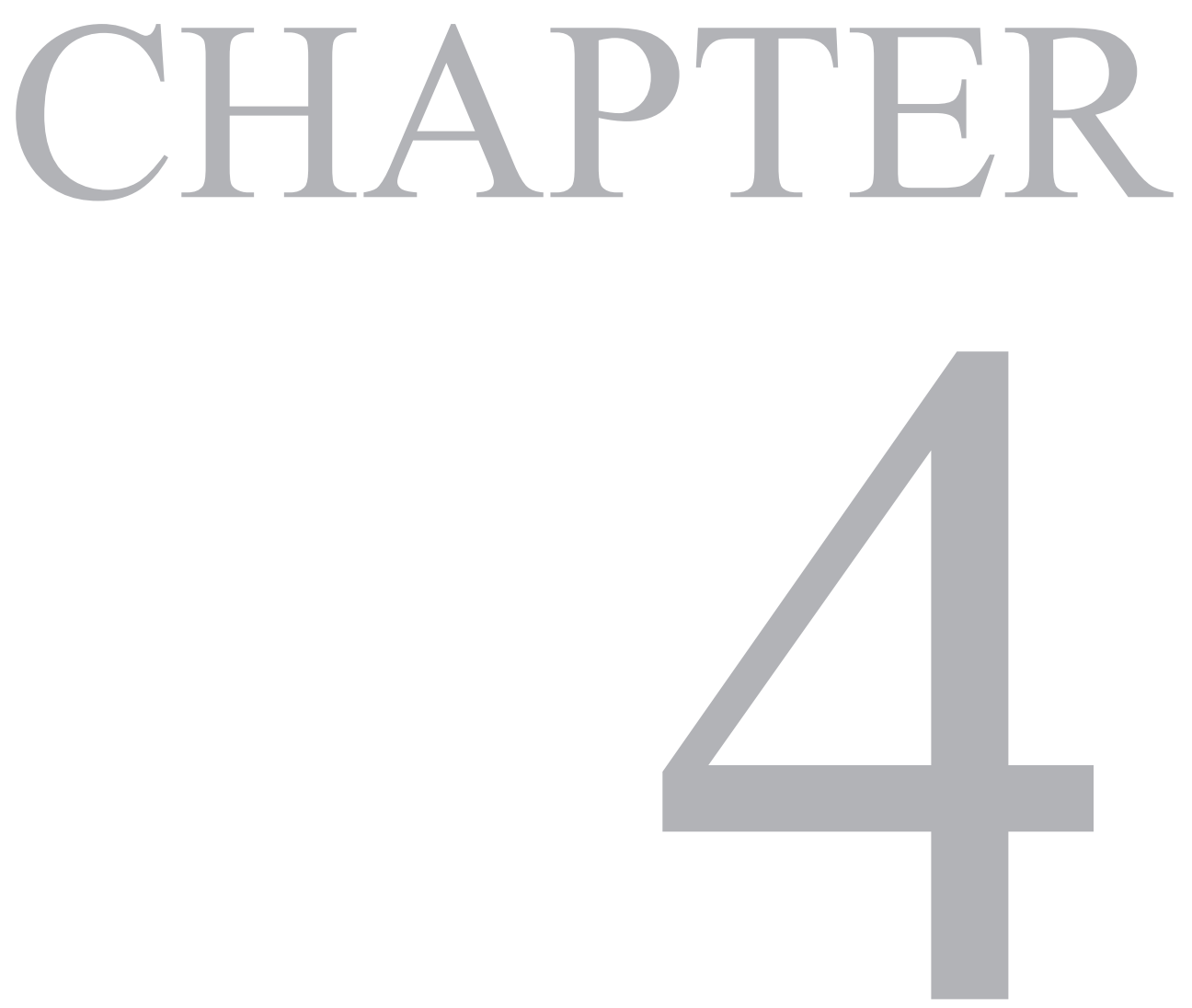

How to set up criteria for evaluating a building's changeability? 
This page is intentionally left blank. 


\section{Chapter 4's purpose}

The project goal is to create a method that can evaluate a building's changeability, and therewith support the design of changeable buildings. Chapter 4's purpose is to develop both a review-based understanding of, and comprehensive support for, changeability in building design. However, changeable buildings is not the societal end goal, it is the means through which the end goal is pursued. This dissertation's societal end goal is to contribute towards mitigating the problem of resource depletion. The need for a method that can evaluate a building's changeability is based on the following premise: (1) a method for evaluating a building's changeability will improve the changeability of future buildings; (2) buildings with greater changeability will have greater longevity; and (3) when buildings have greater longevity, the problem of resource depletion is significantly reduced. Chapter 4's outcome must explain what makes a building changeable, and how this works. 


\subsection{Introduction}

\subsubsection{Background}

In Zurich (Switzerland), buildings do not even last half as long as they used to (Aksözen et al., 2017, p. 254, Fig. 10). Furthermore, a study (O'Connor, 2004) in MinneapolisSaint Paul (USA) shows that especially non-residential buildings generally do not last as long as architects, engineers and developers expect them to last. In Finland, for example, non-residential buildings are on average only 43 years old when they are demolished (Huuhka and Lahdensivu, 2016, p. 87, Table 10). The premature demolition of buildings is a major waste of resources, and improving buildings' longevity will help solve the problem of depleting resources (see de Laat, 2019).

In design, it is good practice to first try to blame the product for a fault, instead of the users (see Norman, 2013, pp. 162-216). However, it is already a challenge to create a building or product that meets people's current needs, let alone people's future needs. A designer must first learn how to evaluate how well a building performs in terms of expected longevity, before he or she can learn to create long-lasting buildings (see Krathwohl, 2002). A building's expected longevity is determined by both its maintainability, i.e. the ability to allow for wear and tear, and its changeability, i.e. the ability to comply with future change. This chapter's focus is on evaluating a building's changeability.

A changeable building is a building that is optimized from the perspective of future change. However, future change is neither a single nor a specific event; future change represents countless possible events. In other words, the optimization goal is nonspecific. This makes it difficult to evaluate a building's changeability. Evaluation methods are mostly useful when they are generally applicable. This means that the subject of an evaluation, in an evaluation method, must be non-specific. Methods of evaluating a building's changeability already exist (see Heidrich et al., 2017, pp. 289290; Schmidt III, 2014, pp. 97-99). However, in most of these methods, the problem of an uncertain future is simplified to a problem that has a few universal solutions. In other words, these methods prescribe specific solutions to optimize a non-specific object for a non-specific goal. When the optimization goal is unclear, solutions - and the methods that prescribe them - cannot be validated.

\subsubsection{Proposal}

\subsubsection{Introduction}

In this chapter, a method of evaluating a building's changeability is proposed in which 
optimization goals are specified during the evaluation process. Since the optimization goals are specified in the method, the solutions that the method prescribes can be validated. This method has a scenario-based approach. In most forecasting methods, the logic of scenario development is the primary focus; "very little is said about the actual creation of the stories [scenarios] in most methods" (Bishop et al., 2007, p. 6). For this chapter, the opposite is true: the primary focus is the development of support for the actual creation of both scenarios and the optimizations associated with each of these scenarios. But first, the general method, and the role of scenarios in it, is briefly introduced. Figure 27 shows the proposed method of evaluating a building's changeability.

\subsubsection{Scenarios}

As shown in Figure 27, step 1 is developing scenarios. A scenario is a description of a mismatch that can arise when a building is confronted with a certain change. For example, when a couple that is living in an apartment decides to have children, their apartment can quickly become too small. Scenarios are developed to identify potential problems, and potential problems are identified to determine which design solutions are useful.

Figure 27 also shows that changeability levels are used to support step 1. A categorization into levels contains both: (1) a breakdown of the subject into parts; and (2) a manner of arranging these parts. Therefore, the changeability levels show both the parts of the subject that need to be taken into account and the sequence in which these parts should be taken into account. As will be discussed further in "4.3.1. Changeability levels", this will be very helpful when developing scenarios.

\subsubsection{Design solutions}

As shown in Figure 27, step 2 is developing design solutions. These design solutions are solutions to potential problems, i.e. problems that have not arisen yet. Unlike existing problems, potential problems are solved by making sure that, when they arise, they are not such a big deal. In this study, a problem refers to a mismatch between what people demand and what the building provides. Furthermore, a design solution refers to a set of designable conditions that make a certain manner of addressing a certain mismatch significantly easier. For example, outdated installations are replaced more easily when they are entirely accessible.

In addition, the following is shown in Figure 27: (1) changeability levels are used to limit the possible outcomes of step 2; and (2) types of design tactics are used to support 
step 2. Concerning the use of changeability levels, each design solution specifies a manner of addressing the mismatch when it arises. However, the effort that is still needed to address the problem, when it arises, must be proportional to the size of the problem - otherwise who would address it? In step 2, the changeability levels help make sure that no such unfeasible design solutions are developed.

Concerning the use of types of design tactics, a design solution refers to a set of designable conditions, while a design tactic refers to an individual designable condition. To develop a design solution one must first identify the individual designable conditions that are beneficial when addressing a certain mismatch in a certain manner, and then combine them into a complete solution. As will be discussed further in "4.3.2. Types of design tactics", the types of design tactics will be very helpful when identifying individual conditions.

\subsubsection{Likelihood \& severity}

As shown in Figure 27, step 3 is assessing the likelihood and severity of scenarios. Not every scenario is equally important. Scenarios that are likely to arise should be prioritized over scenarios that are not likely to arise. Furthermore, scenarios with severe consequences should be prioritized over scenarios with minor consequences. In the field of risk management, risk managers generally use risk matrices to prioritize which risk needs to be addressed first (see Duijm, 2015). In step 3 a similar procedure is followed: a weighting factor is determined for each scenario based on likelihood $\mathrm{x}$ severity.

\subsubsection{Weighted evaluation criteria}

As shown in Figure 27, in step 5, weighted criteria are used to evaluate a building. The criteria are based on the design solutions that have been developed. Thus, to what degree have these design solutions been implemented in the building? Furthermore, the weighting is based on the importance of each scenario (likelihood x severity). Thus, how useful is it that a design solution has been implemented, or how severe is it that a design solution has not been implemented? 


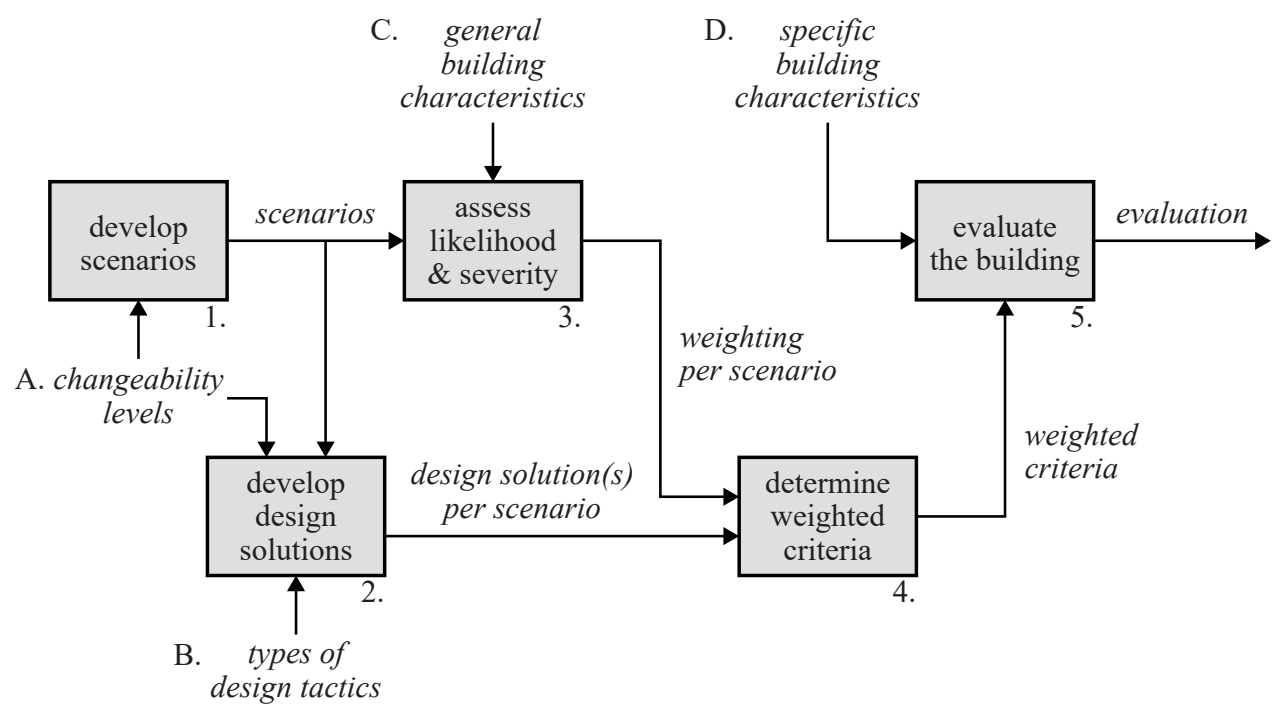

Figure 27. The proposed method of evaluating a building's changeability. This figure was made according to the principles of Structured Analysis (Ross, 1977). Thus, each box represents an activity in which input is transformed into output. Furthermore, arrows connected to the left, right, bottom and top side of a box represent input, output, support and control, respectively. 
This page is intentionally left blank. 


\subsection{Method}

\subsubsection{Introduction}

This chapter's aim is to determine: how to set up criteria for evaluating a building's changeability? In other words, how to do step 1 and 2 of the proposed method (see Figure 27). The basics of these steps have already been discussed (see 4.1.2. Proposal). However, for these steps to work, some inputs still need to be developed, i.e. changeability levels and types of design tactics. Therefore, the rest of this chapter will mainly focus on both the development of these inputs and their use within the method.

\subsubsection{Changeability levels}

A top-down approach is used to define changeability levels. This means that the approach's starting point is a theoretical concept, i.e. a building's changeability. This concept is then broken down into parts. To do such a breakdown, there are only two rules that must be followed: (1) the parts are mutually exclusive, i.e. non-overlapping (Leupen and Mooij, 2011, p. 38); and (2) every single aspect of the concept must go into the parts (Ross, 1977, p. 18). Afterwards, the changeability levels are defined by these parts.

\subsubsection{Types of design tactics}

A bottom-up approach is used to define types of design tactics. This means that numerous design tactics are the approach's starting point. These design tactics are then grouped into types. This set of types must then represent all conceivable design tactics. However, first, numerous design tactics must be collected and, before that, sources must be identified from which they can be extracted. Figure 28 describes the various searches that have been conducted to find relevant literature. As a result of these searches, 92 relevant journal papers were identified. In addition, the book "How buildings learn" (Brand, 1994) was added to this list of sources - it seemed to be an essential source. In the end, there was no mention of a design tactic in 20 of the 93 sources. Throughout the other 73 sources, a total of 549 instances have been identified in which a design tactic was mentioned. Table 10 shows the number of instances that have been identified per source. All 549 mentions of a design tactic are included in Appendix 2.

Finally, the "constant comparative method" (Glaser and Strauss, 1967, pp. 105113 ) is used to define types of design tactics. This method prescribes the following procedure: (1) design tactics must be put into categories; (2) categories must constantly be compared to avoid any overlap between categories; and (3) the number of categories 
must be reduced to an appropriate number.

\begin{tabular}{|c|c|c|c|c|c|c|c|c|}
\hline $\begin{array}{l}\text { relevant } \\
\text { hits / hits }\end{array}$ & \multicolumn{5}{|c|}{ description of search activity } & $\begin{array}{l}\text { publication } \\
\text { range }\end{array}$ & $\begin{array}{l}\text { discipline } \\
\text { excluded }\end{array}$ & $\begin{array}{l}\text { keyword } \\
\text { excluded }\end{array}$ \\
\hline & \multicolumn{3}{|c|}{ all text } & \multicolumn{2}{|r|}{ all text } & \multirow[b]{2}{*}{$\begin{array}{c}\text { Jan. } 2000 \\
\downarrow \\
\text { Apr. } 2016\end{array}$} & \multirow[b]{2}{*}{$\begin{array}{l}\text { non- } \\
\text { relevant } \\
\text { ones }\end{array}$} & \multirow[b]{2}{*}{ none } \\
\hline $\begin{array}{r}8 / 36 \\
7 / 20 \\
3 / 47 \\
16 / 62 \\
11 / 80 \\
25 / 200\end{array}$ & \multicolumn{3}{|c|}{$\begin{array}{l}\text { ("design for change") or } \\
\text { ("design for adaptability") or } \\
\text { ("adaptable architecture") or } \\
\text { ("adaptable building") or } \\
\text { ("building flexibility") or } \\
\text { ("adaptive reuse") }\end{array}$} & \multicolumn{2}{|c|}{$\begin{array}{l}\text { (product) or (building) } \\
\text { or } \\
\text { (“build environment”) }\end{array}$} & & & \\
\hline \multirow[b]{2}{*}{$5 / 42$} & \multicolumn{5}{|c|}{ all text } & \multirow{2}{*}{$\begin{array}{c}\text { Jan. } 2000 \\
\downarrow \\
\text { Apr. } 2016\end{array}$} & \multirow{2}{*}{$\begin{array}{l}\text { non- } \\
\text { relevant } \\
\text { ones }\end{array}$} & \multirow[b]{2}{*}{ none } \\
\hline & \multicolumn{5}{|c|}{$\begin{array}{l}\text { ("transformable structure") or ("transformable } \\
\text { building") or ("building transformation") }\end{array}$} & & & \\
\hline \multirow[b]{2}{*}{$26 / 386$} & keywc & ords & & & all text & \multirow{2}{*}{$\begin{array}{c}\text { Jan. } 2000 \\
\downarrow \\
\text { Apr. } 2016\end{array}$} & \multirow{2}{*}{$\begin{array}{l}\text { non- } \\
\text { relevant } \\
\text { ones }\end{array}$} & \multirow{2}{*}{$\begin{array}{l}\text { non- } \\
\text { relevant } \\
\text { ones }\end{array}$} \\
\hline & \multicolumn{3}{|c|}{ (flexib*) or (adapt*) } & \multicolumn{2}{|c|}{$\begin{array}{l}\text { (product) or (building) or } \\
\text { ("build environment") }\end{array}$} & & & \\
\hline \multirow[b]{2}{*}{$24 / 306$} & abstract & abstract & $a b$ & tract & abstract & & \multirow[b]{2}{*}{ none } & \multirow[b]{2}{*}{ none } \\
\hline & $\begin{array}{c}\text { (building) or } \\
\text { ("build } \\
\text { environment") }\end{array}$ & (chang*) & $\begin{array}{l}\operatorname{arch} \\
\text { or }(\end{array}$ & $\begin{array}{l}\text { tecture) } \\
\text { lesign) }\end{array}$ & $\mid \begin{array}{c}\text { (flexibility) or } \\
\text { (flexible) or } \\
\text { (adaptability) or } \\
\text { (adaptable) or } \\
\text { (transformable) } \\
\text { or } \\
\text { (transformation) }\end{array}$ & $\begin{array}{c}\text { May } 2011 \\
\downarrow \\
\text { Apr. } 2016\end{array}$ & & \\
\hline
\end{tabular}

Figure 28. The various searches that have been conducted to find relevant literature. The following is described, per search activity: (1) the components (e.g. specific phrases or variations on words) a search activity comprises, and whether these components apply to keywords, abstracts or all of the texts; (2) the regarded publication range; (3) whether or not specific keywords or disciplines were excluded from a search; and (4) the number of total and relevant hits encountered. 


\begin{tabular}{|c|c|c|c|}
\hline sources & $\begin{array}{c}\# \text { of } \\
\text { mentions }\end{array}$ & sources & $\begin{array}{c}\text { \# of } \\
\text { mentions }\end{array}$ \\
\hline Altan et al., 2015 & 7 & Langston et al., 2008 & 2 \\
\hline Arge, 2005 & 13 & Lin, 2011 & 4 \\
\hline Beisi and Yingying, 2011 & 12 & Mantab-uz-Zaman, 2011 & 4 \\
\hline Belausteguigoitia et al., 2011 & 11 & March et al., 2012 & 14 \\
\hline Brand, 1994 & 77 & Meins et al., 2010 & 2 \\
\hline Bruce et al., 2015 & 8 & Nijs et al., 2011 & 4 \\
\hline Bullen and Love, 2011a & 16 & Paslawski and Rozdzynska, 2013 & 2 \\
\hline Bullen and Love, 2011b & 1 & Pinder et al., 2013 & 14 \\
\hline Bullen and Love, 2011c & 3 & Remøy and van der Voordt, 2014a & 11 \\
\hline Conejos et al., 2016 & 2 & Remøy and van der Voordt, 2014b & 2 \\
\hline de Neufville, 2008 & 3 & Remøy et al., 2011 & 7 \\
\hline Dhar et al., 2013 & 12 & Ren et al., 2014 & 6 \\
\hline Dovey and Fisher, 2014 & 6 & Ross et al., 2016 & 14 \\
\hline Eguchi et al., 2011 & 20 & Saari et al., 2007 & 3 \\
\hline Engel and Browning, 2008 & 6 & Saghafi and Ahmadi, 2011 & 1 \\
\hline Engel and Reich, 2015 & 7 & Saigo et al., 2011 & 9 \\
\hline Fawcett et al., 2012 & 2 & Schmidt III and Eguchi, 2014 & 9 \\
\hline Fernandez, 2003 & 5 & Schmidt III et al., 2014 & 7 \\
\hline Fletcher et al., 2009 & 9 & Schwehr, 2011 & 5 \\
\hline Georgiadou et al., 2012 & 3 & Slaughter, 2001 & 11 \\
\hline Gijsbers and Lichtenberg, 2014 & 8 & Steadman, 2006 & 2 \\
\hline Gosling et al., 2013 & 9 & Sung-Hwa and Beisi, 2012 & 7 \\
\hline Greden and Glicksman, 2005 & 3 & Vandenbroucke et al., 2015 & 3 \\
\hline Grover and Grover, 2015 & 8 & Vimpari and Junnila, 2016 & 3 \\
\hline Halvitigala and Reed, 2015 & 22 & Walker, 2010 & 4 \\
\hline Hamraz et al., 2013 & 1 & Walker et al., 2013 & 2 \\
\hline Hassanain, 2006 & 18 & Wiendahl et al., 2007 & 10 \\
\hline Hein and Houck, 2008 & 1 & Wilkinson et al., 2009 & 1 \\
\hline Hertzberger, 2014 & 8 & Wilkinson, 2012a & 5 \\
\hline Hunter, 2006 & 10 & Wilkinson, 2012b & 7 \\
\hline Isaac et al., 2014 & 7 & Wilkinson, 2014a & 12 \\
\hline Israelsson and Hansson, 2009 & 3 & Wilkinson, 2014b & 4 \\
\hline Itard and Klunder, 2007 & 5 & Wilkinson and Reed, 2011 & 8 \\
\hline Khan and Dhar, 2012 & 11 & Wong, 2010 & 8 \\
\hline Langston and Shen, 2007 & 1 & Worthington, 2001 & 4 \\
\hline
\end{tabular}

Table 10. The number of mentions of a design tactic that have been identified per source. 


\subsection{Results}

\subsubsection{Changeability levels}

\subsubsection{Introduction}

In the Introduction (see 4.1.), changeability is defined as the ability to comply with future change. A change is the cause of a mismatch. Thus, the level of change says something about the scale of this cause. Furthermore, a building is referred to as 'able' when its design includes design solutions to address mismatches in feasible manners. However, such a manner is only thought to be feasible when the level of adjustments it involves is, at least, proportional to the severity of the mismatch's consequences. Therefore, when defining changeability levels, both aspects are important: (1) the level of change a building can comply with; and (2) the level of adjustments a building can allow for.

Schmidt III et al. (2010) defined six adaptability types: (1) adjustability; (2) versatility; (3) refitability; (4) convertibility; (5) scalability; and (6) movability. These adaptability types range from types related to small adaptations, that are frequently needed, to types related to major adaptations, that are hardly ever needed (Schmidt III, 2014, p. 174). Schmidt's adaptability types partially fulfil this chapter's aim. However, these adaptability types are arranged in terms of type of change, and not necessarily in terms of the scale of change. Therefore, some revisions are necessary. The result of these revisions is shown in Figure 29.

As shown in Figure 29, a building's most basic ability to comply with changes, i.e. changeability level 1 , is adjustability. A building's adjustability is determined by how capable it is in complying with small-scale changes, by allowing for small-scale adjustments. Changeability level 2 is versatility. A building's versatility is determined by how capable it is in complying with medium-scale changes, by allowing for small-scale and medium-scale adjustments. Changeability level 3 is convertibility. A building's convertibility is determined by how capable it is in complying with largescale changes, by allowing for small-scale, medium-scale and large-scale adjustments. Finally, a building's most advanced ability to comply with changes, i.e. changeability level 4 , is reconfigurability. A building's reconfigurability is determined by how capable it is in complying with extra-large-scale changes, by allowing for small-scale, mediumscale, large-scale and extra-large-scale adjustments.

The following section will explain the differences between both the different scales of change and the different scales of adjustments. 


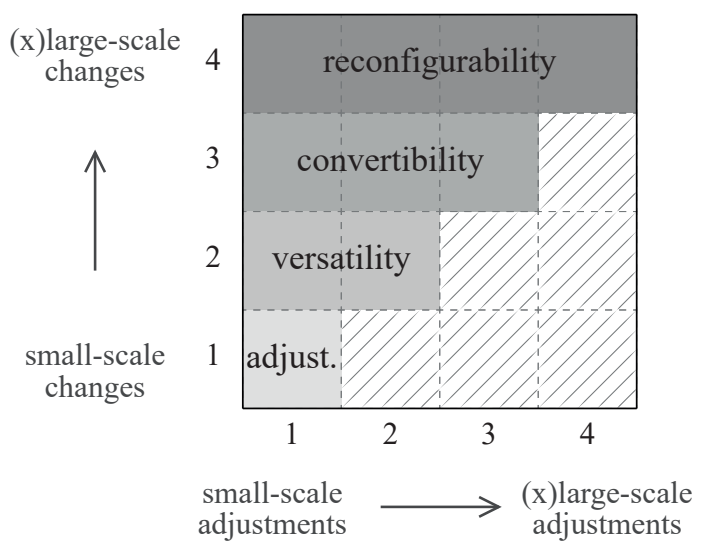

Figure 29. The subject area that each changeability level covers, in terms of both: (1) the scale of changes a building can comply with; and (2) the scale of adjustments a building can allow for.

\subsubsection{The level of change}

As previously mentioned, a change is the cause of a mismatch. In this study, a change refers to a change at the user's side, i.e. a change in the user's characteristics or activities. The level of change is mainly determined by the number of persons involved. A distinction is made between four size classes: (1) individual; (2) group; (3) organization; and (4) community.

The group size class refers to 7 to 20 occupants. A set of 7 or more persons are primarily perceived as a group of people, instead of a number of distinct individuals (see Alexander et al., 1977, p. 505). The organization size class refers to 20 or more occupants. For such a group, it is no longer possible for each member to interact individually with every other member (Caplow, 1957, pp. 486-487), and therefore an organizational structure is required. The community size class refers to all occupants and numerous non-occupants. This is the only category that has little to do with the use of the building, instead it is concerned with how the building fits in with its surroundings.

A change on the individual, group, organization and community level is categorized as a small-scale, medium-scale, large-scale and extra-large-scale change, respectively.

\subsubsection{The level of adjustments}

As previously mentioned, a building is referred to as 'able' when its design includes design solutions to address mismatches in feasible manners. However, such a manner is only thought to be feasible when the level of adjustments it involves is, at least, proportional to the severity of the mismatch's consequences. The level of adjustments 
is determined by both: (1) the type of elements involved; and (2) the type of intervention involved. The type of elements are categorized according to Brand's (1994, p. 13) wellknown building layers: (1) stuff; (2) space plan; (3) services; (4) skin; and (5) structure. Brand's sixth layer, i.e. site, has been left out.

Concerning the type of intervention, a distinction is made between five types: (1) reinterpret, i.e. change how something is used; (2) adjust, i.e. switch between preestablished settings; (3) modify, i.e. alter the finishing layer; (4) alter, i.e. add and remove elements; and (5) reconfigure, i.e. change the composition of elements. In this study, adjustments are categorized as either small-scale, medium-scale, large-scale or extra-large-scale adjustments. In Table 11, each combination of a type of elements and a type of intervention has been put into one of these four categories.

\begin{tabular}{|c|c|c|c|c|c|}
\cline { 2 - 6 } \multicolumn{1}{c|}{ stuff } & space plan & services & skin & structure \\
\hline reinterpret & small & small & small & small & small \\
\hline adjust & small & medium & small & small & large \\
\hline modify & medium & medium & medium & medium & medium \\
\hline alter & medium & large & large & large & extra large \\
\hline reconfigure & medium & large & large & extra large & extra large \\
\hline
\end{tabular}

Table 11. How the type of elements involved and the type of intervention involved determines whether an adjustment is categorized as a small-scale, medium-scale, large-scale or extra-large-scale adjustment.

\subsubsection{How to do step 1: developing scenarios}

Now that the changeability levels have been defined, how are they used to support step 1, i.e. developing scenario? As previously mentioned (see 4.1.2.2. Scenarios), a scenario is a description of a mismatch that can arise when a building is confronted with a certain change. Thus, a scenario describes a causal relation, i.e. an if-this-than-that relation, that contains two primary components: (1) the change; and (2) the mismatch. The changeability levels mainly support the development of the first component, i.e. the change. 
Based on the different levels of change, 13 changes can be developed. These changes are listed in Table 12. Not all of these 13 changes are equally realistic, however that is something that will be sorted out in the method's step 3. Firstly, a change on the individual level can either be a change in the user's characteristics or a change in the user's activities. Secondly, starting from the group level, the user refers to multiple

\begin{tabular}{|c|c|c|c|c|}
\hline level & type of change & sub-type & specific change & mismatch \\
\hline 1 & $\begin{array}{c}\text { user's } \\
\text { characteristics }\end{array}$ & $\begin{array}{l}\text { average } \\
\text { individual }\end{array}$ & person $\mathrm{A}>$ person $\mathrm{B}$ & $\begin{array}{c}\text { local } \\
\text { insufficiency }\end{array}$ \\
\hline 1 & $\begin{array}{c}\text { user's } \\
\text { activities }\end{array}$ & - & personal task $\mathrm{A}>$ personal task $\mathrm{B}$ & $\begin{array}{c}\text { local } \\
\text { insufficiency }\end{array}$ \\
\hline 2 & $\begin{array}{c}\text { user's } \\
\text { characteristics }\end{array}$ & $\begin{array}{c}\text { average } \\
\text { individual }\end{array}$ & group $\mathrm{A}>$ group $\mathrm{A} / \mathrm{B}$ & $\begin{array}{c}\text { local } \\
\text { insufficiency }\end{array}$ \\
\hline 2 & $\begin{array}{c}\text { user's } \\
\text { characteristics }\end{array}$ & $\begin{array}{l}\text { total \# of } \\
\text { individuals }\end{array}$ & group $\mathrm{A}>$ group $\mathrm{A}+$ & $\begin{array}{c}\text { local } \\
\text { insufficiency }\end{array}$ \\
\hline 2 & $\begin{array}{c}\text { user's } \\
\text { activities }\end{array}$ & - & group task A > group task B & $\begin{array}{c}\text { local } \\
\text { insufficiency }\end{array}$ \\
\hline 3 & $\begin{array}{c}\text { user's } \\
\text { characteristics }\end{array}$ & $\begin{array}{c}\text { average } \\
\text { individual }\end{array}$ & organization $\mathrm{A}>$ organization $\mathrm{A} / \mathrm{B}$ & $\begin{array}{c}\text { total } \\
\text { insufficiency }\end{array}$ \\
\hline 3 & $\begin{array}{c}\text { user's } \\
\text { characteristics }\end{array}$ & $\begin{array}{l}\text { total \# of } \\
\text { individuals }\end{array}$ & organization $\mathrm{A}>$ organization $\mathrm{A}+$ & $\begin{array}{c}\text { total } \\
\text { insufficiency }\end{array}$ \\
\hline 3 & $\begin{array}{c}\text { user's } \\
\text { characteristics }\end{array}$ & relations & organization $\mathrm{A}>$ organization A.2 & $\begin{array}{c}\text { total } \\
\text { insufficiency }\end{array}$ \\
\hline 3 & $\begin{array}{c}\text { user's } \\
\text { activities }\end{array}$ & - & organization $\mathrm{A}>$ organization $\mathrm{B}$ & $\begin{array}{c}\text { total } \\
\text { insuf./excess }\end{array}$ \\
\hline 4 & $\begin{array}{c}\text { user's } \\
\text { characteristics }\end{array}$ & $\begin{array}{c}\text { average } \\
\text { individual }\end{array}$ & community $\mathrm{A}>$ community $\mathrm{A} / \mathrm{B}$ & $\begin{array}{c}\text { total } \\
\text { insufficiency }\end{array}$ \\
\hline 4 & $\begin{array}{c}\text { user's } \\
\text { characteristics }\end{array}$ & $\begin{array}{c}\text { total \# of } \\
\text { individuals }\end{array}$ & community $\mathrm{A}>$ community $\mathrm{A}+$ or $\mathrm{A}-$ & $\begin{array}{l}\text { local/total } \\
\text { insufficiency }\end{array}$ \\
\hline 4 & $\begin{array}{c}\text { user's } \\
\text { characteristics }\end{array}$ & relations & community A > community A. 2 & $\begin{array}{l}\text { local/total } \\
\text { insufficiency }\end{array}$ \\
\hline 4 & $\begin{array}{c}\text { user's } \\
\text { activities }\end{array}$ & - & district task $\mathrm{A}>$ district task $\mathrm{B}$ & $\begin{array}{c}\text { total } \\
\text { insufficiency }\end{array}$ \\
\hline
\end{tabular}

Table 12. A list of 13 changes that have been developed based on the different levels of change. The levels 1, 2, 3 and 4 represent a small-scale, medium-scale, large-scale and extra-large-scale change, respectively. 
individuals. Therefore, the user's characteristics can change both in average and in total. Thirdly, starting from the organization level, individuals interact according to formalized relations. Therefore, the user's characteristics can change both in terms of individuals and in terms of relations.

All these individual changes can result in mismatches. A mismatch generally means that a building no longer fulfils people's requirements - something is lacking. For example, there can be insufficient operating space, ventilation capacity or privacy. Such problems can occur locally or throughout the entire building. Furthermore, there is also one situation in which too much of something is a bad thing, i.e. when the building is being sold. When there is a significant excess of something, e.g. cooling capacity, a potential buyer will feel like they are asked to pay extra for something that they do not need.

Thus, to develop a scenario, a person has to select one of the changes in Table 12 and then ask him- or herself: what could go wrong?

\subsubsection{Types of design tactics}

\subsubsection{Introduction}

As previously mentioned (see 4.1.2.2. Scenarios), scenarios are developed to identify potential problems, and potential problems are identified to determine which design solutions are useful. Thus, after the scenarios have been developed, the next step is to link each scenario to at least one design solution. A design solution refers to a set of designable conditions that make a certain manner of addressing a certain mismatch significantly easier. To develop a design solution one must first identify the individual designable conditions that are beneficial when addressing a certain mismatch in a certain manner, i.e. the design tactics, and then one must combine them into a complete solution.

There are three manners to address a mismatch: (1) reinterpret the use of a part of the building to make the use more suitable for the new setting; (2) alter a part of the building to make the part more suitable for the new setting; and (3) accept that not every part of the building will be precisely as it should be in the new setting. For each of these actions, i.e. reinterpret, alter and accept, there are certain conditions that will help their execution. These beneficial conditions are described in the design tactics. A design solution is often composed of several design tactics, and it will also often involve multiple different actions.

The development of a design tactic is no different from the process of coming up with an idea: people go through their memories and they select something that is 
appropriate. Therefore, it is important that people have adequate knowledge about the specific subject matter, because nothing can be found what is not already there (Jungermann and Thüring, 1987, p. 250). Furthermore, not all information that is stored in a person's memory is always fully accessible. Information is retrieved more easily, from a person's memory, when he or she is reminded of the heading under which it is mentally filed (Tulving and Pearlstone, 1966). A categorization into types supports the development of design tactics by making it easier to retrieve relevant information. Furthermore, the specific examples on which each type is based can help a person gain adequate knowledge about the subject matter.

In this chapter, the 549 mentions of a design tactic, that are included in Appendix 2, have been grouped into 10 types of design tactics. Table 13 shows: (1) the 10 types of design tactics; (2) the action, i.e. reinterpret, alter or accept, that each type is meant to support; and (3) the number of mentions that each type is based on. In the following section, each of these types will be described individually. Furthermore, in each description, two or three examples are provided of the design tactics on which the type is based. All mentions on which each type is based are included in Appendix 2.

\begin{tabular}{|c|c|c|}
\hline type & action & \# of mentions \\
\hline overdesigned & reinterpret & 91 \\
blank & reinterpret & 76 \\
uniform & reinterpret & 82 \\
diverse & reinterpret & 23 \\
appropriate & reinterpret & 69 \\
undemanding & alter & 82 \\
convenient & alter & 58 \\
robust & alter & 14 \\
unique & accept & 14 \\
intelligible & reinterpret / alter & 29 \\
\hline
\end{tabular}

Table 13. A list of the types of design tactics. The table also shows: the action, i.e. reinterpret, alter or accept, that each type is meant to support; and the number of mentions that each type is based on.

\subsubsection{Benefit of overdesigned things}

To reinterpret the use of a part of the building, it is beneficial to have overdesigned parts and properties. Overdesigned things, i.e. things that have been designed to 
a higher standard than usual, are less likely to be insufficient for more demanding plans. Therefore, overdesigned things are more likely to be useful in a new setting. For example, Slaughter (2001, p. 213) argued how “...structural members with higher capacity than currently required for the immediate design loads can provide the opportunity to add to the building in the future". Otherwise, the loadbearing structure would need strengthening before, for instance, an extra storey can be added.

Furthermore, Halvitigala and Reed (2015, p. 488) argued that acoustical ceilings that absorb noise and minimize the sound propagation adequately are necessary in an open plan office environment. Therefore, the conversion to an open plan is made easier by already having such ceilings. Finally, according to Brand (1994, p. 170) and Eguchi et al. (2011, p. 82), many of the 1960s and 1970s office buildings lack the floor-to-floor height that is needed to add a raised floor or a suspended ceiling. As a result, the latest service devices cannot be added to those buildings in the conventional manner. This problem would not have occurred if those buildings were built with a greater floor-tofloor height.

\subsubsection{Benefit of blank things}

To reinterpret the use of a part of the building, it is beneficial to have blank parts and properties. Blank things, i.e. things that have been left empty, are less likely to contain features that are misplaced in another setting. Therefore, blank things are more likely to be useful in a new setting. For example, columns and walls are referred to as "restricting" (Bruce et al., 2015, p. 160), a large number of them can make a building "inappropriate for any change of use" (Bullen and Love, 2011c, p. 39) and by keeping large portions of the building free of such things allows for more easy reconfiguration to suit changing requirements (Ross et al., 2016, p. 423).

Furthermore, similarly to how columns and walls can be seen as obstacles in an empty floorplan, windows can be seen as obstacles in a blank wall: Wong (2010, pp. 181-182) argued how the presence of windows "severely" limits the options of placing walls attached to the outer wall. Finally, Dhar et al. (2013, p. 150, Table I) argued that exposed roof beams constrain where one would add partitions - the clear presence of a grid directs the placement of things and therewith confines one's freedom in positioning. However, when a ceiling is completely blank, no situation would occur in which one feels awkward for, for instance, placing an interior wall just next to a structural beam.

\subsubsection{Benefit of uniform things}

To reinterpret the use of a part of the building, it is beneficial to have uniform parts 
and properties. Uniform things, i.e. things that share certain properties throughout the building or system, are likely to be as suitable, for another purpose, as for the original purpose. Therefore, uniform things are more likely to be useful in a new setting. For example, Beisi and Yingying (2011, p. 24, 25) argued that in traditional Chinese architecture, differences in the function of rooms were only evident by the furniture placed within them - rooms shared similar spatial dimensions. As a result, only the furniture needs to be moved to, for instance, change a dining room into a bedroom. Furthermore, Wilkinson (2014a, p. 254) argued that a central location for the services core provides "greater scope for sub-dividing the floor plate". Positioning the entrance to a floor, for both people and pipes, in the centre of a building has the following consequences: (1) the surrounding space naturally breaks down into evenly sized parts; and (2) these parts are positioned equally, in distance, from this services core. Therefore, no single part is more suitable for a particular purpose than another. Finally, Schmidt and Eguchi (2014, p. 79) argued how counters, tables and shelfs can be used as handrails by positioning them on a height which is appropriate for both functions.

\subsubsection{Benefit of diverse things}

To reinterpret the use of a part of the building, it is beneficial to have diverse parts and properties. Diverse things, i.e. things that have certain properties that are unique within the building or system, are less likely to be part of a whole that is - in its entirety - unsuitable for another purpose. Thus, a group of diverse things is more likely to include things that are useful in a new setting. For example, de Neufville (2008, p. 57) argued that to minimize, possibly premature, irrevocable commitments, one can “.... simultaneously create both traditional and low-cost facilities at a new airport, to appeal to the range of possible customers". When either the traditional or the lowcost facilities become more popular, one can always emphasize and expand on those sections of the complex.

Furthermore, Khan and Dhar (2012, p. 58) argued, concerning housing, that "when a choice over moving or improving has to be made, and if the users are tenants, it is probably easier to decide to move". In other words, when a building contains diverselysized apartments, people do not need to alter their apartments to live bigger or smaller - they can also move to a different apartment within the building.

\subsubsection{Benefit of appropriate things}

To reinterpret the use of a part of the building, it is beneficial to have appropriate parts and properties. Appropriate things, i.e. things that have certain properties that 
are common outside the building or system, are less likely to be unsuitable within another setting. Therefore, appropriate things are more likely to be useful in a new setting. For example, Grover and Grover $(2015$, p. 309$)$ argued that “... a cinema may become a bingo club and then a church", since all these function share certain essential characteristics, namely: (1) they need "...to accommodate large numbers of people taking part in a sedentary leisure activity"; and (2) provide "...the ability for large numbers of people to enter or leave the building at the same time".

Furthermore, Eguchi et al. (2011, p. 77) argued how a smaller grid size, one typically used for shopping centres and parking as opposed to offices, can add to the convertibility of an office building. A building with larger spans is considered to be inappropriately costly for this particular conversion, since (1) larger spans are associated with higher costs and (2) it is common for shopping centres and parking to have smaller spans. Finally, Lin (2011, p. 21) argued that "Metabolist" buildings often have a below average floor/area ratio, and that, therefore, a lot of these buildings have been replaced by more "economically viable" buildings.

\subsubsection{Benefit of undemanding things}

To alter a part of the building, it is beneficial to have undemanding parts and properties. Undemanding things, i.e. things that require few activities to be assembled, disassembled and operated, are more likely to be altered, when needed. Therefore, undemanding things are less of an obstacle for new settings. For example, Sung-Hwa and Beisi (2012, p. 21) described how, initially, four separate hanging panels were used as a partition between two rooms in a particular traditional Korean building. These panels were hinged on the structure directly above them. To open up the entire wall, one had to lift up each of the four panels separately and one had to attach each of them to hooks that were hanging from the ceiling. Eventually, three of the four separate panels were replaced by a single much larger panel. As a result, the task of opening up the entire wall was reduced from four to two activities of lifting panels and hooking them up on the ceiling.

Furthermore, Dhar et al. (2013, pp. 150-152) argued that one should avoid installing major wiring work in "relatively non-permanent" walls. Otherwise, a re-installation of wiring systems is required with every removal or replacement of such walls. This would make it a lot harder to make any major alterations to the partition walls.

\subsubsection{Benefit of convenient things}

To alter a part of the building, it is beneficial to have convenient parts and properties. 
Convenient things, i.e. things that require no cumbersome activities to be assembled, disassembled and operated, are more likely to be altered, when needed. Therefore, convenient things are less of an obstacle for new settings. For example, Schmidt et al. (2014) argued "the need to reduce chunks sizes" to end up with dimensions which are "manageable" (p. 162) - especially volumetric solutions provided difficulties (p. 180) when alterations where required. A flat board, for instance, is easier to get a grip on and easier to manoeuvre through an opening than a bulky three-dimensional object. Furthermore, Wilkinson and Reed (2011, p. 732) argued how "internal adaptations are easier to carry out" when one can gain entry without having to disrupt the possible use of adjoining spaces. For instance, it is easier to move materials to a room when it is directly accessible from the outside - transporting stuff through a lot of doors and over stairs is not ideal. Furthermore, transporting materials through spaces that are still in use is no better.

\subsubsection{Benefit of robust things}

To alter a part of the building, it is beneficial to have robust parts and properties. Robust things, i.e. things that are tolerant to physical stress, are more likely to be altered, when needed, because they are less likely to break during alterations. Therefore, robust things are less of an obstacle for new settings. For example, Bruce et al. (2015, p. 160) argued that "...the quality of the building's internal structure and the durability of the materials that it was initially constructed from are very important". When a building is not sturdy enough to endure the additional stress of reconstruction activities, a lot of parts will need replacements.

Furthermore, Saigo et al. (2011, p. 10) argued that buildings in Japan from the late 8th to the late 12th century did not last as long as the buildings from both the preceding and succeeding period. According to Saigo et al., this was caused by the use of structural elements that were not as robust by comparison. Such comparatively fragile structures are less durable in general, but they are also more difficult to adapt.

\subsubsection{Benefit of unique things}

To accept that a part of the building is not exactly as it is supposed to be, it is beneficial to have unique parts and properties. Unique things, i.e. things that have certain properties that are uncommon outside the building or system, are more likely to be cherished because they are difficult to replace. Therefore, unique things are more likely to be forgiven for their flaws. For example, Brand (1994, p. 109) argued that "strangeness" is a "trait that invites longevity". He illustrated this statement with the example of 
an "adorably tiny stone hut" built, in the 16th century, spanning a small brook. This building contains just two rooms, one for each story. Normally, not a lot of uses suit a building of this size. Nonetheless, its uses over the centuries have been numerous and quite diverse.

Furthermore, Eguchi et al. (2011, pp. 80-81) argued, concerning the conversion of an old office building into residential units, that one can drive market value by emphasizing the uniqueness offered by the original characteristics. In other words, that a residential building used to be an office is what sets it apart from all other residential buildings. Furthermore, these unique properties make it a more valuable building.

\subsubsection{Benefit of intelligible things}

It is beneficial to have intelligible parts and properties, both (1) to reinterpret the use of a part of the building and (2) to alter a part of the building. Intelligible things, i.e. things that are easily understandable through common sense, are less likely to be written off by people that do not completely understand their potential. Therefore, intelligible things are more likely to be reinterpreted and altered, when needed. For example, Slaughter (2001, p. 215) argued how "...the predictability of the layout of a system and its components, particularly for those elements that are... hidden... can provide critical signals to reduce the duration and extent of demolition to find the required components". For instance, a change needs to be made to the cables that run through the walls and structure of a building. To do so, it would be easier if all cables had been placed at consistent and recognizable locations (e.g. right next to the columns), instead of behind the walls without a clear logic.

Furthermore, Brand (1994, p. 135) argued that “...huge free-span interior spaces [are] actually a loss for intuitive adaptability". He stated that "...columns articulate space in a way that makes people feel comfortable making and remaking walls..." (p. 135). In other words, the possibilities of a floor plan that includes multiple columns are more easily understood, compared to a floor plan that is free of columns, and therefore it is easier to make the best use of a floor plan with columns.

\subsubsection{How to do step 2: developing design solutions}

Step 2 is developing design solutions. As previously mentioned (see 4.1.2.3. Design solutions): (1) changeability levels are used to limit the possible outcomes of step 2; and (2) types of design tactics are used to support step 2. Now that both the changeability levels and the types of design tactics have been defined, how are they used?

Firstly, a design solution is always developed for a specific scenario. This means that, 
at the start of step 2, the change is known. The change's level determines the maximum level of adjustments that may be involved in a design solution to the problem (see Figure 29) - more effort would not be justified by a problem of that size. Furthermore, once the scenario is known, the mismatch is also known. The mismatch suggests what needs to be adjusted. For example, when there is insufficient cooling capacity, the building's services need an adjustment, or when there is insufficient operating space, the building's space plan needs an adjustment. Based on the maximum level of adjustments that is permitted, one can look up the specific interventions that may be involved in a design solution to the problem in Table 11.

Secondly, once the limitations of a design solution are known, the development can start. A design solution is generally centred around a specific intervention, e.g. a reinterpretation or an alteration. The development of design solutions starts by checking the design tactics that are directly associated with this type of intervention (see Table 13). Afterwards, one must ask him- or herself: which other design tactics can be beneficial to any aspects of the solution?

Two examples will be given. Both are examples of a design solution to the following potential problem: the building's cooling capacity is insufficient. Example 1 is a design solution centred around a reinterpretation of the cooling service. This design solution is rather straightforward: design the building's cooling capacity for the worst-case scenario. It is entirely based on a single type of design tactic: overdesigned building parts and properties.

Example 2 is a design solution centred around an alteration of the cooling service. This design solution is more complicated: (1) situate the installation space in a, for the worker, ergonomically accessible location; (2) cover the installation space by as few parts as possible; (3) use covering parts that are small and light enough for a single person to lift them; (4) use covering parts that are strong enough to withstand disassembly and reassembly; (5) do not use chemical connections to interconnect the covering parts; (6) use covering parts that are identical to one another; (7) overdesign the height of the installation space; and (8) position the parts of the installation systematically. This design solution is based on six types of design tactics: overdesigned, convenient, undemanding, robust, uniform and intelligible building parts and properties. 


\subsection{Discussion and conclusion}

\subsubsection{Discussion}

A scenario-based method of evaluating a building's changeability is proposed in this chapter. In this method, a building is judged by the presence or absence of certain key performance indicators. This is no different from most other methods of evaluating a building's changeability (e.g. Wilkinson, 2014b). However, what is different about this method is that the key performance indicators are not determined before the evaluation, but during the evaluation process: first the optimization goals are specified, and then the key performance indicators are determined.

The difficult part of the key indicator model is not identifying indicators, it is determining valid weighting factors for each of those indicators (see Schmidt III, 2014, pp. 97-99). From the literature that was examined in this chapter (see Table 10), only the studies of Wilkinson (see 2014b) focussed on developing valid weighting factors. Most evaluation methods do not specify the situations that they aim to optimize, and without a specific optimization goal, solutions cannot be validated and valid weighting factors cannot be determined.

Wilkinson's approach is purely quantitative. Such an approach can explain what works in general, but not how it works. Thus, when the numbers change, it is difficult to explain why (e.g. Wilkinson, 2014a, p. 216). Furthermore, when a designer or client wants to prioritize specific aspects of changeability, he or she needs to know more than what works in general. A scenario-based approach does explain how something works. However, the method proposed in this chapter also has its disadvantages: (1) it is very time-consuming; and (2) it requires extensive knowledge about the subject matter. Therefore, the method is probably most suitable for research purposes. However, it can also have a practical use for educational purposes. As mentioned in the Introduction (4.1.), a designer must first learn how to evaluate how well a building performs in terms of expected longevity, before he or she can learn to create long-lasting buildings. By using this evaluation method, it is expected that a designer will learn valuable lessons that will significantly improve his or her future designs, in terms of changeability.

\subsubsection{Conclusion}

This chapter's aim was to determine the following: how to set up criteria for evaluating a building's changeability? The answer is as follows. Firstly, one must develop scenarios. To develop a scenario, a person must select one of the changes in Table 12 and then ask him- or herself: what could go wrong? Secondly, one must develop design solutions. 
To develop a design solution, a person must first select a specific intervention, among those that are permitted (see Figure 29), from Table 11 as the centre of the design solution. Afterwards, one must check the design tactics that are directly associated with this type of intervention and then ask him- or herself: which other design tactics can be beneficial to any aspects of the solution? These results can help both researchers and designers to create scenarios and to develop design solutions to the potential problems described in these scenarios. 


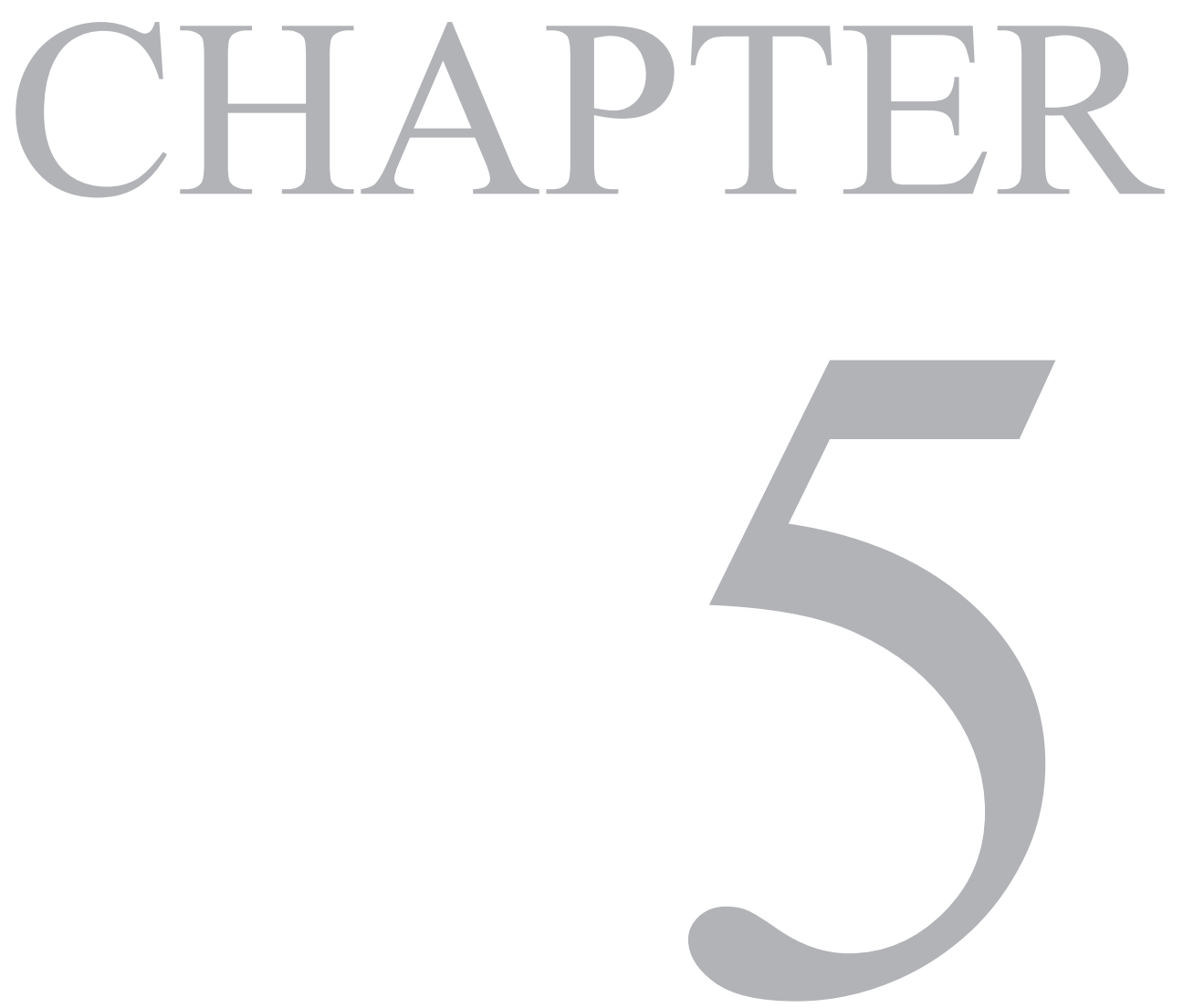

How adjustable is the

Environmental Building? 
This page is intentionally left blank. 


\section{Chapter 5's purpose}

In Chapter 4, a method of evaluating a building's changeability is proposed. Chapter 5 's purpose is to develop an initial evaluation of this evaluation method. There are two distinct aspects of design support that can be evaluated (Blessing and Chakrabarti, 2009, p. 37): (1) its application - can the support be used for the task for which it is intended; and (2) its success - does the support have the expected impact. Due to time constraints, the initial evaluation, of this method for evaluating a building's changeability, only focusses on the method's application. Chapter 5's outcome must provide an indication of whether or not specific strengths and weaknesses of the building's design, in relation to the user's changing requirements, can be identified by using the evaluation method proposed in Chapter 4. 
This page is intentionally left blank. 


\subsection{Introduction}

In Chapter 4, a method of evaluating a building's changeability is proposed. This method's aim is to not only grade a building, but to also provide an explanation of what that grade means, i.e. which changes can the building comply with, and which changes can the building not comply with. This may not seem so noteworthy - to explain what an evaluation is based on. However, in this field, a common problem with existing methods is that their numbers are often not or insufficiently backed up by rational explanations (see Schmidt III, 2014, pp. 97-99). Therein lies the value of the proposed method - it should not have this problem. However, does it work?

There are two distinct aspects of the method that can be evaluated (Blessing and Chakrabarti, 2009, p. 37): (1) its application - can the support be used for the task for which it is intended; and (2) its success - does the support have the expected impact. The expected impact is greater longevity; buildings with greater changeability will have greater longevity. However, monitoring the effects, of an intervention, on the lifespan of a building is practically not feasible. The alternative is to test whether or not specific design solutions are beneficial, for the building's users and owners, during specific change scenarios, under various conditions. This approach is theoretically feasible, but it is still very time-consuming. Therefore, this initial evaluation, of the method for evaluating a building's changeability, will only focus on the method's application.

To do so, an existing building is evaluated in terms of adjustability by following the steps described in the method. Adjustability is the first of four changeability levels (see 4.3.1.). Covering only the first changeability level should be enough to get an indication of whether or not specific strengths and weaknesses of the building's design, in relation to the user's changing requirements, can be identified by using the evaluation method. The building that is evaluated is BRE's (Building Research Establishment)Environmental Building. The Environmental Building was completed in 1996 (Feilden Clegg Bradley Studios, n.d.) to demonstrate how to implement various sustainable practices in the built environment (EOF Group, 1995a, p. 1). Since the Environmental Building was a demonstration project, a lot of information about the project has been published. A lot of information of a building is required in order to evaluate its changeability. Therefore, the Environmental Building is both an interesting and accessible subject for the evaluation. The most innovative aspect of this building is the design of its services systems (Bunn, 1997, p. 18). However, the aforementioned innovation was only implemented in the building's main section, i.e. a three storey office block (Herbert, 1998, pp. 87-88). Therefore, only this section of the building will be evaluated. 


\subsection{Method}

\subsubsection{Introduction}

This chapter's aim is to test whether or not specific strengths and weaknesses of the building's design, in relation to the user's changing requirements, can be identified by using the evaluation method proposed in Chapter 4. To do so, the Environmental Building's adjustability is evaluated by following the steps described in this method. The method comprises five steps: (1) develop scenarios; (2) develop design solution(s) per scenario; (3) assess scenarios' likelihood and severity; (4) establish weighted criteria based on both the scenarios' design solutions and the scenarios' likelihood and severity; and (5) use these weighted criteria to evaluate the building (see Chapter 4, Fig. 27).

\subsubsection{Develop scenarios}

A scenario describes a causal relation, i.e. an if-this-than-that relation, that contains two primary components: (1) the change; and (2) the mismatch. To develop scenarios, one starts by developing changes. Then, these changes must be linked to mismatches to form scenarios. The changes are drawn from the changeability levels' description (see 4.3.1.), while the mismatches are drawn from literature regarding the physical environment's effect on workers' satisfaction and performance (e.g. Al Horr et al., 2016, p. 385, Fig. 3; Carnevale, 1992, p. 427, Fig. 1; Sundstrom, 1986, p. 80, Fig. 4.3).

\subsubsection{Develop design solutions}

To develop a design solution, one starts by determining the type of intervention that the solution will centre around. These types of intervention are drawn from the changeability levels' description (see 4.3.1.). Then, design tactics are developed and combined into a design solution. The design tactics are drawn from the following 10 types of design tactics: (1) overdesigned; (2) blank; (3) uniform; (4) diverse; (5) appropriate; (6) undemanding; (7) convenient; (8) robust; (9) unique; and (10) intelligible (see 4.3.2.). During the development of a design solution, one should first consider the inclusion of design tactics that are directly associated with the type of intervention that the solution centres around. Afterwards, the inclusion of other design tactics must also be considered.

\subsubsection{Assess likelihood and severity}

A scenario's likelihood is determined by both: (1) the change's expected frequency; and (2) the probability that this change, when it occurs, will result in a certain mismatch. 
Generally, such statistics are often not recorded. Therefore, estimates will be based on any information that is found, and thus a lot of assumptions will be necessary. Furthermore, a scenario's severity is described by the percentage of productivity decrease that it is associated with. Differences in scenarios' severity are mostly based on the result of five different studies on the relative importance of various determinants on workers' self-rated satisfaction with the physical work environment (see Kim and de Dear, 2013; Leder et al., 2016; O’Neill, 1994; Sakellaris et al., 2016; Veitch et al., 2007).

\subsubsection{Evaluate the building}

In step 5 of the method, one must evaluate to what degree the design solutions have been implemented. A design solution generally comprises multiple design tactics. Each individual design tactic's implementation will be rated separately. Afterwards, these results are added together into the ratings of design solutions' implementation. This process is termed the Analytic Hierarchy Process (Saaty, 1990). Finally, for the overall evaluation, the rating of each design solution's implementation is multiplied by a weighting factor, that is based on the associated scenario's likelihood and severity, and then the weighted ratings are added together. 


\subsection{Results}

\subsubsection{Evaluation criteria}

\subsubsection{Introduction}

In the method, the first four out of five steps describe how to set up weighted evaluation criteria. Thus, a significant amount of preliminary work is needed. These elements are dealt with in the following sequence: (1) the changes and their expected frequency; (2) the mismatches and their severity; and (3) the design solutions and their weighting. Furthermore, the probability estimates, i.e. estimates about the probability that a change will result in a certain mismatch, are dealt with in Appendix 3.

\subsubsection{Changes and their expected frequency}

A building's adjustability is its ability to comply with individual-level changes. On the individual level, in an office setting, the reference situation is as follows: person $\mathrm{X}$ does work $\mathrm{X}$ at workstation $\mathrm{X}$. In this situation, two changes can occur. Firstly, change 1: person $\mathrm{X}$ is replaced by person $\mathrm{Y}$ while both work $\mathrm{X}$ and workstation $\mathrm{X}$ stay the same. Three real-life situations will result in such a change: (1) a person voluntarily leaves his/her job; (2) a person involuntarily leaves his/her job; or (3) a person is reassigned to another workstation. In the UK, annual employee turnover is on average about $13 \%$ (Martin, 2003, p. 395, Table 1). Therefore, it is assumed that change 1 will occur 15 times per year in a 100-person organization.

Secondly, change 2: work $\mathrm{X}$ is replaced by work $\mathrm{Y}$ while both person $\mathrm{X}$ and workstation $\mathrm{X}$ stay the same. Two real-life situations can result in such a change: (1) a person is given another status; or (2) a person is given another function. However, such changes are often accompanied by a change in workstation ( 1 out of 2 times is assumed) - which would change the nature of the change. In a study of West and Nicholson (1989, pp. $338-340$ ), about $26 \%$ of the respondents changed jobs within their organization within the studied timespan of about 15 months. Therefore, it is assumed that change 2 will occur 10 times per year in a 100-person organization.

\subsubsection{Mismatches and their severity}

A mismatch generally means that a building no longer fulfils people's requirements something is lacking. In Table 14, a ranking is shown in which mismatches are ranked in terms of severity, i.e. according to how much they affect workers' satisfaction with the work environment.

Firstly, thermal comfort, air quality and lighting conditions are equally important factors 


\begin{tabular}{|c|l|c|}
\hline rank & \multicolumn{1}{|c|}{ mismatch } & effect \\
\hline 1 & insuf. privacy & $-4 \%$ \\
\hline 2 & insuf. ergonomics & $-4 \%$ \\
& insuf. thermal comfort & $-2 \%$ \\
& insuf. air quality & $-2 \%$ \\
& insuf. lighting conditions & $-2 \%$ \\
& insuf. operating space & $-2 \%$ \\
\hline 3 & insuf. closeness & $-1 \%$ \\
\hline
\end{tabular}

Table 14. A list of mismatches that are ranked according to how much they affect workers' satisfaction with the work environment. The effect is stated in percentage of productivity decrease.

for workers' satisfaction with the work environment (Sakellaris et al., 2016, Table 4) (cf. Kim and de Dear, 2013, p. 23; Veitch et al., 2007, p. 182, Table 2). Concerning thermal comfort, according to Saari et al. (2006, pp. 1964-1966), a higher temperature than $25^{\circ} \mathrm{C}$ will result in a productivity decrease of $2 \%$ per degree. Concerning air quality, according to Seppänen et al. (2006), a higher ventilation rate will generally result in a 1-3\% increase in performance per $10 \mathrm{l} / \mathrm{s}$-person. Concerning visual comfort, in a study of Juslén et al. (2007), higher lighting levels (+400 lux) resulted in a 3\% increase in productivity in an industry where the work is visually demanding. Therefore, it is assumed that in general each degree of deviation from a person's optimum, in terms of either thermal comfort, air quality or lighting conditions, will have consequences that are equivalent to a productivity decrease of $2 \%$.

Secondly, the amount of privacy is a more important factor, for workers' satisfaction with the work environment, than thermal comfort, air quality or lighting conditions (Sakellaris et al., 2016, Table 4; Veitch et al., 2007, p. 182, Table 2) (cf. O’Neill, 1994, p. 517, Table 1). Furthermore, ergonomic comfort is also one of the most important factors for workers' satisfaction with the work environment (cf. Kim and de Dear, 2013, p. 23). Concerning privacy, in a study of Jahncke et al. (2013), a noisy room resulted in a 6\% productivity decrease specifically for employees whose work involves the processing of new information. Concerning ergonomic comfort, in a study of Robertson (2007), improving an office space with among others ergonomically designed workstations resulted in a 5,5\% productivity increase. Furthermore, an even greater productivity increase $(10,5 \%)$ was achieved by also providing ergonomic training. Therefore, it is assumed that in general each degree of deviation from a person's optimum, in terms 
of either the amount of privacy or ergonomic comfort, will have consequences that are equivalent to a productivity decrease of $4 \%$.

Thirdly, in a study of Kim and de Dear (2013, p. 23), the amount of space at occupants' individual workstations was the most important factor for workers' satisfaction with the work environment. However, one of the reasons why this factor was rated so highly is because it is associated with privacy (see Leder et al., 2016, p. 42, Table 6) - more space per worker means that workers are further apart from each other. On the other hand, the amount of personal storage space is also an important factors for workers' satisfaction with the work environment (O’Neill, 1994, p. 517, Table 1) (cf. Veitch et al., 2007, p. 182, Table 2). Therefore, it is assumed that in general each degree of deviation from a person's optimum, in terms of the amount of operating space, will have consequences that are equivalent to a productivity decrease of about $2 \%$.

Finally, the amount of closeness is ranked as the least important factor in Table 14 (cf. Kim and de Dear, 2013, p. 23; O’Neill, 1994, p. 517, Table 1). In an office, there is both a need for privacy and a need for socializing (Haans et al., 2007). For informal interaction to happen, there must first be a chance that people encounter each other having people both close together and accessible increases this chance. However, for an encounter to become an interaction, privacy is needed (see Fayard and Weeks, 2007, pp. 620-623). Thus, privacy is needed for both solitude purposes and social interaction purposes. Furthermore, office employees generally prefer privacy over accessibility (Sundstrom et al., 1980, p. 114). Therefore, it is assumed that in general each degree of deviation from a person's optimum, in terms of closeness, will have consequences that are equivalent to a productivity decrease of about $1 \%$.

\subsubsection{Design solutions and their weighting}

Scenarios are developed to identify potential problems, and potential problems are identified to determine which design solutions are useful. In Table 15, a list of all scenarios and their weighting is shown. For these scenarios, three different types of design solutions are relevant. Firstly, type 1: a design solution that centres around changing to what extent a capacity of the workstation is used. This type of design solution only comprises a single design tactic: (1) overdesign the capacity (overdesigned). Secondly, type 2: a design solution that centres around changing who uses which type of workstation. This type of design solution comprises the following design tactics: (1) use multiple types of workstations throughout the building (diversity); (2) use workstations that are, besides their type differences, identical in functionality (uniform); and (3) use a surplus of each type of workstation (overdesigned). 


\begin{tabular}{|c|c|c|c|c|c|}
\hline scenario & change & mismatch & likelihood & severity & weighting \\
\hline 1 & change 1 & insuf. privacy & $3,00 \mathrm{x}$ & $0,04 \%$ & 1,20 \\
2 & change 1 & insuf. ergonomic comfort & $9,38 \mathrm{x}$ & $0,04 \%$ & 3,75 \\
3 & change 1 & insuf. thermal comfort & $3,75 \mathrm{x}$ & $0,02 \%$ & 0,75 \\
4 & change 1 & insuf. air quality & $1,5 \mathrm{x}$ & $0,02 \%$ & 0,30 \\
5 & change 1 & insuf. lighting conditions & $1,83 \mathrm{x}$ & $0,02 \%$ & 0,37 \\
6 & change 1 & insuf. operating space & $0,23 \mathrm{x}$ & $0,5 \%$ & 1,17 \\
7 & change 1 & insuf. closeness & $3,00 \mathrm{x}$ & $0,01 \%$ & 0,30 \\
8 & change 2 & insuf. privacy & $2,00 \mathrm{x}$ & $0,04 \%$ & 0,80 \\
9 & change 2 & insuf. ergonomic comfort & $1,36 \mathrm{x}$ & $0,01 \%$ & 0,14 \\
10 & change 2 & insuf. thermal comfort & $1,25 \mathrm{x}$ & $0,02 \%$ & 0,25 \\
11 & change 2 & insuf. air quality & $1,25 \mathrm{x}$ & $0,02 \%$ & 0,25 \\
12 & change 2 & insuf. lighting conditions & $0,10 \mathrm{x}$ & $0,02 \%$ & 0,00 \\
13 & change 2 & insuf. operating space & $2 \mathrm{x}$ & $0,02 \%$ & 0,40 \\
14 & change 2 & insuf. closeness & $2,22 \mathrm{x}$ & $0,01 \%$ & 0,22 \\
\hline
\end{tabular}

Table 15. A list of all scenarios and their weighting. Weighting equals likelihood multiplied by severity multiplied by 10 .

Thirdly, type 3: a design solution that centres around switching between pre-established settings. This type of design solution comprises the following design tactics: (1) use pre-established settings (appropriate); (2) use independent settings for each social territory (uniform): (3) use intuitive controls for the settings (intelligible); (4) situate the controls in an ergonomically accessible location (convenient); (5) use controls that do not require a lot of force to operate (convenient); and (6) use controls that do not require a lot of actions to operate (undemanding). Finally, in Table 16, a list of all relevant design solutions and their weightings is shown. In Table 16, there are some scenarios that have two design solutions. Of those design solutions, only the best implemented solution will affect the final score, since a problem only needs to be solved once. 


\begin{tabular}{|c|l|c|}
\hline scenarios & \multicolumn{1}{|c|}{ design solution } & weighting \\
\hline 2 & adjustable furniture settings & 3,75 \\
1,8 & overdesigned workstations in terms of privacy & 2,00 \\
1,8 & diverse workstations in terms of openness & 2,00 \\
6,13 & overdesigned workstations in terms of space & 1,57 \\
6,13 & diverse workstations in terms of spaciousness & 1,57 \\
3,10 & adjustable thermal settings & 1,00 \\
4,11 & adjustable ventilation settings & 0,55 \\
7,14 & diverse workstations in terms of closeness & 0,52 \\
5,12 & adjustable lighting settings & 0,37 \\
9 & diverse workstations in terms of ergonomics & 0,14 \\
\hline
\end{tabular}

Table 16. A list of all relevant design solutions, the scenarios that each design solution is a solution to and the design solutions' weightings.

\subsubsection{Evaluating the building}

\subsubsection{Introduction}

In Figure 30, an illustration of the Environmental Building's interior is shown in which several of the building's elements are highlighted. Furthermore, in Figure 31, a floor plan of the building's main section is shown. Finally, in Figure 32, an illustration of the top floor's furniture layout is shown. Most of the information, about the Environmental Building, that is presented in this chapter is drawn from six different articles and reports (see Bunn, 1997; Cawthorne, 1997; Herbert, 1998; Ní Riain et al., n.d.; Ní Riain et al., 1999; White et al., n.d.). In the following section, each design solution's implementation is dealt with, except for the two design solutions related to ergonomics. The adjustability of the office chairs and desks will not be evaluated in this chapter. However, for an thorough study on the adjustability of various office chairs, see Helander et al. (1995).

\subsubsection{Adjustable lighting settings}

In terms of lighting settings, the Environmental Building contains three components that are relevant: (1) external motorised fritted-glass louvers; (2) roller blinds; and (3) interior luminaires (see Figure 30). Both the factors on which the implementation of adjustable lighting settings is scored and the score for each factor are shown in Table 17. 


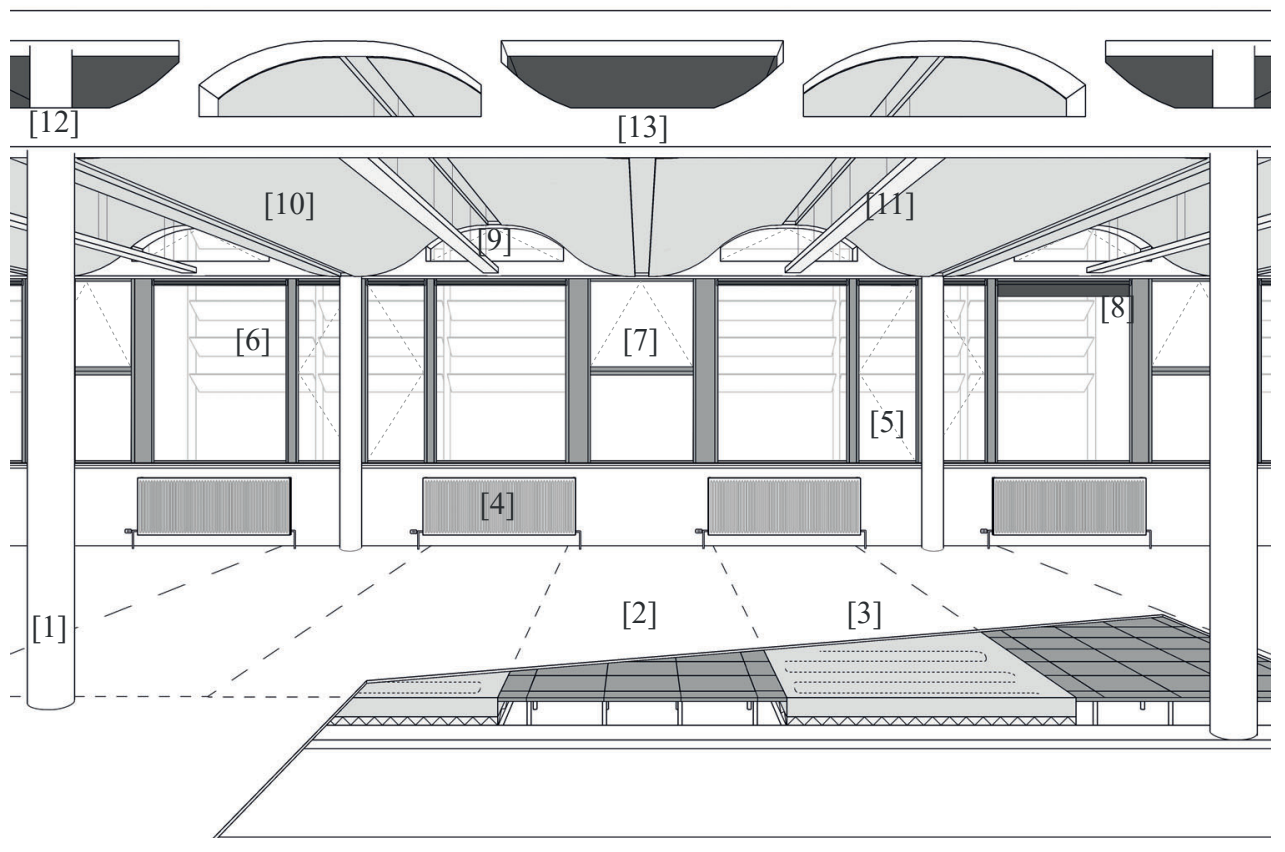

Figure 30. An illustration of the building's interior without furniture. The following elements are shown: (1) steel column, 219mm in diameter; (2) raised floor, 1,5m in width; (3) under-floor pipes embedded in the screed, $1,5 \mathrm{~m}$ in width; (4) peripheral radiator; (5) manually openable windows; (6) external motorised fritted-glass louvers; (7) frosted glass windows which open into a thermal chimney; (8) manually controlled roller blinds; (9) computer operated top openings, openable directly to the occupied space; (10) sinusoidal hollow-core concrete slab; (11) luminaire with both upward and downward light output; (12) duct connected directly to the outside by a computer operated top opening; and (13) duct connected to a thermal chimney by a computer operated top opening.

Concerning the number of settings, firstly, the external louvers can rotate from their vertical position $\left(0^{\circ}\right)$ to $10^{\circ}$ beyond their horizontal position $\left(100^{\circ}\right)$ (Cawthorne, 1997 , p. 8). When the louvers are set beyond their horizontal position, daylight is reflected from their upper surfaces into the interior. Secondly, roller blinds are manually operable and they can be set at any position between fully open and fully closed. Thirdly, for artificial lighting, there are luminaires in the building that produce both an upward light output (approximately 40\%) and a downward light output (approximately 60\%) (Bunn, 1997, p. 22). These lights can be dimmed to any value between 0 and $100 \%$. Therefore, the number of lighting settings is given a score of 5 out of 5 . 


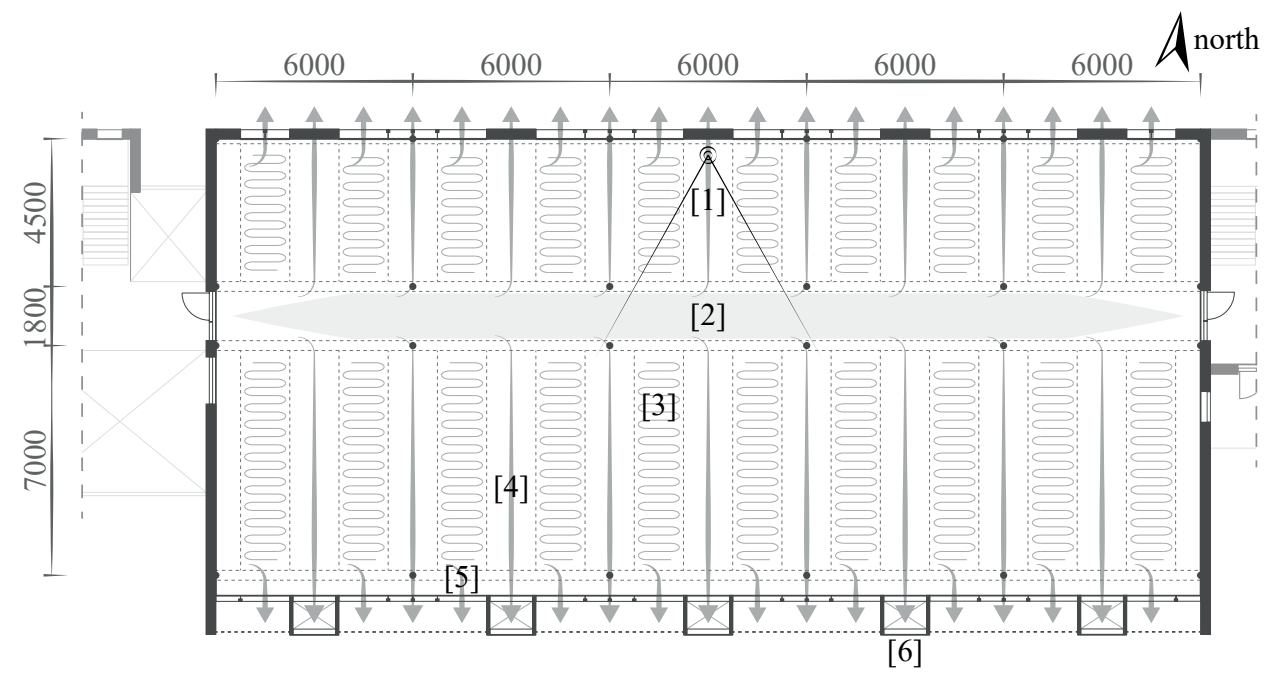

Figure 31. A floor plan of the first floor of the building's main section without furniture or partitioning (scale is $1: 300$ ). The following elements are shown: (1) viewpoint on which Figure 30 is based; (2) service zone / "central spine" (EOF Group, 1995b); (3) under-floor pipes embedded in the screed; (4) hallway ventilation through hollow-core concrete ducts; (5) direct ventilation of the occupied space through top openings; and (6) thermal chimney.

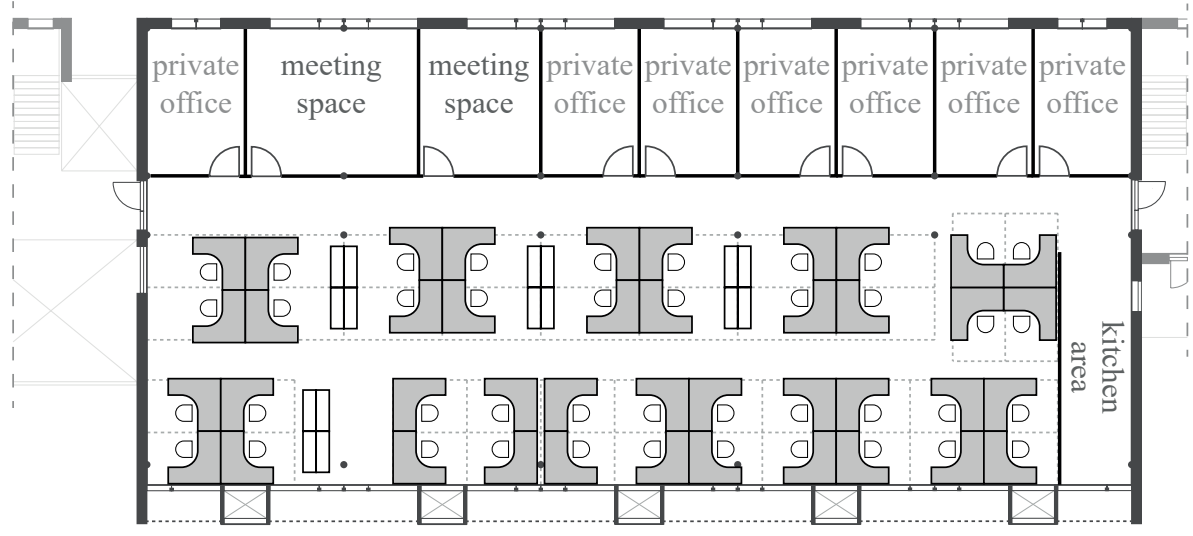

Figure 32. An illustration of the top floor's furniture layout (scale is $1: 300$ ). This illustration is based on photos made (on the 11th of April 2019) and provided by Ben Cartwright from BRE. 
Concerning the independence in exercising control, the lights can be operated per individually fitting (Herbert, 1998, p. 89), and the roller blinds are operable per window. Furthermore, the louvres in front of the south-facing façade are controlled for each section $(4,5 \mathrm{~m})$ in between two chimneys (see photos at https://www.coltinfo.co.uk/ case-studies/bre-building-16.html). Therefore, the independence in exercising control is given a score of 4 out of 5 .

Concerning the intuitiveness of controls, two factors are important: (1) the type of feedback provided by the system; and (2) the independence of functions. Firstly, for all three lighting components, i.e. external louvers, roller blinds and luminaires, one can instantly see the effects of exercising control. Secondly, controls are more simple when each control affects a single function. Typically, the functions of preventing glare and obstructing incoming daylight are dependent in a building, i.e. glare cannot be stopped without obstructing incoming daylight. However, the Environmental Building's louvers are coated with a translucent white coating (37\% transmittance) to keep a diffused form of natural illumination when the louvers are fully closed during the day (Cawthorne, 1997, p. 11, 13). Therefore, glare can be prevented without obstruct all incoming daylight. Furthermore, incoming daylight typically both lights up and heats up the building. However, in the Environmental Building, the thermal energy of incoming daylight is first temporarily stored in the exposed-concrete celling. Thus, one can allow daylight to light up the space without having to worry about it heating the space up as well. Therefore, the intuitiveness of controls is given a score of 5 out of 5 .

Concerning the ease of operating, both the position of the louvres and the luminaires' light output can be changed via handheld controls (Herbert, 1998, p. 89; Ni Riain et al., n.d., p. 5). Furthermore, the roller blinds can be operated manually. Therefore, the ease of operating is given a score of 5 out of 5. Overall, the implementation of adjustable lighting settings is given a score of 4,75 out of 5 .

\begin{tabular}{|l|c|}
\hline \multicolumn{1}{|c|}{ factors } & score \\
\hline number of settings & $5 / 5$ \\
\hline independence in exercising control & $4 / 5$ \\
intuitiveness of controls & $5 / 5$ \\
ease of operating & $5 / 5$ \\
\hline
\end{tabular}

Table 17. A list of both the factors on which the implementation of adjustable lighting settings is scored and the score for each factor. 


\subsubsection{Adjustable temperature settings}

In terms of temperature settings, the Environmental Building contains four components that are relevant: (1) working-height windows; (2) top openings; (3) under-floor pipes; and (4) peripheral radiators (see Figure 30). Both the factors on which the implementation of adjustable temperature settings is scored and the score for each factor are shown in Table 18.

Concerning the number of settings, firstly, about one-third of the working-height windows are openable, and they can only be opened by turning them inward - not by tilting them inward (see https://fcbstudios.com/images/Raw/Feilden_Clegg_Bradley_ Studios--Environmental_Office_BRE-Garston-Elevation.jpg). Secondly, the top openings are computer controlled and they can be tilted at any position between 0 and 100\% open (see Bunn, 1997, p. 20; Ni Riain et al.,1999, p. 315). Thirdly, under-floor pipes can either actively heat or cool the occupied space, depending on the type of water run through them. For cooling the system of under-floor pipes draws cool water from a 75m-deep borehole (Ni Riain et al., 1999, p. 310). This feature was designed to reduce the peak internal temperatures by $2^{\circ} \mathrm{C}$ (Ni Riain et al., n.d., p. 5). For heating the system uses water heated in a boiler room in the building's east wing (Bunn, 1997, p. 19, 21). Finally, the peripheral radiators can be set at different temperatures by turning the radiator valves. Therefore, the number of temperature settings is given a score of 5 out of 5 .

Concerning the independence in exercising control, each peripheral radiators can be operated individually. Furthermore, over the long axis, each section that includes under-floor pipes is placed in between two other sections without any active heating or cooling system (see Figure 31). Thus, temperature is controlled by this system in three-meter-wide sections. Finally, an openable window, i.e. either a working-height window or a top opening, is present at every section of $1,5 \mathrm{~m}$ in width. Therefore, the independence in exercising control is given a score of 4 out of 5 .

Concerning the intuitiveness of controls, two factors are important: (1) the type of feedback provided by the system; and (2) the independence of functions. Firstly, in the Environmental Building, the under-floor pipes are controlled by a building management system (Herbert, 1998, p. 89). Users cannot control this element directly, they can only exercise control over it by overriding the local temperature settings ( $\mathrm{Ni}$ Riain et al., n.d., p. 5). However, for the working-height windows, the top openings and peripheral radiators, one can instantly feel or hear the effects of exercising control. Secondly, controls are more simple when each control affects a single function. In the Environmental Building, one can both increase or decrease the temperature without 
negatively affecting other functions. However, the function of the windows to cool the interior space cannot be used without interfering with another one of its functions, i.e. to keep out external noise. Therefore, the intuitiveness of controls is given a score of 4 out of 5 .

Concerning the ease of operating, both the local temperature settings and the top openings can be operated via handheld controls. Furthermore, both the working-height windows and peripheral radiators can be operated manually. Therefore, the ease of operating is given a score of 5 out of 5. Overall, the implementation of adjustable temperature settings is given a score of 4,5 out of 5 .

\begin{tabular}{|l|c|}
\hline \multicolumn{1}{|c|}{ factors } & score \\
\hline number of settings & $5 / 5$ \\
independence in exercising control & $4 / 5$ \\
intuitiveness of controls & $4 / 5$ \\
ease of operating & $5 / 5$ \\
\hline
\end{tabular}

Table 18. A list of both the factors on which the implementation of adjustable temperature settings is scored and the score for each factor.

\subsubsection{Adjustable ventilation settings}

In terms of ventilation settings, the Environmental Building contains four components that are relevant: (1) working-height windows; (2) top openings that open directly into the occupied space; (3) top openings that connect the outside air to hollow-core concrete ducts which guide the fresh air directly into the corridor zone; and (4) top openings that connect thermal chimneys to the hollow-core concrete ducts (Ni Riain et al.,1999, pp. 314-315) (see Fig 30). Both the factors on which the implementation of adjustable ventilation settings is scored and the score for each factor are shown in Table 19. Concerning the number of settings, firstly, about one-third of the working-height windows are openable, and they can only be opened by turning them inward - not by tilting them inward (see https://fcbstudios.com/images/Raw/Feilden_Clegg_Bradley_ Studios--Environmental_Office_BRE-Garston-Elevation.jpg). Secondly, all top openings are computer controlled and they can be tilted at any position between 0 and $100 \%$ open (see Bunn, 1997, p. 20; Ni Riain et al.,1999, p. 315). Thirdly, the thermal chimneys are meant to compensate for a lack of wind-driven air flow by generating a stack-driven air flow. However, each tower is also equipped with an internal propeller 


\begin{tabular}{|l|c|}
\hline \multicolumn{1}{|c|}{ factors } & score \\
\hline number of settings & $5 / 5$ \\
\hline independence in exercising control & $5 / 5$ \\
intuitiveness of controls & $5 / 5$ \\
ease of operating & $5 / 5$ \\
\hline
\end{tabular}

Table 19. A list of both the factors on which the implementation of adjustable ventilation settings is scored and the score for each factor.

fan for when the stack effect is also not sufficient (Bunn, 1997, p. 20). Therefore, the number of ventilation settings is given a score of 5 out of 5 .

Concerning the independence in exercising control, at both the north-facing and southfacing façades, there is an openable window present, i.e. either a working-height window or a top opening, at every section of $1,5 \mathrm{~m}$ in width. Furthermore, the hollowcore concrete ducts are used as unobstructed pathways to guide fresh air directly into the corridor zone. In the corridor, there are concrete ducts connected to the outside for every $3 \mathrm{~m}$ of corridor space. This system can theoretically facilitate the spaces on both sides of the corridor. However, since the northern section of the building is not directly open to the corridor space - it contains cellular offices (Bunn, 1997, p. 18) - the system will mainly facilitate the southern section. In other words, over the building's short axis, it can be divided into three individual control areas. Therefore, the independence in exercising control is given a score of 5 out of 5 .

Concerning the intuitiveness of controls, two factors are important: (1) the type of feedback provided by the system; and (2) the independence of functions. Firstly, for the working-height windows and some of the top openings, one can instantly see and feel the effects of exercising control. However, these effects are less apparent for the top openings connected to the concrete duct system. Secondly, controls are more simple when each control affects a single function. Incoming outdoor air typically affects both the ventilation and the temperature within the building. However, in the Environmental Building, when only the concrete duct system is used to bring in fresh air, the incoming air will have less of an effect on the temperature; heat is exchanged between the incoming air and the concrete mass that tempers any fresh air before entering the occupied space. Furthermore, by using the concrete duct system to bring in fresh air, as opposed to conventional windows, it is more difficult for external noise to get into the 
building. Therefore, the intuitiveness of controls is given a score of 5 out of 5 . Concerning the ease of operating, the top openings can be operated via handheld controls (Ni Riain et al., n.d., p. 5). Furthermore, the working-height windows can be operated manually. Therefore, the ease of operating is given a score of 5 out of 5 . Overall, the implementation of adjustable ventilation settings is given a score of 5 out of 5 .

\subsubsection{Overdesigned workstations in terms of space}

In the Environmental Building, on the top floor, there are three types of workstations: (1) the open-office workstation of $3,6 \mathrm{~m}^{2}$; (2) the open-office workstation of $4,8 \mathrm{~m}^{2}$, with filling cabinet; and (3) the private office of $12,5 \mathrm{~m}^{2}$ (see Figure 32). In the open-office section, workstations are grouped in u-shaped sets of two. At minimum, this set-up (without circulation space) requires $2,3 \mathrm{~m}^{2}$ of space per workstation (see Panero and Zelnik, 1979, p. 180). In addition, at least $650 \mathrm{~mm}$ (or in this case $1 \mathrm{~m}^{2}$ ) of clear space is needed to be able to walk behind a workstation (Pheasant, 2003, p. 51). However, for a wheelchair user to be able to turn around, this clear space must be at least $1600 \mathrm{~mm}$ (or in this case 2,6m²) (see Steinfeld et al., 2010, p. 65, Fig. 8). Furthermore, according to Neufert and Neufert (2000, p. 346), in an average organization, roughly $30 \%$ of the non-managerial workers require a workspace of 3,6 to $4,6 \mathrm{~m}^{2}$ - the rest of the workers need more space. Thus, the Environmental Building's smallest type of workstation is using its operating space to the fullest. Therefore, the implementation of overdesigned workstations, in terms of space, is given a score of 1 out of 5 .

\subsubsection{Diverse workstations in terms of spaciousness}

The Environmental Building, on the top floor, contains the following workstations: (1) 26 open-office workstations of $3,6 \mathrm{~m}^{2}$; (2) 16 open-office workstations of $4,8 \mathrm{~m}^{2}$, with filling cabinet; and (3) 7 private offices of $12,5 \mathrm{~m}^{2}$ (see Figure 32). Both the factors on which the implementation of diverse workstations, in terms of spaciousness, is scored and the score for each factor are shown in Table 20.

Concerning the use of multiple types, in terms of size, there are two types of openoffice workstations and there is one type of private office workstation. Therefore, the use of multiple types is given a score of 3 out of 5. Concerning uniform functionality, all larger open-office workstations are located directly next to the corridor zone (see Figure 32). Thus, in comparison to the smaller open-office workstations, the larger ones do not have any access to a window. Otherwise, they are both practically identical in functionality. Therefore, uniform functionality is given a score of 4 out of 5 . 
Concerning the surplus of workstations, as previously mentioned, in an average organization, roughly $30 \%$ of the non-managerial workers require a workspace of 3,6 to $4,6 \mathrm{~m}^{2}$ - the rest of the workers need more space (Neufert and Neufert, 2000, p. 346). Furthermore, according to Blau (1970, p. 211), about $15 \%$ of a 100-person organisation comprises managerial personnel. In the Environmental Building, on the top floor, $14 \%$ of the workstations are private offices. Furthermore, $62 \%$ of the openoffice workstations are smaller workstations, i.e. workstations of $3,6 \mathrm{~m}^{2}$. Thus, in the Environmental Building, there is not a surplus of larger workstations. Therefore, the surplus of workstations is given a score of 1 out of 5. Overall, the implementation of diverse workstations, in terms of spaciousness, is given a score of 2,67 out of 5 .

\begin{tabular}{|l|c|}
\hline \multicolumn{1}{|c|}{ factors } & score \\
\hline the use of multiple types & $3 / 5$ \\
uniform functionality & $4 / 5$ \\
the surplus of workstations & $1 / 5$ \\
\hline
\end{tabular}

Table 20. A list of both the factors on which the implementation of diverse workstations, in terms of spaciousness, is scored and the score for each factor.

\subsubsection{Overdesigned workstations in terms of privacy}

In terms of privacy, there are four basic settings: (1) having both acoustic and visual privacy, e.g. private office; (2) having visual privacy, but not acoustic privacy, e.g. high screens; (3) having acoustic privacy, but not visual privacy, e.g. a glass box; and (4) not having either acoustic or visual privacy, e.g. open space. In the Environmental Building, on the top floor, $86 \%$ of the workstations are unscreened open-office workstations. Therefore, the implementation of overdesigned workstations, in terms of privacy, is given a score of 1 out of 5 .

\subsubsection{Diverse workstations in terms of openness}

Both the factors on which the implementation of diverse workstations, in terms of openness, is scored and the score for each factor are shown in Table 21. Concerning the use of multiple types, in terms of openness, there are two types of workstations: (1) the open-office workstation; and (2) the private-office workstation. Therefore, the use of multiple types is given a score of 3 out of 5. Concerning uniform functionality, all private-office workstations are significantly larger than the open-office workstations, 
i.e. either 2,6 or 3,5 times as large. Otherwise, they are both practically identical in functionality. Therefore, uniform functionality is given a score of 2 out of 5 .

Concerning the surplus of workstations, as previously mentioned, about $15 \%$ of a 100-person organisation comprises managerial personnel (Blau, 1970, p. 211). Furthermore, in the Environmental Building, on the top floor, $14 \%$ of the workstations are private offices. Thus, in the Environmental Building, there is not a surplus of more enclosed workstations. Therefore, the surplus of workstations is given a score of 1 out of 5. Overall, the implementation of diverse workstations, in terms of openness, is given a score of 2 out of 5 .

\begin{tabular}{|l|c|}
\hline \multicolumn{1}{|c|}{ factors } & score \\
\hline the use of multiple types & $3 / 5$ \\
uniform functionality & $2 / 5$ \\
the surplus of workstations & $1 / 5$ \\
\hline
\end{tabular}

Table 21. A list of both the factors on which the implementation of diverse workstations, in terms of openness, is scored and the score for each factor.

\subsubsection{Diverse workstations in terms of closeness}

Alexander et al. (1977, pp. 610-613) and Habraken (1998, pp. 134-179) both described a similar phenomenon which the former referred to as an "intimacy gradient" and the latter as "territorial hierarchy". This phenomenon is concerned with a space being perceived as more private when it is more remote and less directly accessible (e.g. through another space). Thus, a space that is perceived as closer by is less repellent for people, and thus such a space is more likely to have chance encounters. However, it is argued that this feature cannot be overdesigned; when all office space is open, social considerate behaviour will hinder any social interaction - as it would otherwise disturb people who are trying to concentrate. This is probably why people in an open-plan office have a higher need for socializing (see Haans et al., 2007). Therefore, the only design solution to changing requirements in terms of closeness is diverse workstations. In Table 22, both the factors on which the implementation of diverse workstations, in terms of closeness, is scored and the score for each factor are shown. Concerning the use of multiple types, in terms of closeness, there is not much diversity as is shown in Figure 33. Within the open space, there are two visual breaks or subdivisions, i.e. between the corridor and the open spaces and between the open-office space and the 
kitchen area. However, all rooms and separate areas are directly accessible from the corridor space. Therefore, the use of multiple types is given a score of 1 out of 5 . Without there being multiple types, no one can move from one type of workstation to another, regardless of the implementation of the other factors. Therefore, overall, the implementation of diverse workstations, in terms of closeness, is given a score of 1 out of 5 .

\begin{tabular}{|l|c|}
\hline \multicolumn{1}{|c|}{ factors } & score \\
\hline the use of multiple types & $1 / 5$ \\
\hline uniform functionality & - \\
the surplus of workstations & - \\
\hline
\end{tabular}

Table 22. A list of both the factors on which the implementation of diverse workstations, in terms of closeness, is scored and the score for each factor.

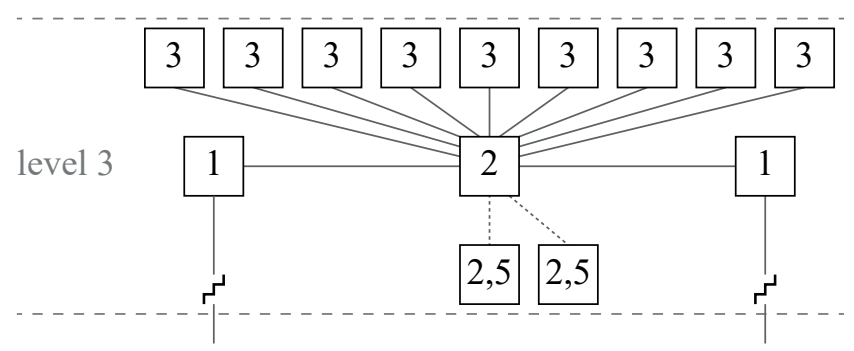

level 2

Figure 33. The remoteness of spaces of the Environmental Building's top floor. In this figure, a box represents a separate space, and a line between two boxes represents a subdivisions between those two spaces (e.g. a door or a visual break). Furthermore, the number within each box indicates the box's degree of remoteness.

\subsubsection{Final score}

In Table 23, an overview of the score and weighting of each design solution's implementation is shown. The final score is calculated by: (1) multiplying each score by the weighting factor; (2) adding the weighted scores together; and (3) comparing this number to the highest possible score. Overall, the Environmental Building's adjustability is given a score of 17,72 out of 30,05 , i.e. 2,95 out of 5 . 


\begin{tabular}{|l|c|c|}
\hline \multicolumn{1}{|c|}{ design solution } & score & weighting \\
\hline adjustable furniture settings & - & 3,75 \\
overdesigned workstations in terms of privacy & 1,00 & 2,00 \\
diverse workstations in terms of openness & 2,00 & 2,00 \\
overdesigned workstations in terms of space & 1,00 & 1,57 \\
diverse workstations in terms of spaciousness & 2,67 & 1,57 \\
adjustable thermal settings & 4,50 & 1,00 \\
adjustable ventilation settings & 5,00 & 0,55 \\
diverse workstations in terms of closeness & 1,00 & 0,52 \\
adjustable lighting settings & 4,75 & 0,37 \\
diverse workstations in terms of ergonomics & - & 0,14 \\
\hline
\end{tabular}

Table 23. A list of all relevant design solutions, the design solutions' scores and the design solutions' weightings. The final score is only based on the design solutions that are presented in black text in this figure, those that are presented in grey text are not taken into account. 
This page is intentionally left blank. 


\subsection{Discussion and conclusion}

\subsubsection{Discussion}

As shown in Table 23, the Environmental Building has the ability to comply with changing requirements of the individual in terms of indoor climate conditions. However, it lacks the ability to comply with changing requirements of the individual in terms of space, privacy and interaction. Overall, this resulted in a score of 2,95 out of 5. The score itself is not very important; it is based on 22 estimates ( 2 expected frequency estimates, 12 probability estimates and 8 severity estimates) that are all certainly not perfectly accurate.

More importantly however, the use of this method resulted in clear improvement points. Furthermore, the improvement points match expectations. As mentioned in the introduction (5.1.), the most innovative aspect of this building was the design of its services systems - that was the design team's main focus (see EOF Group, 1995a). Therefore, it is not surprising that the building is mainly able to comply with changing requirements of the individual in terms of indoor climate conditions, instead of other types of changing requirements.

\subsubsection{Conclusion}

This chapter's aim was to evaluate the application of the method of evaluating a building's changeability, that has been proposed in Chapter 4. As has been demonstrated in this chapter, by using this method, specific strengths and weaknesses of the building's design in relation to the user's changing requirements can be identified. Furthermore, by following this method, an assessment is made of the significance of each strength and weakness. In other words, the use of this method will result in clear improvement points. However, the method also has its disadvantages, especially in terms of practicality: (1) it is very time-consuming; and (2) it requires extensive knowledge about the subject matter. The method is very elaborate in nature. However, a lot of the information that is needed in such an analysis can be carried over from one analysis to another, especially when a building with a similar function is analysed in the subsequent analysis, e.g. change scenarios, changes' likelihood, probability estimates and mismatches' severity. Thus, the method works as intended. However, it is not yet practically viable. First, the method must be developed further through repeated use. 


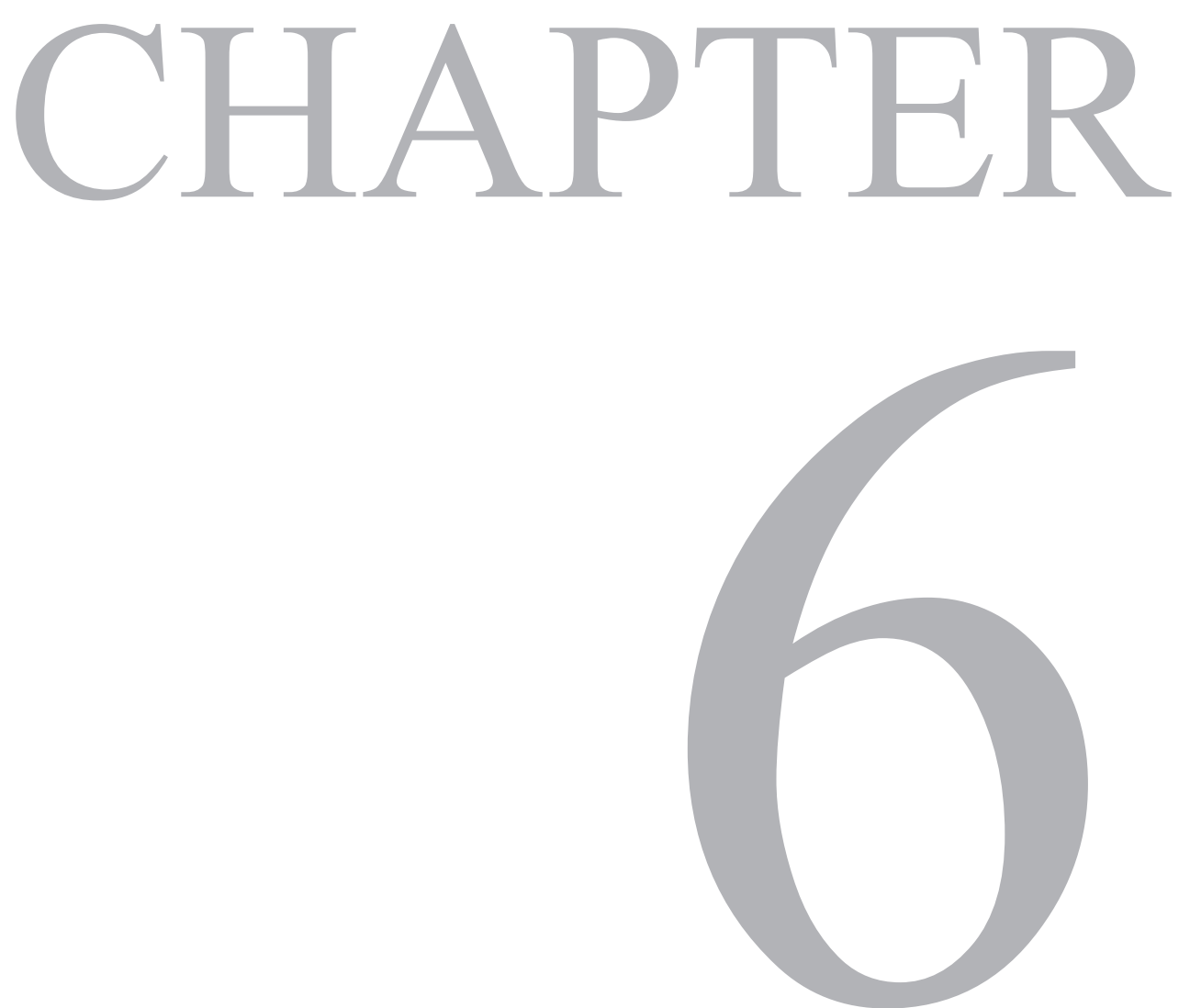

Discussion and conclusion. 


\subsection{Discussion}

\subsubsection{Introduction}

In this discussion section, three elements of this dissertation are reflected upon: (1) the methods for setting up a classification, that have been used in this dissertation; (3) the scientific contribution of this dissertation; and (4) the practical relevance, or utility, of the results.

\subsubsection{Classification}

The majority of the methods used in this dissertation, Structured Analysis, Analytic Hierarchy Process and the Constant Comparative Method, have the same purpose: to set up a classification. A classification can be used as a representation of knowledge - it is "a way of seeing" (Kwasnik, 1999, p. 46). As such, a classification is "...useful in communication and in generating a fresh cycle of exploration, comparison, and theorizing" (Kwasnik, 1999, p. 24). Setting up a classification is such a fundamental part of science that the process if often not explicitly explained. This dissertation also contains multiple classifications of which is not explained how they came to be. However, the most important classifications, in this dissertation, where developed according to a formal method.

The method that differs most from the other methods, that have been used for setting up a classification in this dissertation, is the Constant Comparative Method. In Chapter 4 this difference was described as using a bottom-up approach, instead of a top-down approach. A classification is composed of two parts: the concepts; and the structure. The top-down approach starts with the development of a logical structure, while the bottomup approach starts with the development of valid concepts. At the beginning of this research project, the author had assumed that it is generally preferable to prioritize the development of a classification's structure over its concepts. A classification's structure determines its information density (see Kwasnik, 1999); information that is associated with the classification structure applies to all of its concepts, while information that is associated with a concept, within the classification, only applies to the particular concept. The results of this dissertation confirm the author's initial assumption: (1) the top-down approach results in a more developed structure, while the bottom-up approach results in more developed concepts; and (2) a classification with a more developed structure is more comprehensible, than a classification with more developed concepts, due to its greater information density. This dissertation's classification into types of design tactics is more difficult to communicate than the other classifications - 
the amount of text needed to explain it is a clear sign of this.

However, the more structure-focused classification approach mostly works for welldefined, or well-definable, topics. For ambiguous topics, like the ability to comply with future change, it is very difficult, and may even be misleading, to define the topic through a relatively narrow structure, instead of the broad range of underlying concepts. In hindsight, the Constant Comparative Method was the appropriate method to set up a classification into types of design tactics, despite the more elaborate nature of the results.

\subsubsection{Scientific contribution}

This dissertation's scientific novelty lies in the combination of its topic, goal and approach. Regarding the topic, the topic of this dissertation is broader in comparison to numerous similar studies. Much of the research to date only, or primarily, focussed on the physical alterability of the building fabric (Heidrich et al., 2017, p. 294). The topic of changeability however, comprises both the topic of adaptability, i.e. a building's ability to comply with changes through physical alterations to the building fabric; and (2) the topic of flexibility, i.e. a building's ability to comply with changes without physical alterations to the building fabric. Previous results of evaluation research, in relation to the relatively narrower topic of adaptability, also seem more advanced (e.g. see Schmidt et al., 2014), in comparison to those related to the relatively broader topic of changeability. Presumably this is the result of both the topic's smaller scope and the topic's greater popularity.

Regarding the goal, the goal of this dissertation was to develop a method that facilitates the evaluation of the topic as a whole. Much of the research to date mainly focussed on identifying all the relevant elements, i.e. factors, indicators or strategies (e.g. Halvitigala and Reed, 2015; Hassanain, 2006; Remøy and van der Voordt, 2014). However, to evaluate the topic as a whole requires not only knowledge about the relevant elements, but also knowledge about the relations between them. In the literature, there are some results that hint at the importance of individual indicators in relation to each other. Some studies, including this one (see Table 13), counted the number of times that an indicator or strategy was mentioned in the literature (see Heidrich et al., 2017, p. 293; Schmidt III, 2014, p. 83, 86). Schmidt III (2014, pp. 244-245) also counted the number of times that an indicator or strategy was either explicitly mentioned or implied during interviews with experts. Pinder et al. (2013, p. 448) ranked strategies in terms of both certainty of benefits and investments costs. Furthermore, Ross et al. (2016, pp. 423424) asked experts, through a survey, to quantify the relative effectiveness of indicators 
and strategies. However, from the literature that was examined (see Table 10), only the studies of Wilkinson (see 2014b) focussed on developing valid weighting factors.

Regarding the approach, Wilkinson's approach is purely quantitative. Such an approach can explain what works in general, but not how it works. Wilkinson's approach is referred to as the black box approach, i.e. an approach which primarily focusses on the design solutions and the resulting impact. In contrast to the black box approach, the white box approach primarily focusses on the "mechanisms" that describe how and why certain design solutions have an impact (see Astbury and Leeuw, 2010). This research's main contribution is that it provides a method for unpacking the black box of design for change. The whole reason for unpacking the black box is that it enables validation.

Validation is the main problem of the black box approach. How can you know for certain whether or not a design solution has a positive effect on a building's lifespan without monitoring this effect? Wilkinson (see 2014b) circumvented this problem by focussed on a different resulting impact: the number of adaptation occurrences. However, more adaptation occurrences are not necessarily beneficial to a building's lifespan. More adaptation occurrences may indicate that the building is highly adaptable, or it may indicate that the building was highly in need of adaptation. The white box approach solves this problem as follows: you know for certain, whether or not a design solution has a positive effect on a building's lifespan, by understanding how, to what extent and in which situations, each design solution contributes to prolonging the use period of a building, and by validating this understanding. The downside of the white box approach is that the task of both identifying and testing all mechanisms is a seemingly insurmountable amount of work. For example, Chapter 5 shows how much work can go into identifying and prioritizing mechanisms. However, it is a way forward, specifically for science.

\subsubsection{Practical relevance}

Evaluation research is similar to fundamental research; the primary difference between the two is that evaluation research is concerned with "utilization" (Vedung, 2004, p. 118 ) - the research output must be usable. In design research terminology one would say that evaluation research, similar to fundamental research, has a strong focus on understanding. However, unlike fundamental research, evaluation research also has the goal to create support to help improve the situation or process. In terms of utilization, a distinction can be made between two types of uses: "instrumental use"; and "conceptual use" (Vedung, 2004, p. 119). For an evaluation to have an instrumental use, it must 
directly result in specific actions, i.e. the result must describe the most efficient means to reach the indicated goal. An evaluation with a conceptual use does not result in specific actions; it informs - helps to understand - and shapes one's attitude towards the issue, but it does not trigger any specific actions.

What is the use of the evaluation method presented in this dissertation? The evaluation method is composed in a step-by-step manner, in which of each step is specified what the required input and output is (see Figure 27). This is a characteristic of an instrumental method. However, what is missing, for the method to be truly instrumental, is a comprehensive description of how to execute each of these steps. Some tools have been developed to support the execution of the method's first two steps, but these tools have a conceptual use. Furthermore, in Chapter 5 is demonstrated how the method, and its tools, can be used to carry out an evaluation that has an instrumental use. However, to do so involves more than simply following instructions. During the evaluation method's development, instrumental use was strived for, but not to the extent that concessions in the topic's complexity were permitted. As a result, the evaluation method's use can not be classified, in its entirety, as instrumental and should thus be seen, at this stage, as conceptual.

The evaluation methods used in practice should remain practical. Therefore, the evaluation method presented in this dissertation is not an example of what they should become. Methods, such as the one presented in this dissertation, should be used to develop a better understanding of the various mechanisms that describe how and why certain design solutions have an impact. Then, this understanding must first be tested. After which, the more practical evaluation methods can be improved based on this improved, and validated, understanding of the workings of design solutions.

Future research should focus more on validating the workings of design solutions in relation to design for change. A nice example of such research is a study of Gijsbers (2011, pp. 143-162), in which he studied the density at which a column grid starts to hinder the designer in developing a suitable floorplan. In the future, researchers should be able to substantiate, with rational explanations that have also been tested, why certain design solutions are more important than others, for the changeability of a specific building. This dissertation's outcome shows how these rational explanations can be developed. The next step is to develop and test them. 
This page is intentionally left blank. 


\subsection{Conclusion}

\subsubsection{Introduction}

This research aimed to both understand design and to create support to help improve design, specifically regarding the topic of design for change in relation to sustainable resource usage. This dissertation aimed to increase understanding regarding the overall subject matter by gaining: (1) an initial understanding of the topic of building longevity; (2) a review-based understanding of the topic of changeability; and (3) a comprehensive understanding of the topic of resource depletion. Furthermore, this dissertation aimed to set up support regarding the overall subject matter by developing: (1) initial support for the topic of resource depletion; and (2) comprehensive support for the topic of changeability. Lastly, this dissertation includes an initial evaluation of the design support that has been developed for the topic of changeability.

\subsubsection{Understanding}

In Chapter 2, a model is presented (see Figure 2) that describes how the process of using resources works, and why this process works the way it does. Based on this model, five intervention areas have been identified: (1) material inputs to manufacturing; (2) process inputs to manufacturing; (3) material inputs to operations; (4) process inputs to operations; and (5) products' longevity. In this model, an intervention area is an area in which a change, or "intervention" if it is a conscious change, affects the size of the problem of resource depletion. Thus, a change in one of the intervention areas can either mitigate or aggravate the problem of resource depletion. This dissertation focusses specifically on the intervention area of longevity. To make sure that an intervention in the area of longevity actually contributes towards mitigating the problem of resource depletion, one must examine if, and how, these interventions affect the other intervention areas. The understanding of the topic of resource depletion, gained in Chapter 2, supports this process.

In Chapter 3, a first indication of to what extent a building's longevity is determined by its design is presented. In a way Chapter 3 fulfils the role of devil's advocate - does a changeable design in buildings even matter? Conclusion: for residential buildings it might not matter. Households are significantly more flexible than large organizations; moving is relatively easy for a small family. Furthermore, when a house is a scarce commodity, it is less likely to be demolished prematurely. However, Chapter 3 lacks the evidence to confidently support this statement. What can be stated with confidence however, is that a changeable design has a greater impact on the longevity of non- 
residential buildings, compared to the impact on the longevity of residential buildings. The understanding of the topic of longevity, gained in Chapter 3, contributes to a more valid assessment of changeability's contribution towards mitigating the problem of resource depletion.

In Chapter 4, a list is presented (see Table 13) of the types of design tactics of changeability. These design tactics can be used to develop design solutions to potential problems of future change. Such a list is not new - many researchers have developed their own list, and how the topic is categorized is partly dependent on personal preference. The main reason why another list has been developed, in this research, is the following: for similar, already existing, lists, it was not exactly clear on what information the categorizations were based on. Therefore, there was no way to verify whether or not these lists were comprehensive. In this dissertation, all the information that the categorization of design tactics is based on is included in Appendix 2.

\subsubsection{Support}

In Chapter 2, intervention areas, in relation to the problem of resource depletion, are ranked according to how much of a change can be expected from interventions in the area. Longevity was ranked as the second most effective intervention area. So, it is a very significant solution area for the problem of resource depletion. Furthermore, the outcome of Chapter 2 shows that interventions in longevity can be prioritized over interventions in the manufacturing phase. This also means that, if they are done right, solutions meant to prolong the use period of products, parts and buildings will contribute towards mitigating the problem of resource depletion, even if they require a greater resource input in the manufacturing phase.

In Chapter 4, both a scenario-based method of evaluating a building design's changeability (see Figure 27), and the support needed to use this method, is presented. A list of general changes (see Table 12) has been set up to support the development of scenarios, that are, in turn, meant to identify potential problems. Furthermore, to support the development of design solutions to these potential problems the following things have been set up: (1) a list of types of design tactics (see Table 13); (2) a categorization of changeability into changeability levels (see Figure 29); and (3) a categorization of various types of adjustments into different scales (from small-scale to extra-large-scale) (see Table 11). The support for the topic of changeability, that has been developed in Chapter 4, helps to: (1) specify optimization goals, in relation to future change, that are relevant for a specific situation, i.e. building plus context; (2) determine key performance indicators, in relation to these specified optimization goals; 
and (3) determine valid weighting factors for each of those indicators.

\subsubsection{Evaluation}

In Chapter 5, an initial evaluation of the method of evaluating a building's changeability is presented. The method's application was evaluated - thus, can the method be used for the task for which it is intended. The evaluation shows that specific strengths and weaknesses of the building's design in relation to the user's changing requirements can be identified by using this method. Furthermore, by following the method, an assessment is made of the significance of each strength and weakness.

\subsubsection{Main research question}

This dissertation's main research question was: 'How can a building design's changeability, and the effect of this changeability on the problem of resource depletion, be evaluated?'. To what extent has this question been answered? First, rules of thumb have been developed to help prioritise interventions in relation to the problem of resource depletion. Second, a method of evaluating a building's changeability has been developed. Third, conceptual tools have been developed to help use the evaluation method. Fourth, how to use the method, and its tools, to carry out an evaluation, that has an instrumental use, has been demonstrated through an example. However, the evaluation method, at this stage, is not entirely instrumental; it lacks a comprehensive description of how to execute each of the steps, instead conceptual tools have been developed to help the execution of these steps. Thus, this dissertation provides an answer to the main research question, however this answer is still somewhat open for interpretation. 

References. 
Aksözen, M., Hassler, U. and Kohler, N. (2017), "Reconstitution of the dynamics of an urban building stock”, Building Research \& Information, Vol. 45 No. 3, pp. 239-258.

Al Horr, Y., Arif, M., Kaushik, A., Mazroei, A., Katafygiotou, M. and Elsarrag, E. (2016), “Occupant productivity and office indoor environment quality: A review of the literature", Building and Environment, Vol. 105, pp. 369-389.

Alexander, C., Ishikawa, S., Silverstein, M., Jacobson, M., Fiksdahl-King, I. and Angel, S. (1977), A pattern language: Towns, buildings, construction, Oxford University Press, New York, NY.

Allwood, J.M., Ashby, M.F., Gutowski, T.G. and Worrell, E. (2011), "Material efficiency: A white paper", Resources, Conservation and Recycling, Vol. 55 No. 3, pp. 362-381.

Altan, H., Gasperini, N., Moshaver, S. and Frattari, A. (2015), "Redesigning terraced social housing in the UK for flexibility using building energy simulation with consideration of passive design", Sustainability, Vol. 7 No. 5, pp. 5488-5507.

Archidat and Bouwinformatie (2012), Bouwdetailwijzer: Handboek duurzaam en energiezuinig renoveren.

Arge, K. (2005), “Adaptable office buildings: Theory and practice”, Facilities, Vol. 23 No. 3/4, pp. 119-127.

Ashby, M.F. (2012), Materials and the environment: Eco-informed material choice (2nd ed.), Butterworth-Heinemann, Waltham, MA.

Astbury, B. and Leeuw, F.L. (2010), "Unpacking black boxes: Mechanisms and theory building in evaluation”, American Journal of Evaluation, Vol. 31 No. 3, pp. 363-381.

Babbitt, C.W., Kahhat, R., Williams, E. and Babbitt, G.A. (2009), "Evolution of product lifespan and implications for environmental assessment and management: A case study of personal computers in higher education", Environmental Science \& Technology, Vol. 43 No. 13, pp. 5106-5112.

Baker, R., Brick, J.M., Bates, N.A., Battaglia, M., Couper, M.P., Dever, J.A., Gile, K.J. and Tourangeau, R. (2013), Report of the AAPOR task force on non-probability sampling.

Beisi, J. and Yingying, J. (2011), "Flexibility of traditional buildings and craftsmanship in China", Open House International, Vol. 36 No. 4, pp. 20-31.

Belausteguigoitia, J., Laurenz, J. and Gómez, A. (2011), "Modular ecotechnological architecture: A response to the demands of the 21st century", Open House International, Vol. 36 No. 1, pp. 95-102.

Bishop, P., Hines, A. and Collins, T. (2007), “The current state of scenario development: An overview of techniques", Foresight, Vol. 9 No. 1, pp. 5-25.

Blau, P.M. (1970), “A formal theory of differentiation in organizations”, American Sociological Review, Vol. 35 No. 2, pp. 201-218.

Blengini, G.A. and Di Carlo, T. (2010), “The changing role of life cycle phases, subsystems and 
materials in the LCA of low energy buildings", Energy and Buildings, Vol. 42 No. 6, pp. 869-880.

Blessing, L.T.M. and Chakrabarti, A. (2009), DRM, A design research methodology, Springer.

Bocken, N.M.P., de Pauw, I., Bakker, C. and van der Grinten, B. (2016), "Product design and business model strategies for a circular economy", Journal of Industrial and Production Engineering, Vol. 33 No. 5, pp. 308-320.

Boekholt, J.T., Thijssen, A.P., Dinjens, P.J.M. and Habraken, N.J. (1974), Denken in varianten: Het methodisch ontwerpen van dragers, Samson Uitgeverij Alphen aan den Rijn, Brussel.

Boulding, K.E. (1966), “The economics of the coming spaceship earth", In H. Jarrett (Ed.), Environmental quality in a growing economy (3-14), Johns Hopkins University Press, Baltimore, MD.

Boyce, P.R., Veitch, J.A., Newsham, G.R., Jones, C.C., Heerwagen, J., Myer, M. and Hunter, C.M. (2006), "Occupant use of switching and dimming controls in offices", Lighting Research \& Technology, Vol. 38 No. 4, pp. 358-378.

Brand, S. (1994), How buildings learn: What happens after they're built, Viking Press, New York, NY.

Brill, M., Weidemann, S. and BOSTI associates (2001), Disproving widespread myths about workplace design, Kimball International.

Bruce, T., Zuo, J., Rameezdeen, R. and Pullen, S. (2015), "Factors influencing the retrofitting of existing office buildings using Adelaide, South Australia as a case”, Structural Survey, Vol. 33 No. 2, pp. 150-166.

Bruggeman, L.A. (1981), Kwalitatieve woningdocumentatie (KWD) 1948-1977: Enkele kwaliteitsaspecten van de nieuwbouw van woningen over de afgelopen 30 jaar, Staatsuitgeverij, 's-Gravenhage.

Bull, B. (2005), "Exemplar sampling: Nonrandom methods of selecting a sample which characterizes a finite multivariate population”, The American Statistician, Vol. 59 No. 2, pp. 166-172.

Bullen, P.A. and Love, P.E.D. (2011a), "A new future for the past: A model for adaptive reuse decisionmaking", Built Environment Project and Asset Management, Vol. 1 No. 1, pp. 32-44.

Bullen, P.A. and Love, P.E.D. (2011b), “Adaptive reuse of heritage buildings”, Structural Survey, Vol. 29 No. 5, pp. 411-421.

Bullen, P.A. and Love, P.E.D. (2011c), "Factors influencing the adaptive re-use of buildings", Journal of Engineering, Design and Technology, Vol. 9 No. 1, pp. 32-46.

Bunn, R. (1997), "Green demo: Building analysis environmental office of the future", Building Services Journal, March 1997, pp. 18-23.

BZK (Ministerie van Binnenlandse Zaken en Koninkrijksrelaties) and CBS (Centraal Bureau voor de Statistiek) (2013), WoON2012: WoonOnderzoek Nederland 2012, version 1.1 (retrieved from: http://dx.doi.org/10.17026/dans-z3b-7vjh). 
Caplow, T. (1957), “Organizational size”, Administrative Science Quarterly, Vol. 1 No. 4, pp. 484505.

Carnevale, D.G. (1992), "Physical settings of work: A theory of the effects of environmental form", Public Productivity \& Management Review, Vol. 15 No. 1, pp. 423-436.

Cassidy, G. and MacDonald, R.A.R. (2007), "The effect of background music and background noise on the task performance of introverts and extraverts", Vol. 35 No. 3, pp. 517-537.

Cawthorne, D. (1997), "Intelligent daylighting design and control in UK buildings", available at: https://www.researchgate.net/publication/303189575_Intelligent_Daylighting_Design_and_ Control_in_UK_Buildings (accessed 28 February 2018).

CBS (Centraal Bureau voor de Statistiek) (2018), Landelijke Monitor Leegstand, 2017-2018 (retrieved from: https://www.cbs.nl/nl-nl/maatwerk/2018/45/landelijke-monitor-leegstand-2017-2018).

Chen, C.-J. and Huang, J.-W. (2007), "How organizational climate and structure affect knowledge management: The social interaction perspective", International Journal of Information Management, Vol. 27 No. 2, pp. 104-118.

Conejos, S., Langston, C., Chan, E.H.W. and Chew, M.Y.L. (2016), "Governance of heritage buildings: Australian regulatory barriers to adaptive reuse”, Building Research \& Information, Vol. 44 No. 5/6, pp. 507-519.

Czichos, H. (2006), "Materials and their characteristics: Overview", In H. Czichos, T. Saito and L. Smith (Eds.), Springer handbook of materials measurement methods (95-102), Springer Science+Business Media, Inc.

de Chiara, J., Panero, J. and Zelnik, M. (1992), Time-saver standards for interior design and space planning, McGraw-Hill.

de Laat, P. (2019), "Resource depletion, where is an intervention most effective?", Smart and Sustainable Built Environment, Vol. 8 No. 4, pp. 307-321.

de Neufville, R. (2008), "Low-cost airports for low-cost airlines: Flexible design to manage the risks", Transportation Planning and Technology, Vol. 31 No. 1, pp. 35-68.

Department for Work and Pensions (2018), Family resources survey 2016/17, available at: https:// www.gov.uk/government/statistics/family-resources-survey-financial-year-201617 (accessed 9 April 2019).

Despenic, M., Chraibi, S., Lashina, T. and Rosemann, A. (2017), "Lighting preferences profiles of users in an open office environment”, Building and Environment, Vol. 116, pp. 89-107.

Dhar, T.K., Hossain, M. and Rahaman, K.R. (2013), "How does flexible design promote resource efficiency for housing? A study of Khulna, Bangladesh", Smart and Sustainable Built Environment, Vol. 2 No. 2, pp. 140-157.

Diederen, A. (2010), Global resource depletion: Managed austerity and the elements of hope, Eburon Academic Publishers, Delft. 
Dovey, K. and Fisher, K. (2014), "Designing for adaptation: The school as socio-spatial assemblage”, The Journal of Architecture, Vol. 19 No. 1, pp. 43-46.

Duijm, N.J. (2015), "Recommendations on the use and design of risk matrices", Safety Science, Vol. 76, pp. 21-31.

Eekhout, M. (1997), POPO: Process organisatie voor product ontwikkeling, Delft University Press, Delft.

Eguchi, T., Schmidt III, R., Dainty, A., Austin, S. and Gibb, A. (2011), "The cultivation of adaptability in Japan", Open House International, Vol. 36 No. 1, pp. 73-85.

Einstein, A. (1936) "Physics and reality" (translation by Jean Piccard), Journal of the Franklin Institute, Vol. 221, No. 3, pp. 349-382.

Ekkers, P. and Ganzevles, T. (2005), "Ruimtelijke ontwikkeling in de negentiende en twintigste eeuw", In J. Brabers (Ed.), Nijmegen: Geschiedenis van de oudste stad van Nederland - negentiende en twintigste eeuw (17-32), Inmerc Uitgeverij, Wormer.

Engel, A. and Browning, T.R. (2008), "Designing systems for adaptability by means of architecture options”, Systems Engineering, Vol. 11 No. 2, pp. 125-146.

Engel, A. and Reich, Y. (2015), “Advancing architecture options theory: Six industrial case studies", Systems Engineering, Vol. 18 No. 4, pp. 396-414.

Entrop, A.G. and Brouwers, H.J.H. (2010), "Assessing the sustainability of buildings using a framework of triad approaches", Journal of Building Appraisal, Vol. 5 No. 4, pp. 293-310.

EOF Group (1995a), A performance specification for the energy efficient office of the future, available at: https://www.cibse.org/getmedia/1e00e7e2-2e09-4ddb-8636-0cf88b52db9e/GIR30-APerformance-Specification-for-the-Energy-Efficient-Office-of-the-Future.pdf.aspx (accessed 11 April 2019).

EOF Group (1995b), Future practice R\&D: The energy efficient office of the future, available at: https:/www.cibse.org/knowledge/knowledge-items/ detail?id=a0q20000008JgVvAAK\&viewmode=livesite (accessed 12 July 2018).

European Parliament (2010), Directive 2010/31/EU on the energy performance of buildings, available at: http:// eur-lex.europa.eu/ (accessed 8 February 2018).

Fawcett, W., Hughes, M., Krieg, H., Albrecht, S. and Vennström, A. (2012), "Flexible strategies for long-term sustainability under uncertainty”, Building Research \& Information, Vol. 40 No. 5, pp. 545-557.

Fayard, A.-L. and Weeks, J. (2007), "Photocopiers and water-coolers: The affordances of informal interaction”, Organization Studies, Vol. 28, pp. 605-634.

Feilden Clegg Bradley Studios (n.d.), New Environmental Office: BRE, available at: https:// fcbstudios.com/work/view/New-Environmental-Office-BRE (accessed 27 March 2019).

Fernandez, J.E. (2003), "Design for change: Part 1: diversified lifetimes", Architectural Research 
Quarterly, Vol. 7 No. 2, pp. 169-182.

Fletcher, D., Brennan, R.W. and Gu, P. (2009), “A method for quantifying adaptability in engineering design”, Concurrent Engineering: Research and Applications, Vol. 17 No. 4, pp. 279-289.

Fisher, C.D. (1998), "Effects of external and internal interruptions on boredom at work: Two studies", Journal of Organizational Behavior, Vol. 19 No. 5, pp. 503-522.

Georgiadou, M.C., Hacking, T. and Guthrie, P. (2012), “A conceptual framework for future-proofing the energy performance of buildings”, Energy Policy, Vol. 47, pp. 145-155.

Gijsbers, R. (2011), Aanpasbaarheid van de draagstructuur: Veranderbaarheid van de drager op basis van gebruikerseisen in het kader van Slimbouwen, Universiteitsdrukkerij Technische Universiteit Eindhoven, Eindhoven.

Gijsbers, R. and Lichtenberg, J. (2014), "Demand driven selection of adaptable building technologies for flexibility-in-use", Smart and Sustainable Built Environment, Vol. 3 No. 3, pp. 237-260.

Glaser, B.G. and Strauss, A.L. (1967), The discovery of grounded theory: Strategies for qualitative research, AldineTransaction, New Brunswick, NJ.

Gosling, J., Sassi, P., Naim, M. and Lark, R. (2013), "Adaptable buildings: A systems approach”, Sustainable Cities and Society, Vol. 7, pp. 44-51.

Greden, L. and Glicksman, L. (2005), “A real options model for valuing flexible space”, Journal of Corporate Real Estate, Vol. 7 No. 1, pp. 34-48.

Groenesteijn, L., Ellegast, R.P., Keller, K., Krause, F., Berger, H. and de Looze, M.P. (2012), “Office task effects on comfort and body dynamics in five dynamic office chairs", Applied Ergonomics, Vol. 43 No. 2, pp. 320-328.

Grover, R. and Grover, C. (2015), “Obsolescence-a cause for concern?”, Journal of Property Investment \& Finance, Vol. 33 No. 3, pp. 299-314.

Haans, A., Kaiser, F.G. and de Kort, Y.A.W. (2007), "Privacy needs in office environments: Development of two behavior-based scales, Vol. 12 No. 2, pp. 93-102.

Habraken, N.J. (1998), The structure of the ordinary: Form and control in the built environment, MIT Press, Cambridge, MA.

Hagihara, A., Tarumi, K. and Miller, A.S. (1998), "Social support at work as a buffer of work stressstrain relationship: A signal detection approach”, Stress Medicine, Vol. 14 No. 2, pp. 75-81.

Hakfoort, J. and Lie, R. (1996), “Office space per worker: Evidence from four European markets", The Journal of Real Estate Research, Vol. 11 No. 2, pp. 183-196.

Halvitigala, D. and Reed, R.G. (2015), "Identifying adaptive strategies employed by office building investors”, Property Management, Vol. 33 No. 5, pp. 478-493.

Hamraz, B., Hisarciklilar, O., Rahmani, K., Wynn, D.C., Thomson, V. and Clarkson, P.J. (2013), "Change prediction using interface data", Concurrent Engineering, Research and Applications, Vol. 21 No. 2, pp. 141-154. 
Hassanain, M.A. (2006), "Factors affecting the development of flexible workplace facilities", Journal of Corporate Real Estate, Vol. 8 No. 4, pp. 213-220.

Hasselaar, E. (2001), Hoe gezond is de Nederlandse woning?, DUP Science, Delft.

Hayek, F.A. (1967), Studies in philosophy, politics and economics, The University of Chicago Press, Chicago, IL.

Haymes, S.A. and Lee, J. (2006), "Effects of task lighting on visual function in age-related macular degeneration”, Ophthalmic and Physiological Optics, Vol. 26 No. 2, pp. 169-179.

Heidrich, O., Kamara, J., Maltese, S., Cecconi, F.R., Dejaco, M.C. (2017), “A critical review of the developments in building adaptability", International Journal of Building Pathology and Adaptation, Vol. 35 No. 4, pp. 284-303.

Hein, M.F. and Houck, K.D. (2008), "Construction challenges of adaptive reuse of historical buildings in Europe", International Journal of Construction Education and Research, Vol. 4 No. 2, pp. 115-131.

Helander, M.G., Zhang, L. and Michel, D. (1995), "Ergonomics of ergonomic chairs: A study of adjustability features", Ergonomics, Vol. 38 No. 10, pp. 2007-2029.

Herbert, P. (1998), “The environmental building”, Structural Survey, Vol. 16 No. 2, pp. 87-90.

Hertzberger, H. (2014), "Polyvalence: The competence of form and space with regard to different interpretations", Architectural Design, Vol. 84 No. 5, pp. 106-113.

Hicks, C., Heidrich, O., McGrovern, T. and Donnelly, T. (2004), “A functional model of supply chains and waste", International Journal of Production Economics, Vol. 89 No. 2, pp. 165-174.

Hillier, B. (1993), "Specifically architectural theory: A partial account of the ascent from building as cultural transmission to architecture as theoretical concretion", Harvard Architecture Review, Vol. 9 , pp. 8-27.

Hunter, B. (2006), "The espaces study: Designing, developing and managing learning spaces for effective learning”, New Review of Academic Librarianship, Vol. 12 No. 2, pp. 61-81.

Huuhka, S. and Lahdensivu, J. (2016), "Statistical and geographical study on demolished buildings", Building Research \& Information, Vol. 44 No. 1, pp. 73-96.

Isaac, S., Bock, T. and Stoliar, Y. (2014), “A new approach to building design modularization”, Procedia Engineering, Vol. 85, pp. 274-282.

Israelsson, N. and Hansson, B. (2009), "Factors influencing flexibility in buildings", Structural Survey, Vol. 27 No. 2, pp. 138-147.

Itard, L. and Klunder, G. (2007), "Comparing environmental impacts of renovated housing stock with new construction”, Building Research \& Information, Vol. 35 No. 3, pp. 252-267.

Jahncke, H., Hongisto, V. and Virjonen, P. (2013), “Cognitive performance during irrelevant speech: Effects of speech intelligibility and office-task characteristics", Applied Acoustics, Vol. 74 No. 3, pp. 307-316. 
Jungermann, H. and Thüring, M. (1987), “The use of mental models for generating scenarios”, In G. Wright and P. Ayton (Eds.), Judgmental forecasting (245-266), John Wiley \& Sons, Oxford, England.

Juslén, H.T., Wouters, M.C.H.M. and Tenner, A.D. (2007), "Lighting level and productivity: A field study in the electronics industry", Ergonomics, Vol. 50 No. 4, pp. 615-624.

Karjalainen, S. (2012), "Thermal comfort and gender: A literature review”, Indoor Air, Vol. 22 No. 2, pp. 96-109.

Khan, T.H. and Dhar, T.K. (2012), "Flexibility in Hong Kong private housing", Open House International, Vol. 37 No. 3, pp. 48-59.

Kim, J. and de Dear, R. (2013), "Workspace satisfaction: The privacy-communication trade-off in open-plan offices”, Journal of Environmental Psychology, Vol. 36, pp. 18-26.

Klaasen, I. (2002), “Modelling reality”, In T.M. de Jong and D.J.M. van der Voordt (Eds.), Ways to study and research urban, architectural and technical design (181-188), DUP Science, Delft.

Krathwohl, D.R. (2002), “A revision of Bloom's taxonomy: An overview”, Theory Into Practice, Vol. 41 No. 4, pp. 212-218.

Krausmann, F., Gingrich, S., Eisenmenger, N., Erb, K., Haberl, H. and Fischer-Kowalski, M. (2009), "Growth in global materials use, GDP and population during the 20th century", Ecological Economics, Vol. 68 No. 10, pp. 2696-2705.

Kwasnik, B.H. (1999), "The role of classification in knowledge representation and discovery", Library Trends, Vol. 48 No. 1, pp. 22-47.

Langston, C. and Shen, L.Y. (2007), “Application of the adaptive reuse potential model in Hong Kong: A case study of Lui Seng Chun", International Journal of Strategic Property Management, Vol. 11 No. 4, pp. 193-207.

Langston, C., Wong, F.K.W., Hui, E.C.M. and Shen, L.Y. (2008), "Strategic assessment of building adaptive reuse opportunities in Hong Kong”, Building and Environment, Vol. 43 No. 10, pp. 1709-1718.

Leder, S., Newsham, G.R., Veitch, J.A., Mancini, S. and Charles, K.E. (2016), "Effects of office environment on employee satisfaction: A new analysis", Building Research \& Information, Vol. 44 No. 1, pp. 34-50.

Leupen, B. and Mooij, H. (2011), Housing design: A manual, NAi Publishers, Rotterdam, the Netherlands.

Lichtenberg, J.J.N. (2004), Slimbouwen: Een herbezinning op bouwen - een strategie voor productontwikkeling, Technische Universiteit Eindhoven, Eindhoven.

Liebregts, M. and van Nunen, H. (2014), Essay: De toekomst van de woningvoorraad, Æneas, Boxtel.

Lin, Z. (2011), "Nakagin capsule tower: Revisiting the future of the recent past", Journal of Architectural Education, Vol. 65 No. 1, pp. 13-32. 
Lundin, L. (1999), "Allergic and non-allergic students' perception of the same high school environment”, Indoor Air, Vol. 9 No. 2, pp. 92-102.

Mantab-uz-Zaman, Q.M. (2011), “Adaptive re-use and urban regeneration in Dhaka - a theoretical exploration”, Open House International, Vol. 36 No. 2, pp. 45-58.

March, A., Rijal, Y., Wilkinson, S. and Özgür, E.F. (2012), "Measuring building adaptability and street vitality”, Planning Practice \& Research, Vol. 27 No. 5, pp. 531-552.

Martin, C. (2003), "Explaining labour turnover: Empirical evidence from UK establishments", Labour, Vol. 17 No. 3, pp. 391-412.

McDonough, W. and Braungart, M. (2002), Cradle to cradle: Remaking the way we make things, North Point Press, New York, NY.

Meadows, D.H. (1999), Leverage points: Places to intervene in a system, The Sustainability Institute, Hartland, VT.

Meadows, D.H., Meadows, D.L., Randers, J. and Behrens, W.W. (1972), The limits to growth: A report for the club of Rome's project on the predicament of mankind, Universe Books, New York, NY.

Meikle, J.L. and Connaughton, J.N. (1994), "How long should housing last? Some implications of the age and probable life of housing in England", Construction Management and Economics, Vol. 12 No. 4, pp. 315-321.

Meins, E., Wallbaum, H., Hardziewski, R. and Feige, A. (2010), "Sustainability and property valuation: A risk-based approach”, Building Research \& Information, Vol. 38 No. 3, pp. 280-300.

Miller, N.G. (2014), "Workplace trends in office space: Implications for future office demand", Journal of Corporate Real Estate, Vol. 16 No. 3, pp. 159-181.

Neufert, E. and Neufert, P. (2000), Architects' data, Blackwell Science.

Ní Riain, C., Fisher, J., MacKenzie, F. and Littler, J. (n.d.), BRE's environmental building: Energy performance in use, available at: https://www.researchgate.net/publication/237586351 BRE's_Environmental_Building_Energy_Performance_in_Use (accessed 28 February 2018).

Ní Riain, C., Kolokotroni, M., Davies, M., Fisher, J., White, M., Littler, J. (1999), "Cooling effectiveness of south façade passive stacks in a naturally ventilated office building”, Indoor and Built Environment, Vol. 8 No. 5 pp. 309-321.

Nijs, J.C., Durmisevic, E. and Halman, J.I.M. (2011), "Interface design for open systems building”, Open House International, Vol. 36 No. 1, pp. 35-43.

Norman, D. (2013), The design of everyday things: Revised and expanded edition, Basic Books.

NVM, VastgoedPro, VBO Makelaar, VNG and Waarderingskamer (2013), Fotowijzer woningen: Uniformering begrippen en definities woningen, report version 1.1 (retrieved from: http:// www.waarderingskamer.nl/).

O’Connor, J. (2004), “Survey on actual service lives for North American buildings”, In proceedings 
of the Woodframe Housing Durability and Disaster Issues conference, Las Vegas, NV.

O’Neill, M.J. (1994), "Work space adjustability, storage, and enclosure as predictors of employee reactions and performance", Environment and Behavior, Vol. 26 No. 4, pp. 504-526.

Office for Disability Issues (2011), Disability and mobility: London, available at: https://data.london. gov.uk/dataset/disability-and-mobility-london (accessed 15 April 2019).

ONS (2008), Diversity and different experiences in the UK: National statistician's annual article on society, available at: http://www.mighealth.net/uk/images/4/4b/Divdiff.pdf (accessed 9 April 2019).

Oxford Dictionary of Chemical Engineering (2014), Oxford University Press, Oxford.

Oxford Dictionary of Economics, 4th ed. (2012), Oxford University Press, Oxford.

Panero, J. and Zelnik, M. (1979), Human dimension \& interior space, Whitney Library of Design, New York, NY.

Paslawski, J. and Rozdzynska, M. (2013), "Flexible approach in infrastructure design buffer parking case study”, Procedia Engineering, Vol. 57, pp. 882-888.

Persily, A. and de Jonge, L. (2017), “Carbon dioxide generation rates for building occupants", Indoor Air, Vol. 27 No. 5, pp. 868-879.

Persson, A. and Ryals, L. (2014), "Making customer relationship decisions: Analytics v rules of thumb", Journal of Business Research, Vol. 67 No. 8, pp. 1725-1732.

Pheasant, S. (2003), Bodyspace: Anthropometry, ergonomics and the design of work, Taylor \& Francis, London.

Pinder, J., Schmidt III, R. and Saker, J. (2013), "Stakeholder perspectives on developing more adaptable buildings", Construction Management and Economics, Vol. 31 No. 5, pp. 440-459.

Prak, N.L. (1991), Het Nederlandse woonhuis van 1800 tot 1940, Delfse Universitaire Pers, Delft.

Priemus, H. and van Elk, R.S.F.J. (1970), Niet-traditionele woningbouwmethoden in Nederland, Stichting Bouwresearch, No. 26, Rotterdam.

Pries, F (1995), Innovatie in de bouwnijverheid, Eburon, Delft.

Pries, F. and Dorée, A. (2005), "A century of innovation in the Dutch construction industry", Construction Management and Economics, Vol. 23 No. 6, pp. 561-564.

Rant, Z. (1956), "Exergie, ein neues wort für 'technische arbeitsfähigkeit”, Forschung im Ingenieurwesen, Vol. 22 No. 1, pp. 36-37.

Reijula, K. and Sundman-Digert, C. (2004), “Assessment of indoor air problems at work with a questionnaire", Occupational and Environmental Medicine, Vol. 61 No. 1, pp. 33-38.

Remøy, H., de Jong, P. and Schenk, W. (2011), “Adaptable office buildings”, Property Management, Vol. 29 No. 5, pp. 443-453.

Remøy, H. and van der Voordt, T.J.M. (2014a), "Adaptive reuse of office buildings into housing: Opportunities and risks”, Building Research \& Information, Vol. 42 No. 3, pp. 381-390. 
Remøy, H. and van der Voordt, T.J.M. (2014b), "Priorities in accommodating office user preferences: Impact on office users decision to stay or go", Journal of Corporate Real Estate, Vol. 16 No. 2, pp. 140-154.

Ren, L., Shih, L. and McKercher, B. (2014), "Revitalization of industrial buildings into hotels: Anatomy of a policy failure", International Journal of Hospitality Management, Vol. 42, pp. 32-38.

Rentier, C., Reymers, J. and Salden, M.W.R. (2005), Jellema 4B: Omhulling - gevels, ThiemeMeulenhoff, Utrecht/Zutphen.

Rittel, H.W.J. and Webber, M.M. (1973), "Dilemmas in a general theory of planning”, Policy Sciences, Vol. 4 No. 2, pp. 155-169.

Robertson, M.M. (2007), "Health and performance consequences of office ergonomic interventions among computer workers", In M.J. Dainoff (Ed.), Ergonomics and Health Aspects of Work with Computers (135-143), Springer, Berlin.

Ross, D.T. (1977), "Structured analysis (SA): A language for communicating ideas”, IEEE Transactions on Software Engineering, Vol. SE-3 No. 1, pp. 16-34.

Ross, B.E., Chen, D.A., Conejos, S. and Khademi, A. (2016), "Enabling adaptable buildings: Results of a preliminary expert survey", Procedia Engineering, Vol. 145, pp. 420-427.

Rowe, D.M. (2001), “Activity rates and thermal comfort of office occupants in Sydney”, Journal of Thermal Biology, Vol. 26 No. 4/5, pp. 415-418.

Saari, A., Kruus, M., Hämälainen, A. and Kiiras, J. (2007), "Flexibuild - a systematic flexibility management procedure for building projects", Facilities, Vol. 25 No. 3/4, pp. 104-114.

Saari, A., Tissari, T., Valkama, E. and Seppänen, O. (2006), "The effect of a redesigned floor plan, occupant density and the quality of indoor climate on the cost of space, productivity and sick leave in an office building: A case study", Building and Environment, Vol. 41, pp. 1961-1972.

Saaty, T.L. (1990), "How to make a decision: The analytic hierarchy process", European Journal of Operational Research, Vol. 48 No. 1, pp. 9-26.

Saghafi, M.D. and Ahmadi, M. (2011), “A study of adaptable architecture pertinence in Iran”, Procedia Engineering, Vol. 21, pp. 656-665.

Sakellaris, I.A., Saraga, D.E., Mandin, C., Roda, C., Fossati, S., de Kluizenaar, Y., Carrer, P., Dimitroulopoulou, S., Mihucz, V.G., Szigeti, T., Hänninen, O., de Oliveira Fernandes, E., Bartzis, J.G. and Bluyssen, P.M. (2016), "Perceived indoor environment and occupants' comfort in European 'modern' office buildings: The OFFICAIR study”, International Journal of Environmental Research and Public Health, Vol. 13 No. 5.

Saigo, T., Sawada, S. and Utida, Y. (2011), "Future direction of sustainable buildings in Japan”, Open House International, Vol. 36 No. 4, pp. 5-19.

Schmidt III, R. (2014), Designing for adaptability in architecture, Loughborough University, 
Loughborough, England.

Schmidt III, R. and Eguchi, T. (2014), "Mediating change: A Japanese perspective on adaptable architecture", Architectural Design, Vol. 84 No. 2, pp. 74-79.

Schmidt III, R., Eguchi, T., Austin, S. and Gibb, A. (2010), "What is the meaning of adaptability in the building industry?", In proceedings of the CIB 16th International Conference on Open and Sustainable Building, Bilbao, Spain, 17-19 May.

Schmidt III, R., Vibaek, K.S. and Austin, S. (2014), "Evaluating the adaptability of an industrialized building using dependency structure matrices", Construction Management and Economics, Vol. 32 No. 1/2, pp. 160-182.

Scholten, N.P.M. (2001), Technische en juridische grondslagen van bouwregelgeving: Woningwet en Bouwbesluit.

Schwehr, P. (2011), "Evolutionary algorithms in architecture", Open House International, Vol. 36 No. 1, pp. 16-24.

Schweizer, C., Edwards, R.D., Bayer-Oglesby, L., Gauderman, W.J., Ilacqua, V., Jantunen, M.J., Lai, H.K., Nieuwenhuijsen, M. and Künzli, N. (2006), "Indoor time-microenvironment-activity patterns in seven regions of Europe", Journal of Exposure Science and Environmental Epidemiology, Vol. 17 No. 2, pp. 170-181.

Seppänen, O., Fisk, W.J. and Lei, Q.H. (2006), “Ventilation and performance in office work”, Indoor Air, Vol. 16 No. 1, pp. 28-36.

Shahbazi, S., Wiktorsson, M., Kurdve, M., Jönsson, C. and Bjelkemyr, M. (2016), "Material efficiency in manufacturing: Swedish evidence on potential, barriers and strategies", Journal of Cleaner Production, Vol. 127, pp. 438-450.

Slaughter, E.S. (2001), "Design strategies to increase building flexibility", Building Research \& Information, Vol. 29 No. 3, pp. 208-217.

Soeter, J.P. (2010), Bouw- en voorraadeconomie 1960-2025, VSSD, Delft.

Stahel, W.R. (1984), "The product-life factor", In S. G. Orr (Ed.), An inquiry into the nature of sustainable societies: The role of the private sector (72-96), HARC, Houston, TX.

Stahel, W.R. (2010), The performance economy (2nd ed.), Palgrave Macmillan, London.

Steadman, P. (2006), "Why are most buildings rectangular?", Architectural Research Quarterly, Vol. 10 No. 2, pp. 119-130.

Steinfeld, E., Maisel, J., Feathers, D. and D'Souza, C. (2010), “Anthropometry and standards for wheeled mobility: An international comparison”, Assistive Technology, Vol. 22 No. 1, pp. 51-67.

Sundstrom, E. (1986), Work places: The psychology of the physical environment in offices and factories, Cambridge University Press, New York, NY.

Sundstrom, E., Burt, R.E. and Kamp, D. (1980), "Privacy at work: Architectural correlates of job 
satisfaction and job performance", The Academy of Management Journal, Vol. 23 No. 1, pp. 101-117.

Sung-Hwa, K. and Beisi, J. (2012), "Flexible building and construction systems in traditional Korean architecture”, Open House International, Vol. 37 No. 3, pp. 16-27.

Thijssen, C.C.F. (1999), Bouwconstructieve analyse van naoorlogse eengezinshuizen in de non-profit huursector 1946-1965, Delfse Universitaire Pers, Delft.

Thijssen, C.C.F. and Meijer, C.J. (1988), Bouwconstructieve analyse van naoorlogse meergezinshuizen in de non-profit huursector 1946-1965, Delfse Universitaire Pers, Delft.

Thomsen, A. (2006), Levensloop van woningen, Technische Universiteit Delft, Delft.

Thomsen, A. and van der Flier, K. (2009), "Replacement or renovation of dwellings: The relevance of a more sustainable approach", Building Research \& Information, Vol. 37 No. 5/6, pp. 649659.

Tomiyama, T., Gu, P., Jin, Y., Lutters, D., Kind, Ch. and Kimura, F. (2009), “Design methodologies: Industrial and educational applications", CIRP Annals - Manufacturing Technology, Vol. 58 No. 2, pp. 543-565.

Tulving, E. and Pearlstone, Z. (1966), "Availability versus accessibility of information in memory for words", Journal of Verbal Learning and Verbal Behavior, Vol. 5 No. 4, pp. 381-391.

Tversky, A. and Kahneman, D. (1974), “Judgment under uncertainty: Heuristics and biases”, Science, Vol. 185 No. 4157, pp. 1124-1131.

van Hoof, J. and Hensen, J.L.M. (2006), “Thermal comfort and older adults”, Gerontechnology, Vol. 4 No. 4 , pp. 223-228.

Vandenbroucke, M., Galle, W., de Temmerman, N., Debacker, W. and Paduart, A. (2015), "Using life cycle assessment to inform decision-making for sustainable buildings", Buildings, Vol. 5 No. 2, pp. 536-559.

Vedung, E. (2004), "Evaluation research and fundamental research", In R. Stockmann (Ed.), Evaluationsforschung: Grundlagen und ausgewählte forschungsfelder (111-134), Leske + Budrich, Opladen.

Veitch, J.A., Charles, K.E., Farley, K.M.J. and Newsham, G.R. (2007), “A model of satisfaction with open-plan office conditions: COPE field findings”, Journal of Environmental Psychology, Vol. 27 No. 3, pp. 177-189.

Vimpari, J. and Junnila, S. (2016), "Theory of valuing building life-cycle investments", Building Research \& Information, Vol. 44 No. 4, pp. 345-357.

von Bertalanffy, L. (1968), General system theory: Foundations, development, applications, George Braziler, New York, NY.

Vreeze, A.S.G.D. (2001), 6,5 Miljoen woningen: 100 jaar woningwet en wooncultuur in Nederland, Uitgeverij 010, Rotterdam. 
Wagenaar, M. (1992), "Hoogbouw in het vlakke land: Hoge woongebouwen en kantoortorens in Holland 1900-1992”, Regionaal-historisch tijdschrift Holland, Vol. 24 No. 4/5, pp. 270-286.

Walker, S. (2010), “Temporal objects: Design, change and sustainability”, Sustainability, Vol. 2 No. 3, pp. 812-832.

Walker, W.E., Haasnoot, M. and Kwakkel, J.H. (2013), “Adapt or perish: A review of planning approaches for adaptation under deep uncertainty", Sustainability, Vol. 5 No. 3, pp. 955-979.

West, M.A. and Nicholson, N. (1989), "The outcomes of job change”, Journal of Vocational Behavior, Vol. 34 No. 3, pp. 335-349.

White, M.K., Kolokotroni, M., Shaw, R., Pike, J., Ní Riain, C. and Perera, M.D.A.E.S. (n.d.), Detailed monitoring report: BRE energy efficient office of the future (GB1), available at: http://projects. bre.co.uk/natvent/reports/monitoring/detailed/gb1 det.pdf (accessed 6 July 2018).

Wiendahl, H.P., ElMaraghy, H.A., Nyhuis, P., Zäh, M.F., Wiendahl, H.H., Duffie, N. and Brieke, M. (2007), "Changeable manufacturing: Classification, design and operation", CIRP Annals, Vol. 56 No. 2, pp. 783-809.

Wilkinson, S.J. (2012a), “Adaptation patterns in premium office buildings over time in the Melbourne CBD”, Journal of Corporate Real Estate, Vol. 14 No. 3, pp. 157-170.

Wilkinson, S.J. (2012b), "Analysing sustainable retrofit potential in premium office buildings", Structural Survey, Vol. 30 No. 5, pp. 398-410.

Wilkinson, S.J. (2014a), "Office building adaptation and the growing significance of environmental attributes", Journal of Corporate Real Estate, Vol. 16 No. 4, pp. 252-265.

Wilkinson, S.J. (2014b), "The preliminary assessment of adaptation potential in existing office buildings", International Journal of Strategic Property Management, Vol. 18 No. 1, pp. 77-87.

Wilkinson, S.J. and Reed, R. (2011), "Examining and quantifying the drivers behind alterations and extensions to commercial buildings in a central business district", Construction Management and Economics, Vol. 29 No. 7, pp. 725-735.

Wilkinson, S.J., Reed, R. and James, K. (2009), "Using building adaptation to deliver sustainability in Australia", Structural survey, Vol. 27 No. 1, pp. 46-61.

Wong, J.F. (2010), "Factors affecting open building implementation in high density mass housing design in Hong Kong”, Habitat International, Vol. 34 No. 2, pp. 174-182.

Worthington, J. (2001), “Accommodating change: Emerging real estate strategies", Journal of Corporate Real Estate, Vol. 3 No. 1, pp. 81-95.

Zhou, X., Zhang, H., Lian, Z. and Zhang, Y. (2014), "A model for predicting thermal sensation of Chinese people”, Building and Environment, Vol. 82, pp. 237-246. 
This page is intentionally left blank. 

Appendix 1.

Cases' information. 


\begin{tabular}{|c|c|c|c|c|c|c|c|c|c|}
\hline No. & year & address & type of house & $\begin{array}{l}\text { unit } \\
\text { size }\end{array}$ & $\begin{array}{l}\text { project size } \\
\text { (in units) }\end{array}$ & $\begin{array}{l}\text { width } \\
(\mathrm{mm})\end{array}$ & $\begin{array}{c}\text { length } \\
(\mathrm{mm})\end{array}$ & $\begin{array}{l}\text { ceiling height } \\
\text { main floor }\end{array}$ & $\begin{array}{l}\text { ceiling height } \\
\text { first floor }\end{array}$ \\
\hline 1 & 1900 & Pater brugmanstraat 3 & row & $284 \mathrm{~m}^{2}$ & 15 & 6000 & 13200 & $3600 \mathrm{~mm}$ & $3300 \mathrm{~mm}$ \\
\hline 2 & 1902 & Jan van Galenstraat 28 & row & $97 \mathrm{~m}^{2}$ & 8 & 5600 & 7900 & $3000 \mathrm{~mm}$ & $3000 \mathrm{~mm}$ \\
\hline 3 & 1911 & Weurtseweg 228 & row & $70 \mathrm{~m}^{2}$ & 41 & 4600 & 6600 & $3000 \mathrm{~mm}$ & $2500 \mathrm{~mm}$ \\
\hline 4 & 1913 & Jan van Galenstraat 33 & row & $110 \mathrm{~m}^{2}$ & 21 & 5200 & 7800 & $3100 \mathrm{~mm}$ & $2500 \mathrm{~mm}$ \\
\hline 5 & 1913 & Sumatrastraat 8 & row & $220 \mathrm{~m}^{2}$ & 8 & 6300 & 9500 & $3500 \mathrm{~mm}$ & $3500 \mathrm{~mm}$ \\
\hline 6 & 1922 & Maasplein 18 & row & $83 m^{2}$ & 68 & 4820 & 7160 & $2780 \mathrm{~mm}$ & $2480 \mathrm{~mm}$ \\
\hline 7 & 1923 & Anna van Bijnsstraat 8 & row & $81 \mathrm{~m}^{2}$ & 54 & 4380 & 7160 & $2700 \mathrm{~mm}$ & $2400 \mathrm{~mm}$ \\
\hline 8 & 1923 & Beetsplein 31 & row & $96 m^{2}$ & 139 & 4380 & 7160 & $2780 \mathrm{~mm}$ & $2400 \mathrm{~mm}$ \\
\hline 9 & 1930 & Sweelinckstraat 57 & row & $80 \mathrm{~m}^{2}$ & 75 & 5130 & 6760 & $2700 \mathrm{~mm}$ & $2400 \mathrm{~mm}$ \\
\hline 10 & 1938 & Distelstraat 24 & row & $84 m^{2}$ & 88 & 4630 & 6360 & $2700 \mathrm{~mm}$ & $2500 \mathrm{~mm}$ \\
\hline 11 & 1939 & Leeuwstraat 57 & row & $114 \mathrm{~m}^{2}$ & 66 & 5270 & 8360 & $2750 \mathrm{~mm}$ & $2400 \mathrm{~mm}$ \\
\hline 12 & 1940 & Lingestraat 19 & row & $73 \mathrm{~m}^{2}$ & 126 & 4780 & 7060 & $2730 \mathrm{~mm}$ & $2500 \mathrm{~mm}$ \\
\hline 13 & 1948 & Klaverstraat 15 & row & $90 \mathrm{~m}^{2}$ & 101 & 5480 & 6960 & $2700 \mathrm{~mm}$ & $2500 \mathrm{~mm}$ \\
\hline 14 & 1949 & Corduwenerstraat 64 & row & $102 \mathrm{~m}^{2}$ & 83 & 5480 & 6960 & $2700 \mathrm{~mm}$ & $2500 \mathrm{~mm}$ \\
\hline 15 & 1950 & Barneveldse Beekstraat 9 & row & $89 \mathrm{~m}^{2}$ & 86 & 5500 & 7200 & $2700 \mathrm{~mm}$ & $2400 \mathrm{~mm}$ \\
\hline 16 & 1951 & Duindoornstraat 67 & row & $74 m^{2}$ & 190 & 5370 & 6830 & $2635 \mathrm{~mm}$ & $2405 \mathrm{~mm}$ \\
\hline 17 & 1956 & Kaaplandstraat 14 & row & $95 \mathrm{~m}^{2}$ & 77 & 5680 & 6690 & $2600 \mathrm{~mm}$ & $2400 \mathrm{~mm}$ \\
\hline 18 & 1957 & Albertus Magnusstraat 14 & row & $120 \mathrm{~m}^{2}$ & 81 & 6100 & 7710 & $2620 \mathrm{~mm}$ & $2400 \mathrm{~mm}$ \\
\hline 19 & 1959 & Edisonstraat 24 & row & $87 \mathrm{~m}^{2}$ & 468 & 5870 & 6520 & $2600 \mathrm{~mm}$ & $2450 \mathrm{~mm}$ \\
\hline 20 & 1960 & Kanunnik Pelsstraat 34 & row & $111 \mathrm{~m}^{2}$ & 294 & 5930 & 7360 & $2600 \mathrm{~mm}$ & $2400 \mathrm{~mm}$ \\
\hline 21 & 1965 & Cimbaalstraat 53 & row & $113 \mathrm{~m}^{2}$ & 194 & 5800 & 8050 & $2600 \mathrm{~mm}$ & $2400 \mathrm{~mm}$ \\
\hline 22 & 1965 & Groen van Prinstererstraat 35 & row & $83 \mathrm{~m}^{2}$ & 244 & 5940 & 6840 & $2600 \mathrm{~mm}$ & $2400 \mathrm{~mm}$ \\
\hline 23 & 1967 & Aldenhof 2303 & row & $113 \mathrm{~m}^{2}$ & 423 & 5910 & 7500 & $2600 \mathrm{~mm}$ & $2400 \mathrm{~mm}$ \\
\hline 24 & 1973 & Tolhuis 4304 & row & $114 \mathrm{~m}^{2}$ & 290 & 4460 & 12840 & $2600 \mathrm{~mm}$ & $2400 \mathrm{~mm}$ \\
\hline 25 & 1977 & de Voorstenkamp 1021 & row & $115 \mathrm{~m}^{2}$ & 244 & 5220 & 8400 & $2600 \mathrm{~mm}$ & $2400 \mathrm{~mm}$ \\
\hline 26 & 1978 & Zwaluwstraat 72 & row & $96 \mathrm{~m}^{2}$ & 215 & 5220 & 8240 & $2600 \mathrm{~mm}$ & $2850 \mathrm{~mm}$ \\
\hline 27 & 1981 & Horstacker 2108 & row & $104 \mathrm{~m}^{2}$ & 90 & 5600 & 7800 & $2600 \mathrm{~mm}$ & $2400 \mathrm{~mm}$ \\
\hline 28 & 1982 & Hillekensacker 2122 & row & $113 \mathrm{~m}^{2}$ & 115 & 5500 & 7700 & $2600 \mathrm{~mm}$ & $2400 \mathrm{~mm}$ \\
\hline 29 & 1990 & Harriët Freezerlaan 48 & linked double & $169 \mathrm{~m}^{2}$ & 42 & 5500 & 9000 & $2470 \mathrm{~mm}$ & $2470 \mathrm{~mm}$ \\
\hline 30 & 1996 & Albert Schweitzerlaan 100 & linked double & $148 \mathrm{~m}^{2}$ & 56 & 5400 & 9500 & $2440 \mathrm{~mm}$ & $2440 \mathrm{~mm}$ \\
\hline 31 & 1997 & Keplerstraat 141 & row & $122 \mathrm{~m}^{2}$ & 93 & 5170 & 9100 & $2440 \mathrm{~mm}$ & $2440 \mathrm{~mm}$ \\
\hline 32 & 2000 & Bellefleurstraat 36 & linked double & $151 \mathrm{~m}^{2}$ & 144 & 5480 & 9910 & $2440 \mathrm{~mm}$ & $2440 \mathrm{~mm}$ \\
\hline 33 & 2001 & Akkerwinde 17 & row & $118 \mathrm{~m}^{2}$ & 89 & 5480 & 8610 & $2440 \mathrm{~mm}$ & $2440 \mathrm{~mm}$ \\
\hline 34 & 2005 & Weefgewichtstraat 58 & row & $162 \mathrm{~m}^{2}$ & 62 & 5450 & 10500 & $2670 \mathrm{~mm}$ & $2670 \mathrm{~mm}$ \\
\hline 35 & 2005 & Tegulastraat 8 & row & $111 \mathrm{~m}^{2}$ & 78 & 5150 & 9580 & $2570 \mathrm{~mm}$ & $2570 \mathrm{~mm}$ \\
\hline 36 & 2006 & Pink Floydstraat 84 & row & $101 \mathrm{~m}^{2}$ & 94 & 5100 & 9400 & $2450 \mathrm{~mm}$ & $2450 \mathrm{~mm}$ \\
\hline 37 & 2008 & Vrouwe Udasingel 159 & row & $175 \mathrm{~m}^{2}$ & 115 & 5400 & 9980 & $2700 \mathrm{~mm}$ & $2700 \mathrm{~mm}$ \\
\hline
\end{tabular}




\begin{tabular}{|c|c|c|c|c|c|c|c|c|c|}
\hline No. & year & address & type of house & $\begin{array}{l}\text { unit } \\
\text { size }\end{array}$ & $\begin{array}{l}\text { project size } \\
\text { (in units) }\end{array}$ & $\begin{array}{l}\text { width } \\
(\mathrm{mm})\end{array}$ & $\begin{array}{l}\text { length } \\
(\mathrm{mm})\end{array}$ & $\begin{array}{l}\text { ceiling height } \\
\text { main floor }\end{array}$ & $\begin{array}{l}\text { ceiling height } \\
\text { first floor }\end{array}$ \\
\hline 38 & 1901 & Goorstraat 72 & two-family & $191 \mathrm{~m}^{2}$ & 10 & 5700 & 8100 & $3000 \mathrm{~mm}$ & - \\
\hline 39 & 1907 & Graafsedwarsstraat 19 & two-family & $108 \mathrm{~m}^{2}$ & 8 & 5650 & 8550 & $3020 \mathrm{~mm}$ & - \\
\hline 40 & 1909 & Van den Havestraat 36 & two-family & $103 \mathrm{~m}^{2}$ & 11 & 5700 & 9300 & $3000 \mathrm{~mm}$ & - \\
\hline 41 & 1912 & Parkweg 72 & two-family & $130 \mathrm{~m}^{2}$ & 5 & 7200 & 11330 & $3200 \mathrm{~mm}$ & - \\
\hline 42 & 1925 & Maerlantstraat 31 & two-family & $84 m^{2}$ & 34 & 4280 & 7060 & $2780 \mathrm{~mm}$ & - \\
\hline 43 & 1927 & Van 't Santstraat 31 & two-family & $91 \mathrm{~m}^{2}$ & 98 & 5010 & 7060 & $2700 \mathrm{~mm}$ & - \\
\hline 44 & 1934 & Hengstdalseweg 73 & two-family & $121 \mathrm{~m}^{2}$ & 21 & 5400 & 7760 & $2710 \mathrm{~mm}$ & - \\
\hline 45 & 1934 & Marsstraat 9 & two-family & $69 \mathrm{~m}^{2}$ & 21 & 5400 & 8700 & $2750 \mathrm{~mm}$ & - \\
\hline 46 & 1939 & Sterreschansweg 13 & block of flats & $83 \mathrm{~m}^{2}$ & 42 & 8020 & 11500 & $2900 \mathrm{~mm}$ & - \\
\hline 47 & 1950 & Barneveldse Beekstraat 10 & two-family & $100 \mathrm{~m}^{2}$ & 78 & 5950 & 7200 & $2700 \mathrm{~mm}$ & - \\
\hline 48 & 1951 & Vogelkersstraat 38 & block of flats & $50 \mathrm{~m}^{2}$ & 251 & 6730 & 8090 & $2830 \mathrm{~mm}$ & - \\
\hline 49 & 1953 & Wolfstraat 138 & block of flats & $74 \mathrm{~m}^{2}$ & 200 & 8000 & 8350 & $2600 \mathrm{~mm}$ & - \\
\hline 50 & 1954 & Pieter Postplein 18 & block of flats & $51 \mathrm{~m}^{2}$ & 377 & 6940 & 9185 & $2600 \mathrm{~mm}$ & - \\
\hline 51 & 1955 & Wijnbesstraat 93 & block of flats & $83 m^{2}$ & 222 & 6045 & 9014 & $2600 \mathrm{~mm}$ & - \\
\hline 52 & 1959 & Newtonstraat 83 & block of flats & $74 m^{2}$ & 241 & 6785 & 9640 & $2600 \mathrm{~mm}$ & - \\
\hline 53 & 1963 & Einsteinstraat 113 & block of flats & $60 \mathrm{~m}^{2}$ & 60 & 6460 & 10210 & $2630 \mathrm{~mm}$ & - \\
\hline 54 & 1966 & Motetpad 31 & block of flats & $78 \mathrm{~m}^{2}$ & 96 & 7965 & 9000 & $2520 \mathrm{~mm}$ & - \\
\hline 55 & 1970 & Meijhorst 3122 & block of flats & $66 \mathrm{~m}^{2}$ & 189 & 8780 & 10100 & $2600 \mathrm{~mm}$ & - \\
\hline 56 & 1973 & Meijhorst 1488 & block of flats & $95 \mathrm{~m}^{2}$ & 270 & 10320 & 12000 & $2600 \mathrm{~mm}$ & - \\
\hline 57 & 1977 & Zwaluwstraat 49 & two-family & $44 \mathrm{~m}^{2}$ & 215 & 5220 & 8120 & $2580 \mathrm{~mm}$ & - \\
\hline 58 & 1981 & Rosa de Limastraat 14 & block of flats & $44 m^{2}$ & 86 & 5500 & 8500 & $2600 \mathrm{~mm}$ & - \\
\hline 59 & 1983 & Minervaplaats 106 & block of flats & $32 \mathrm{~m}^{2}$ & 340 & 4870 & 6500 & $2500 \mathrm{~mm}$ & - \\
\hline 60 & 1987 & Veemarkt 75 & block of flats & $73 \mathrm{~m}^{2}$ & 152 & 5770 & 11310 & $2450 \mathrm{~mm}$ & - \\
\hline 61 & 1992 & Boeckstaetehof 607 & block of flats & $68 \mathrm{~m}^{2}$ & 144 & 6500 & 11500 & $2420 \mathrm{~mm}$ & - \\
\hline 62 & 1994 & Blaise Pascalplein 38 & block of flats & $71 \mathrm{~m}^{2}$ & 119 & 7134 & 9770 & $2470 \mathrm{~mm}$ & - \\
\hline 63 & 1996 & Rode Kruislaan 118 & block of flats & $104 \mathrm{~m}^{2}$ & 115 & 10530 & 10570 & $2470 \mathrm{~mm}$ & - \\
\hline 64 & 1998 & Pater Leijdekkersstraat 34 & block of flats & $134 \mathrm{~m}^{2}$ & 54 & 7686 & 18810 & $2488 \mathrm{~mm}$ & - \\
\hline 65 & 2006 & Deken Hensburchstraat 32 & block of flats & $80 \mathrm{~m}^{2}$ & 72 & 6650 & 12110 & $2600 \mathrm{~mm}$ & - \\
\hline 66 & 2008 & Beatlesstraat 44 & block of flats & $115 \mathrm{~m}^{2}$ & 20 & 8300 & 15350 & $2610 \mathrm{~mm}$ & - \\
\hline 67 & 2009 & Draaiom 98 & block of flats & $92 \mathrm{~m}^{2}$ & 115 & 7300 & 12300 & $2600 \mathrm{~mm}$ & - \\
\hline 68 & 2010 & Henk van Tienhovenstraat 31 & block of flats & $77 \mathrm{~m}^{2}$ & 78 & 8400 & 9300 & $2620 \mathrm{~mm}$ & - \\
\hline
\end{tabular}




\begin{tabular}{|c|c|c|c|c|c|c|c|c|}
\hline No. & year & $\begin{array}{c}\text { bathroom } \\
\text { low. unit ; up. unit }\end{array}$ & $\begin{array}{l}\text { underground stor. } \\
\text { low. unit i up. unit }\end{array}$ & $\begin{array}{l}\text { type of } \\
\text { kitchen }\end{array}$ & $\begin{array}{l}\text { private rooms } \\
\text { low. unit up. unit }\end{array}$ & $\begin{array}{l}\text { extra doors } \\
\text { low. unit up. unit }\end{array}$ & $\begin{array}{c}\text { first-floor } \\
\text { spatial layout }\end{array}$ & $\begin{array}{c}\text { type of } \\
\text { exterior wall }\end{array}$ \\
\hline 1 & 1900 & no & basement & separate & 1 & 3 & non-basic & massive \\
\hline 2 & 1902 & no & basement & separate & 3 & 0 & basic (2 room) & massive \\
\hline 3 & 1911 & no & b. closet & separate & disregarded & 0 & basic (2 room) & massive \\
\hline 4 & 1913 & $?$ & basement & $?$ & $?$ & $?$ & $?$ & massive \\
\hline 5 & 1913 & no & basement & separate & 0 & 1 & basic (6 room) & massive \\
\hline 6 & 1922 & no & b. closet & separate & 3 & 0 & basic (3 room) & cavity \\
\hline 7 & 1923 & no & basement & separate & 3 & 0 & basic (2 room) & cavity \\
\hline 8 & 1923 & no & basement & separate & 3 & 0 & basic (3 room) & cavity \\
\hline 9 & 1930 & no & basement & separate & 4 & 0 & basic (3 room) & cavity \\
\hline 10 & 1938 & no & basement & separate & 3 & 0 & basic (3 room) & cavity \\
\hline 11 & 1939 & $?$ & basement & $?$ & $?$ & $?$ & $?$ & cavity \\
\hline 12 & 1940 & no & b. closet & separate & 3 & 0 & basic (3 room) & cavity \\
\hline 13 & 1948 & yes & basement & separate & 0 & 1 & basic (4 room) & cavity \\
\hline 14 & 1949 & yes & basement & separate & 0 & 1 & basic (4 room) & cavity \\
\hline 15 & 1950 & yes & basement & separate & 0 & 1 & basic (4 room) & massive \\
\hline 16 & 1951 & yes & no & separate & 0 & 0 & basic (4 room) & insul. cavity \\
\hline 17 & 1956 & yes & b. closet & separate & 0 & 1 & basic (4 room) & cavity \\
\hline 18 & 1957 & yes & basement & separate & 0 & 2 & basic (4 room) & cavity \\
\hline 19 & 1959 & yes & basement & separate & 0 & 0 & basic (4 room) & cavity \\
\hline 20 & 1960 & yes & basement & separate & 0 & 2 & basic (4 room) & cavity \\
\hline 21 & 1965 & yes & b. closet & separate & 0 & 0 & $?$ & cavity \\
\hline 22 & 1965 & yes & b. closet & separate & 0 & 0 & basic (4 room) & cavity \\
\hline 23 & 1967 & yes & no & separate & 0 & 1 & basic (4 room) & cavity \\
\hline 24 & 1973 & yes & no & open & 1 & 0 & basic (5 room) & cavity \\
\hline 25 & 1977 & yes & no & open & 1 & 0 & basic (4 room) & insul. cavity \\
\hline 26 & 1978 & yes & no & open & 0 & 0 & basic (4 room) & insul. cavity \\
\hline 27 & 1981 & yes & no & open & 0 & 0 & basic (4 room) & insul. cavity \\
\hline 28 & 1982 & yes & no & open & 0 & 0 & basic (4 room) & insul. cavity \\
\hline 29 & 1990 & yes & no & open & 0 & 0 & basic (5 room) & insul. cavity \\
\hline 30 & 1996 & yes & no & open & 0 & 0 & basic (5 room) & insul. cavity \\
\hline 31 & 1997 & yes & no & open & disregarded & 0 & basic (5 room) & insul. cavity \\
\hline 32 & 2000 & yes & no & open & 0 & 0 & basic (5 room) & insul. cavity \\
\hline 33 & 2001 & yes & no & open & 0 & 0 & basic (4 room) & insul. cavity \\
\hline 34 & 2005 & yes & no & open & 0 & 0 & basic (4 room) & insul. cavity \\
\hline 35 & 2005 & yes & no & separate & 0 & 1 & basic (5 room) & insul. cavity \\
\hline 36 & 2006 & yes & no & open & 0 & 0 & basic (4 room) & insul. cavity \\
\hline 37 & 2008 & yes & no & open & 0 & 0 & basic (5 room) & insul. cavity \\
\hline
\end{tabular}




\begin{tabular}{|c|c|c|c|c|c|c|c|c|c|c|c|}
\hline \multirow{2}{*}{\begin{tabular}{|l|} 
No. \\
38
\end{tabular}} & \multirow{2}{*}{\begin{tabular}{|l|} 
year \\
1901
\end{tabular}} & \multicolumn{2}{|c|}{$\begin{array}{l}\text { bathroom } \\
\text { low. unit up. unit }\end{array}$} & $\begin{array}{l}\text { underground stor. } \\
\text { low. unit up. unit }\end{array}$ & \multirow{2}{*}{\begin{tabular}{|l|}
$\begin{array}{l}\text { type of } \\
\text { kitchen }\end{array}$ \\
separate
\end{tabular}} & \multicolumn{2}{|c|}{$\begin{array}{l}\text { private rooms } \\
\text { low. uniti up. unit }\end{array}$} & \multicolumn{2}{|c|}{$\begin{array}{l}\text { extra doors } \\
\text { low. uniti up. unit }\end{array}$} & \multirow{2}{*}{\begin{tabular}{|c|c}
$\begin{array}{c}\text { first-floor } \\
\text { spatial layout }\end{array}$ \\
-
\end{tabular}} & \multirow{2}{*}{$\begin{array}{c}\begin{array}{c}\text { type of } \\
\text { exterior wall }\end{array} \\
\text { massive }\end{array}$} \\
\hline & & yes & yes & basement basement & & 3 & 1 & 0 & 1 & & \\
\hline 39 & 1907 & no & no & basement basement & separate & 2 & 0 & 1 & 1 & non-basic & massive \\
\hline 40 & 1909 & no & no & basement basement & separate & 2 & 0 & 1 & 1 & basic (4 room) & massive \\
\hline 41 & 1912 & no & no & basement basement & separate & 0 & 0 & 1 & 1 & basic (5 room) & massive \\
\hline 42 & 1925 & no & no & \multirow{2}{*}{ basement basement } & separate & 1 & 0 & 0 & 0 & basic (2 room) & cavity \\
\hline 43 & 1927 & no & no & & separate & 1 & 1 & 1 & 1 & basic (3 room) & cavity \\
\hline 44 & 1934 & no & no & basement basement & separate & 0 & 1 & 1 & 1 & basic (3 room) & cavity \\
\hline 45 & 1934 & no & no & b. closet & separate & 0 & 0 & 1 & 1 & basic (3 room) & cavity \\
\hline 46 & 1939 & \multicolumn{2}{|c|}{ yes } & basement & separate & \multicolumn{2}{|c|}{3} & \multicolumn{2}{|c|}{2} & - & cavity \\
\hline 47 & 1950 & no & yes & basement basement & separate & 0 & 0 & 0 & 0 & - & cavity \\
\hline 48 & 1951 & \multicolumn{2}{|c|}{ no } & basement & separate & \multicolumn{2}{|c|}{0} & \multicolumn{2}{|c|}{1} & - & cavity \\
\hline 49 & 1953 & \multicolumn{2}{|c|}{ yes } & basement & separate & & 2 & & & - & cavity \\
\hline 50 & 1954 & \multicolumn{2}{|c|}{ yes } & basement & separate & & 1 & & & - & cavity \\
\hline 51 & 1955 & & es & no & separate & & 1 & & & - & insul. cavity \\
\hline 52 & 1959 & & es & no & separate & & 2 & & & - & cavity \\
\hline 53 & 1963 & & & basement & separate & & 2 & & & - & cavity \\
\hline 54 & 1966 & & & no & separate & & 2 & & & - & cavity \\
\hline 55 & 1970 & & & no & separate & dis & garded & & & - & cavity \\
\hline 56 & 1973 & & es & no & separate & dis & zarded & & & - & cavity \\
\hline 57 & 1977 & yes & yes & no & open & 2 & 1 & 0 & 0 & basic (4 room) & insul. cavity \\
\hline 58 & 1981 & & es & no & open & & 0 & & & - & insul. cavity \\
\hline 59 & 1983 & & es & no & open & & 1 & & & - & insul. cavity \\
\hline 60 & 1987 & & es & basement & open & & 0 & & & - & insul. cavity \\
\hline 61 & 1992 & & es & no & open & & 2 & & & - & insul. cavity \\
\hline 62 & 1994 & & es & basement & open & & 2 & & & - & insulated \\
\hline 63 & 1996 & & es & basement & open & & 0 & & & - & insul. cavity \\
\hline 64 & 1998 & & es & basement & open & & 0 & & & - & insul. cavity \\
\hline 65 & 2006 & & es & no & open & & 3 & & & - & insul. cavity \\
\hline 66 & 2008 & & es & basement & open & & 0 & & & - & insul. cavity \\
\hline 67 & 2009 & & s & basement & open & & 1 & & & - & insul. cavity \\
\hline 68 & 2010 & & es & no & open & & 0 & & & - & insul. cavity \\
\hline
\end{tabular}




\begin{tabular}{|c|c|c|c|c|c|c|c|c|c|c|}
\hline \multirow[t]{2}{*}{ No. } & \multirow[t]{2}{*}{ year } & \multirow{2}{*}{ type of structure } & \multirow{2}{*}{$\begin{array}{c}\text { first floor } \\
\text { material/system }\end{array}$} & \multirow[t]{2}{*}{ type of roof } & \multicolumn{4}{|c|}{ material of insulation (mm) } & \multirow{2}{*}{$\begin{array}{c}\text { type of } \\
\text { sep. wall }\end{array}$} & \multirow{2}{*}{$\begin{array}{l}\text { sep. wall's } \\
\text { thickness }\end{array}$} \\
\hline & & & & & & wall & roof & floor & & \\
\hline 1 & 1900 & beams + walls + multiple span & wood & flat/single-slop. & wood & 0 & 0 & 0 & massive & $220 \mathrm{~mm}$ \\
\hline 2 & 1902 & beams + walls + multiple span & wood & flat/single-slop. & wood & 0 & 0 & 0 & massive & $220 \mathrm{~mm}$ \\
\hline 3 & 1911 & beams + walls + multiple span & wood & side-gabled & wood & 0 & 0 & 0 & massive & $220 \mathrm{~mm}$ \\
\hline 4 & 1913 & beams + walls + multiple span & wood & flat/single-slop. & wood & 0 & 0 & 0 & massive & $220 \mathrm{~mm}$ \\
\hline 5 & 1913 & beams + walls + multiple span & wood & flat & wood & 0 & 0 & 0 & massive & $220 \mathrm{~mm}$ \\
\hline 6 & 1922 & beams + walls + multiple span & wood & side-gabled & wood & 0 & 0 & 0 & massive & $180 \mathrm{~mm}$ \\
\hline 7 & 1923 & beams + walls + multiple span & wood & side-gabled & wood & 0 & 0 & 0 & massive & $220 \mathrm{~mm}$ \\
\hline 8 & 1923 & beams + walls + multiple span & wood & side-gabled & wood & 0 & 0 & 0 & massive & $220 \mathrm{~mm}$ \\
\hline 9 & 1930 & beams + walls + multiple span & wood & side-gabled & wood & 0 & 0 & 0 & massive & $220 \mathrm{~mm}$ \\
\hline 10 & 1938 & beams + walls + multiple span & wood & side-gabled & wood & 0 & 0 & 0 & massive & $220 \mathrm{~mm}$ \\
\hline 11 & 1939 & beams + walls + multiple span & wood & flat/single-slop. & wood & 0 & 0 & 0 & massive & $220 \mathrm{~mm}$ \\
\hline 12 & 1940 & beams + walls + multiple span & wood & side-gabled & wood & 0 & 0 & 0 & massive & $220 \mathrm{~mm}$ \\
\hline 13 & 1948 & slabs + walls + multiple span & "perfora" system & side-gabled & wood & 0 & 0 & 0 & massive & $220 \mathrm{~mm}$ \\
\hline 14 & 1949 & slabs + walls + multiple span & "perfora" system & & & 0 & 0 & 0 & massive & $220 \mathrm{~mm}$ \\
\hline 15 & 1950 & slabs + walls + multiple span & in-situ concrete & side-gabled & & 0 & 0 & 0 & massive & $200 \mathrm{~mm}$ \\
\hline 16 & 1951 & beams + posts + multiple span & steel & & & 25 & 8 & 0 & massive & $0 \mathrm{~mm}$ \\
\hline 17 & 1956 & beams + walls + multiple span & wood & side-gabled & wood & 0 & 0 & 0 & massive & $220 \mathrm{~mm}$ \\
\hline 18 & 1957 & slabs + walls + multiple span & “gemij" system & side-gabled & wood & 0 & 0 & 0 & massive & $220 \mathrm{~mm}$ \\
\hline 19 & 1959 & slabs + walls + multiple span & "isoliet" system & flat & wood & 0 & 50 & 0 & massive & $210 \mathrm{~mm}$ \\
\hline 20 & 1960 & slabs + walls + multiple span & "hollith" system & side-gabled & & 0 & 0 & 0 & massive & $220 \mathrm{~mm}$ \\
\hline 21 & 1965 & slabs + walls + multiple span & prefab con. slabs & side-gabled & & 0 & 30 & 0 & massive & $220 \mathrm{~mm}$ \\
\hline 22 & 1965 & slabs + walls + multiple span & in-situ concrete & flat & od & 0 & 0 & 0 & massive & $220 \mathrm{~mm}$ \\
\hline 23 & 1967 & slabs + walls + multiple span & in-situ concrete & side-gable & & 0 & 0 & 0 & oup. & $270 \mathrm{~mm}$ \\
\hline 24 & 1973 & slabs + walls + single span & in-situ concrete & flat & wood & 0 & 50 & 0 & massive & $240 \mathrm{~mm}$ \\
\hline 25 & 1977 & slabs + walls + single span & in-situ concrete & side-gabled & wood & 35 & 0 & 0 & massive & $180 \mathrm{~mm}$ \\
\hline 26 & 1978 & slabs + walls + single span & wide slab floor & front-gabled & & 40 & 40 & 0 & massive & $180 \mathrm{~mm}$ \\
\hline 27 & 1981 & slabs + walls + multiple span & "dato" system & side-gabled & wood & 40 & 40 & 0 & decoup. & $350 \mathrm{~mm}$ \\
\hline 28 & 1982 & slabs + walls + single span & in-situ concrete & side-gabled & wood & 40 & 40 & 0 & massive & $200 \mathrm{~mm}$ \\
\hline 29 & 1990 & slabs + walls + single span & in-situ concrete & front-gabled & wood & 70 & 75 & 100 & massive & $200 \mathrm{~mm}$ \\
\hline 30 & 1996 & slabs + walls + single span & wide slab floor & & wood & 75 & 100 & 100 & decoup. & $300 \mathrm{~mm}$ \\
\hline 31 & 1997 & slabs + walls + single span & wide slab floor & single-sloped & wood & 100 & 100 & 120 & massive & $230 \mathrm{~mm}$ \\
\hline 32 & 2000 & slabs + walls + single span & hollow chan. floor & hipped & wood & 120 & 196 & 150 & decoup. & $220 \mathrm{~mm}$ \\
\hline 33 & 2001 & slabs + walls + single span & hollow chan. floor & flat & concrete & 120 & 120 & 150 & decoup. & $220 \mathrm{~mm}$ \\
\hline 34 & 2005 & slabs + walls + single span & in-situ concrete & side-gabled & wood & 125 & 195 & 200 & massive & $250 \mathrm{~mm}$ \\
\hline 35 & 2005 & slabs + walls + single span & in-situ concrete & flat & concrete & 90 & 100 & 205 & massive & $250 \mathrm{~mm}$ \\
\hline 36 & 2006 & slabs + walls + single span & hollow chan. floor & flat & concrete & 100 & 100 & 200 & decoup. & $300 \mathrm{~mm}$ \\
\hline 37 & 2008 & slabs + walls + single span & hollow chan. floor & flat & concrete & 100 & 100 & 120 & decoup. & $300 \mathrm{~mm}$ \\
\hline
\end{tabular}




\begin{tabular}{|c|c|c|c|c|c|c|c|c|c|c|}
\hline No. & year & type of structure & $\begin{array}{c}\text { first floor } \\
\text { material/system }\end{array}$ & type of roof & $\begin{array}{l}\text { material of } \\
\text { roof struc. }\end{array}$ & $\begin{array}{l}\text { insul } \\
\text { wall }\end{array}$ & $\begin{array}{l}\text { ation } \\
\text { roof } \\
\end{array}$ & \begin{tabular}{|l|}
$(\mathrm{mm})$ \\
floor \\
\end{tabular} & $\begin{array}{c}\text { type of } \\
\text { sep. wall }\end{array}$ & $\begin{array}{l}\text { sep. wall's } \\
\text { thickness }\end{array}$ \\
\hline 38 & 1901 & beams + walls + multiple span & wood & flat/single-slop. & wood & 0 & 0 & 0 & massive & $220 \mathrm{~mm}$ \\
\hline 39 & 1907 & beams + walls + multiple span & wood & flat & wood & 0 & 0 & 0 & massive & $220 \mathrm{~mm}$ \\
\hline 40 & 1909 & beams + walls + multiple span & wood & flat/single-slop. & wood & 0 & 0 & 0 & massive & $220 \mathrm{~mm}$ \\
\hline 41 & 1912 & beams + walls + mixed span & wood & flat/single-slop. & wood & 0 & 0 & 0 & massive & $220 \mathrm{~mm}$ \\
\hline 42 & 1925 & slabs + walls + single span & st. beams/in-situ c. & side-gabled & wood & 0 & 0 & 0 & massive & $220 \mathrm{~mm}$ \\
\hline 43 & 1927 & beams + walls + multiple span & wood & side-gabled & wood & 0 & 0 & 0 & massive & $220 \mathrm{~mm}$ \\
\hline 44 & 1934 & beams + walls + multiple span & wood & side-gabled & wood & 0 & 0 & 0 & massive & $220 \mathrm{~mm}$ \\
\hline 45 & 1934 & beams + walls + multiple span & wood & side-gabled & wood & 0 & 0 & 0 & massive & $220 \mathrm{~mm}$ \\
\hline 46 & 1939 & beams + walls + multiple span & wood & side-gabled & wood & 0 & 0 & 0 & massive & $220 \mathrm{~mm}$ \\
\hline 47 & 1950 & slabs + walls + multiple span & in-situ concrete & side-gabled & wood & 0 & 0 & 0 & massive & $200 \mathrm{~mm}$ \\
\hline 48 & 1951 & slabs + walls + multiple span & "cusveller" system & side-gabled & wood & 0 & 50 & 0 & massive & $220 \mathrm{~mm}$ \\
\hline 49 & 1953 & slabs + walls + multiple span & "gemy" system & side-gabled & wood & 0 & 0 & 0 & massive & $220 \mathrm{~mm}$ \\
\hline 50 & 1954 & beams + walls + multiple span & wood & side-gabled & wood & 0 & 0 & 0 & massive & $220 \mathrm{~mm}$ \\
\hline 51 & 1955 & beams + posts + multiple span & steel & flat & steel & 25 & 22 & 0 & massive & $250 \mathrm{~mm}$ \\
\hline 52 & 1959 & slabs + walls + multiple span & "isoliet" system & flat & concrete & 0 & 0 & 0 & massive & $210 \mathrm{~mm}$ \\
\hline 53 & 1963 & slabs + walls + multiple span & in-situ concrete & flat & concrete & 0 & 50 & 0 & massive & $220 \mathrm{~mm}$ \\
\hline 54 & 1966 & slabs + walls + multiple span & "muwi" system & flat & concrete & 0 & 0 & 0 & massive & $210 \mathrm{~mm}$ \\
\hline 55 & 1970 & slabs + walls + multiple span & in-situ concrete & flat & concrete & 0 & 70 & 0 & massive & $220 \mathrm{~mm}$ \\
\hline 56 & 1973 & slabs + walls + multiple span & prefab con. slabs & flat & concrete & 0 & 0 & 0 & massive & $180 \mathrm{~mm}$ \\
\hline 57 & 1977 & slabs + walls + single span & wide slab floor & side-gabled & wood & 30 & 40 & 0 & massive & $180 \mathrm{~mm}$ \\
\hline 58 & 1981 & slabs + walls + single span & wide slab floor & single-sloped & wood & 40 & 30 & 0 & massive & $200 \mathrm{~mm}$ \\
\hline 59 & 1983 & slabs + walls + single span & wide slab floor & single-sloped & concrete & 40 & 0 & 40 & massive & $230 \mathrm{~mm}$ \\
\hline 60 & 1987 & slabs + walls + single span & wide slab floor & flat/single-slop. & - concrete & 40 & 40 & 50 & massive & $230 \mathrm{~mm}$ \\
\hline 61 & 1992 & slabs + walls + single span & in-situ concrete & flat & concrete & 70 & 110 & 40 & massive & $230 \mathrm{~mm}$ \\
\hline 62 & 1994 & slabs + mix + multiple span & in-situ concrete & flat & concrete & 90 & 60 & 0 & massive & $230 \mathrm{~mm}$ \\
\hline 63 & 1996 & slabs + walls + multiple span & wide slab floor & flat & concrete & 80 & 80 & 80 & massive & $250 \mathrm{~mm}$ \\
\hline 64 & 1998 & slabs + walls + single span & wide slab floor & flat & concrete & 80 & 80 & 75 & massive & $300 \mathrm{~mm}$ \\
\hline 65 & 2006 & slabs + walls + single span & wide slab floor & side-gabled & wood & 140 & 100 & 50 & massive & $180 \mathrm{~mm}$ \\
\hline 66 & 2008 & slabs + mix + multiple span & wide slab floor & flat & concrete & 170 & 120 & 160 & massive & $200 \mathrm{~mm}$ \\
\hline 67 & 2009 & slabs + walls + single span & wide slab floor & flat & concrete & 120 & 100 & 100 & massive & $300 \mathrm{~mm}$ \\
\hline 68 & 2010 & slabs + walls + multiple span & wide slab floor & single-sloped & concrete & 100 & 90 & 170 & massive & $300 \mathrm{~mm}$ \\
\hline
\end{tabular}



Appendix 2.

Design tactics' mentions. 


\begin{tabular}{|c|c|c|c|c|c|c|c|c|}
\hline source & page & mentions of a design tactic & 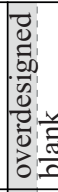 & $:$\begin{tabular}{c}
$:$ \\
\hdashline \\
\hdashline
\end{tabular} & & 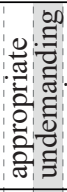 & $\stackrel{0}{2}$ & 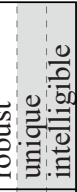 \\
\hline $\begin{array}{l}\text { Altan et al., } \\
2015\end{array}$ & :5493 & $\begin{array}{l}\text {...the off-center position [of the main entry] permits the creation of two } \\
\text { spaces, for big and small windows, a solution that allows a division of } \\
\text { the interior space in the future. }\end{array}$ & & & $\mathrm{x}$ & & & \\
\hline $\begin{array}{l}\text { Altan et al., } \\
2015\end{array}$ & 5493 & $\begin{array}{l}\text {...the bathroom found the right arrangements at the opposite side of the } \\
\text { central area. In this particular situation, an inflexible space such as the } \\
\text { bathroom, helped to create a distinct division of the apartment into three } \\
\text { different areas, and at the same time, the possibility of considering all } \\
\text { the remaining spaces as unique zones (Figure } 4 \mathrm{~b} \text { ). }\end{array}$ & ? & & & & & $\begin{array}{l}1 \\
? ? \\
?\end{array}$ \\
\hline $\begin{array}{l}\text { Altan et al., } \\
2015\end{array}$ & 5493 & $\begin{array}{l}\text { The positioning of the staircase and washroom... These are, in effect, } \\
\text { two inflexible elements that once placed cannot be easily moved... }\end{array}$ & & $\mathrm{x}$ & & & & \\
\hline $\begin{array}{l}\text { Altan et al., } \\
2015\end{array}$ & 5493 & $\begin{array}{l}\text { The washroom in the back might have an external window that would } \\
\text { also allow natural ventilation... }\end{array}$ & & & & $\mathrm{x}$ & & \\
\hline $\begin{array}{l}\text { Altan et al., } \\
2015\end{array}$ & 5493 & $\begin{array}{l}\text {...the stairs in that position creates an independent nucleus and a new } \\
\text { entry to the building, and to each independent level of the building. }\end{array}$ & & $\mathrm{x}$ & & & & \\
\hline $\begin{array}{l}\text { Altan et al., } \\
2015\end{array}$ & 5494 & $\begin{array}{l}\text { Tenants can convert different zones using sliding walls, i.e., sliding } \\
\text { walls for daily changes or through more or less flexible walls (Figure } \\
5 \mathrm{~b} \text { ). }\end{array}$ & & & & $\mathrm{x}$ & & \\
\hline $\begin{array}{l}\text { Altan et al., } \\
2015\end{array}$ & 5495 & $\begin{array}{l}\text { The internal space resulting from the division is a long and dynamic } \\
\text { space of } 48 \mathrm{~m} 2 \text { that can meet the needs of different tenants. }\end{array}$ & $\mathrm{x}$ & & & & & \\
\hline Arge, 2005 & 121 & $\begin{array}{l}\text { The most important measures giving high generality in office buildings } \\
\text { are: building width }- \text { allowing for different work place designs or } \\
\text { solutions; }\end{array}$ & $\mathrm{x}$ & & & & & \\
\hline Arge, 2005 & 121 & $\begin{array}{l}\text {...floor to floor height net }- \text { allowing for different work place designs } \\
\text { or solutions, for example, work stations across the whole floor; }\end{array}$ & $\mathrm{x}$ & & & & & \\
\hline Arge, 2005 & 121 & $\begin{array}{l}\text {...technical grid }- \text { allowing for different work place designs or } \\
\text { solutions. }\end{array}$ & & $\mathrm{x}$ & & & & \\
\hline Arge, 2005 & 121 & $\begin{array}{l}\text { In addition, raised floor... contribute to high generality in office } \\
\text { buildings. }\end{array}$ & & & & & $\mathrm{X}$ & \\
\hline Arge, 2005 & 121 & $\begin{array}{l}\text { In addition, ... zone based electrical and ICT service... contribute to high } \\
\text { generality in office buildings. }\end{array}$ & & $\mathrm{X}$ & & & & \\
\hline Arge, 2005 & 122 & $\begin{array}{l}\text { The most important measures giving high flexibility in office buildings } \\
\text { are: modularity - the most commonly used flexibility measure... }\end{array}$ & & & & $\mathrm{X}$ & & \\
\hline Arge, 2005 & 122 & $\begin{array}{l}\text {...plug and play building elements - allowing for fast changes of } \\
\text { layouts or technical services parts; }\end{array}$ & & & & & $\mathrm{x}$ & \\
\hline Arge, 2005 & 122 & $\begin{array}{l}\text {...flat... suspended ceiling }- \text { contributing to rapid and easy moving of } \\
\text { internal walls. }\end{array}$ & & $\mathrm{x}$ & & & & \\
\hline Arge, 2005 & 122 & $\begin{array}{l}\text {...soundproof suspended ceiling }- \text { contributing to rapid and easy } \\
\text { moving of internal walls. }\end{array}$ & $\mathrm{x}^{\prime}$ & & & & & \\
\hline Arge, 2005 & 122 & $\begin{array}{l}\text {...building form or organization of space }- \text { allowing for parts of the } \\
\text { building to be used by different organisations or user groups; }\end{array}$ & & & & & & \\
\hline Arge, 2005 & 122 & $\begin{array}{l}\text {...functional organisation }-\underline{\text { separating functions with different }} \\
\text { functional performance, allowing for the building to be used by } \\
\text { different organisations or user groups; }\end{array}$ & & & $\mathrm{x}$ & & & \\
\hline
\end{tabular}




\begin{tabular}{|c|c|c|c|c|c|c|c|c|c|c|}
\hline source & page & mentions of a design tactic & 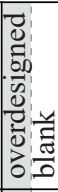 & & & 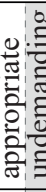 & & & & 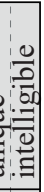 \\
\hline Arge, 2005 & 122 & $\begin{array}{l}\text { The most important measures giving high elasticity in office buildings } \\
\text { are:... fire sprinkling - allowing for continuous space units; }\end{array}$ & $x$ & & & & & & & \\
\hline Arge, 2005 & 122 & $\begin{array}{l}\text {...EIB/LonWorks - easing changes in the configuration of spaces to be } \\
\text { rented or sold. }\end{array}$ & $? ?$ & & & & & & & $?$ \\
\hline $\begin{array}{l}\text { Beisi and } \\
\text { Yingying, } 2011\end{array}$ & 20 & $\begin{array}{l}\text { The building's walls, unfettered by weight, could be extremely thin; } \\
\text { they could even be replaced by doors, windows, or pieces of furniture. }\end{array}$ & & & & & $\mathrm{X}$ & & & \\
\hline $\begin{array}{l}\text { Beisi and } \\
\text { Yingying, } 2011\end{array}$ & 22 & $\begin{array}{l}\text { Another equally important factor is the separation of the structure from } \\
\text { the enclosure. As a result, immense flexibility is created... }\end{array}$ & & & & $\mathrm{X}$ & $\mathrm{x}$ & & & \\
\hline $\begin{array}{l}\text { Beisi and } \\
\text { Yingying, } 2011\end{array}$ & 22 & $\begin{array}{l}\text {...the key to changing an element in an ancient building... is to support } \\
\text { the weight from the upside temporarily (Du, 1993)... [due to] the } \\
\text { systematic assembly of the elements of the structure. }\end{array}$ & & & & $\mathrm{x}$ & $\mathrm{x}$ & & & \\
\hline $\begin{array}{l}\text { Beisi and } \\
\text { Yingying, } 2011\end{array}$ & 22 & $\begin{array}{l}\text { Large woodwork... is composed of beams, columns, bracket sets, and } \\
\text { roofs that are connected without the use of nails (Figure 2)... All parts } \\
\text { of large woodwork can be changed independently. }\end{array}$ & & & & & $\mathrm{X}$ & & & \\
\hline $\begin{array}{l}\text { Beisi and } \\
\text { Yingying, } 2011\end{array}$ & $\begin{array}{l}23, \\
24\end{array}$ & $\begin{array}{l}\text {...spatial extension of the house is controlled by certain patterns that are } \\
\text { planned and designed at the start of construction... In short, interactive } \\
\text { influence between the house and the particular culture determines the } \\
\text { development pattern of a house. }\end{array}$ & $?$ & ? & & & & & & $?$ \\
\hline $\begin{array}{l}\text { Beisi and } \\
\text { Yingying, } 2011\end{array}$ & 24 & $\begin{array}{l}\text { This represents another characteristic of Chinese traditional buildings: } \\
\text { neutrality of space... [example] The name of the left-wing of the back } \\
\text { hall depended on the activity held in it... }\end{array}$ & & $\mathrm{X}$ & & & & & & \\
\hline $\begin{array}{l}\text { Beisi and } \\
\text { Yingying, } 2011\end{array}$ & 25 & $\begin{array}{l}\text { Differences in function as bedroom, living room, and hall were only } \\
\text { evident } \underline{\text { in }} \text { the types of furniture placed within the rooms while a similar } \\
\text { spatial dimension was shared (Jia \& Wang, 1998:3-4). }\end{array}$ & & $\mathrm{x}$ & & & & & & \\
\hline $\begin{array}{l}\text { Beisi and } \\
\text { Yingying, } 2011\end{array}$ & 27 & $\begin{array}{l}\text { Standardization... existed among parts of a single building... As all part } \\
\text { sizes were confirmed by a certain modulus unit... all parts could be } \\
\text { manufactured offsite. }\end{array}$ & & $\mathrm{x}$ & & & & & & \\
\hline $\begin{array}{l}\text { Beisi and } \\
\text { Yingying, } 2011\end{array}$ & 28 & $\begin{array}{l}\text { The separation of two levels, large woodwork, and small woodwork } \\
\text { allows Chinese traditional buildings to be changeable and flexible. }\end{array}$ & & & & & $\mathrm{x}$ & & & \\
\hline $\begin{array}{l}\text { Beisi and } \\
\text { Yingying, } 2011\end{array}$ & 29 & $\begin{array}{l}\text { A... building with fixed components will only shorten its life span } \\
\text { because of functional deterioration. An alternative solution is to divide } \\
\text { the structure into different levels... }\end{array}$ & & & & & $\mathrm{X}$ & & & \\
\hline $\begin{array}{l}\text { Beisi and } \\
\text { Yingying, } 2011\end{array}$ & $\begin{array}{l}28- \\
29\end{array}$ & $\begin{array}{l}\text {...standardization, which provided great possibilities in the develop- } \\
\text { ment of infill components. }\end{array}$ & & & & & & & & $x$ \\
\hline $\begin{array}{l}\text { Beisi and } \\
\text { Yingying, } 2011\end{array}$ & 30 & $\begin{array}{l}\text {...these [standardization and industrialization] may be considered as... } \underline{\text { a }} \\
\text { way to pay greater attention to the specific design of certain } \\
\text { components. }\end{array}$ & & & & & & & & $x$ \\
\hline $\begin{array}{l}\text { Belausteguigoi- } \\
\text { tia et al., } 2011\end{array}$ & 95 & $\begin{array}{l}\text {...it is the great structures... what enables a physical polyvalence to host } \\
\text { a variety of uses. }\end{array}$ & $\mathrm{X}$ & & & & & & & \\
\hline $\begin{array}{l}\text { Belausteguigoi- } \\
\text { tia et al., } 2011\end{array}$ & 95 & $\begin{array}{l}\text {...it is the... absence of partitions what enables a physical polyvalence to } \\
\text { host a variety of uses. }\end{array}$ & $\mathrm{x}$ & & & & & & & \\
\hline $\begin{array}{l}\text { Belausteguigoi- } \\
\text { tia et al., } 2011\end{array}$ & 96 & $\begin{array}{l}\text {....are built with post and beam concrete structures... and could } \\
\text { therefore allow for change in the floor plan layout. }\end{array}$ & $\mathrm{X}$ & & & & & & & \\
\hline
\end{tabular}




\begin{tabular}{|c|c|c|c|c|c|c|c|c|c|}
\hline source & page & mentions of a design tactic & 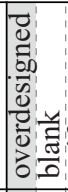 & & & 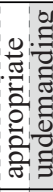 & & & $\frac{0}{0}$ \\
\hline $\begin{array}{l}\text { Belausteguigoi- } \\
\text { tia et al., } 2011\end{array}$ & 96 & 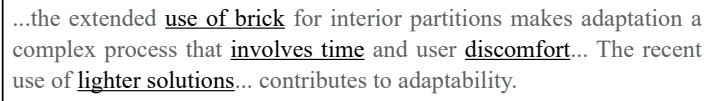 & & & & & $x$ & & \\
\hline $\begin{array}{l}\text { Belausteguigoi- } \\
\text { tia et al., } 2011\end{array}$ & 98 & $\begin{array}{l}\text {...those with less structural elements in plan provide the maximum } \\
\text { adaptability to different user-activities... a clear plan with few master } \\
\text { partitions enables versatility for a variety of uses... }\end{array}$ & $x$ & & & & & & \\
\hline $\begin{array}{l}\text { Belausteguigoi- } \\
\text { tia et al., } 2011\end{array}$ & 98 & $\begin{array}{l}\text {...off-site industrialized systems... allows buildings to grow or reduce in } \\
\text { size according to their needs, with little impact for their inhabitants. }\end{array}$ & & & & & $x$ & & \\
\hline $\begin{array}{l}\text { Belausteguigoi- } \\
\text { tia et al., } 2011\end{array}$ & 98 & $\begin{array}{l}\text { These [open building] systems are... able to be collocated in different } \\
\text { types of buildings... and in different contexts; usually make use of } \\
\text { pretentiously universal joints, delimited modular ranges... }\end{array}$ & & $x$ & & & & & \\
\hline $\begin{array}{l}\text { Belausteguigoi- } \\
\text { tia et al., } 2011\end{array}$ & 99 & $\begin{array}{l}\text { The choice of modules only consisting of the minimum number of } \\
\text { pillars is the cornerstone to provide an adaptable space. }\end{array}$ & $\mathrm{x}$ & & & & & & \\
\hline $\begin{array}{l}\text { Belausteguigoi- } \\
\text { tia et al., } 2011\end{array}$ & 101 & $\begin{array}{l}\text {...bathrooms... poses a certain design limitation, as, once built, these } \\
\text { elements prevail throughout the different plan distributions. }\end{array}$ & $\mathrm{x}$ & & & & & & \\
\hline $\begin{array}{l}\text { Belausteguigoi- } \\
\text { tia et al., } 2011\end{array}$ & 101 & $\begin{array}{l}\text { Interior partitions are made up of industrialized plaster boards that offer } \\
\text { a simple assembly and are able to be taken entirely apart... }\end{array}$ & & & & & & & $X$ \\
\hline $\begin{array}{l}\text { Belausteguigoi- } \\
\text { tia et al., } 2011\end{array}$ & 101 & $\begin{array}{l}\text {....although partitions do have to follow the modules to a certain degree. } \\
\text { This can be considered a design limitation. }\end{array}$ & $x$ & & & & & & \\
\hline Brand, 1994 & 13 & $\begin{array}{l}\text { Many buildings are demolished early if their outdated systems are too } \\
\text { deeply embedded to replace easily. }\end{array}$ & & & & $\mathrm{X}$ & & & \\
\hline Brand, 1994 & 18 & $\begin{array}{l}\text {... it] is kept adaptable... by its modest lot size... [when] property } \\
\text { remains in many hands... many people make many different decisions, } \\
\text { thereby ensuring variety in the resulting environment. }\end{array}$ & & & $\mathrm{X}$ & & & & \\
\hline Brand, 1994 & 20 & $\begin{array}{l}\text { An adaptive building has to allow slippage between the different- } \\
\text { ly-paced systems... Otherwise the slow systems block the flow of the } \\
\text { quick ones, and the quick ones tear up the slow ones... }\end{array}$ & & & & $\mathrm{X}$ & & & \\
\hline Brand, 1994 & 20 & $\begin{array}{l}\text { Timber-frame buildings... conveniently separate Structure, Skin, and } \\
\text { Services, while balloon-frame... over-connects them. }\end{array}$ & & & & $\mathrm{X}$ & & & \\
\hline Brand, 1994 & 23 & $\begin{array}{l}\text { Or the building may be blessed with durable construction and resilient } \\
\text { design which can forgive insult and hard swerves of usage. }\end{array}$ & & & & & & $\mathrm{X}$ & \\
\hline Brand, 1994 & 24 & $\begin{array}{l}\text { They can't wait to... put it [the space] immediately to work. What these } \\
\text { buildings have in common is that they are... spacious. }\end{array}$ & $\mathrm{x}$ & & & & & & \\
\hline Brand, 1994 & 24 & $\begin{array}{l}\text {...its } 3000 \text {-square-foot space column-free... [others] found the space } \\
\text { easily converted to their special needs. }\end{array}$ & $\mathrm{x}$ & & & & & & \\
\hline Brand, 1994 & 24 & $\begin{array}{l}\text { The building was too humble for anyone to worry about whether they } \\
\text { were violating its historical or aesthetic integrity. }\end{array}$ & $x$ & & & & & & \\
\hline Brand, 1994 & 60 & $\begin{array}{l}\text { Redefining space inside [domes] was } \underline{\text { difficult }} \text {, adding anything to the } \\
\text { outside nearly impossible }- \text { a cut-and-try process... }\end{array}$ & & & & $\mathrm{x}$ & & & \\
\hline Brand, 1994 & 60 & $\begin{array}{l}\text { Worst of all, domes couldn't grow or adapt... a cut-and-try process of } \\
\text { matching compound angles and curves. }\end{array}$ & & & & $x$ & & & \\
\hline Brand, 1994 & 60 & $\begin{array}{l}\text { [octagon-shaped] Like domes, they proved awkward to subdivide or } \\
\text { add to... }\end{array}$ & & & & $\mathrm{X}$ & & & \\
\hline
\end{tabular}




\begin{tabular}{|c|c|c|c|c|c|c|c|c|c|c|}
\hline source & page & mentions of a design tactic & 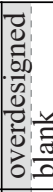 & & & & & & & 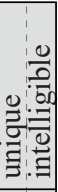 \\
\hline Brand, 1994 & $\begin{array}{c}60- \\
61\end{array}$ & $\begin{array}{l}\text { Right-angled shapes nest and tile with each other universally,... The } \\
\text { "specious old box" is old because it is profoundly adaptive. }\end{array}$ & & $\mathrm{X}$ & & & & & & \\
\hline Brand, 1994 & 74 & $\begin{array}{l}\text { The codes... requiring heavy-duty wiring in case more electricity is } \\
\text { needed later, strong walls in case extra stories are added later... }\end{array}$ & $x$ & & & & & & & \\
\hline Brand, 1994 & 75 & $\begin{array}{l}\text { Small lots give greater individual control and thus greater variety... The } \\
\text { more owners, the more gradual and adaptive the ongoing change. }\end{array}$ & & & $\mathrm{X}$ & & & & & \\
\hline Brand, 1994 & 80 & $\begin{array}{l}\text {... do you want the prospective buyer to see... [a neighbouring house } \\
\text { with] a metal roof instead of tile, or a nonstandard dormer sticking out? } \\
\text { Well, if they can't, you can't. This... prevents buildings from... getting } \\
\text { better with time. }\end{array}$ & & & $\mathrm{X}$ & & & & & \\
\hline Brand, 1994 & 89 & $\begin{array}{l}\text { Large houses are exceptionally skilled at being comfortable, being } \\
\text { loved, and being adaptable... }\end{array}$ & $x$ & & & & & & & \\
\hline Brand, 1994 & 89 & $\begin{array}{l}\text { Large houses are exceptionally skilled at being comfortable, being } \\
\text { loved, and being adaptable... }\end{array}$ & & & & $\mathrm{X}$ & & & & \\
\hline Brand, 1994 & 104 & $\begin{array}{l}\text { The best buildings are... those that are strong enough to retain their } \\
\text { character as they accommodate different functions over time." }\end{array}$ & & & & & & & & $\mathrm{x}$ \\
\hline Brand, 1994 & 108 & $\begin{array}{l}\text { Some kinds of buildings are impossible... to find new uses for, usually } \\
\text { because they are too specialized or too large... [e.g.] Theatres have a } \\
\text { huge, oddly segmented space with few horizontal surfaces... }\end{array}$ & & & & $\mathrm{X}$ & & & & \\
\hline Brand, 1994 & 108 & $\begin{array}{l}\text { Houses are the one species of building most thoroughly coevolved with } \\
\text { human use, and that congeniality carries over... }\end{array}$ & & & & $\mathrm{X}$ & & & & \\
\hline Brand, 1994 & $\begin{array}{l}108- \\
109\end{array}$ & $\begin{array}{l}\text { Warehouses and factories... built between } 1860 \text { and } 1930 \text { are endlessly } \\
\text { adaptable. They are broad,... and high ceilings of } 12 \text { to } 18 \text { feet. The } \\
\text { floors, built strong enough for storage... can handle any new use... }\end{array}$ & $x$ & & & & & & & \\
\hline Brand, 1994 & $\begin{array}{l}108- \\
109\end{array}$ & $\begin{array}{l}\text { Warehouses and factories... built between } 1860 \text { and } 1930 \text { are endlessly } \\
\text { adaptable. They are... clear-spanned or widely columned... }\end{array}$ & $x$ & & & & & & & \\
\hline Brand, 1994 & 108 & $\begin{array}{l}\text { Warehouses and factories... built between } 1860 \text { and } 1930 \text { are endlessly } \\
\text { adaptable. They are... with good natural illumination and ventilation... } \\
\text { Architectural ornament... is... } \underline{\text { modest and therefore appreciated. }}\end{array}$ & & & & $\mathrm{X}$ & & & & \\
\hline Brand, 1994 & 109 & $\begin{array}{l}\text { Another trait that invites longevity is strangeness. Almost any } \\
\text { sufficiently odd building that has a modicum of functionality... will } \\
\text { attract supportive community bemusement... }\end{array}$ & & & & & & & & $\mathbf{X}$ \\
\hline Brand, 1994 & 113 & $\begin{array}{l}\text {...buildings look and feel increasingly like movie sets: impressive to the } \\
\text { eye, flimsy to the touch, and incapable of aging well. }\end{array}$ & & & & & & & & \\
\hline Brand, 1994 & 115 & $\begin{array}{l}\text { The simpler the roof, the better. Chimneys... and other complications all } \\
\text { invite problems with flashing, and the make reroofing difficult. }\end{array}$ & & & & & & & & $\mathrm{x}$ \\
\hline Brand, 1994 & 120 & $\begin{array}{l}\text { Who builds in wood builds a shack... The exception is timber-framed } \\
\text { buildings... it is massive,... }\end{array}$ & & & & & & & & \\
\hline Brand, 1994 & 120 & $\begin{array}{l}\text {...adaptable now, gone soon. The exception is timber-framed } \\
\text { buildings... it is exposed. Air and eyeballs can get at it to keep it dry and } \\
\text { inspected. }\end{array}$ & & & & & & & & $x$ \\
\hline Brand, 1994 & 125 & $\begin{array}{l}\text { Concrete is so solid and so laced with steel reinforcing that cutting a } \\
\text { new door or window is virtually unthinkable. }\end{array}$ & & & & & & $\mathrm{x}$ & & \\
\hline
\end{tabular}




\begin{tabular}{|c|c|c|c|c|c|c|c|c|c|c|}
\hline source & page & mentions of a design tactic & 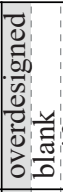 & $\begin{array}{l} \\
\vdots \\
0 \\
0 \\
0 \\
0 \\
0 \\
0\end{array}$ & & 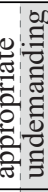 & & & & 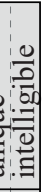 \\
\hline Brand, 1994 & 126 & $\begin{array}{l}\text { Wood and brick walls invite change by involving us in their upkeep. } \\
\text { What begins as repair easily becomes improvement... }\end{array}$ & & & & & & & & $x$ \\
\hline Brand, 1994 & 127 & $\begin{array}{l}\text {...the building wears down so fast... solidifying stud construction a bit } \\
\text { more may get a better result. }\end{array}$ & & & & & & $\mathrm{x}$ & & \\
\hline Brand, 1994 & 129 & $\begin{array}{l}\text {...whose systems and materials are intuitively obvious, }, . . \text { As they } \\
\text { become more complicated,... [they] require the attention of } \underline{\text { specialists }} \\
\text { to inspect and maintain... }\end{array}$ & & & & & & & & $x$ \\
\hline Brand, 1994 & 129 & $\begin{array}{l}\text { Too much is invisible }- \text { the pressure regulator in the gas meter, the rot } \\
\text { in the walls, the location of the short circuit... }\end{array}$ & & & & & & & & $x$ \\
\hline Brand, 1994 & 134 & $\begin{array}{l}\text {...columns articulate space in a way that makes people feel comfortable } \\
\text { making and remaking... You can always visualize what you might do... } \\
\text { huge free-span interior spaces is... a loss for intuitive adaptability. }\end{array}$ & & & & & & & & $x$ \\
\hline Brand, 1994 & 134 & $\begin{array}{l}\text { The identical bays... and the additive identical rooms... had been found } \\
\text { to be the most inexpensively adaptable over time... }\end{array}$ & & $\mathrm{X}$ & & & & & & \\
\hline Brand, 1994 & 139 & $\begin{array}{l}\text { Medium to large houses survived the best, because there is always use } \\
\text { for them.... Everybody can find a use for a } 12 \text { - or } 14 \text { foot-square } \\
\text { building. }\end{array}$ & & & & $\mathrm{X}$ & & & & \\
\hline Brand, 1994 & 139 & $\begin{array}{l}\text { Medium to large houses survived the best... Small houses were built } \\
\text { shoddy and } \underline{\text { disposable... }}\end{array}$ & & & & & & $\mathrm{x}$ & & \\
\hline Brand, 1994 & 139 & Barns survived fairly well, thanks to being solidly constructed... & & & & & & $\mathrm{x}$ & & i \\
\hline Brand, 1994 & 150 & Specialized knowledge distances buildings from users. & & & & & & & & $x$ \\
\hline Brand, 1994 & 150 & Specialized space hinders future flexibility. & & & & $x^{\prime}$ & & & & \\
\hline Brand, 1994 & 150 & ... devoid of interruption or ornament... made it... easy to add to. & $\mathrm{x}$ & & & & & & & $:$ \\
\hline Brand, 1994 & 150 & $\begin{array}{l}\text { The roof's simplicity made it leak-free, cheap to build and maintain, } \\
\text { and easy to add to. }\end{array}$ & & & & & & & & $x$ \\
\hline Brand, 1994 & 151 & $\begin{array}{l}\text { What are the traits, then, that selection preferred... It looks respectable } \\
\text { but stands apart from fashion, secure in the conservatism... }\end{array}$ & & & & $\mathrm{X}$ & & & & \\
\hline Brand, 1994 & 155 & $\begin{array}{l}\text { So long as people of modest means outnumber the rich, small will } \\
\text { always win. }\end{array}$ & & & & $\mathrm{x}$ & & & & \\
\hline Brand, 1994 & $\begin{array}{l}162- \\
163\end{array}$ & $\begin{array}{l}\text {...the easiest, } \text {, cheapest and quietest direction [to expand]... is into } \\
\text { existing "raw" space whose initial function is deemed dispensable... }\end{array}$ & & & & & $\mathrm{x}$ & & & \\
\hline Brand, 1994 & $\begin{array}{l}162- \\
163\end{array}$ & Houses evidently need more low-definition space for later expansion... & $\mathrm{X}$ & & & & & & & \\
\hline Brand, 1994 & 163 & $\begin{array}{l}\text { Another frequent error is installing built-in furniture... Soon enough } \\
\text { you have to demolish the walls to move the furniture. }\end{array}$ & & & & $\mathrm{X}$ & & & & \\
\hline Brand, 1994 & 169 & $\begin{array}{l}\text {... standing on an old chair } \\
\text { stringing } 100 \text { feet of... telephone wire... through the dropped ceiling... }\end{array}$ & & & & & $\mathrm{x}$ & & & \\
\hline Brand, 1994 & 170 & $\begin{array}{l}\text { Their floor-to-ceiling height was too low. There was no room for both a } \\
\text { dropped ceiling and a raised floor, and no way to fix the problem. }\end{array}$ & $\mathbf{x}$ & & & & & & & \\
\hline Brand, 1994 & 171 & $\begin{array}{l}\text { When the trends moved on, the buildings were left standing... Their } \\
\text { failure is the failure of optimization as a design strategy. }\end{array}$ & & & & $\mathrm{X}$ & & & & \\
\hline
\end{tabular}




\begin{tabular}{|c|c|c|c|c|c|c|c|c|c|c|}
\hline source & page & mentions of a design tactic & 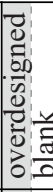 & & & & & & & 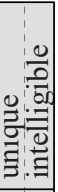 \\
\hline Brand, 1994 & 174 & $\begin{array}{l}\text { Their high ceilings, daylit shallow depth, and openable windows turned } \\
\text { from embarrassments back into virtues without benefit of intent. }\end{array}$ & & & & $\mathrm{X}$ & & & & \\
\hline Brand, 1994 & $\begin{array}{l}174- \\
175\end{array}$ & $\begin{array}{l}\text {...humane design } . . . \text { Modest depth, high ceilings, } \text { operable windows, }, . . \\
\text { and individually controllable amenities such as window awnings. }\end{array}$ & & & & $\mathrm{X}$ & & & & \\
\hline Brand, 1994 & $\begin{array}{l}174- \\
175\end{array}$ & $\begin{array}{l}\text {... any new office building he designs be potentially convertible into } \\
\text { housing... [due to] massive construction... }\end{array}$ & $\mathrm{x}$ & & & & & & & \\
\hline Brand, 1994 & $\begin{array}{l}174- \\
175\end{array}$ & $\begin{array}{l}\text {... any new office building he designs be potentially convertible into } \\
\text { housing... [due to] raised floor rather than dropped ceiling for services.. }\end{array}$ & & & & & & $\mathrm{X}$ & & \\
\hline Brand, 1994 & 176 & So MIT's Main Building... [a] narrow 64 feet wide - just right... & & & & $x$ & & & & \\
\hline Brand, 1994 & 176 & $\begin{array}{l}\text {...64 feet wide - just right for a wide corridor in the middle, with space } \\
\text { for a variety of [spaces]... (A later MIT building of 55-foot width was } \\
\text { found to be inflexibly restrictive.) }\end{array}$ & $\mathrm{x}$ & & & & & & & \\
\hline Brand, 1994 & 179 & $\begin{array}{l}\ldots[\mathrm{It}] \text { is burdened with... expensive overspecified spaces, such as... } \\
\text { rooms designed for... research that was no longer even going on... }\end{array}$ & & & & $\mathrm{X}$ & & & & \\
\hline Brand, 1994 & 186 & $\begin{array}{l}\text {...overbuild Structure... provide } \underline{\text { excess }} \text { Services capacity; go for } \\
\text { oversize ("loose fit") rather than differently. }\end{array}$ & $\mathrm{x}$ & & & & & & & \\
\hline Brand, 1994 & 186 & $\begin{array}{l}\text { "Use materials from near at hand,"... "They'll be easier to match or } \\
\text { replace." }\end{array}$ & & & & & & $\mathrm{X}$ & & \\
\hline Brand, 1994 & 186 & $\begin{array}{l}\text { A spatially diverse building is easier to make use adjustments in than a } \\
\text { spatially monotonous one - people can just move around. }\end{array}$ & & & $\mathrm{X}$ & & & & & \\
\hline Brand, 1994 & 187 & $\begin{array}{l}\text { The most convenient form of expansion is cellular... made up of a series } \\
\text { of bays... If the company expands... take over its [a neighbour's] } \\
\text { space... In hard times, shrink back... }\end{array}$ & & $\mathrm{X}$ & & & & & & \\
\hline Brand, 1994 & 191 & $\begin{array}{l}\text { COLUMNS... make it easy to imagine changes, easy to put them in, } \\
\text { easy to remove them. }\end{array}$ & & & & & & & & $x$ \\
\hline Brand, 1994 & 192 & 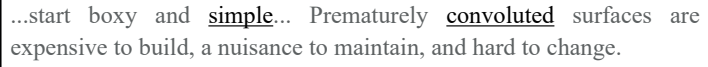 & & & & & & & & $\mathrm{x}$ \\
\hline Brand, 1994 & $\begin{array}{l}192- \\
193\end{array}$ & $\begin{array}{l}\text { The generous width [six feet on average] of the hall is also the major } \\
\text { reason for the inherent flexibility of the box. }{ }^{3}\end{array}$ & $\mathrm{x}$ & & & & & & & \\
\hline Brand, 1994 & 193 & $\begin{array}{l}\text { Each is lit and ventilated... each has access to the corridor, each is } \\
\text { capable of opening into adjoining rooms... simple, autonomous rooms } \\
\text { can be constantly readapted without stress to the building. }\end{array}$ & & $\mathrm{X}$ & & & & & & \\
\hline Brand, 1994 & $\begin{array}{l}194- \\
195\end{array}$ & $\begin{array}{l}\text { Wood is already the most adaptive of all building materials because } \\
\text { amateurs are comfortable messing with it... }\end{array}$ & & & & & & & & $x$ \\
\hline Brand, 1994 & $\begin{array}{l}194- \\
195\end{array}$ & $\begin{array}{l}\text { Timber frame was the original design-for-disassembly building } \\
\text { material - just knock out the pegs... }\end{array}$ & & & & & & $\mathrm{X}$ & & \\
\hline Brand, 1994 & 195 & $\begin{array}{l}\text { Roofs that are built fussy at the beginning are an obstacle to later } \\
\text { change. }\end{array}$ & $\mathrm{x}$ & & & & & & & \\
\hline Brand, 1994 & 195 & 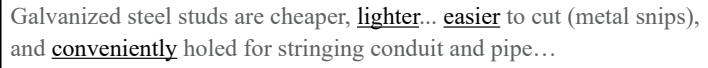 & & & & & & $\mathrm{X}$ & & \\
\hline Brand, 1994 & 195 & They [galvanized steel studs] take less skill to work with than wood... & & & & & & & & \\
\hline
\end{tabular}




\begin{tabular}{|c|c|c|c|c|c|c|c|c|c|c|}
\hline source & page & mentions of a design tactic & 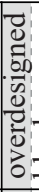 & & & & & & & 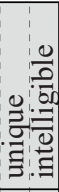 \\
\hline Brand, 1994 & 195 & 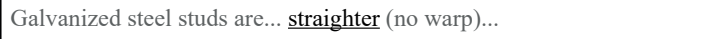 & & & $\mathrm{x}$ & & & & & \\
\hline Brand, 1994 & 196 & $\begin{array}{l}\text {...keeping Services separate from Skin as well as from Structure... } \\
\text { hiding wires and pipes in walls makes maintenance and improvement a } \\
\text { major hassle... }\end{array}$ & & & & & $\mathrm{X}$ & & & \\
\hline Brand, 1994 & 196 & $\begin{array}{l}\text {...installing over-capacity electrical feeders and breakers, } \underline{\text { oversize }} \\
\text { chases, and an apparent excess of outlets is nearly always rewarded. }\end{array}$ & $\mathrm{x}$ & & & & & & & \\
\hline Brand, 1994 & 196 & $\begin{array}{l}\text { The general rule is: oversize your components... All new buildings } \\
\text { should have extra conduit laid throughout... }\end{array}$ & $\mathrm{x}$ & & & & & & & \\
\hline Brand, 1994 & 203 & $\begin{array}{l}\text { Buildings that last are made of quality materials and with quality } \\
\text { craftsmanship... [it pays] in terms of durability and flexibility. }\end{array}$ & & & & & & & $\mathrm{X}$ & \\
\hline Brand, 1994 & 206 & $\begin{array}{l}\text {...part... lovingly and carefully ... and... parts... very roughly... the } \\
\text { compensation between the two is necessary in a real thing." Undifferen- } \\
\text { tiated, unpartitioned, unspecialized... spaces are essential. }\end{array}$ & & & & X & & & & \\
\hline Brand, 1994 & 208 & $\begin{array}{l}\text {...people's dislike of grossly pure shapes... "simple shapes are inhuman. } \\
\text { They fail to resonate with the way nature organizes itself... }\end{array}$ & & & & X & & & & \\
\hline $\begin{array}{l}\text { Bruce et al., } \\
2015\end{array}$ & 151 & $\begin{array}{l}\text {...some structures... can... provoke a demand for retrofitting purely } \\
\text { through their architectural and historical merit... }\end{array}$ & & & & & & & & $\mathbf{X}$ \\
\hline $\begin{array}{l}\text { Bruce et al., } \\
2015\end{array}$ & 151 & $\begin{array}{l}\ldots \text {... } \text { some] buildings... cannot be easily demolished due to their proximi- } \\
\text { ty to... [others] as well as sharing common footings with... [others] }\end{array}$ & & & & & & $\mathrm{X}$ & & \\
\hline $\begin{array}{l}\text { Bruce et al., } \\
2015\end{array}$ & 160 & $\begin{array}{l}\text {...the quality of the building's internal structure and the durability of the } \\
\text { materials that it was initially constructed from are very important... }\end{array}$ & & & & & & & & \\
\hline $\begin{array}{l}\text { Bruce et al., } \\
2015\end{array}$ & 160 & $\begin{array}{l}\text {...the layout of the structural system.... are all factors that can seriously } \\
\text { restrict the end use of the building. }\end{array}$ & & X & & & & & & \\
\hline $\begin{array}{l}\text { Bruce et al., } \\
2015\end{array}$ & 160 & $\begin{array}{l}\text {...the... floor to ceiling heights... are all factors that can seriously restrict } \\
\text { the end use of the building. }\end{array}$ & $\mathrm{X}$ & & & & & & & \\
\hline $\begin{array}{l}\text { Bruce et al., } \\
2015\end{array}$ & 160 & $\begin{array}{l}\text {...windows could present a barrier to retrofitting of multi-storey } \\
\text { building and the ease of replacement would be an important factor. }\end{array}$ & & & & & X & & & \\
\hline $\begin{array}{l}\text { Bruce et al., } \\
2015\end{array}$ & 160 & $\begin{array}{l}\text {...tenants and investors are now looking for large.... spaces and do not } \\
\text { want columns and walls restricting their floor plans. }\end{array}$ & $\mathrm{X}$ & & & & & & & \\
\hline $\begin{array}{l}\text { Bruce et al., } \\
2015\end{array}$ & 160 & $\begin{array}{l}\text {...tenants and investors are now looking for... open spaces and do not } \\
\text { want columns and walls restricting their floor plans. }\end{array}$ & & X & & & & & & \\
\hline $\begin{array}{l}\text { Bullen and } \\
\text { Love, 2011a }\end{array}$ & 34 & $\begin{array}{l}\text { When considering a building for adaptive reuse it is essential to } \\
\text { examine the... condition of... systems... }\end{array}$ & & & & & & & & \\
\hline $\begin{array}{l}\text { Bullen and } \\
\text { Love, 2011a }\end{array}$ & 34 & $\begin{array}{l}\text { When considering a building for adaptive reuse it is essential to } \\
\text { examine the... their [systems'] capacity for modification; }\end{array}$ & $\mathrm{X}$ & & & & & & & \\
\hline $\begin{array}{l}\text { Bullen and } \\
\text { Love, 2011a }\end{array}$ & 34 & $\begin{array}{l}\text { When considering a building for adaptive reuse... examine the... } \\
\text { building's structural layout and its capacity to accommodate required } \\
\text { spaces and functions; }\end{array}$ & & $\mathrm{X}$ & & & & & & \\
\hline $\begin{array}{l}\text { Bullen and } \\
\text { Love, 2011a }\end{array}$ & 39 & $\begin{array}{l}\text { Buildings such as a prison would not present many opportunities for } \\
\text { reuse due to extensive compartmentalization. }\end{array}$ & & $\mathrm{X}$ & & & & & & \\
\hline $\begin{array}{l}\text { Bullen and } \\
\text { Love, 2011a }\end{array}$ & 39 & $\begin{array}{l}\text {... low-rise buildings... did not... utilize the available plot ratio or } \\
\text { zoning... a greater financial return may be obtained from... high-rise... }\end{array}$ & & & & $\mathrm{X}$ & & & & \\
\hline
\end{tabular}




\begin{tabular}{|c|c|c|c|c|c|c|c|c|c|c|}
\hline source & page & mentions of a design tactic & 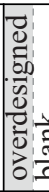 & & & & & & & $\frac{0}{0}$ \\
\hline $\begin{array}{l}\text { Bullen and } \\
\text { Love, 2011a }\end{array}$ & 39 & $\begin{array}{l}\text { Small cottages in a terrace would be extremely hard to adapt due to } \\
\text { limitations of space. }\end{array}$ & $\mathrm{x}$ & & & & & & & \\
\hline $\begin{array}{l}\text { Bullen and } \\
\text { Love, 2011a }\end{array}$ & 39 & $\begin{array}{l}\text { Large steel sheds... while spacious may generate little value for } \\
\text { retention... }\end{array}$ & $x$ & & & & & & & \\
\hline $\begin{array}{l}\text { Bullen and } \\
\text { Love, 2011a }\end{array}$ & 39 & $\begin{array}{l}\text { Large steel sheds... may generate little value for retention as they are } \\
\text { too specialized. }\end{array}$ & & & & & & & & \\
\hline $\begin{array}{l}\text { Bullen and } \\
\text { Love, 2011a }\end{array}$ & 39 & $\begin{array}{l}\text { Unless a built asset has some redeeming esthetic features... its reuse } \\
\text { may not be an... option. }\end{array}$ & & & & & & & & $\mathbf{X}_{1}^{1}$ \\
\hline $\begin{array}{l}\text { Bullen and } \\
\text { Love, 2011a }\end{array}$ & 40 & $\begin{array}{l}\text { Conversion... to a functional new building was ultimately influenced by } \\
\text { its structural integrity... }\end{array}$ & & & & & & & $\mathrm{X}$ & \\
\hline $\begin{array}{l}\text { Bullen and } \\
\text { Love, 2011a }\end{array}$ & 40 & $\begin{array}{l}\text { Conversion... to a functional new building was ultimately influenced by } \\
\text { its... spatial layout... }\end{array}$ & & $\mathrm{X}$ & & & & & & \\
\hline $\begin{array}{l}\text { Bullen and } \\
\text { Love, 2011a }\end{array}$ & 40 & $\begin{array}{l}\text { Other issues.. how technically difficult it would be to convert and install } \\
\text { new services that would be required... }\end{array}$ & & & & & $x$ & & & \\
\hline $\begin{array}{l}\text { Bullen and } \\
\text { Love, 2011a }\end{array}$ & 40 & ...have low suitability for reuse as they were... poorly constructed... & & & & & & & $\mathrm{x}$ & \\
\hline $\begin{array}{l}\text { Bullen and } \\
\text { Love, 2011a }\end{array}$ & 40 & $\begin{array}{l}\text {...have low suitability for reuse as they... used thermally inefficient } \\
\text { materials and techniques. }\end{array}$ & $\mathrm{x}$ & & & & & & & \\
\hline $\begin{array}{l}\text { Bullen and } \\
\text { Love, 2011a }\end{array}$ & 41 & $\begin{array}{l}\text {...layout... of the existing building rendered it economically unviable to } \\
\text { adapt to the current building code. }\end{array}$ & & $\mathrm{x}$ & & & & & & \\
\hline $\begin{array}{l}\text { Bullen and } \\
\text { Love, 2011a }\end{array}$ & 41 & $\begin{array}{l}\text {.... spatial attributes of the existing building rendered it economically } \\
\text { unviable to adapt to the current building code. }\end{array}$ & $\mathrm{x}$ & & & & & & & \\
\hline $\begin{array}{l}\text { Bullen and } \\
\text { Love, 2011b }\end{array}$ & 413 & ...or their layout may be inappropriate for any change of function... & & $\mathrm{X}$ & & & & & & \\
\hline $\begin{array}{l}\text { Bullen and } \\
\text { Love, 2011c }\end{array}$ & 39 & $\begin{array}{l}\text { The current layout... may also be inappropriate for any change of use, } \\
\text { particularly if it contains a large number of columns... }\end{array}$ & & $\mathrm{X}$ & & & & & & \\
\hline $\begin{array}{l}\text { Bullen and } \\
\text { Love, 2011c }\end{array}$ & 39 & $\begin{array}{l}\text {...older buildings typically do not provide voids or access ways.... to } \\
\text { retrofit modern services such as air-conditioning. }\end{array}$ & & & & & $x$ & & & \\
\hline $\begin{array}{l}\text { Bullen and } \\
\text { Love, 2011c }\end{array}$ & 39 & $\begin{array}{l}\text {...older buildings typically do not provide... sufficient room to retrofit } \\
\text { modern services such as air-conditioning. }\end{array}$ & & & & & & $\mathrm{X}$ & & \\
\hline $\begin{array}{l}\text { Conejos et al., } \\
2016\end{array}$ & 509 & $\begin{array}{l}\text { (2) Physical restrictions: Restrictions due to existing floor layouts, } \\
\text { number of columns/walls and structural system layouts... }\end{array}$ & & $\mathrm{X}$ & & & & & & \\
\hline $\begin{array}{l}\text { Conejos et al., } \\
2016\end{array}$ & 512 & $\begin{array}{l}\text { A new lightweight structure of steel and glass that clipped inside the } \\
\text { church was also provided to ensure reversibility in the future. }\end{array}$ & & & & & & $\mathrm{X}$ & & \\
\hline $\begin{array}{l}\text { de Neufville, } \\
2008\end{array}$ & 53 & $\begin{array}{l}\text {...easily adjust to short- and long-term shifts of traffic through the } \\
\text { building. In the short run, operators open and close doors between } \\
\text { various sectors. In the long run, they can displace panels. }\end{array}$ & & & & & $\mathrm{x}$ & & & \\
\hline $\begin{array}{l}\text { de Neufville, } \\
2008\end{array}$ & 57 & $\begin{array}{l}\text { Flexible designs... simultaneously create both traditional and low-cost } \\
\text { facilities at a new airport, to appeal to the range of possible customers. }\end{array}$ & & & & & & & & \\
\hline $\begin{array}{l}\text { de Neufville, } \\
2008\end{array}$ & 62 & $\begin{array}{l}\text {... a half-sized standard building } \underline{\text { supplemented by low-cost facilities and }} \\
\text { featuring bus services to remotely parked aircraft... suitable... for easy } \\
\text { expansion emphasizing either traditional or low-cost carriers... }\end{array}$ & & & & & & & & \\
\hline
\end{tabular}




\begin{tabular}{|c|c|c|c|c|c|c|c|c|c|c|}
\hline source & page & mentions of a design tactic & 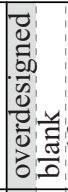 & & & & & & & 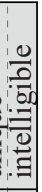 \\
\hline Dhar et al., 2013 & 143 & 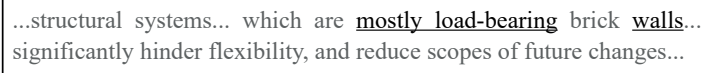 & $\mathrm{x}$ & & & & & & & \\
\hline Dhar et al., 2013 & 144 & $\begin{array}{l}\text {...the support places limitation on the layout possibilities due to the } \\
\text { positions and dimensions of walls, floors, columns, ducts... }\end{array}$ & $\mathrm{x}$ & & & & & & & \\
\hline Dhar et al., 2013 & 150 & ....irregular... column spans may limit the number of possible layouts... & & $\mathrm{X}$ & & & & & & \\
\hline Dhar et al., 2013 & 150 & ...s smaller column spans may limit the number of possible layouts... & $\mathrm{x}$ & & & & & & & \\
\hline Dhar et al., 2013 & 150 & $\begin{array}{l}\text { A layout having a staircase at the middle, or around middle position of } \\
\text { a building, can allow for more flexibility than placing it at the corner. }\end{array}$ & & $\mathrm{X}$ & & & & & & \\
\hline Dhar et al., 2013 & 150 & $\begin{array}{l}\text {... roof beams } \ldots \text { often guide to configure the livable space and have } \\
\text { impact on it... }\end{array}$ & $\mathrm{x}$ & & & & & & & \\
\hline Dhar et al., 2013 & $\begin{array}{l}150- \\
151\end{array}$ & $\begin{array}{l}{[\text { By] ...installing these wiring systems between partitioning walls... A }} \\
\underline{\text { re-installation of wiring systems is required in every renovation work }}\end{array}$ & & & & & & & & \\
\hline Dhar et al., 2013 & $\begin{array}{c}150- \\
151\end{array}$ & $\begin{array}{l}\text { Vertical service distribution ducts... are very difficult to adapt for a new } \\
\text { layout. The position of ducts often limits the options of future changes. }\end{array}$ & $\mathrm{x}$ & & & & & & & \\
\hline Dhar et al., 2013 & 152 & $\begin{array}{l}\text {...column/load-bearing wall-free space may be able to be used for any } \\
\text { purpose and be ready to go for any future changes. }\end{array}$ & $\mathrm{x}$ & & & & & & & \\
\hline Dhar et al., 2013 & 152 & $\begin{array}{l}\text {...major wiring work in... adaptable walls... involves technical challeng- } \\
\text { es for moving or altering into a new layout... }\end{array}$ & & & & & & & & \\
\hline Dhar et al., 2013 & 154 & $\begin{array}{l}\text { Moderate flexibility... frame structure... Minimum flexibility... } \\
\text { load-bearing brick-wall structure... }\end{array}$ & $x$ & & & & & & & \\
\hline Dhar et al., 2013 & 154 & Moderate flexibility... Flat plate structural system... & $x$ & & & & & & & \\
\hline $\begin{array}{l}\text { Dovey and } \\
\text { Fisher, } 2014\end{array}$ & 54 & $\begin{array}{l}\text {...these are learning clusters where... two or more traditional } \\
\text { classrooms... [can] be converted into a single commons. }\end{array}$ & & $X$ & & & & & & \\
\hline $\begin{array}{l}\text { Dovey and } \\
\text { Fisher, } 2014\end{array}$ & 54 & $\begin{array}{l}\text {...these are learning clusters where flexible walls enable... classrooms... } \\
\text { to be converted... }\end{array}$ & & & & & & & & \\
\hline $\begin{array}{l}\text { Dovey and } \\
\text { Fisher, } 2014\end{array}$ & 58 & $\begin{array}{l}\text {...fluidity is an adaptive condition produced by a conjunction of } \\
\text { openness and closure rather than one or other end of this continuum. }\end{array}$ & & & $\mathrm{X}$ & & & & & \\
\hline $\begin{array}{l}\text { Dovey and } \\
\text { Fisher, } 2014\end{array}$ & 58 & $\begin{array}{l}\text {...high level of reversibility through the use of removable (folding, } \\
\text { sliding) walls... }\end{array}$ & & & & & & & & \\
\hline $\begin{array}{l}\text { Dovey and } \\
\text { Fisher, } 2014\end{array}$ & 58 & $\begin{array}{l}\text {... since the closed classroom constrains new pedagogies and the open } \\
\text { plan constrains traditional teaching. }\end{array}$ & & & $X$ & & & & & \\
\hline $\begin{array}{l}\text { Dovey and } \\
\text { Fisher, } 2014\end{array}$ & 60 & $\begin{array}{l}\text { The most resilient of the plans are those with a diversity of learning } \\
\text { spaces and high levels of fluidity. }\end{array}$ & & & $\mathrm{X}$ & & & & & \\
\hline $\begin{array}{l}\text { Eguchi et al., } \\
2011\end{array}$ & 74 & The house contains no load bearing walls and uses... columns... & $\mathrm{x}$ & & & & & & & \\
\hline $\begin{array}{l}\text { Eguchi et al., } \\
2011\end{array}$ & 74 & $\begin{array}{l}\text { The house... uses a system of thin columns... that can be removed or } \\
\text { extended... }\end{array}$ & & & & & & & & \\
\hline $\begin{array}{l}\text { Eguchi et al., } \\
2011\end{array}$ & 74 & $\begin{array}{l}\text {...the entire house is based on a single philosophy of measurement... } \\
\text { making it easy to change and extend. }\end{array}$ & & $\mathrm{X}$ & & & & & & \\
\hline $\begin{array}{l}\text { Eguchi et al., } \\
2011\end{array}$ & $\begin{array}{l}74- \\
75\end{array}$ & $\begin{array}{l}\text {...with light double sliding windows and partitions (fusuma) allowing } \\
\text { them to be shifted or stored easily. }\end{array}$ & & & & & & & & \\
\hline
\end{tabular}




\begin{tabular}{|c|c|c|c|c|c|c|c|c|}
\hline source & page & mentions of a design tactic & 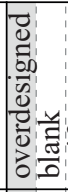 & 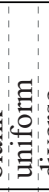 & 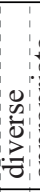 & 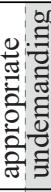 & 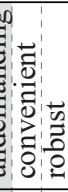 & 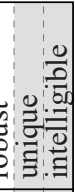 \\
\hline $\begin{array}{l}\text { Eguchi et al., } \\
2011\end{array}$ & 75 & $\begin{array}{l}\text {...rooms bore no functional labels, } \\
\text { deriving its identity from its temporary occupants... }\end{array}$ & & $\mathbf{X}$ & & & & \\
\hline $\begin{array}{l}\text { Eguchi et al., } \\
2011\end{array}$ & 75 & $\begin{array}{l}\text { This system divides the building parts... so that parts with long life } \\
\text { spans are not damaged when parts with short life spans are replaced... }\end{array}$ & & & & $\mathrm{x}$ & $\mathbf{r}$ & \\
\hline $\begin{array}{l}\text { Eguchi et al., } \\
2011\end{array}$ & 77 & $\begin{array}{l}\text { A key tactic was shifting to a } 10.8 \mathrm{~m} \text { uniform-grid offering a low cost } \\
\text { solution, which is typically used for shopping centres and parking - in } \\
\text { contrast to the typical office span of } 16-18 \mathrm{~m} . .\end{array}$ & & & & $\mathrm{x}$ & & \\
\hline $\begin{array}{l}\text { Eguchi et al., } \\
2011\end{array}$ & 77 & $\begin{array}{l}\text {...external lateral bracing... creates a rigid shell and allows for a free } \\
\text { internal space that was envisioned to incorporate future changes... }\end{array}$ & $x$ & & & & & \\
\hline $\begin{array}{l}\text { Eguchi et al., } \\
2011\end{array}$ & 77 & $\begin{array}{l}\text {...by positioning... static core spaces } \\
\text { the center } \underline{\text { up }} . . . \text { allowing the design to accommodate ongoing changes... }\end{array}$ & $x$ & & & & & \\
\hline $\begin{array}{l}\text { Eguchi et al., } \\
2011\end{array}$ & $\begin{array}{l}77- \\
78\end{array}$ & $\begin{array}{l}\text { The convertibility... is augmented by the decentralization of... services } \\
\text { into } 10 \text { modules along the east and west periphery. }\end{array}$ & & $\mathrm{X}$ & & & & \\
\hline $\begin{array}{l}\text { Eguchi et al., } \\
2011\end{array}$ & 78 & ...they are removable, being fastened through $\underline{\text { dry }}$ connections. & & & & & $x$ & \\
\hline $\begin{array}{l}\text { Eguchi et al., } \\
2011\end{array}$ & 79 & $\begin{array}{l}\text {...MK utilizes a 'universal space' which they signify through a } \\
\text { column-free work space. }\end{array}$ & $x$ & & & & & \\
\hline $\begin{array}{l}\text { Eguchi et al., } \\
2011\end{array}$ & 79 & $\begin{array}{l}\text { Wooden components... all of which are made with standard sizes - } \\
\text { providing easy availability in the future... }\end{array}$ & & & & $\mathrm{X}$ & & \\
\hline $\begin{array}{l}\text { Eguchi et al., } \\
2011\end{array}$ & 79 & $\begin{array}{l}\text {...Wooden parts... are assembled with dry joints (screws) increasing } \\
\text { their refitability in the future. }\end{array}$ & & & & & $\mathbf{x}$ & \\
\hline $\begin{array}{l}\text { Eguchi et al., } \\
2011\end{array}$ & 79 & $\begin{array}{l}\text {...the building also decentralizes services to the outside which help } \\
\text { allow for distributed control of the services amongst different tenants. }\end{array}$ & & $\mathrm{x}$ & & & & \\
\hline $\begin{array}{l}\text { Eguchi et al., } \\
2011\end{array}$ & $\begin{array}{l}80- \\
81\end{array}$ & $\begin{array}{l}\text {...drive market value by emphasizing the uniqueness offered by the } \\
\text { original characteristics... }\end{array}$ & & & & & & $\mathbf{X}$ \\
\hline $\begin{array}{l}\text { Eguchi et al., } \\
2011\end{array}$ & 82 & $\begin{array}{l}\text {...where the structural floor height is not large enough due to the } \\
\text { demand for raised flooring to equip the latest service devices... }\end{array}$ & $\mathrm{x}$ & & & & & \\
\hline $\begin{array}{l}\text { Eguchi et al., } \\
2011\end{array}$ & 82 & $\begin{array}{l}\text { "If the building has a good enough structural frame, including large } \\
\text { open spaces, there are no obstacles to realize adaptability". }\end{array}$ & $x$ & & & & & \\
\hline $\begin{array}{l}\text { Eguchi et al., } \\
2011\end{array}$ & 82 & $\begin{array}{l}\text {...to be able to } \underline{\text { subdivide }} \text { services to a minimum floor area due to greater } \\
\text { demand to partition larger spaces... for more individual control. }\end{array}$ & & $x$ & & & & \\
\hline $\begin{array}{l}\text { Eguchi et al., } \\
2011\end{array}$ & 83 & $\begin{array}{l}\text {...to maximize profitable space allowances, lock buildings into specific } \\
\underline{\text { uses, }} \text {, making change of use difficult... }\end{array}$ & & & & $\mathrm{X}$ & & \\
\hline $\begin{array}{l:l}\text { Engel and } \\
\text { Browning, 2008 }\end{array}$ & 127 & $\begin{array}{l}\text {...certain parts of a system should be designed so as to be easily } \\
\text { decoupled from the rest of the system to facilitate partial upgrades. }\end{array}$ & & & & $\mathrm{X}$ & $\mathrm{K}$ & \\
\hline $\begin{array}{l:l}\text { Engel and } \\
\text { Browning, 2008 }\end{array}$ & $\begin{array}{l}130- \\
131\end{array}$ & $\begin{array}{l}\text {...modular design of a complex system facilitates adaptations to future } \\
\text { uncertainty by decreasing the cost of the option to modify the system. }\end{array}$ & & & & $\mathrm{x}$ & $\mathrm{K}$ & \\
\hline $\begin{array}{l:l}\text { Engel and } \\
\text { Browning, } 2008\end{array}$ & $\begin{array}{l}130- \\
131\end{array}$ & $\begin{array}{l}\text { From an engineering perspective, modularization has three main } \\
\text { purposes: } 1 \text {. To make a system's complexity manageable,... }\end{array}$ & & & & & & $\mathrm{x}$ \\
\hline $\begin{array}{l:l}\text { Engel and } \\
\text { Browning, } 2008\end{array}$ & 136 & $\begin{array}{l}\text {...there is more overall architectural option value in many small design } \\
\text { clusters than in a few large ones. }\end{array}$ & & $\mathbf{X}$ & & & & \\
\hline
\end{tabular}




\begin{tabular}{|c|c|c|c|c|c|c|c|c|c|c|}
\hline source & page & mentions of a design tactic & & 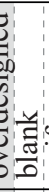 & $\begin{array}{l} \\
\vdots \\
0 \\
0 \\
0 \\
\Xi \\
\Xi\end{array}$ & & 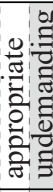 & 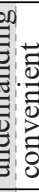 & & $\frac{0}{0}$ \\
\hline $\begin{array}{l}\text { Engel and } \\
\text { Browning, } 2008\end{array}$ & 136 & $\begin{array}{l}\text {...the overall cost of interfaces increases linearly with their number and } \\
\text { individual attributes. }\end{array}$ & & & & & $\mathrm{X}$ & $\mathrm{x}$ & & \\
\hline $\begin{array}{l}\text { Engel and } \\
\text { Browning, } 2008\end{array}$ & 143 & $\begin{array}{l}\text {...the likely ease with which its modules can be changed without } \\
\text { disrupting other modules. }\end{array}$ & & & & & $\mathrm{X}$ & $\mathrm{X}$ & & \\
\hline $\begin{array}{l}\text { Engel and Reich, } \\
2015\end{array}$ & $\begin{array}{lll}396-1 \\
397\end{array}$ & $\begin{array}{l}\text {...increasing system's modularity... may decrease the lifetime value of a } \\
\text { system due to excessive costs related to the system's interfaces. }\end{array}$ & & & & & $x$ & & & \\
\hline $\begin{array}{l}\text { Engel and Reich, } \\
2015\end{array}$ & 397 & $\begin{array}{l}\text {...systems... composed of } \underline{\text { separate functional modules... could be }} \\
\text { adapted to new requirements with relative ease and at a low cost... }\end{array}$ & & & & & $\mathrm{X}$ & $\mathrm{x}$ & & \\
\hline $\begin{array}{l}\text { Engel and Reich, } \\
2015\end{array}$ & 397 & $\begin{array}{l}\text {...systems... interacting via standard interfaces, could be adapted to new } \\
\text { requirements with relative ease and at a low cost... }\end{array}$ & & & $x$ & & & & & \\
\hline $\begin{array}{l}\text { Engel and Reich, } \\
2015\end{array}$ & 399 & $\begin{array}{l}\text {.... an optimal system design between a monolithic, nonadaptive, but less } \\
\text { expensive system... }\end{array}$ & & & & & $x$ & $\mathrm{x}$ & & \\
\hline $\begin{array}{l}\text { Engel and Reich, } \\
2015\end{array}$ & 399 & $\begin{array}{l}\text {... a fully adaptive but expensive }[\text { system]...The tradeoff is found by } \\
\text { combining some components... and thus saving their intramodule ICs. }\end{array}$ & & & & & $\mathbf{X}$ & & & \\
\hline $\begin{array}{l}\text { Engel and Reich, } \\
2015\end{array}$ & 400 & $\begin{array}{l}\text {...the tradeoff between the benefits of having many small options.... and } \\
\text { the costs of the interfaces to maintain them. }\end{array}$ & & & & & $\mathrm{x}$ & $\mathrm{x}$ & & \\
\hline $\begin{array}{l}\text { Engel and Reich, } \\
2015\end{array}$ & 411 & $\begin{array}{l}\text {.... an adaptable system is... to base the design on a large number of small } \\
\text { modules... such architecture requires dealing with more interfaces... }\end{array}$ & & & & & $\mathrm{x}$ & $\mathrm{x}$ & & \\
\hline $\begin{array}{l}\text { Fawcett et al., } \\
2012\end{array}$ & 549 & $\begin{array}{l}\text {...to expand/upgrade: this often involves the provision of redundancy or } \\
\text { overcapacity in the initial design/construction... }\end{array}$ & $\mathrm{x}$ & $\mathrm{x}$ & & & & & & \\
\hline $\begin{array}{l}\text { Fawcett et al., } \\
2012\end{array}$ & 549 & $\begin{array}{l}\text {...installing a highcost dual-fuel boiler because it creates the option to } \\
\text { switch fuels in response to future changes... }\end{array}$ & & & & $x$ & & & & \\
\hline Fernandez, 2003 & 171 & $\begin{array}{l}\text { Flexible and adaptable buildings... Included here are moveable } \\
\text { workplace partition systems... knock-out panels for expansion... }\end{array}$ & & & & & & $\mathrm{x}$ & & \\
\hline Fernandez, 2003 & 172 & $\begin{array}{l}\text {....aspired to significant capabilities to alter its internal spaces through } \\
\text { movable floors and partitions... }\end{array}$ & & & & & $\mathrm{x}$ & $\mathrm{x}$ & & \\
\hline Fernandez, 2003 & $\begin{array}{l}172- \\
173\end{array}$ & $\begin{array}{l}\text { The design did not use any welded connections, laminated glass... that } \\
\text { would make difficult material reclamation and recycling. }\end{array}$ & & & & & & $\mathrm{x}$ & & \\
\hline Fernandez, 2003 & 174 & $\begin{array}{l}\text {... a diversified lifetimes (DL) strategy is that a project... may reduce the } \\
\text { risk of misutilization by distributing a range of building lifetimes } \\
\text { throughout the physical systems of the architecture... }\end{array}$ & & & & $\mathrm{X}$ & 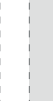 & & & \\
\hline Fernandez, 2003 & 181 & $\begin{array}{l}\text { A tectonic that is based on change is a very different assembly than that } \\
\text { based on the idea of a monolithic, unchanging building. }\end{array}$ & & & & & $\mathrm{x}$ & $\mathrm{x}$ & & \\
\hline $\begin{array}{l}\text { Fletcher et al., } \\
2009\end{array}$ & 280 & ....disassembly... was quite difficult. Three tools were needed... & & & & & & $\mathrm{x}$ & & \\
\hline $\begin{array}{l}\text { Fletcher et al., } \\
2009\end{array}$ & 280 & $\begin{array}{l}\text { The internal components... are permanently affixed to the } \\
\text { motherboard... making user changes... difficult if not impossible. }\end{array}$ & & & & & & $\mathrm{X}$ & & \\
\hline $\begin{array}{l}\text { Fletcher et al., } \\
2009\end{array}$ & 280 & $\begin{array}{l}\text { The computer is easily disassembled with only one tool necessary to } \\
\text { remove all of the components (a generic Phillips head screwdriver)... }\end{array}$ & & & & & & $\mathrm{x}$ & & \\
\hline $\begin{array}{l}\text { Fletcher et al., } \\
2009\end{array}$ & 282 & $\begin{array}{l}\text {...with increasing numbers of interconnections, } \\
\text { more difficult to perform an adaptation task in the future... }\end{array}$ & & & & & $x$ & $\mathrm{x}$ & & \\
\hline
\end{tabular}




\begin{tabular}{|c|c|c|c|c|c|c|c|c|c|c|}
\hline source & page & mentions of a design tactic & 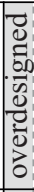 & & & & & $\begin{array}{l}0 \\
0 \\
0 \\
0 \\
0 \\
0\end{array}$ & & 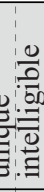 \\
\hline $\begin{array}{l}\text { Fletcher et al., } \\
2009\end{array}$ & 282 & $\begin{array}{l}\text {...for maximum adaptability... a perfect hierarchical structure ( } \underline{\text { no }} \\
\underline{\text { cross-connections) }} \text { ) is referred to as a segregated product architecture. }\end{array}$ & & & & & $x$ & & & \\
\hline $\begin{array}{l}\text { Fletcher et al., } \\
2009\end{array}$ & 286 & Adaptability is defined here as a function of the product architecture... & & & & & $x$ & & & \\
\hline $\begin{array}{l}\text { Fletcher et al., } \\
2009\end{array}$ & 286 & $\begin{array}{l}\text { Adaptability is defined here as a function of... the relative size of the } \\
\text { various system components. }\end{array}$ & & & & & & $\mathrm{x}$ & & \\
\hline $\begin{array}{l}\text { Fletcher et al., } \\
2009\end{array}$ & 287 & $\begin{array}{l}\text {...the model is capable of various configurations through the use of } \\
\text { repeated components... common interfaces... }\end{array}$ & & & & & & & & \\
\hline $\begin{array}{l}\text { Fletcher et al., } \\
2009\end{array}$ & 287 & $\begin{array}{l}\text {...the model is capable of various configurations through the use of... } \\
\text { functional independence... }\end{array}$ & & & & & $x$ & & & \\
\hline $\begin{array}{l}\text { Georgiadou et } \\
\text { al., } 2012\end{array}$ & 148 & $\begin{array}{l}\text {..."a good low-energy design offers the best future-proof solutions", as } \\
\text { buildings of the future must be energy efficient. }\end{array}$ & $\mathrm{x}$ & & & & & & & \\
\hline $\begin{array}{l}\text { Georgiadou et } \\
\text { al., } 2012\end{array}$ & 152 & $\begin{array}{l}\text { Flexibility in the building envelope; i.e., space for energy storage } \\
\text { systems, PV-ready roofs. }\end{array}$ & $\mathrm{x}$ & & & & & & & \\
\hline $\begin{array}{l}\text { Georgiadou et } \\
\text { al., } 2012\end{array}$ & 152 & $\begin{array}{l}\text { Designing to higher standards to remain complaint with imminent } \\
\text { policy, such as the zero carbon homes requirement... }\end{array}$ & $\mathrm{x}$ & & & & & & & \\
\hline $\begin{array}{l}\text { Gijsbers and } \\
\text { Lichtenberg, } \\
2014\end{array}$ & 240 & 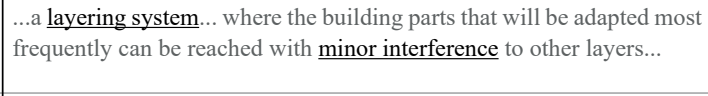 & & & & & $\mathrm{X}$ & & & \\
\hline $\begin{array}{l}\text { Gijsbers and } \\
\text { Lichtenberg, } \\
2014\end{array}$ & 240 & $\begin{array}{l}\text { Essential features to realize adaptations are among others: demounta- } \\
\text { bility, accessibility of connections, } \underline{\text { modulation and reusability... }}\end{array}$ & & & & & $\mathrm{X}$ & & & \\
\hline $\begin{array}{l}\text { Gijsbers and } \\
\text { Lichtenberg, } \\
2014\end{array}$ & 247 & $\begin{array}{l}\text { These wall elements consist of... storey high... panels... The } \\
\text { advantage... is the construction speed... }\end{array}$ & & & & & $\mathrm{X}$ & & & \\
\hline $\begin{array}{l}\text { Gijsbers and } \\
\text { Lichtenberg, } \\
2014\end{array}$ & 247 & $\begin{array}{l}\text { These wall elements consist of... lightweight panels... The advantage... } \\
\text { is the construction speed... }\end{array}$ & & & & & & $\mathrm{X}$ & & \\
\hline $\begin{array}{l}\text { Gijsbers and } \\
\text { Lichtenberg, } \\
2014\end{array}$ & 247 & $\begin{array}{l}\text {...a wall block system consisting of rectangular blocks }(400 \times 300 \times \\
100 \mathrm{~mm}) \ldots \text { stand out for their freedom in wall composition. }\end{array}$ & & & & & & & & \\
\hline $\begin{array}{l}\text { Gijsbers and } \\
\text { Lichtenberg, } \\
2014\end{array}$ & 247 & The blocks are fixated using removable adhesive strips... & & & & & & $x$ & & \\
\hline $\begin{array}{l}\text { Gijsbers and } \\
\text { Lichtenberg, } \\
2014\end{array}$ & 250 & $\begin{array}{l}\text { In general, less coupling means less effort to perform adaptations in } \\
\text { practice. }\end{array}$ & & & & & $x$ & & & \\
\hline $\begin{array}{l}\text { Gijsbers and } \\
\text { Lichtenberg, } \\
2014\end{array}$ & 250 & $\begin{array}{l}\text { Wiring... is... partly embedded in the concrete flooring... a hollow floor } \\
\text { that contains freely dividable installation space is preferable... }\end{array}$ & & & & & $x$ & & & \\
\hline $\begin{array}{l}\text { Gosling et al., } \\
2013\end{array}$ & 46 & $\begin{array}{l}\text {...layering involves dividing the building elements... so these can be } \\
\text { maintained or adapted without affecting... other layers... }\end{array}$ & & & & & $X$ & & & \\
\hline $\begin{array}{l}\text { Gosling et al., } \\
2013\end{array}$ & 46 & $\begin{array}{l}\text {...separates a 'base-building' and its interior 'fit-out', which should be } \\
\text { able to be installed or changed with a minimum of interface problems... }\end{array}$ & & & & & $x$ & & & \\
\hline $\begin{array}{l}\text { Gosling et al., } \\
2013\end{array}$ & $\begin{array}{l}46- \\
47\end{array}$ & $\begin{array}{l}\text { Overcapacity... can be applied effectively to the structure, services } \\
\text { systems and space standards to make buildings more adaptable... }\end{array}$ & $\mathrm{x}$ & & & & & & & \\
\hline
\end{tabular}




\begin{tabular}{|c|c|c|c|c|c|c|c|c|c|}
\hline source & page & mentions of a design tactic & 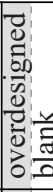 & & & 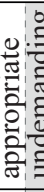 & 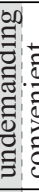 & & 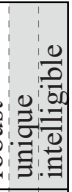 \\
\hline $\begin{array}{l}\text { Gosling et al., } \\
2013\end{array}$ & 47 & $\begin{array}{l}\text {...it can only be adapted easily if the integration of the components } \\
\text { allows for the component removal from the building. }\end{array}$ & & & & & $\mathrm{X}$ & & \\
\hline $\begin{array}{l}\text { Gosling et al., } \\
2013\end{array}$ & 47 & $\begin{array}{l}\text { Accessible floors and ceiling systems that facilitating services } \\
\text { adaptations are standard sizes and } \underline{\text { interchangeable. }}\end{array}$ & & $\mathrm{X}$ & & & & & \\
\hline $\begin{array}{l}\text { Gosling et al., } \\
2013\end{array}$ & 47 & $\begin{array}{l}\text {...the more open plan the building is the more permutations of internal } \\
\text { layouts are possible. }\end{array}$ & $\mathrm{x}$ & & & & & & \\
\hline $\begin{array}{l}\text { Gosling et al., } \\
2013\end{array}$ & 47 & $\begin{array}{l}\ldots \text { building width and floor to floor height contribute to... the ability to } \\
\text { meet changing user or owner needs without changing its properties. }\end{array}$ & $\mathrm{x}$ & & & & & & \\
\hline $\begin{array}{l}\text { Gosling et al., } \\
2013\end{array}$ & 48 & $\begin{array}{l}\text { Adaptable buildings would allow service plant... to be removed from } \\
\text { the building through suitably sized openings that allow safe access... }\end{array}$ & & & & & $\mathrm{x}$ & $\mathrm{x}$ & \\
\hline $\begin{array}{l}\text { Gosling et al., } \\
2013\end{array}$ & 48 & 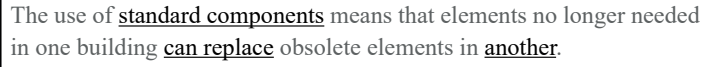 & & $x$ & & & & & \\
\hline $\begin{array}{l}\text { Greden and } \\
\text { Glicksman, } 2005\end{array}$ & 38 & $\begin{array}{l}\text {...the building with extra floor-to-ceiling height... so as to have the } \\
\text { flexibility to convert to office space at a modest cost. }\end{array}$ & $x$ & & & & & & \\
\hline $\begin{array}{l}\text { Greden and } \\
\text { Glicksman, } 2005\end{array}$ & 38 & $\begin{array}{l}\text {...the building with... removable spandrel glass so as to have the } \\
\text { flexibility to convert to office space at a modest cost. }\end{array}$ & & & & & $\mathbf{X}$ & & \\
\hline $\begin{array}{l}\text { Greden and } \\
\text { Glicksman, } 2005\end{array}$ & 40 & $\begin{array}{l}\text {... an office space with a moveable wall system has a low renovation } \\
\text { cost to convert... }\end{array}$ & & & & & $\mathrm{x}$ & & \\
\hline $\begin{array}{l}\text { Grover and } \\
\text { Grover, } 2015\end{array}$ & 301 & $\begin{array}{l}\text {...obsolescence is unsystematic requiring investors to diversify their } \\
\text { portfolios if they are to mitigate its consequences... }\end{array}$ & & & $\mathrm{X}$ & & & & \\
\hline $\begin{array}{l}\text { Grover and } \\
\text { Grover, } 2015\end{array}$ & 305 & $\begin{array}{l}\text {...identified as important were the... internal specifications... and } \\
\text { configuration, which is the horizontal... layout of a building. }\end{array}$ & $\mathrm{x}$ & & & & & & \\
\hline $\begin{array}{l}\text { Grover and } \\
\text { Grover, } 2015\end{array}$ & 305 & $\begin{array}{l}\text {...identified as important were the... internal specifications... and } \\
\text { configuration, which is the... vertical layout of a building. }\end{array}$ & $\mathrm{x}$ & & & & & & \\
\hline $\begin{array}{l}\text { Grover and } \\
\text { Grover, } 2015\end{array}$ & 308 & $\begin{array}{l}\text { Iconic buildings may be adapted..., either because their aesthetic } \\
\text { features... or because... demolition... will not be forthcoming. }\end{array}$ & & & & & & & $\mathbf{X}^{\prime}$ \\
\hline $\begin{array}{l}\text { Grover and } \\
\text { Grover, } 2015\end{array}$ & 309 & A shell is capable of being re-used... & $\mathrm{x}$ & & & & & & \\
\hline $\begin{array}{l}\text { Grover and } \\
\text { Grover, } 2015\end{array}$ & 309 & ...an integrated system cannot... [be re-used] & & & & & X & & \\
\hline $\begin{array}{l}\text { Grover and } \\
\text { Grover, } 2015\end{array}$ & 309 & $\begin{array}{l}\text {... a cinema may become a bingo club and then a church... the building } \\
\text { was designed... [with] characteristics required by each of its subsequent } \\
\text { uses. }\end{array}$ & & & & $\mathrm{x}$ & & & \\
\hline $\begin{array}{l}\text { Grover and } \\
\text { Grover, } 2015\end{array}$ & 309 & $\begin{array}{l}\text {... p prison may be converted into a hotel... the building was designed to } \\
\text { provide residential accommodation but not permanent residence. }\end{array}$ & & & & $\mathrm{x}$ & & & \\
\hline $\begin{array}{l}\text { Halvitigala and } \\
\text { Reed, } 2015\end{array}$ & 483 & $\begin{array}{l}\text {...smaller floor plates are in decreasing demand... any future } \\
\text { alternations would be restricted by the floor plates... }\end{array}$ & $\mathrm{x}$ & & & & & & \\
\hline $\begin{array}{l}\text { Halvitigala and } \\
\text { Reed, } 2015\end{array}$ & 485 & $\begin{array}{l}\text {...structures were... based on a modular concept with consistent floor to } \\
\text { ceiling height... for increased flexibility and an efficient use of space. }\end{array}$ & & X & & & & & \\
\hline $\begin{array}{l}\text { Halvitigala and } \\
\text { Reed, } 2015\end{array}$ & 485 & $\begin{array}{l}\text {...floor plates deeper than } 20 \mathrm{~m} \text { were considered inefficient as it may } \\
\text { cause lighting and ventilation issues. }\end{array}$ & & & & $\mathrm{X}$ & & & \\
\hline
\end{tabular}




\begin{tabular}{|c|c|c|c|c|c|c|c|c|c|c|}
\hline source & page & mentions of a design tactic & 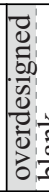 & & & & & & & $\frac{0}{0}$ \\
\hline $\begin{array}{l}\text { Halvitigala and } \\
\text { Reed, } 2015\end{array}$ & 485 & $\begin{array}{l}\text { It was suggested that increased floor-to-floor heights enhanced lighting, } \\
\text { ventilation and the "feeling" of space. }\end{array}$ & & & & $\gamma$ & $\mathrm{X}$ & & & \\
\hline $\begin{array}{l}\text { Halvitigala and } \\
\text { Reed, } 2015\end{array}$ & 485 & $\begin{array}{l}\text {...a high level of flexible buildings using higher floor to ceiling } \\
\text { heights... }\end{array}$ & $\mathrm{x}$ & & & & & & & \\
\hline $\begin{array}{l}\text { Halvitigala and } \\
\text { Reed, } 2015\end{array}$ & 485 & $\begin{array}{l}\text {...a high level of flexible buildings using... soundproof suspended } \\
\text { ceilings... }\end{array}$ & $\mathrm{x}$ & & & & & & & \\
\hline $\begin{array}{l}\text { Halvitigala and } \\
\text { Reed, } 2015\end{array}$ & $485-$ & $\begin{array}{l}\text { Improved floor plate efficiencies were achieved by... large } \ldots \text { floor } \\
\text { plates with } \underline{\text { large vertical risers... }}\end{array}$ & $\mathrm{x}$ & & & & & & & \\
\hline $\begin{array}{l}\text { Halvitigala and } \\
\text { Reed, } 2015\end{array}$ & $485-$ & $\begin{array}{l}\text { Improved floor plate efficiencies were achieved by... uninterrupted } \\
\text { floor plates... }\end{array}$ & 1 & & & & & & & \\
\hline $\begin{array}{l}\text { Halvitigala and } \\
\text { Reed, } 2015\end{array}$ & $485-$ & $\begin{array}{l}\text { Improved floor plate efficiencies were achieved by... simple geometri- } \\
\underline{\text { cally shaped floor plates... }}\end{array}$ & & & & $x$ & $\mathrm{X}$ & & & \\
\hline $\begin{array}{l}\text { Halvitigala and } \\
\text { Reed, } 2015\end{array}$ & $485-$ & $\begin{array}{l}\text { Improved floor plate efficiencies were achieved by... good natural light } \\
\text { penetration throughout the floor plate. }\end{array}$ & & & & & $\mathrm{x}$ & & & \\
\hline $\begin{array}{l}\text { Halvitigala and } \\
\text { Reed, } 2015\end{array}$ & 486 & $\begin{array}{l}\text {...the shape of floor plate... where simple geometric shapes, } \text {, such as } \\
\text { squares or rectangles, were used to improve spatial efficiency. }\end{array}$ & & & & & $\mathrm{X}$ & & & \\
\hline $\begin{array}{l}\text { Halvitigala and } \\
\text { Reed, } 2015\end{array}$ & 486 & $\begin{array}{l}\text {...the majority of service cores... were along one edge of the building } \\
\text { perimeter... to provide more flexibility relating to maximum depth... }\end{array}$ & 2 & & & & & & & \\
\hline $\begin{array}{l}\text { Halvitigala and } \\
\text { Reed, } 2015\end{array}$ & 486 & $\begin{array}{l}\text {...more natural light and ventilation were used to enhance efficiency in } \\
\text { building services. }\end{array}$ & & & & & $\mathrm{X}$ & & & \\
\hline $\begin{array}{l}\text { Halvitigala and } \\
\text { Reed, } 2015\end{array}$ & 486 & $\begin{array}{l}\text {...the AC system... is serviced on a part-floor basis, so after hours the } \\
\text { AC is on only in one zone instead of the whole floor... }\end{array}$ & & $: 2$ & & & & & & \\
\hline $\begin{array}{l}\text { Halvitigala and } \\
\text { Reed, } 2015\end{array}$ & 487 & $\begin{array}{l}\text {...to develop... properties that have "unique characteristics with designs } \\
\text { of the highest aesthetic quality and sense of pride for occupiers"... }\end{array}$ & & & & & & & & $\mathbf{x}$ \\
\hline $\begin{array}{l}\text { Halvitigala and } \\
\text { Reed, } 2015\end{array}$ & 487 & $\begin{array}{l}\text { At the same time, over-specification and over-complication of building } \\
\text { design and specifications were avoided... }\end{array}$ & & & & & $\mathrm{X}$ & & & \\
\hline $\begin{array}{l}\text { Halvitigala and } \\
\text { Reed, } 2015\end{array}$ & 487 & $\begin{array}{l}\text {...the IT networks in their office buildings were divided into zones so } \\
\text { each zone can perform independently... }\end{array}$ & & & & & & & & \\
\hline $\begin{array}{l}\text { Halvitigala and } \\
\text { Reed, } 2015\end{array}$ & 487 & $\begin{array}{l}\text {...the cabling... were installed using "low profile raised floor system" } \\
\text { and can be easily accessed... }\end{array}$ & & & & & & $\mathrm{x}$ & & \\
\hline $\begin{array}{l}\text { Halvitigala and } \\
\text { Reed, } 2015\end{array}$ & 487 & $\begin{array}{l}\text {...to facilitate the... reticulation of data... so tenants can take data from } \\
\text { the demarcation point in the basement up through the risers and } \underline{\text { round }} \\
\text { the building through the perimeter duct system". }\end{array}$ & & 12 & & & & & & \\
\hline $\begin{array}{l}\text { Halvitigala and } \\
\text { Reed, } 2015\end{array}$ & $487-$ & $\begin{array}{l}\text {...ceilings with high-noise reduction co-efficient and high-articulation } \\
\text { class values were used... So when you go to an open plan office } \\
\text { environment they are much quieter now". }\end{array}$ & $\mathrm{x}$ & & & & & & & \\
\hline $\begin{array}{l}\text { Halvitigala and } \\
\text { Reed, } 2015\end{array}$ & 488 & $\begin{array}{l}\text {...interior partitions could be easily dismantled and removed where } \\
\text { complex partitions and...were avoided... }\end{array}$ & & & & & & & & \\
\hline $\begin{array}{l}\text { Halvitigala and } \\
\text { Reed, } 2015\end{array}$ & 488 & $\begin{array}{l}\text {...interior partitions could be easily dismantled and removed where } \\
\text { complex.... and building specifications were avoided... }\end{array}$ & & & & & $\mathrm{x}$ & & & \\
\hline $\begin{array}{l}\text { Hamraz et al., } \\
2013\end{array}$ & 142 & $\begin{array}{l}\text {...the dependencies between component pairs to compute the overall } \\
\text { risk of change propagation imposed on other components... }\end{array}$ & & & & & $\mathrm{x}$ & & & \\
\hline
\end{tabular}




\begin{tabular}{|c|c|c|c|c|c|c|c|c|c|c|}
\hline source & page & mentions of a design tactic & 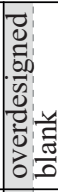 & & & & & & & 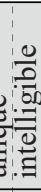 \\
\hline Hassanain, 2006 & 214 & $\begin{array}{l}\text {...giving high flexibility in office buildings are... plug and play building } \\
\text { elements which allows for fast changes of layout... }\end{array}$ & & & & & $X$ & $\mathrm{x}$ & & \\
\hline Hassanain, 2006 & 214 & $\begin{array}{l}\text {...giving high flexibility in office buildings are flat... ceiling for rapid } \\
\text { and easy moving of internal walls... }\end{array}$ & $x$ & $\mathrm{x}$ & & & & & & \\
\hline Hassanain, 2006 & 214 & $\begin{array}{l}\text {... giving high flexibility in office buildings are... soundproof ceiling for } \\
\text { rapid and easy moving of internal walls... }\end{array}$ & $\mathrm{x}$ & & & & & & & \\
\hline Hassanain, 2006 & 217 & $\begin{array}{l}\text { Keeping the design of the building simple: designers should avoid... } \\
\text { over-complication... }\end{array}$ & & & & & & & & \\
\hline Hassanain, 2006 & 217 & $\begin{array}{l}\text {...designers should avoid over-specification... and design based on } \\
\text { short-lived quick-fix technologies. }\end{array}$ & & & & : & & & & \\
\hline Hassanain, 2006 & 217 & $\begin{array}{l}\text { A shell and core approach makes it easier to adapt areas of the building } \\
\text { to individual corporate client needs. }\end{array}$ & $\mathrm{X}$ & $x$ & & & & & & \\
\hline Hassanain, 2006 & 217 & $\begin{array}{l}\text { Designing on a grid basis, for example, a planning grid of } 1.5 \mathrm{~m} \text {, } \\
\text { provides for good flexibility (Brittain et al., 2004). }\end{array}$ & & $\mathrm{X}$ & & & & & & \\
\hline Hassanain, 2006 & 217 & $\begin{array}{l}\text {...simplifying the range of settings... The trend for providing office } \\
\text { space should be a single office size, rather than two or three sizes. }\end{array}$ & & X & & & & & & \\
\hline Hassanain, 2006 & 217 & 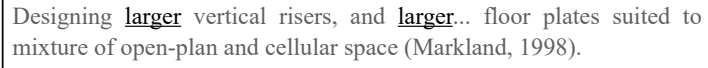 & $\mathrm{x}$ & & & & & & & \\
\hline Hassanain, 2006 & 217 & $\begin{array}{l}\text { Designing... uninterrupted floor plates suited to mixture of open-plan } \\
\text { and cellular space (Markland, 1998). }\end{array}$ & $\mathrm{X}$ & $x$ & & & & & & \\
\hline Hassanain, 2006 & 217 & $\begin{array}{l}\text {...using walls of offices that are mobile ones, that is merging or } \\
\text { separation of units can be managed by little effort. }\end{array}$ & & & & & $\mathrm{x}$ & & & \\
\hline Hassanain, 2006 & 218 & $\begin{array}{l}\text {...Designing building services with overcapacity only where it is too } \\
\text { expensive to add in later. }\end{array}$ & $\mathrm{x}$ & & & & & & & \\
\hline Hassanain, 2006 & 218 & $\begin{array}{l}\text {...being aware of over-congested services by leaving space to alter... } \\
\text { the service in the future. }\end{array}$ & & & & & & & & \\
\hline Hassanain, 2006 & 218 & $\begin{array}{l}\text {...being aware of over-congested services by leaving space.... add to the } \\
\text { service in the future. }\end{array}$ & $\mathrm{x}$ & & & & & & & \\
\hline Hassanain, 2006 & 218 & $\begin{array}{l}\text { Systems should be able to operate on a part-floor basis where large } \\
\text { floor plates are designed. }\end{array}$ & & $x$ & & & & & & \\
\hline Hassanain, 2006 & 218 & $\begin{array}{l}\text { IT networks should be divided into separate zones so that each zone can } \\
\text { perform independently... }\end{array}$ & & $\mathrm{x}$ & & & & & & \\
\hline Hassanain, 2006 & 218 & $\begin{array}{l}\text { The telecommunication infrastructure should be built to be replaced or } \\
\text { renovated easily with a minimum damage to the main structure... }\end{array}$ & & & & & X & & & \\
\hline Hassanain, 2006 & 218 & $\begin{array}{l}\text {...to recast shared settings as multi-use (flex) facilities, for example, } \\
\text { conference centers, lunchroom or cafés, meeting room and libraries... }\end{array}$ & & $X$ & & & & & & \\
\hline $\begin{array}{l}\text { Hein and Houck, } \\
2008\end{array}$ & 124 & $\begin{array}{l}\text {...alterations to a structure can be hazardous, although... the original } \\
\text { concrete frame was over-designed for the... loads of warehouse floors... }\end{array}$ & $\mathrm{x}$ & & & & & & & \\
\hline $\begin{array}{l}\text { Hertzberger, } \\
2014\end{array}$ & 108 & $\begin{array}{l}\text {...generic space would seem the best antidote... Yet we should not } \\
\text { simply strip architecture of all its qualities and meanings... Architecture } \\
\text { must always have that competence, availed as it were of an inherent } \\
\text { charge that can generate specific responses to each new situation. }\end{array}$ & $?$ & & & & & & & \\
\hline
\end{tabular}




\begin{tabular}{|c|c|c|c|c|c|c|c|c|}
\hline source & page & mentions of a design tactic & 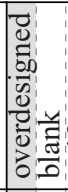 & $\begin{array}{l}\vdots \\
\vdots \\
\vdots \\
\vdots \\
\vdots \\
\vdots \\
\vdots\end{array}$ & & 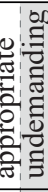 & 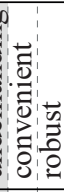 & 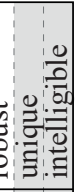 \\
\hline $\begin{array}{l}\text { Hertzberger, } \\
2014\end{array}$ & 109 & $\begin{array}{l}\text {...polyvalence entails introducing the greatest number of spatial } \\
\text { conditions that can play a part in every situation... [they] arouse and } \\
\text { incite them to a more intensive use of space... }\end{array}$ & & $\mathrm{X}$ & & & & \\
\hline $\begin{array}{l}\text { Hertzberger, } \\
2014\end{array}$ & 110 & $\begin{array}{l}\text {...of polyvalent space, we can articulate a floor surface area as separated } \\
\text { repeated space units. Thus, for example... [a building] consists of the } \\
\text { consistent repetition of a single-space unit of } 9 \times 9 \text { metres... }\end{array}$ & & $X$ & & & & \\
\hline $\begin{array}{l}\text { Hertzberger, } \\
2014\end{array}$ & 112 & $\begin{array}{l}\text {...polyvalence... a quality that gives people a reference point and even } \\
\text { incites them to turn their living environment into familiar ground... }\end{array}$ & & & & & & $\mathrm{x}$ \\
\hline $\begin{array}{l}\text { Hertzberger, } \\
2014\end{array}$ & 112 & $\begin{array}{l}\text { That quality can be achieved... by making them [partitions] fundamen- } \\
\text { tally inclusive. And this requires... } \underline{\text { depth... }}\end{array}$ & $\mathrm{x}$ & & & & & \\
\hline $\begin{array}{l}\text { Hertzberger, } \\
2014\end{array}$ & 112 & $\begin{array}{l}\text { That quality can be achieved... for the space unit to be able to take up } \\
\text { ever-new content and still remain itself... }\end{array}$ & & & & & & $\mathbf{X}$ \\
\hline $\begin{array}{l}\text { Hertzberger, } \\
2014\end{array}$ & 113 & $\begin{array}{l}\text {...we should abstain from over-specific and over-expressive } \\
\text { fabrications... }\end{array}$ & & & & $\mathrm{X}$ & & \\
\hline $\begin{array}{l}\text { Hertzberger, } \\
2014\end{array}$ & 113 & $\begin{array}{l}\text { Architects must provide... buildings with } \underline{\text { character, }} \text { explicit, recognisa- } \\
\text { ble, authentic, original yet without imposing a particular taste... }\end{array}$ & & & & & & $\mathbf{x}$ \\
\hline Hunter, 2006 & 65 & $\begin{array}{l}\text {...new... spaces should... not be limited by the physical structure of the } \\
\text { building with the ever increasing use of learning technologies they do } \\
\text { expand beyond the physical space. }\end{array}$ & & & 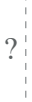 & & & $\begin{array}{l:l}1 \\
?\end{array} ?$ \\
\hline Hunter, 2006 & 65 & $\begin{array}{l}\text {...predicting what technologies might be used in the future is difficult, } \\
\text { so robustness as well as flexibility is important. }\end{array}$ & $?$ & $?$ & ? & & & $? ?$ \\
\hline Hunter, 2006 & 68 & $\begin{array}{l}\text {...video surveillance of users, swipecard access locks, radio frequency } \\
\text { identification tagging... most of these 'locks' degrade the environment, } \\
\text { especially in terms of flexibility and ease of use. }\end{array}$ & & & & & $\mathbf{X}$ & \\
\hline Hunter, 2006 & 71 & $\begin{array}{l}\text { The fusion of library spaces, open access learning spaces and teaching } \\
\text { spaces... Bringing these together into a single building... }\end{array}$ & & & $\mathrm{X}$ & & & \\
\hline Hunter, 2006 & 71 & $\begin{array}{l}\ldots[\text { This] also facilitates 'multiple-uses' of rooms, with teaching and } \\
\text { meeting rooms doubling up as group or individual work areas... }\end{array}$ & & $\mathrm{X}$ & & & & \\
\hline Hunter, 2006 & 72 & ...providing spacious and flexible areas for students... & $\mathrm{x}$ & & & & & \\
\hline Hunter, 2006 & 72 & $\begin{array}{l}\text { By creating a flexible space with easy access to power, data and } \\
\underline{\text { infrastructure, }} \text {, the university hopes to embrace the 'unexpected'... }\end{array}$ & & $\mathrm{x}$ & & & & \\
\hline Hunter, 2006 & 73 & $\begin{array}{l}\text {...the } \underline{\text { restrictions }} \text { imposed by the building have been turned to } \\
\text { advantage... }\end{array}$ & $\mathrm{x}$ & & & & & \\
\hline Hunter, 2006 & 73 & $\begin{array}{l}\text { [They] ... break-up the space and provide some separation of groups } \\
\text { without subdividing the space. }\end{array}$ & & $\mathrm{x}$ & & & & \\
\hline Hunter, 2006 & $\begin{array}{l}73- \\
74\end{array}$ & $\begin{array}{l}\text { Moveable acoustic screens act as ad-hoc dividers and help to manage } \\
\text { the noise levels. }\end{array}$ & & & & $x$ & & \\
\hline Isaac et al., 2014 & 275 & $\begin{array}{l}\text {... adaptability of buildings through the systematic separation of } \\
\text { building components with different replacement rates. }\end{array}$ & & & & $\mathrm{x}$ & & \\
\hline Isaac et al., 2014 & 275 & $\begin{array}{l}\text {... modularization of the design can reduce the interdependencies } \\
\text { between construction activities... }\end{array}$ & & & & $x$ & & \\
\hline
\end{tabular}




\begin{tabular}{|c|c|c|c|c|c|c|c|c|c|}
\hline source & page & mentions of a design tactic & 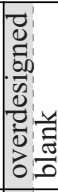 & & & & & & $\frac{0}{0}$ \\
\hline Isaac et al., 2014 & 275 & $\begin{array}{l}\text { The standardization of the interfaces between modules... makes it easier } \\
\text { to accommodate the user's requirements... }\end{array}$ & & & & & & & \\
\hline Isaac et al., 2014 & 275 & $\begin{array}{l}\text { [it is] ...easier to accommodate the user's requirements... through a } \\
\text { large number of different types of modules. }\end{array}$ & & & $x$ & & & & \\
\hline Isaac et al., 2014 & 278 & $\begin{array}{l}\text {...buffers are applied by designing components with a capacity larger } \\
\text { than that required... This extra capacity can be used in the future... }\end{array}$ & $\mathrm{x}$ & & & & & & \\
\hline Isaac et al., 2014 & 278 & $\begin{array}{l}\text {...when components connect too large a number of other components, } \\
\text { relationships can be reduced through modularization... }\end{array}$ & & & & & $\mathrm{X}$ & & \\
\hline Isaac et al., 2014 & 278 & ...relationships can be reduced through... easily disconnected interfaces. & & & & & $Y$ & $x$ & \\
\hline $\begin{array}{l}\text { Israelsson and } \\
\text { Hansson, } 2009\end{array}$ & 140 & $\begin{array}{l}\text { Materials with a life suitable for both existing and future activities } \\
\text { create flexibility in buildings... }\end{array}$ & ? & & & & & & \\
\hline $\begin{array}{l}\text { Israelsson and } \\
\text { Hansson, } 2009\end{array}$ & 140 & $\begin{array}{l}\text { One small error in manufacturing can result in consequences for future } \\
\text { rebuilding and therefore affect flexibility. }\end{array}$ & $?$ & & & & & & \\
\hline $\begin{array}{l}\text { Israelsson and } \\
\text { Hansson, } 2009\end{array}$ & 141 & $\begin{array}{l}\text { Modern installations generally take up more space } \ldots \text { the problem arises } \\
\text { because of difficulty in changing installations. }\end{array}$ & $\mathrm{x}$ & & & & & & \\
\hline $\begin{array}{l}\text { Itard and } \\
\text { Klunder, } 2007\end{array}$ & 256 & $\begin{array}{l}\text { The load-bearing structure } \ldots \text { do not preclude implementing new } \\
\text { technical solutions to attract new target groups. }\end{array}$ & $\mathrm{X}$ & & & & & & \\
\hline $\begin{array}{l}\text { Itard and } \\
\text { Klunder, } 2007\end{array}$ & 256 & $\begin{array}{l}\text { The... and dimensions do not preclude implementing new technical } \\
\text { solutions to attract new target groups. }\end{array}$ & $\mathrm{x}$ & & & & & & \\
\hline $\begin{array}{l}\text { Itard and } \\
\text { Klunder, } 2007\end{array}$ & 266 & $\begin{array}{l}\text {...by using construction that does not depend on load-bearing inner } \\
\text { walls, enabling the walls to be removed easily. }\end{array}$ & $\mathrm{X}$ & & & & & & \\
\hline $\begin{array}{l}\text { Itard and } \\
\text { Klunder, } 2007\end{array}$ & 266 & $\begin{array}{l}\text { Significant space between load-bearing elements... also facilitate } \\
\text { redesign of housing blocks and buildings. }\end{array}$ & $\mathrm{X}$ & & & & & & \\
\hline $\begin{array}{l}\text { Itard and } \\
\text { Klunder, } 2007\end{array}$ & 266 & ...floor height also facilitate redesign of housing blocks and buildings. & $\mathrm{X}$ & & & & & & \\
\hline $\begin{array}{l}\text { Khan and Dhar, } \\
2012\end{array}$ & 48 & $\begin{array}{l}\text {.... great variety of family types can live in the same shell or one... can } \\
\text { also change layouts of the same shell according to their changing needs }\end{array}$ & $\mathrm{X}$ & & & & & & \\
\hline $\begin{array}{l}\text { Khan and Dhar, } \\
2012\end{array}$ & 49 & $\begin{array}{l}\text { The location... of the columns or structural shear wall determines the } \\
\text { possibility to expand spaces inside. }\end{array}$ & $\mathrm{X}$ & & & & & & \\
\hline $\begin{array}{l}\text { Khan and Dhar, } \\
2012\end{array}$ & 49 & $\begin{array}{l}\text { Façade Envelop has window zones and windowless zones, which can } \\
\text { limit the possibility of re-arranging layouts in case of transformation. }\end{array}$ & & & & $x$ & & & \\
\hline $\begin{array}{l}\text { Khan and Dhar, } \\
2012\end{array}$ & 50 & $\begin{array}{l}\text { Private flats usually did not come as empty shells } \ldots \text { Therefore, these } \\
\text { housing units were assumed to be less flexible... }\end{array}$ & $X$ & & & & & & \\
\hline $\begin{array}{l}\text { Khan and Dhar, } \\
2012\end{array}$ & 50 & $\begin{array}{l}\text {...flexibility of shells was gradually reduced... } \underline{\text { Structural walls invaded }} \\
\text { the freedom at infill level. }\end{array}$ & $\mathrm{X}$ & & & & & & \\
\hline $\begin{array}{l}\text { Khan and Dhar, } \\
2012\end{array}$ & 54 & $\begin{array}{l}\ldots . . . \text { column, } \\
\text { the options to transform internal spaces. }\end{array}$ & $\mathrm{X}$ & & & & & & \\
\hline $\begin{array}{l}\text { Khan and Dhar, } \\
2012\end{array}$ & 56 & $\begin{array}{l}\text {...the units can have variety in sizes. Therefore they have more potential } \\
\text { for flexibility in one single block. }\end{array}$ & & & $X$ & & & & \\
\hline $\begin{array}{l}\text { Khan and Dhar, } \\
2012\end{array}$ & 57 & $\begin{array}{l}\text {...partition walls... are equipped with different concealed wiring and } \\
\text { piping; therefore it makes difficult for users to make changes in } \\
\text { layout... }\end{array}$ & & & & & $\mathrm{X}$ & & \\
\hline
\end{tabular}




\begin{tabular}{|c|c|c|c|c|c|c|c|c|c|c|}
\hline source & page & mentions of a design tactic & 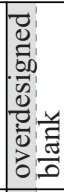 & & & & & 苟 & & 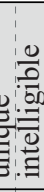 \\
\hline $\begin{array}{l}\text { Khan and Dhar, } \\
2012\end{array}$ & 57 & $\begin{array}{l}\text {...the way the partition walls or the infill are constructed in-situ, later } \\
\text { transformations increase construction hazards... }\end{array}$ & & & & & & $\mathrm{X}$ & & \\
\hline $\begin{array}{l}\text { Khan and Dhar, } \\
2012\end{array}$ & 57 & $\begin{array}{l}\text { The absence of shear wall or column on the sharing wall is therefore an } \\
\text { advantage for that kind of transformation. }\end{array}$ & $\mathrm{x}$ & $x$ & & & & & & \\
\hline $\begin{array}{l}\text { Khan and Dhar, } \\
2012\end{array}$ & 58 & $\begin{array}{l}\text { The increased rigidity in layouts can be compensated by the variety } \\
\text { offered in sizes... it is probably easier to decide to move. }\end{array}$ & & & $x$ & & & & & \\
\hline $\begin{array}{l}\text { Langston and } \\
\text { Shen, } 2007\end{array}$ & 200 & $\begin{array}{l}\text { The building being largely open design would attract a low churn cost } \\
\text { for alterations... }\end{array}$ & $\mathrm{X}$ & $\mathrm{x}$ & & & & & & \\
\hline $\begin{array}{l}\text { Langston et al., } \\
2008\end{array}$ & 1711 & $\begin{array}{l}\text { It is wise to design future buildings for change... with sufficient } \\
\text { structural integrity to support alternative functional use. }\end{array}$ & $\mathrm{x}$ & & & & & & & \\
\hline $\begin{array}{l}\text { Langston et al., } \\
2008\end{array}$ & 1716 & $\begin{array}{l}\text { The building being of largely open design would attract a low churn } \\
\text { cost for alterations... }\end{array}$ & $\mathrm{X}$ & $\mathrm{x}$ & & & & & & \\
\hline Lin, 2011 & 13 & $\begin{array}{l}\text { supporting a total of } 144 \underline{\text { interchangeable "capsules"... Each capsule }} \\
\text { houses a self-contained residential unit... showcasing... adaptability... }\end{array}$ & & $\mathrm{X}$ & & & & & & \\
\hline Lin, 2011 & 19 & $\begin{array}{l}\text { Each capsule is tied to one of the concrete cores with only four } \\
\text { high-tension bolts... That means that every unit is removable... }\end{array}$ & & & & & $\mathrm{X}$ & & & \\
\hline Lin, 2011 & 19 & $\begin{array}{l}\text { Each capsule was installed independently and cantilevered from the } \\
\text { shaft so that it could be removed without affecting others. }\end{array}$ & & & & & X & & & \\
\hline Lin, 2011 & 21 & $\begin{array}{l}\text {...the floor/area ratios of Metabolist buildings are often below average, } \\
\text { making them less economically viable. }\end{array}$ & & & & & & & & \\
\hline $\begin{array}{l}\text { Mantab-uz-Zam- } \\
\text { an, } 2011\end{array}$ & 48 & $\begin{array}{l}\text {...residential conversion is the best option for... [those] which were built } \\
\text { in strong load bearing structures that can easily be remodelled. }\end{array}$ & & & & & & & $\mathrm{x}$ & \\
\hline $\begin{array}{l}\text { Mantab-uz-Zam- } \\
\text { an, } 2011\end{array}$ & 48 & $\begin{array}{l}\text {...prerequisites to... adaptable building... the architectural or historic } \\
\text { quality of the building... }\end{array}$ & & & & & & & & $\mathbf{X}$ \\
\hline $\begin{array}{l}\text { Mantab-uz-Zam- } \\
\text { an, } 2011\end{array}$ & 48 & $\begin{array}{l}\text {...prerequisites to... adaptable building... [the }] \text { potential market } \\
\text { demand... }\end{array}$ & & & & $\mathrm{X}$ & & & & \\
\hline $\begin{array}{l}\text { Mantab-uz-Zam- } \\
\text { an, } 2011\end{array}$ & 52 & $\begin{array}{l}\text {...the original construction method poses challenge in reconstruction } \\
\text { works as buildings often are made of load bearing construction walls. }\end{array}$ & $\mathrm{X}$ & $x$ & & & & & & \\
\hline $\begin{array}{l}\text { March et al., } \\
2012\end{array}$ & 547 & $\begin{array}{l}\text {...reducing its score were excessively small floor size... } \underline{\text { awkward plan }} \\
\underline{\text { shapes and difficult service core locations... }}\end{array}$ & & & & $\mathrm{X}$ & & & & \\
\hline $\begin{array}{l}\text { March et al., } \\
2012\end{array}$ & 547 & ....redeeming features... were that many had site access on 2 sides... & & & & & & $\mathrm{x}$ & & \\
\hline $\begin{array}{l}\text { March et al., } \\
2012\end{array}$ & $547-$ & $\begin{array}{l}\text { The majority of buildings in Case B have floor areas greater than } 700 \\
\mathrm{~m} 2 \text { and large adaptable floor plans... }\end{array}$ & $\mathrm{x}$ & & & & & & & \\
\hline $\begin{array}{l}\text { March et al., } \\
2012\end{array}$ & $\begin{array}{c}547- \\
548\end{array}$ & $\begin{array}{l}\text {...despite negative features of many of the buildings... excessively wide } \\
\text { street frontages. }\end{array}$ & & & & $X$ & & & & \\
\hline $\begin{array}{l}\text { March et al., } \\
2012\end{array}$ & 548 & $\begin{array}{l}\text { Plan shape: }<\text { Deep plan }(1)><\text { Irregular }(0.8)><\underline{\text { Narrow frontage }(0.6)>} \\
<\underline{\text { Wide plan }(0.4)><\underline{\text { Curved }}(0.2)>}\end{array}$ & & & & $\mathrm{X}$ & & & & \\
\hline $\begin{array}{l}\text { March et al., } \\
2012\end{array}$ & 548 & $\begin{array}{l}\text { Site boundaries: }<\underline{\text { None }}(1)>\ldots<\text { Bounded on } 3 \text { sides }(0.4)><\underline{\text { Bounded }} \\
\text { on all sides }(0.2)>\end{array}$ & & $\mathrm{X}$ & & & & & & \\
\hline $\begin{array}{l}\text { March et al., } \\
2012\end{array}$ & 548 & $\begin{array}{l}\text { Access to building: }<\text { Access all sides }(1)><\text { Street and side access } \\
(0.8)><\text { Street and rear access }(0.6)><\text { Street only }(0.4)>\end{array}$ & & & & & & $\mathrm{X}$ & & \\
\hline
\end{tabular}




\begin{tabular}{|c|c|c|c|c|c|c|c|c|c|}
\hline source & page & mentions of a design tactic & 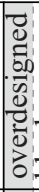 & & 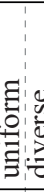 & & & $\left\{\begin{array}{l}0 \\
0 \\
0 \\
0 \\
0 \\
0 \\
0 \\
0\end{array}\right.$ & 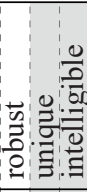 \\
\hline $\begin{array}{l}\text { March et al., } \\
2012\end{array}$ & 548 & $\begin{array}{l}\text { Height of building (storey): }<\underline{6 \text { or less }}(1)><7-20(0.2)><21-45(0.4)> \\
<\underline{46 \text { above }}(0.1)>\end{array}$ & & & & $x$ & $\mathrm{~K}$ & & \\
\hline $\begin{array}{l}\text { March et al., } \\
2012\end{array}$ & 548 & $\begin{array}{l}\text { Building width (metres): }<20 \mathrm{~m}(0.1)><\underline{20.01-40} \mathrm{~m}(0.5)><\underline{40.01-60} \\
\mathrm{~m}(1)><60.01-201.25 \mathrm{~m}(0.5)>\end{array}$ & & & & $x$ & $\mathrm{~K}$ & & \\
\hline $\begin{array}{l}\text { March et al., } \\
2012\end{array}$ & 548 & Floor size: $<$ Small $(0.5)><\underline{\text { Large }}(<700 \mathrm{~m} 2)(1)>$ & $\mathrm{x}$ & & & & & & \\
\hline $\begin{array}{l}\text { March et al., } \\
2012\end{array}$ & 548 & Type of construction: $<$ Steel $/$ Concrete $(0.08)><$ Other $(0.92)>$ & $?$ & & & & & & \\
\hline $\begin{array}{l}\text { March et al., } \\
2012\end{array}$ & 548 & $\begin{array}{l}\text { Service core location: }<\underline{\text { Central }}(1)><\text { Dual locations }(0.5)><\text { Other } \\
(0.1)>\end{array}$ & & & $\mathrm{X}$ & & & & \\
\hline $\begin{array}{l}\text { March et al., } \\
2012\end{array}$ & 551 & ...factors that... assist with adaptability, such as large floor plates... & $\mathrm{x}$ & & & & & & \\
\hline $\begin{array}{l}\text { March et al., } \\
2012\end{array}$ & 551 & $\begin{array}{l}\text {...factors that... assist with adaptability... may... hinder adaptation over } \\
\text { time when they are associated with low levels of land use mix. }\end{array}$ & & & & & & & \\
\hline $\begin{array}{l}\text { Meins et al., } \\
2010\end{array}$ & $287-$ & $\begin{array}{l}\text {... are a response to future changes... which are not foreseeable today... } \\
\text { it cannot yet be foreseen today which technological developments will } \\
\text { make it necessary to lay new cables... }\end{array}$ & $\mathrm{x}$ & & & & & & \\
\hline $\begin{array}{l}\text { Meins et al., } \\
2010\end{array}$ & 292 & $\begin{array}{l}\text { Flexibility and Polyvalence Can be improved through: - Sufficienctly } \\
\text { wide aisles - Wheelchair accessible restrooms }\end{array}$ & $\mathrm{x}$ & & & & & & \\
\hline Nijs et al., 2011 & 35 & $\begin{array}{l}\text { Ideally, independency... is required, which achieves that building levels } \\
\text { can be adapted separately, resulting in more freedom to change. }\end{array}$ & & & & & $x$ & & \\
\hline Nijs et al., 2011 & 38 & $\begin{array}{l}\text { If flexibility is to be achieved, it is necessary to design every level apart } \\
\text { from one another. }\end{array}$ & & & & & $x$ & & \\
\hline Nijs et al., 2011 & 39 & $\begin{array}{l}\text { indirect [connection] with additional fixing devices: with change of one } \\
\text { element another stays untouched... }\end{array}$ & & & & & $\mathrm{X}$ & & \\
\hline Nijs et al., 2011 & 41 & $\begin{array}{l}\text {....an indirect connection by using... [a] component such as a clamp or } \\
\text { click connection. This offers the facility to detach/replace... easily... }\end{array}$ & & & & & & $x$ & \\
\hline $\begin{array}{l}\text { Paslawski and } \\
\text { Rozdzynska, } \\
2013\end{array}$ & 884 & $\begin{array}{l}\text {...pertains to consideration of the possibility to implement changes } \\
\text { (expansion should be considered as a standard... }\end{array}$ & $\mathrm{x}$ & & & & & & \\
\hline $\begin{array}{l}\text { Paslawski and } \\
\text { Rozdzynska, } \\
2013\end{array}$ & $884-$ & $\begin{array}{l}\text {...designing heating equipment so as to enable using different fuels } \\
\text { during the operation of the heating system (fuel options). }\end{array}$ & & & & $\mathrm{X}$ & & & \\
\hline $\begin{array}{l}\text { Pinder et al., } \\
2013\end{array}$ & 441 & $\begin{array}{l}\text {...constructing for a high level of adaptability in office buildings, using } \\
\text { solutions such as higher floor-to-ceiling heights... }\end{array}$ & $\mathrm{x}$ & & & & & & \\
\hline $\begin{array}{l}\text { Pinder et al., } \\
2013\end{array}$ & 441 & $\begin{array}{l}\text {...constructing for a high level of adaptability in office buildings, using } \\
\text { solutions such as... soundproof suspended ceilings... }\end{array}$ & $\mathrm{x}$ & & & & & & \\
\hline $\begin{array}{l}\text { Pinder et al., } \\
2013\end{array}$ & 442 & $\begin{array}{l}\text {...specification that involved over-specifying... ultimately... resulted in } \\
\text { more expensive and more energy intensive office buildings... }\end{array}$ & & & & $\mathrm{X}$ & $\mathrm{x}$ & & \\
\hline $\begin{array}{l}\text { Pinder et al., } \\
2013\end{array}$ & 443 & $\begin{array}{l}\text {....adaptability in office buildings can be enabled by ensuring that they } \\
\text { have more generous floor plans and storey heights... }\end{array}$ & $\mathrm{x}$ & & & & & & \\
\hline $\begin{array}{l}\text { Pinder et al., } \\
2013\end{array}$ & 448 & $\begin{array}{l}\text {...over-specifying floor loadings is great... [otherwise] you affect the } \\
\text { floor loadings and you can't let the shop because you can't put a book } \\
\text { store in... }\end{array}$ & $\mathrm{x}$ & & & & & & \\
\hline
\end{tabular}




\begin{tabular}{|c|c|c|c|c|c|c|c|c|c|c|}
\hline source & page & mentions of a design tactic & 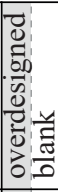 & & & & 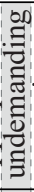 & & & 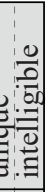 \\
\hline $\begin{array}{l}\text { Pinder et al., } \\
2013\end{array}$ & 448 & $\begin{array}{l}\text {...we try to cater or provide a degree of flexibility for spatial changes so } \\
\text { we over-provide because it's a lot easier... at day one... }\end{array}$ & $\mathbf{x}$ & & & & & & & \\
\hline $\begin{array}{l}\text { Pinder et al., } \\
2013\end{array}$ & 450 & $\begin{array}{l}\text {...office buildings that can be converted... a developer would end up } \\
\text { with either sub-optimal offices or sub-optimal housing. }\end{array}$ & & & & $\mathrm{X}$ & & & & \\
\hline $\begin{array}{l}\text { Pinder et al., } \\
2013\end{array}$ & 450 & $\begin{array}{l}\ldots \text { 'good buys'; low cost solutions that are almost certain to be used in } \\
\text { the future,... the overprovision of power outlets in a retail scheme. }\end{array}$ & $\mathrm{x}$ & & & & & & & \\
\hline $\begin{array}{l}\text { Pinder et al., } \\
2013\end{array}$ & 450 & $\begin{array}{l}\text {...'luxuries'... expensive and there is uncertainty... whether they will } \\
\text { ever be utilized... oversized foundations and increased storey heights. }\end{array}$ & $x$ & & & & & & & \\
\hline $\begin{array}{l}\text { Pinder et al., } \\
2013\end{array}$ & 450 & $\begin{array}{l}\text {...'cheap tricks'... included lintels... into the design of an external wall } \\
\text { to allow new openings to be made in the future. }\end{array}$ & $\mathrm{x}$ & & & & & & & \\
\hline $\begin{array}{l}\text { Pinder et al., } \\
2013\end{array}$ & 450 & 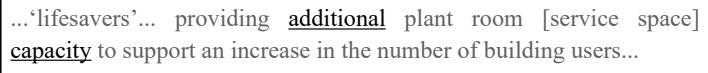 & $\mathrm{x}$ & & & & & & & \\
\hline $\begin{array}{l}\text { Pinder et al., } \\
2013\end{array}$ & 451 & $\begin{array}{l}\text {...'I'm going to do the whole thing in load bearing masonry with short } \\
\text { spans,' and then actual flexibility of use is limited... (Architect \#2) }\end{array}$ & $\mathrm{X}$ & $x$ & & & & & & \\
\hline $\begin{array}{l}\text { Pinder et al., } \\
2013\end{array}$ & 453 & $\begin{array}{l}\text {...because they were considered to be less durable } \ldots \text { and were therefore } \\
\text { difficult to change. }\end{array}$ & & & & & & & $x$ & \\
\hline $\begin{array}{l}\text { Pinder et al., } \\
2013\end{array}$ & 453 & $\begin{array}{l}\text {...because they meant that building components were melded together } \\
\text { and were therefore difficult to change. }\end{array}$ & & & & & $\mathrm{X}$ & & & \\
\hline $\begin{array}{l}\text { Remøy and van } \\
\text { der Voordt, } \\
2014 \mathrm{a}\end{array}$ & 384 & $\begin{array}{l}\text { Post-war office buildings were designed to fit closely around the } \\
\text { function... This tight fitting threatens... feasibility of conversion... }\end{array}$ & $\mathrm{x}$ & & & & & & & \\
\hline $\begin{array}{l}\text { Remøy and van } \\
\text { der Voordt, } \\
2014 \mathrm{a}\end{array}$ & 387 & $\begin{array}{l}\text { Office buildings are constructed to bear more weight... and in most } \\
\text { cases additional floors could be carried by the existing structure. }\end{array}$ & 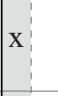 & & & & & & & \\
\hline $\begin{array}{l}\text { Remøy and van } \\
\text { der Voordt, } \\
2014 \mathrm{a}\end{array}$ & 387 & $\begin{array}{l}\text {...before } 1965 \text {, floors were penetrated and shafts were placed without } \\
\text { problems. After 1965, pre-stressed concrete was commonly used... [it] } \\
\text { loses strength when the steel is cut. }\end{array}$ & & $\mathrm{x}$ & & & & & & \\
\hline $\begin{array}{l}\text { Remøy and van } \\
\text { der Voordt, } \\
2014 \mathrm{a}\end{array}$ & 388 & $\begin{array}{l}\text { The large number of columns in older offices may cause a partition } \\
\text { problem for conversions. }\end{array}$ & $\mathrm{x}$ & 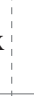 & & & & & & \\
\hline $\begin{array}{l}\text { Remøy and van } \\
\text { der Voordt, } \\
2014 \mathrm{a}\end{array}$ & 388 & $\begin{array}{l}\text {...using pre-stressed concrete floors... makes it difficult to add vertical } \\
\text { shafts. The steel cables in the floors may be located, but are not always } \\
\text { located on the same place in all floors. }\end{array}$ & & & & & & & & $x$ \\
\hline $\begin{array}{l}\text { Remøy and van } \\
\text { der Voordt, } \\
2014 \mathrm{a}\end{array}$ & 388 & $\begin{array}{l}\text { Beams under the floors may cause problems, } \\
\text { height is incidentally lowered, thus creating a challenge for fitting new } \\
\text { installations and services... }\end{array}$ & $\mathrm{x}$ & 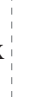 & & & & & & \\
\hline $\begin{array}{l}\text { Remøy and van } \\
\text { der Voordt, } \\
2014 \mathrm{a}\end{array}$ & 388 & $\begin{array}{l}\text { The acoustic insulation of typical office floors is not sufficient for } \\
\text { housing. In most conversions... requires additional acoustic insulation... }\end{array}$ & $\mathrm{x}$ & & & & & & & \\
\hline $\begin{array}{l}\text { Remøy and van } \\
\text { der Voordt, } \\
2014 a\end{array}$ & 389 & $\begin{array}{l}\text { Office buildings are designed for more people per } \mathrm{m} 2 \text { and more traffic... } \\
\text { Therefore, an excess number of lifts is a positive aspect... }\end{array}$ & $x$ & & & & & & & \\
\hline $\begin{array}{l}\text { Remøy and van } \\
\text { der Voordt, } \\
2014 a\end{array}$ & 389 & $\begin{array}{l}\text {...with cantilevering floors and a curtain wall facade. Such a structure } \\
\text { makes the addition of balconies difficult. }\end{array}$ & & $\mathrm{x}$ & & & & & & \\
\hline
\end{tabular}




\begin{tabular}{|c|c|c|c|c|c|c|c|c|c|c|}
\hline source & page & mentions of a design tactic & 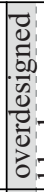 & & & & & & & $\frac{0}{0}$ \\
\hline $\begin{array}{l}\text { Remøy and van } \\
\text { der Voordt, } \\
2014 \mathrm{a}\end{array}$ & 389 & $\begin{array}{l}\text { The building depth may be an obstacle for the conversion... buildings } \\
\text { from the } 1960 \text { s were generally deep and with little daylight access. }\end{array}$ & & & & & $\mathrm{X}$ & & & \\
\hline $\begin{array}{l}\text { Remøy and van } \\
\text { der Voordt, } \\
2014 \mathrm{a}\end{array}$ & 389 & $\begin{array}{l}\text { In most cases, office buildings have higher storeys than required for } \\
\text { residential... }\end{array}$ & $\mathrm{x}$ & & & & & & & \\
\hline $\begin{array}{l}\text { Remøy and van } \\
\text { der Voordt, } \\
2014 b\end{array}$ & 142 & $\begin{array}{l}\text {...the main push factors in the selection of office accommodation... } \\
\text { [One of which is] Lack of expansion space. }\end{array}$ & $\mathrm{x}$ & & & & & & & \\
\hline $\begin{array}{l}\text { Remøy and van } \\
\text { der Voordt, } \\
2014 \text { b }\end{array}$ & 142 & $\begin{array}{l}\text {.... spatially comfortable entrance...was found to decrease the odds of } \\
\text { structural vacancy... Entrances with relatively low ceilings and large } \\
\text { surfaces are... low and unpleasant... }\end{array}$ & & & & & $\mathrm{x}$ & & & \\
\hline $\begin{array}{l}\text { Remøy et al., } \\
2011\end{array}$ & 444 & $\begin{array}{l}\text {...By such a division into layers, each layer can be adapted, replaced or } \\
\text { removed without influencing the other building layers. }\end{array}$ & & & & & $X$ & & & \\
\hline $\begin{array}{l}\text { Remøy et al., } \\
2011\end{array}$ & 449 & $\begin{array}{l}\text { Extendibility - Horizontal: Columns in the façade allow for balconies } \\
\text { or small additions. }\end{array}$ & & & $\mathrm{X}$ & & & & & \\
\hline $\begin{array}{l}\text { Remøy et al., } \\
2011\end{array}$ & 449 & $\begin{array}{l}\text { Extendibility - Vertical: Normally two floors may be added as office } \\
\text { buildings are constructed to carry more weight than housing. }\end{array}$ & $\mathrm{x}$ & & & & & & & \\
\hline $\begin{array}{l}\text { Remøy et al., } \\
2011\end{array}$ & 449 & $\begin{array}{l}\text { Monolithic post-stressed floors make it possible to apply shafts after } \\
\text { completion, as opposed to the standard precast hollow beam floor slabs }\end{array}$ & & & & & & & & \\
\hline $\begin{array}{l}\text { Remøy et al., } \\
2011\end{array}$ & 449 & $\begin{array}{l}\text {....Height: } 3.6 \text { metres is the standard height (floor-to-floor) for offices } \\
\text { and leaves room for transformation into housing... }\end{array}$ & $\mathrm{x}$ & & & & & & & \\
\hline $\begin{array}{l}\text { Remøy et al., } \\
2011\end{array}$ & 449 & $\begin{array}{l}\text { Façade - Replaceable: Not load bearing, easily demountable, replace or } \\
\text { adapt to be decided if transformed. }\end{array}$ & & $\mathrm{X}$ & & & & & & \\
\hline $\begin{array}{l}\text { Remøy et al., } \\
2011\end{array}$ & 452 & $\begin{array}{l}\text { The adaptability of office buildings is determined by the buildings... } \\
\text { separation of the different layers like façade and installations. }\end{array}$ & & & & & $X$ & & & \\
\hline Ren et al., 2014 & 33 & $\begin{array}{l}\text {...low ceilings in many industrial buildings make them functionally } \\
\text { obsolete today... }\end{array}$ & $\mathrm{x}$ & & & & & & & \\
\hline Ren et al., 2014 & 33 & $\begin{array}{l}\text {...corridors can prove to be costly... commercial buildings often have } \\
\text { wide corridors, which can consume valuable guest room space. }\end{array}$ & & & & & $\mathrm{X}$ & & & \\
\hline Ren et al., 2014 & 33 & $\begin{array}{l}\text {...thick concrete slabs... may add to redevelopment costs, especially if } \\
\text { plumbing has to be added... }\end{array}$ & & & & & $X$ & & & \\
\hline Ren et al., 2014 & $\begin{array}{l}35- \\
36\end{array}$ & $\begin{array}{l}\ldots \text { [they] were constructed to much higher loading levels than required } \\
\text { for... hotel developments... The thicker floors drove up ... costs... }\end{array}$ & & & & & $\mathrm{X}$ & & & \\
\hline Ren et al., 2014 & 36 & $\begin{array}{l}\text {...these buildings were clustered... which generated a big problem... } \\
\text { since windows and views were key elements to hotel design. }\end{array}$ & & & & & $\mathrm{X}$ & & & \\
\hline Ren et al., 2014 & 36 & $\begin{array}{l}\text {...all industrial buildings... were constructed right up to the boundary } \\
\text { line, and that adding a curtainwall... meant changing gross floor area. }\end{array}$ & $\mathrm{x}$ & & & & & & & \\
\hline Ross et al., 2016 & 421 & $\begin{array}{l}\text { The... separation of elements allows for maintenance, adaptation, or } \\
\text { replacement with minimized effect on other elements. }\end{array}$ & & & & & ; & K & & \\
\hline Ross et al., 2016 & 422 & $\begin{array}{l}\text { Accordingly, buildings can be initially designed to accommodate a } \\
\text { potential increase in future loads... }\end{array}$ & $\mathrm{x}$ & & & & & & & \\
\hline
\end{tabular}




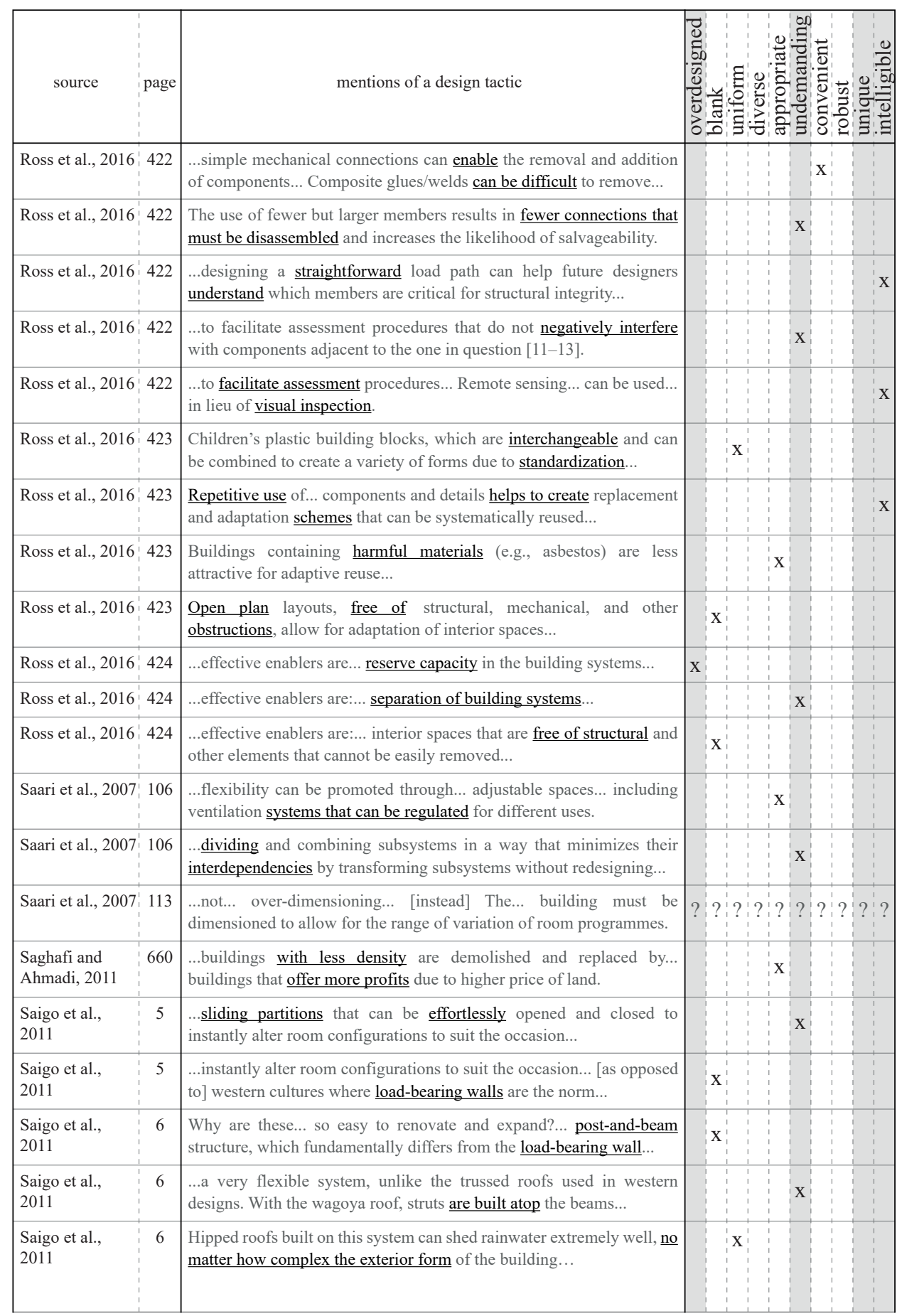




\begin{tabular}{|c|c|c|c|c|c|c|c|c|c|}
\hline source & page & mentions of a design tactic & 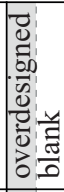 & : & & & & & $\frac{0}{0}$ \\
\hline $\begin{array}{l}\text { Saigo et al., } \\
2011\end{array}$ & 7 & $\begin{array}{l}\text { With the wagoya system... roofs can be constructed with... few special } \\
\text { components, and most of the parts can be reused in renovation. }\end{array}$ & & $x$ & & & & & \\
\hline $\begin{array}{l}\text { Saigo et al., } \\
2011\end{array}$ & 8 & $\begin{array}{l}\text { Structural components have to be replaced from time to time... to } \\
\text { facilitate this process a concept of modular coordination (MC), i.e., } \\
\text { standardization of components... }\end{array}$ & & $x$ & & & & & \\
\hline $\begin{array}{l}\text { Saigo et al., } \\
2011\end{array}$ & 10 & $\begin{array}{l}\text {...relatively few wooden buildings dating from the... late } 8 \text { th to late } 12 \text { th } \\
\text { century) survive today... The reason... is that their pillars are thicker and } \\
\text { their nageshi... are more robust... }\end{array}$ & & & & & & $x$ & \\
\hline $\begin{array}{l}\text { Saigo et al., } \\
2011\end{array}$ & 15 & $\begin{array}{l}\text { Because the sizes are not } \underline{\text { standardized... replacement of these }} \\
\text { components... often requiring replacement of doorframes... }\end{array}$ & & $\mathrm{X}$ & & & & & \\
\hline $\begin{array}{l}\text { Schmidt III and } \\
\text { Eguchi, } 2014\end{array}$ & 77 & $\begin{array}{l}\text {...to construct buildings that could be changed easily through the use of } \\
\text { lightweight materials... }\end{array}$ & & & & & $x$ & & \\
\hline $\begin{array}{l}\text { Schmidt III and } \\
\text { Eguchi, } 2014\end{array}$ & 77 & $\begin{array}{l}\text {...to construct buildings that could be changed easily through the use } \\
\text { of... 'non-permanent' physical connections. }\end{array}$ & & & & & $x$ & & \\
\hline $\begin{array}{l}\text { Schmidt III and } \\
\text { Eguchi, } 2014\end{array}$ & 77 & $\begin{array}{l}\text { Change is further enabled with the structural design as a framed system } \\
\text { of thin columns... }\end{array}$ & $\mathrm{X}$ & & & & & & \\
\hline $\begin{array}{l}\text { Schmidt III and } \\
\text { Eguchi, } 2014\end{array}$ & 77 & $\begin{array}{l}\text {...with the structural design as a framed system of thin columns..., } \\
\text { beams and trusses (wagoya) that can easily be removed or added. }\end{array}$ & & & & & $x$ & & \\
\hline $\begin{array}{l}\text { Schmidt III and } \\
\text { Eguchi, } 2014\end{array}$ & 77 & $\begin{array}{l}\text { Ample storage space, oshiire, is another important aspect as all } \\
\text { furniture is storable. }\end{array}$ & $\mathrm{x}$ & & & & & & \\
\hline $\begin{array}{l}\text { Schmidt III and } \\
\text { Eguchi, } 2014\end{array}$ & 77 & $\begin{array}{l}\text {...by light, double sliding partitions and windows... which are easy to } \\
\text { shift, remove and store. }\end{array}$ & & & & & $x$ & & \\
\hline $\begin{array}{l}\text { Schmidt III and } \\
\text { Eguchi, } 2014\end{array}$ & 78 & $\begin{array}{l}\text {...the buildings were made up of subsets of components... these... } \\
\text { approaches were felt too complex to be easily disseminated... [later] the } \\
\text { skeleton-infill (SI) system was introduced... } \underline{\text { simplified approach... }}\end{array}$ & & & & & & & \\
\hline $\begin{array}{l}\text { Schmidt III and } \\
\text { Eguchi, } 2014\end{array}$ & 79 & $\begin{array}{l}\text { The generous floor-to-floor heights... provide sufficient space for } \\
\text { services, increased storage... }\end{array}$ & $\mathrm{x}$ & & & & & & \\
\hline $\begin{array}{l}\text { Schmidt III and } \\
\text { Eguchi, } 2014\end{array}$ & 79 & $\begin{array}{l}\text { To avoid standard handrails, counters and tables were installed at an } \\
\text { appropriate height... along with a handrail-shaped wooden wall } \\
\text { component that can also be used as a shelf. }\end{array}$ & & $\mathrm{X}$ & & & & & \\
\hline $\begin{array}{l}\text { Schmidt III et } \\
\text { al., } 2014\end{array}$ & 162 & $\begin{array}{l}\text {... isolating discrete functions or systems within chunks, makes it } \\
\text { possible to "change pieces of a system without redoing the whole. }\end{array}$ & & & & $\mathrm{x}$ & & & \\
\hline $\begin{array}{l}\text { Schmidt III et } \\
\text { al., } 2014\end{array}$ & 162 & ...the need to reduce chunk sizes into manageable dimensions... & & & & & $x$ & & \\
\hline $\begin{array}{l}\text { Schmidt III et } \\
\text { al., } 2014\end{array}$ & 162 & $\begin{array}{l}\text {...the advantage of combining chunks with functional purposes, thus } \\
\text { reducing inter-modular complexity and interfaces. }\end{array}$ & & & & : & & & \\
\hline $\begin{array}{l}\text { Schmidt III et } \\
\text { al., } 2014\end{array}$ & 164 & $\begin{array}{l}\text {...the more layers are connected, the greater difficulty and cost of } \\
\text { adaptation (Brand, 1994). }\end{array}$ & & & & $X$ & & & \\
\hline $\begin{array}{l}\text { Schmidt III et } \\
\text { al., } 2014\end{array}$ & 180 & $\begin{array}{l}\text { Volumetric solutions, such as the bathroom pod (22), provide difficulty } \\
\text { in regard to future change in terms of removal... }\end{array}$ & & & & & $\mathrm{X}$ & & \\
\hline $\begin{array}{l}\text { Schmidt III et } \\
\text { al., } 2014\end{array}$ & 180 & $\begin{array}{l}\text { Binding the electrical cables (16) with the structural frame (4) creates a } \\
\text { significant problem in terms of layer separation and access for future } \\
\text { change. }\end{array}$ & & & & $\mathrm{X}$ & & & \\
\hline
\end{tabular}




\begin{tabular}{|c|c|c|c|c|c|c|c|c|c|}
\hline source & page & mentions of a design tactic & 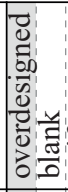 & & & & & 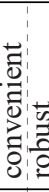 & $\frac{0}{0}$ \\
\hline $\begin{array}{l}\text { Schmidt III et } \\
\text { al., } 2014\end{array}$ & 181 & $\begin{array}{l}\text {...bolts and fasteners... require additional work... compared to other } \\
\text { connection methods (e.g. plug 'n' play). }\end{array}$ & & & & & $\mathrm{X}$ & & \\
\hline Schwehr, 2011 & 20 & $\begin{array}{l}\text {... apartments with specific solutions for a specific way of life are at an } \\
\text { evolutionary dead end. }\end{array}$ & & & & $\mathrm{X}$ & & & \\
\hline Schwehr, 2011 & 20 & equal rooms $=$ adaptable, specific rooms $=$ not adaptable & & $\mathrm{X}$ & & & & & \\
\hline Schwehr, 2011 & 22 & $\begin{array}{l}\text { Flexible buildings have a number of concepts which can react individu- } \\
\text { ally to their context. Variance makes it possible to... be "fitter"... }\end{array}$ & & & & & & & \\
\hline Schwehr, 2011 & 23 & $\begin{array}{l}\text { Flexible buildings have predetermined breaking points to allow } \\
\text { building parts and systems... to be exchanged with little effort. }\end{array}$ & & & & & $\mathrm{X}$ & & \\
\hline Schwehr, 2011 & 23 & Margin of error:... buildings are fault tolerant and not highly specified. & & & & X & & & \\
\hline Slaughter, 2001 & 213 & $\begin{array}{l}\text {...physically separating the major building systems... so that changes in } \\
\text { one area can be isolated from changes in other regions... }\end{array}$ & & & & & $\mathrm{X}$ & & \\
\hline Slaughter, 2001 & 213 & $\begin{array}{l}\text {... overcapacity so that changes can be accommodated without the } \\
\text { replacement or extension of current capacity capabilities... }\end{array}$ & $\mathrm{x}$ & & & & & & \\
\hline Slaughter, 2001 & 213 & $\begin{array}{l}\text {... a new interior partition system uses prefabricated panels that fit into } \\
\text { a ceiling mounted track, with no required on-site activities to... }\end{array}$ & & & & & & $\mathrm{x}$ & \\
\hline Slaughter, 2001 & 214 & $\begin{array}{l}\text {...components may aggregate several smaller units together... [e.g.] } \\
\text { raised panelized floor with data interface boxes attached... with } \\
\text { movement of the special panels thereby relocating the boxes... }\end{array}$ & & & & & $\mathrm{X}$ & & \\
\hline Slaughter, 2001 & 214 & $\begin{array}{l}\text {...reduce the interdependency with other systems... [so that] one system } \\
\text { can be changed without required alterations in other systems. }\end{array}$ & & & & & $\mathrm{X}$ & & \\
\hline Slaughter, 2001 & 214 & $\begin{array}{l}\text {... a modular block partition wall provides... easily move the doorway... } \\
\text { through simply re-arranging the blocks... }\end{array}$ & & $\mathrm{X}$ & & & & & \\
\hline Slaughter, 2001 & 215 & $\begin{array}{l}\text {...regularity of the physical layout can provide critical signals to reduce } \\
\text { the duration and... demolition to find the required components. }\end{array}$ & & & & & & & $\mathrm{x}$ \\
\hline Slaughter, 2001 & 215 & $\begin{array}{l}\text {...improving the physical access }[\mathrm{e} . \mathrm{g}] \ldots \text { demountable drywall panels } \\
\text { that provide easy access to the electrical wiring within the wall cavity. }\end{array}$ & & & & & & $\mathrm{x}$ & \\
\hline Slaughter, 2001 & 215 & $\begin{array}{l}\text {...to create specific zones for each particular system, and to keep those } \\
\text { areas or volumes free from other components and systems... }\end{array}$ & & & & & & & $x$ \\
\hline Slaughter, 2001 & 215 & $\begin{array}{l}\text {...the physical proximity of... [eletrical] systems were set out... below } \\
\text { the suspended floor so the access points could be easily repositioned... }\end{array}$ & & & & & $\mathbf{X}$ & & \\
\hline Slaughter, 2001 & 215 & $\begin{array}{l}\text {...the building cores... can be placed at either end of the building to open } \\
\text { the centre of the floor plate as useable space. }\end{array}$ & $\mathrm{X}$ & & & & & & \\
\hline Steadman, 2006 & 127 & $\begin{array}{l}\text {...in the flexibility of assigning different dimensions to those configura- } \\
\text { tions [of rectangles], while preserving their rectangularity. }\end{array}$ & & $\mathrm{X}$ & & & & & \\
\hline Steadman, 2006 & 127 & $\begin{array}{l}\text {...this flexibility from another point of view: it is always possible to } \\
\text { divide any rectangle within a packing } \underline{\text { into two rectangles... }}\end{array}$ & & $\mathrm{X}$ & & & & & \\
\hline $\begin{array}{l}\text { Sung-Hwa and } \\
\text { Beisi, } 2012\end{array}$ & $\begin{array}{l}20 \\
21\end{array}$ & $\begin{array}{l}\text { Originally, there were four pieces, but later on, three out of the four } \\
\text { doors were made into one for the convenience of easy lifting. }\end{array}$ & & & & & $\mathrm{X}$ & & \\
\hline $\begin{array}{l}\text { Sung-Hwa and } \\
\text { Beisi, } 2012\end{array}$ & 22 & $\begin{array}{l}\text {...the walls were lightweight partitions operable like doors or } \\
\text { windows... accommodating the changes in use in everyday life. }\end{array}$ & & & & & & $\mathrm{x}$ & \\
\hline
\end{tabular}




\begin{tabular}{|c|c|c|c|c|c|c|c|c|c|}
\hline source & page & mentions of a design tactic & 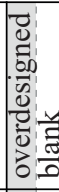 & & & 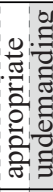 & 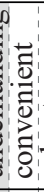 & & $\frac{0}{0}$ \\
\hline $\begin{array}{l}\text { Sung-Hwa and } \\
\text { Beisi, } 2012\end{array}$ & 22 & $\begin{array}{l}\text { Each room had a separate exit outside, which could be used as an } \\
\text { independent space. }\end{array}$ & & $X$ & & & & & \\
\hline $\begin{array}{l}\text { Sung-Hwa and } \\
\text { Beisi, } 2012\end{array}$ & 23 & $\begin{array}{l}\ldots \text { only a few essential pieces of furniture that occupied space along } \\
\text { walls, leaving the middle of the room free for... various activities... }\end{array}$ & $x$ & & & & & & \\
\hline $\begin{array}{l}\text { Sung-Hwa and } \\
\text { Beisi, } 2012\end{array}$ & 23 & $\begin{array}{l}\text { To accommodate the multiple uses of a small room, the furniture and } \\
\text { decoration in sarangbang were minimized... }\end{array}$ & & $X$ & & & & & \\
\hline $\begin{array}{l}\text { Sung-Hwa and } \\
\text { Beisi, } 2012\end{array}$ & 25 & $\begin{array}{l}\text {...was easily repaired by replacing... components... It was built... } \\
\text { without any nails. }\end{array}$ & & & & & $x$ & & \\
\hline $\begin{array}{l}\text { Sung-Hwa and } \\
\text { Beisi, } 2012\end{array}$ & 25 & $\begin{array}{l}\text { By trimming timber with specific measurements and forms... This } \\
\text { prefabrication method facilitates the replacement of elements... }\end{array}$ & & $X$ & & & & & \\
\hline $\begin{array}{l}\text { Vandenbroucke } \\
\text { et al., } 2015\end{array}$ & 539 & $\begin{array}{l}\text {...because the frames have been designed to support up to three storeys } \\
{[22][\text { overcapacity]... the frames can be completely reused... }}\end{array}$ & $\mathrm{x}$ & & & & & & \\
\hline $\begin{array}{l}\text { Vandenbroucke } \\
\text { et al., } 2015\end{array}$ & 546 & $\begin{array}{l}\text {...to these dry and reversible connections.... changes can be made in a } \\
\text { simple way without generating additional construction waste. }\end{array}$ & & & & & $x$ & & \\
\hline $\begin{array}{l}\text { Vandenbroucke } \\
\text { et al., } 2015\end{array}$ & 546 & $\begin{array}{l}\text { Commonly used materials were chosen to enable frequent reuse... such } \\
\text { as plywood instead of gypsum boards. }\end{array}$ & & & & $\mathbf{X}$ & & & \\
\hline $\begin{array}{l}\text { Vimpari and } \\
\text { Junnila, } 2016\end{array}$ & 347 & $\begin{array}{l}\ldots \text {...interaction between } \\
\text { building's adaptability... }\end{array}$ & & & & $\mathrm{X}$ & & & \\
\hline $\begin{array}{l}\text { Vimpari and } \\
\text { Junnila, } 2016\end{array}$ & 349 & $\begin{array}{l}\text {...to switch... office space into retail use... The costs are... whether the } \\
\text { ground floor slabs and ceiling heights can suit future retail use... }\end{array}$ & $\mathrm{x}$ & & & & & & \\
\hline $\begin{array}{l}\text { Vimpari and } \\
\text { Junnila, } 2016\end{array}$ & 349 & $\begin{array}{l}\text {...whether the plan layout and mechanical services can ensure that the } \\
\text { retail premises operate independently of upper floor offices. }\end{array}$ & & $X$ & & & & & \\
\hline Walker, 2010 & 816 & $\begin{array}{l}\text {...each time materials are processed and combined... they become } \\
\text { increasingly complex... making their recycling... more problematic. }\end{array}$ & & & & & & & $\mathrm{X}$ \\
\hline Walker, 2010 & 821 & $\begin{array}{l}\text {...these two sets of components have only a loose connection, allowing } \\
\text { them to be easily separated for purposes of... and change. }\end{array}$ & & & & & $x$ & & \\
\hline Walker, 2010 & 821 & $\begin{array}{l}\text {...because they are standard, off-the-shelf parts, they can be easily } \\
\text { replaced when the need arises. }\end{array}$ & & & & $\mathrm{X}$ & & & \\
\hline Walker, 2010 & 829 & $\begin{array}{l}\text {...local manufacturing and services would allow people to better } \\
\text { understand the nature of their material products... }\end{array}$ & & & & & & & \\
\hline $\begin{array}{l}\text { Walker et al., } \\
2013\end{array}$ & 957 & $\begin{array}{l}\text {...ways for dealing with deep uncertainty in making sustainable plans } \\
\text { [12]: } \bullet \text { resistance: plan for the worst possible case or future situation... }\end{array}$ & $\mathrm{x}$ & & & & & & \\
\hline $\begin{array}{l}\text { Walker et al., } \\
2013\end{array}$ & 958 & $\begin{array}{l}\text { A robust plan is defined to be one that yields outcomes that are deemed } \\
\text { to be satisfactory... across a wide range of future plausible states... }\end{array}$ & & & I & & & & \\
\hline $\begin{array}{l}\text { Wiendahl et al., } \\
2007\end{array}$ & 788 & $\begin{array}{l}\text {...this enabler allows incorporating or disconnecting products, product } \\
\text { groups and work pieces... with little effort, by using uniform interfaces. }\end{array}$ & & $x$ & & & & & \\
\hline $\begin{array}{l}\text { Wiendahl et al., } \\
2007\end{array}$ & 788 & $\begin{array}{l}\text { Modules are autonomously working units or elements that ensure a } \\
\text { high interchangeability with little cost... }\end{array}$ & & $x$ & & & & & \\
\hline $\begin{array}{l}\text { Wiendahl et al., } \\
2007\end{array}$ & 789 & $\begin{array}{l}\text { Flexible manufacturing systems... have more capacity and features than } \\
\text { normally used... }\end{array}$ & $\mathrm{x}$ & & & & & & \\
\hline
\end{tabular}




\begin{tabular}{|c|c|c|c|c|c|c|c|c|c|}
\hline source & page & mentions of a design tactic & 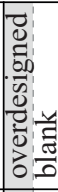 & : & & & & & $\frac{0}{0}$ \\
\hline $\begin{array}{l}\text { Wiendahl et al., } \\
2007\end{array}$ & 792 & $\begin{array}{l}\text {... a mobile machine on wheels does not help much if the supply media } \\
\text { and power distribution in the building is restricted [57]. }\end{array}$ & & $\mathrm{X}$ & & & & & \\
\hline $\begin{array}{l}\text { Wiendahl et al., } \\
2007\end{array}$ & 794 & $\begin{array}{l}\text {...media distribution covers all areas of the factory via the ceiling and } \\
\text { therefore imposes no restrictions... during relocation of equipment. }\end{array}$ & & $: X$ & & & & & \\
\hline $\begin{array}{l}\text { Wiendahl et al., } \\
2007\end{array}$ & 794 & $\begin{array}{l}\text { Each module is autonomous with regard to media and energy supply. } \\
\text { The building can be expanded... without interruption of the production. }\end{array}$ & & $\mathrm{X}$ & & & & & \\
\hline $\begin{array}{l}\text { Wiendahl et al., } \\
2007\end{array}$ & 794 & $\begin{array}{l}\text { Universality... This enabler stipulates an over-dimensioning of objects } \\
\text { to guarantee independence of function and use. }\end{array}$ & $\mathrm{x}$ & & & & & & \\
\hline $\begin{array}{l}\text { Wiendahl et al., } \\
2007\end{array}$ & 794 & The high grid width supports the transformability in the building. & $\mathrm{X}$ & & & & & & \\
\hline $\begin{array}{l}\text { Wiendahl et al., } \\
2007\end{array}$ & 794 & $\begin{array}{l}\text {...the media distribution can be... a grid... is hung from the ceiling and } \\
\text { can be easily accessed by the workers themselves at every location... }\end{array}$ & & $\mathrm{X}$ & & & & & \\
\hline $\begin{array}{l}\text { Wiendahl et al., } \\
2007\end{array}$ & 794 & $\begin{array}{l}\text { The module is mostly self-contained, transportable and has standard- } \\
\text { ized interfaces. Therefore, it can be easily used in different locations... }\end{array}$ & & $x$ & & & & & \\
\hline $\begin{array}{l}\text { Wilkinson et al., } \\
2009\end{array}$ & $\begin{array}{c}49- \\
50\end{array}$ & $\begin{array}{l}\text {.... determining factor... size (i.e. smaller buildings were more marketa- } \\
\text { ble }) \text {... }\end{array}$ & & & & $\mathrm{X}$ & & & \\
\hline $\begin{array}{l}\text { Wilkinson, } \\
\text { 2012a }\end{array}$ & 159 & $\begin{array}{l}\text {...some plan shapes such as deep plan shapes were easier to adapt than } \\
\text { others such as } \underline{\text { irregular shaped ones... }}\end{array}$ & & & & $\mathrm{X}$ & & & \\
\hline $\begin{array}{l}\text { Wilkinson, } \\
\text { 2012a }\end{array}$ & 160 & $\begin{array}{l}\text {... access to the building important during the building works as it } \\
\text { affected builders' access during the construction works. }\end{array}$ & & & & & $\mathrm{X}$ & & \\
\hline $\begin{array}{l}\text { Wilkinson, } \\
\text { 2012a }\end{array}$ & 162 & $\begin{array}{l}\text {...the vertical services cores are either centrally located within the floor } \\
\text { plate or comprise multiple locations on the floor plate which facilitates } \\
\text { a greater degree of flexibility in the sub division of the floor plates... }\end{array}$ & & $x$ & & & & & \\
\hline $\begin{array}{l}\text { Wilkinson, } \\
\text { 2012a }\end{array}$ & 163 & $\begin{array}{l}\text { The building occupies a large site... which makes it flexible for } \\
\text { adaptation... }\end{array}$ & $\mathrm{x}$ & & & & & & \\
\hline $\begin{array}{l}\text { Wilkinson, } \\
\text { 2012a }\end{array}$ & 163 & $\begin{array}{l}\text { The building... has access to all four sides of the building which makes } \\
\text { it flexible for adaptation... }\end{array}$ & & & & & $x$ & & \\
\hline $\begin{array}{l}\text { Wilkinson, } \\
2012 b\end{array}$ & 401 & $\begin{array}{l}\text { Finally aesthetics was asserted to be important attribute in determining } \\
\text { whether or not a building was adapted... }\end{array}$ & & & & & & & $\mathrm{X}$ \\
\hline $\begin{array}{l}\text { Wilkinson, } \\
2012 b\end{array}$ & 401 & $\begin{array}{l}\text {...the floor-to-floor height affected the ability to reconfigure services } \\
\text { installations. }\end{array}$ & $\mathrm{x}$ & & & & & & \\
\hline $\begin{array}{l}\text { Wilkinson, } \\
2012 b\end{array}$ & 401 & $\begin{array}{l}\text {...where shapes such as deep plan were easier to adapt than others such } \\
\text { as } \underline{\text { irregular shaped ones... }}\end{array}$ & & & & $\mathrm{X}$ & & & \\
\hline $\begin{array}{l}\text { Wilkinson, } \\
2012 b\end{array}$ & 404 & $\begin{array}{l}\text {...more attractive stock is retrofitted compared to less attractive } \\
\text { buildings. }\end{array}$ & & & & & & & $x$ \\
\hline $\begin{array}{l}\text { Wilkinson, } \\
2012 b\end{array}$ & 404 & $\begin{array}{l}\text {...Buildings without a mixed land use undergo more frequent levels of } \\
\text { retrofit possibly because less negotiation is required... }\end{array}$ & & $x$ & & & & & \\
\hline $\begin{array}{l}\text { Wilkinson, } \\
2012 b\end{array}$ & 405 & $\begin{array}{l}\text {... attachment to other buildings was important in determining the level } \\
\text { of disruption to tenants of adjoining properties during retrofits... }\end{array}$ & & $\mathrm{X}$ & & & & & \\
\hline $\begin{array}{l}\text { Wilkinson, } \\
2012 b\end{array}$ & 405 & $\begin{array}{l}\text { Access to the building was important in determining the ease of } \\
\text { delivery of construction materials... }\end{array}$ & & & & & $x$ & & \\
\hline
\end{tabular}




\begin{tabular}{|c|c|c|c|c|c|c|c|c|c|}
\hline source & page & mentions of a design tactic & 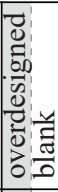 & & & & 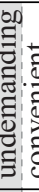 & & 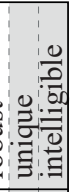 \\
\hline $\begin{array}{l}\text { Wilkinson, } \\
2014 \mathrm{a}\end{array}$ & 254 & Floor strength determined possible land uses... & $\mathrm{x}$ & & & & & & \\
\hline $\begin{array}{l}\text { Wilkinson, } \\
\text { 2014a }\end{array}$ & 254 & $\begin{array}{l}\text { A central [core] location gave greater scope for sub-dividing the floor } \\
\text { plate... }\end{array}$ & & $x$ & & & & & \\
\hline $\begin{array}{l}\text { Wilkinson, } \\
\text { 2014a }\end{array}$ & 254 & $\begin{array}{l}\text { A central [core] location gave greater scope for... minimised loss of net } \\
\text { lettable area. }\end{array}$ & & & & $\mathrm{X}$ & & & \\
\hline $\begin{array}{l}\text { Wilkinson, } \\
2014 \mathrm{a}\end{array}$ & 254 & $\begin{array}{l}\text { Detached buildings were easier and more desirable for adaptation and } \\
\text { contractors worked faster with less user disruption... }\end{array}$ & & $\mathrm{X}$ & & & & & \\
\hline $\begin{array}{l}\text { Wilkinson, } \\
2014 \mathrm{a}\end{array}$ & 254 & $\begin{array}{l}\text { Access or the number of entry and exit points to buildings impacted on } \\
\text { the ease of adaptation... }\end{array}$ & & & & & & $\mathrm{X}$ & \\
\hline $\begin{array}{l}\text { Wilkinson, } \\
\text { 2014a }\end{array}$ & 254 & 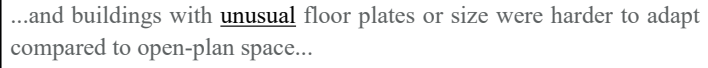 & & & & $\mathrm{X}$ & & & \\
\hline $\begin{array}{l}\text { Wilkinson, } \\
2014 \mathrm{a}\end{array}$ & 254 & $\begin{array}{l}\text { Likewise, the... distance between structural columns, influenced the } \\
\text { ease of adaptation for new uses (Arge, 2005). }\end{array}$ & $\mathrm{x}$ & & & & & & \\
\hline $\begin{array}{l}\text { Wilkinson, } \\
\text { 2014a }\end{array}$ & $254-$ & $\begin{array}{l}\text { The technical grid and services equipment was important to evaluate } \\
\text { whether the building could accommodate extra capacity... }\end{array}$ & $x$ & & & & & & \\
\hline $\begin{array}{l}\text { Wilkinson, } \\
2014 \mathrm{a}\end{array}$ & 255 & $\begin{array}{l}\text { With single tenants, } \text {, when the lease expires owners can adapt... with } \\
\text { multiple tenants... the building may be partly empty... before owner's } \\
\text { can adapt. }\end{array}$ & & $x$ & & & & & \\
\hline $\begin{array}{l}\text { Wilkinson, } \\
2014 \mathrm{a}\end{array}$ & 256 & $\begin{array}{l}\text {...where buildings are complex, adaptation costs can surpass new } \\
\text { construction... }\end{array}$ & & & & & & & $x$ \\
\hline $\begin{array}{l}\text { Wilkinson, } \\
2014 \mathrm{a}\end{array}$ & 259 & $\begin{array}{l}\text {...indicating that buildings having a poor appearance; such as a worn or } \\
\text { outdated form or look are less likely to be adapted. }\end{array}$ & & & & $x$ & & & \\
\hline $\begin{array}{l}\text { Wilkinson, } \\
2014 \mathrm{a}\end{array}$ & 259 & $\begin{array}{l}\text {...either skeleton frame or load bearing, has bearing on the flexibility } \\
\text { and ease and the cost of building alterations. }\end{array}$ & $\mathrm{X}$ & & & & & & \\
\hline $\begin{array}{l}\text { Wilkinson, } \\
2014 \mathrm{~b}\end{array}$ & 82 & $\begin{array}{l}\text { Centrally located services were most likely to be adapted, followed by } \\
\text { multiple locations and 'other locations'... }\end{array}$ & & $\mathrm{X}$ & & & & & \\
\hline $\begin{array}{l}\text { Wilkinson, } \\
2014 b\end{array}$ & 82 & $\begin{array}{l}\text { Narrow buildings were least likely to undergo adaptation whilst } \\
\text { medium width property was most likely to be adapted. }\end{array}$ & & & & $\mathrm{x}$ & & & \\
\hline $\begin{array}{l}\text { Wilkinson, } \\
2014 b\end{array}$ & 82 & $\begin{array}{l}\text {...site access... with buildings having access on all sides being most } \\
\text { likely to be adapted. }\end{array}$ & & & & & & $\mathrm{x}$ & \\
\hline $\begin{array}{l}\text { Wilkinson, } \\
2014 b\end{array}$ & 84 & ...with more attractive stock having a greater likelihood of adaptation. & & & & & & & $\mathbf{X}$ \\
\hline $\begin{array}{l}\text { Wilkinson and } \\
\text { Reed, } 2011\end{array}$ & 727 & $\begin{array}{l}\text {...building accessibility was a critical success factor related to the ease } \\
\text { of the construction works... }\end{array}$ & & & & & & $\mathrm{X}$ & \\
\hline $\begin{array}{l}\text { Wilkinson and } \\
\text { Reed, } 2011\end{array}$ & 731 & $\begin{array}{l}\text {...buildings with large floor plates were more likely to be adapted }(0.59) \\
\text { than those with } \underline{\text { smaller floor plates... }}\end{array}$ & $\mathrm{X}$ & & & & & & \\
\hline $\begin{array}{l}\text { Wilkinson and } \\
\text { Reed, } 2011\end{array}$ & 732 & $\begin{array}{l}\text { Detached buildings are easier to adapt externally as owners can get } \\
\text { access to elevations. }\end{array}$ & & & & & & $\mathrm{X}$ & \\
\hline $\begin{array}{l}\text { Wilkinson and } \\
\text { Reed, } 2011\end{array}$ & 732 & $\begin{array}{l}\text { Internal adaptations are easier to carry out with detached... buildings } \\
\text { because owners can gain entry... without disturbing or negotiating with } \\
\text { neighbours. }\end{array}$ & & $x$ & & & & & \\
\hline
\end{tabular}




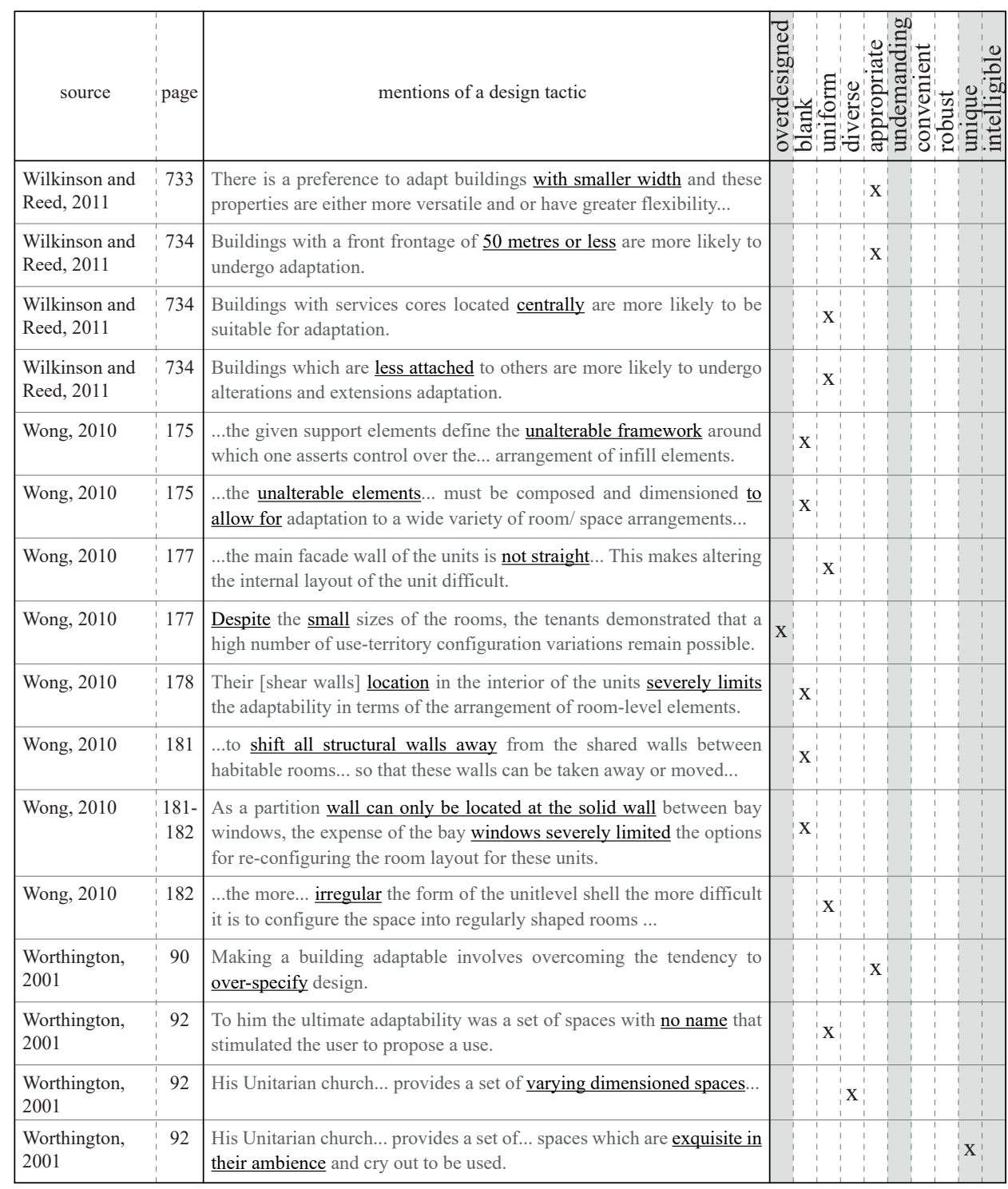



Appendix 3.

Probability estimates. 


\section{Probability of insufficient privacy due to change 1 :}

A person's age or gender does not influence someone's need for privacy (Haans et al., 2007). However, introverts are more negatively affected by background noise than extraverts (Cassidy and MacDonald, 2007). Therefore, it is assumed that in 1 out of 5 times change 1 will result in insufficient privacy.

\section{Probability of insufficient ergonomic comfort due to change 1:}

In the UK, only $5 \%$ of the men are shorter than $1625 \mathrm{~mm}$, while the average height of a woman is $1610 \mathrm{~mm}$ (Pheasant, 2003, p. 45). Thus, the average woman, in terms of height, is shorter than at least $95 \%$ of the male population. Furthermore, even the most optimal height for a workbench - specifically designed for the British male - will not be satisfactory for about $25 \%$ of males (Pheasant, 2003, p. 27, Fig. 2.7). Therefore, it is assumed that in 5 out of 8 times change 1 will result in insufficient ergonomic comfort.

\section{Probability of insufficient thermal comfort due to change 1:}

Perceived thermal comfort differs for people with a different gender (Karjalainen, 2012), age (van Hoof and Hensen, 2006) or ethnic background (e.g. Zhou et al., 2014). For example, there is evidence that older people, compared to younger people, prefer a temperature that is $2^{\circ} \mathrm{C}$ warmer (van Hoof and Hensen, 2006, p. 225). Therefore, it is assumed that in 1 out of 4 times change 1 will result in insufficient thermal comfort.

\section{Probability of insufficient air quality due to change 1:}

About 2 times more women than men experience symptoms related to indoor air problems (Reijula and Sundman-Digert, 2004, p. 35, Table 3). Furthermore, about 1,3 times more allergic people than non-allergic people are dissatisfied with a building's indoor air quality (Lundin, 1999, p. 99). Therefore, it is assumed that in 1 out of 10 times change 1 will result in insufficient air quality.

\section{Probability of insufficient lighting conditions due to change 1:}

In a study of Despenic et al. (2017, p. 100, Fig. 12), only about 13\% of the occupants experienced conflict over the lighting settings with a significant frequency. Therefore, it is assumed that generally in 2 out of 15 times change 1 will result in insufficient lighting conditions. However, people with low vision, compared to people with normal vision, need greater lighting levels to reach their maximum visual performance (Haymes, 2006). In the UK, about $1,8 \%$ of working-age adults has a vision impairment (Department for Work and Pensions, 2018). Disabled people, of working age, in the UK on average are 
$37,5 \%$ less likely to have a job than non-disabled people (ONS, 2008, p. 14).

Therefore, it is assumed that in 9 out of 800 times change 1 will both (1) involve a person with low vision and (2) result in insufficient lighting conditions. Furthermore, it is assumed that in 5 out of 41 times change 1 will result in insufficient lighting conditions, without a person with low vision being involved. This distinction is useful because the severity in both situation is rated differently $(0,2 \%$ and $0,02 \%)$.

\section{Probability of insufficient operating space due to change 1 :}

A person in a wheelchair occupies more space and needs more space to manoeuvre than a person that is not in a wheelchair. In the UK, about $8 \%$ of working-age adults have a mobility impairment (Department for Work and Pensions, 2018), and about $2-3 \%$ of working-age adults uses special equipment to improve their mobility (Office for Disability Issues, 2011). Disabled people, of working age, in the UK on average are $37,5 \%$ less likely to have a job than non-disabled people (ONS, 2008, p. 14). Therefore, it is assumed that in 1 out of 64 times change 1 will result in result in insufficient operating space.

\section{Probability of insufficient closeness due to change 1:}

A person's gender does not influence someone's need for socializing (Haans et al., 2007). However, younger employees do experience a higher need for social interaction (Haans et al., 2007). Therefore, it is assumed that in 1 out of 5 times change 1 will result in insufficient closeness.

\section{Probability of insufficient privacy due to change 2:}

A person's work can require two types of privacy: (1) the privacy to be able to concentrate and work undisturbed; and (2) the privacy to be able to discuss sensitive issues without being overheard. Thus, a new job will likely require more privacy when it involves either more specialized work (thus, more concentration) or more managerial work (thus, more sensitive issues). In a study of West and Nicholson (1989, p. 340), about $54,5 \%$ of the respondents that reported a job change experienced an upward status move, about $36 \%$ of them experienced an lateral move, and about $9,5 \%$ of them experienced a downward status move. It is assumed that in about 1 out of 6 times a lateral move will result in greater privacy requirements. Furthermore, it is assumed that in about 1 out of 4 times an upward move will result in greater privacy requirements. Finally, it is assumed that a downward status move will not result in greater privacy requirements. Therefore, it is assumed that in 1 out of 5 times change 2 will result in 
insufficient privacy.

\section{Probability of insufficient ergonomic comfort due to change 2:}

A different mixture of tasks with different relative duration of tasks causes different body dynamics during office chair use over the day. Therefore, workers with a different job have different ergonomic preferences in furniture (see Groenesteijn et al., 2012). Managerial workers differ most (about 20\%) in terms of mixture of tasks from other types of workers (Brill et al., 2001, pp. 21-23). In a study of West and Nicholson (1989, p. 340), about $54,5 \%$ of the respondents that reported a job change experienced an upward status move. It is assumed that in about 1 out of 4 times an upward move will result in a significant change in mixture of tasks. Therefore, it is assumed that in 3 out of 22 times change 2 will result in insufficient ergonomic comfort.

\section{Probability of insufficient thermal comfort due to change 2:}

A person produces more heat when he or she is more physically active. However, in a study of Rowe (2001, p. 417), only $13 \%$ of reported switches, i.e. a switch from one office activity to another office activity that involves a different activity rate, resulted in a thermal sensation difference of $2,5^{\circ} \mathrm{C}$ or more. Therefore, it is assumed that in 1 out of 8 times change 2 will result in insufficient thermal comfort.

\section{Probability of insufficient air quality due to change 2:}

A person produces more $\mathrm{CO}_{2}$ when he or she is more physically active. For example, an employee who is on his or her feet working (see Rowe, 2001, p. 416) produces about $40 \%$ more $\mathrm{CO}_{2}$ than a worker with an average activity rate (see Persily and de Jonge, 2017, p. 870). In a study of Rowe (2001, p. 417), only 13\% of reported switches, i.e. a switch from an office activity to another office activity that involves a different activity rate, resulted in a thermal sensation difference of $2,5^{\circ} \mathrm{C}$ or more. It is assumed that a similar percentage of switches will result in a significant difference in perceived air quality. Therefore, it is assumed that in 1 out of 8 times change 2 will result in insufficient air quality.

\section{Probability of insufficient lighting conditions due to change 2:}

When workers have a choice "...it is clear that office workers do not generally choose different illuminances for different tasks" (Boyce et al., 2006, p. 367). "The most likely explanation for this lack of effect of task type is that the range of visual difficulty experienced in everyday work is limited" (Boyce et al., 2006, p. 367). Therefore, it is 
assumed that in 1 out of 100 times change 2 will result in insufficient lighting conditions.

\section{Probability of insufficient operating space due to change 2:}

A worker's position in the company's hierarchical structure affects the amount of space that will be reserved for him or her (Hakfoort and Lie, 1996, pp. 189-190; Neufert and Neufert, 2000, p. 346). The main functional reason why a managerial employee's workstation needs more space, than a non-managerial employee's workstation, is so that he or she can formally receive visitors at his or her workspace. This additional space requirement can add about $60 \%$ of extra space to the workstation (de Chiara et al., 1992, pp. 225-226).

Furthermore, in different fields of work, different space requirements per worker are common (Miller, 2014, p. 163, Fig. 4). Besides the need to formally receive visitors at the workstation, the only other functional reason why one person's workstation needs more space, than another person's workstation, is additional storage requirements. A larger desk or working area does not fulfil any additional functional purpose, since a person's "normal working area" is limited by the size of his or her arms (Pheasant, 2003, pp. 55-56).

In a study of West and Nicholson (1989, p. 340), about 54,5\% of the respondents that reported a job change experienced an upward status move, about $36 \%$ of them experienced an lateral move, and about $9,5 \%$ of them experienced a downward status move. It is assumed that in about 1 out of 6 times a lateral move will result in greater space requirements. Furthermore, it is assumed that in about 1 out of 4 times an upward move will result in greater space requirements. Finally, it is assumed that a downward status move will not result in greater space requirements. Therefore, it is assumed that in about 1 out of 5 times change 2 will result in insufficient operating space.

\section{Probability of insufficient closeness due to change 2:}

Social interaction between co-workers has been said to: (1) facilitate the sharing of knowledge (Chen and Huang, 2007); (2) reduce work-related stress (Hagihara et al., 1998); and (3) help prevent a person from becoming bored of straightforward and repetitive work that does not require a lot of his or her attention (Fisher, 1998). These three effects are mostly associated with a lateral (more knowledge based work), upwards (more stressful work) and downwards move (more repetitive work), respectively. In a study of West and Nicholson (1989, p. 340), about 54,5\% of the respondents that reported a job change experienced an upward status move, about $36 \%$ of them experienced an lateral move, and about $9,5 \%$ of them experienced a downward status 
move. It is assumed that in 1 out of 4 times a lateral move will result in greater closeness requirements. Furthermore, it is assumed that in 1 out of 5 times an upward move will result in greater closeness requirements. Finally, it is assumed that in 1 out of 8 times a downward status move will result in greater closeness requirements. Therefore, it is assumed that in 2 out of 9 times change 2 will result in insufficient closeness. 



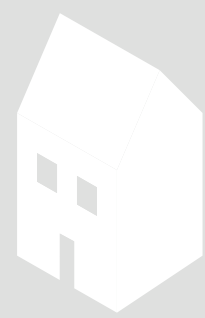

